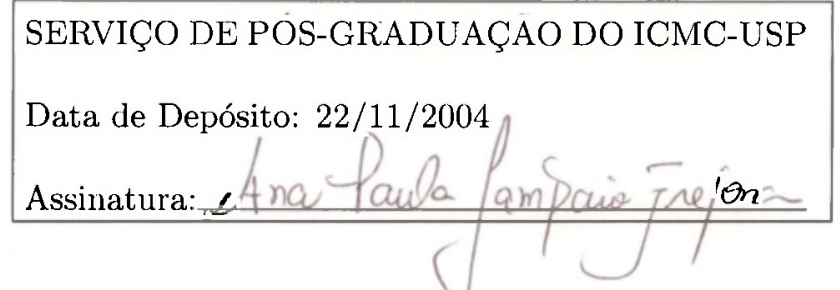

\title{
Sistema de Vișão Baseado em Redes Neurais Artificiais para o Controle de Robôs Móveis ${ }^{1}$
}

\author{
Marcos Gonçalves Quiles
}

Orientadora: Prof $f^{n}$ Dr ${ }^{a}$ Roseli Aparecida Francelin Romero

\begin{abstract}
Dissertação apresentada ao Instituto de Ciências Matcmáticas e de Computação - ICMC/USP, como parte dos requisitos necessários para obtenção do título de Mestre em Ciências de Computação e Matemática Computacional.
\end{abstract}

USP - São Carlos

Novembro/2004

${ }^{1}$ Trabalho realizado com apoio financeiro do CNPq. 


\section{Candidato: Marcos Gonçalves Quiles}

A Comissão Julgadora:

Profa. Dra. Roseli Aparecida Francelin Romero Loweli Cop. Fancelin formero

Prof. Dr. Eduardo do Valle Simões

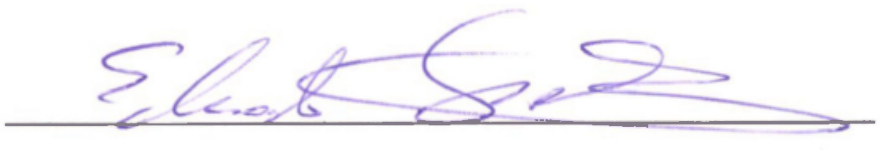

Prof. Dr. Marco Henrique Terra

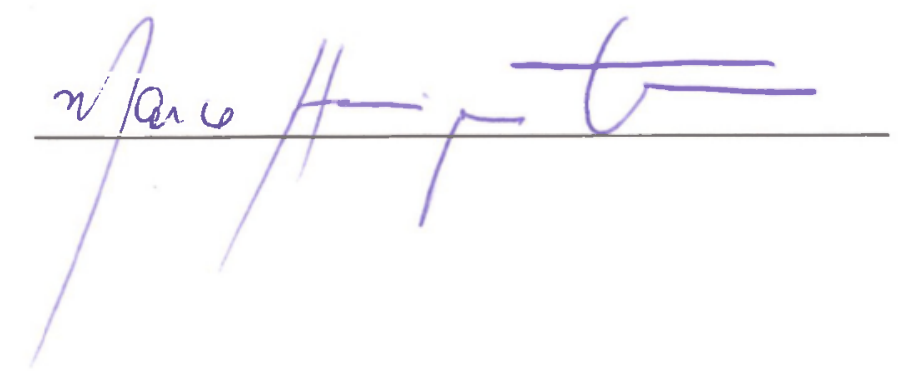




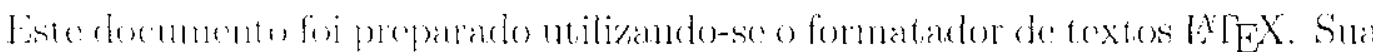

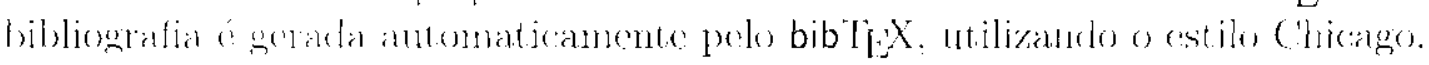

(6) (op)right 2004 - Marres Gomçalves (2uiles

fodos os direitos Reservados 


\section{Resumo}

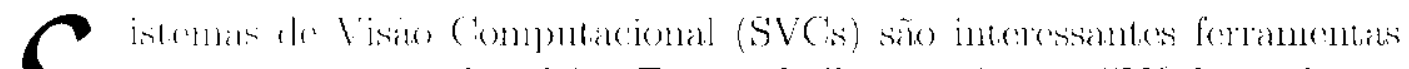

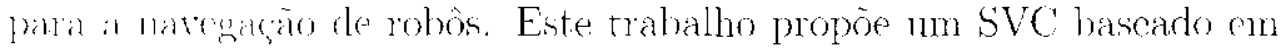

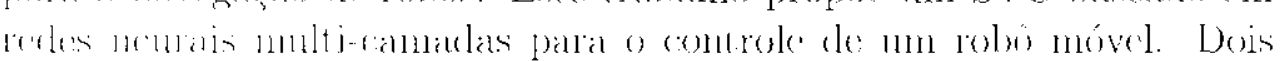

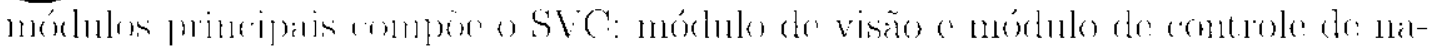

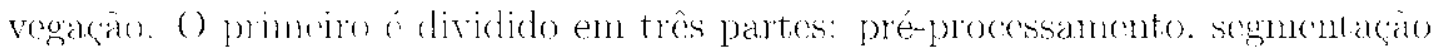

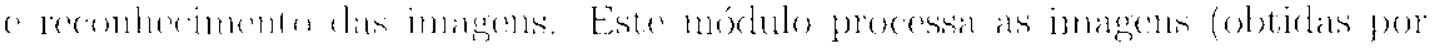

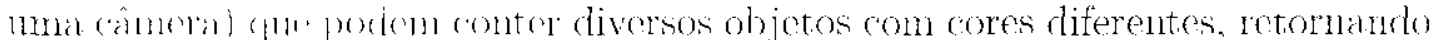

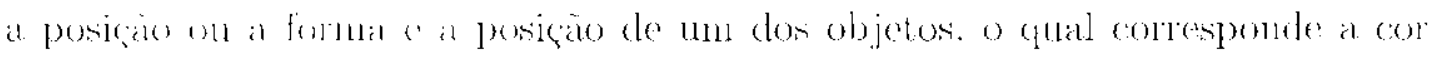

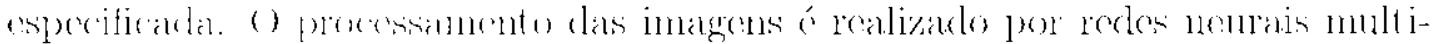
(amadas. () módnlo de controle é responsável por validar as resultados do módulo

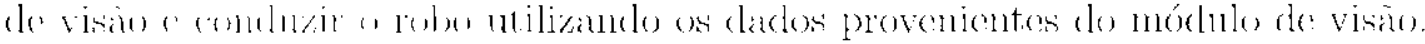

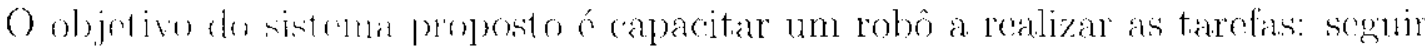
um objeto de con deternimada, seguir um objeto de cor o forma determinada on

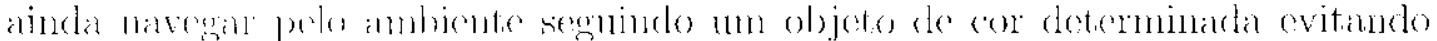
obstácules. Vitros experimentos sào apresentados. em um ambiente real, ulili-

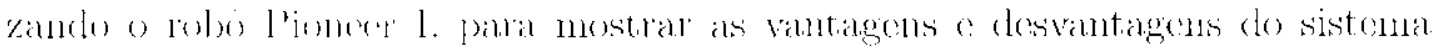
propesisto.
} 


\section{Abstract}

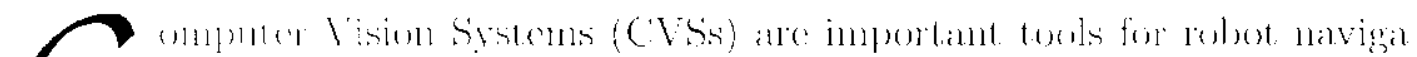
tion. This work propowes a (VS bused on Multi-l ayer Noural Network

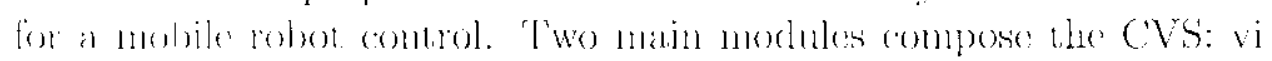

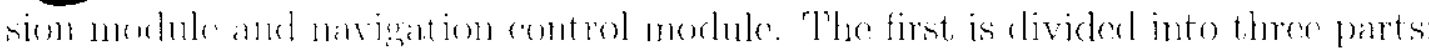
moporessing. sognentation and inage recognition. This module proresses the

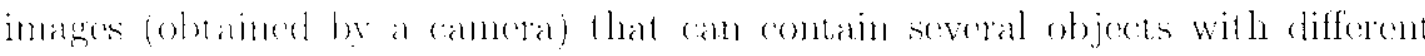

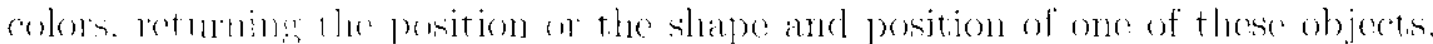

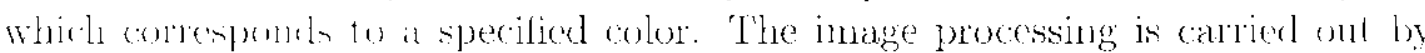

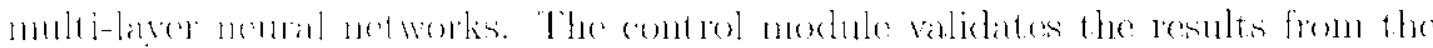

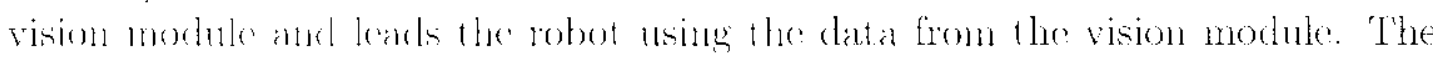

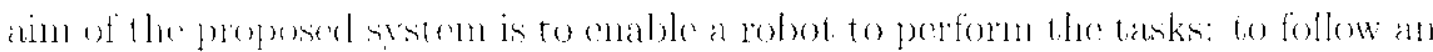

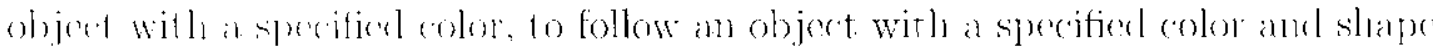

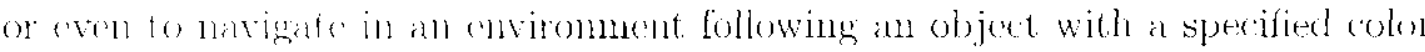

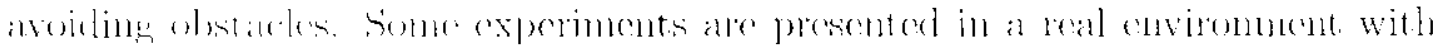

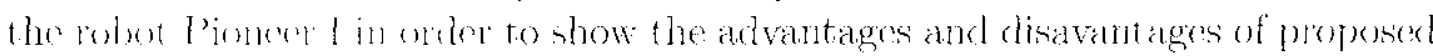
systems. 


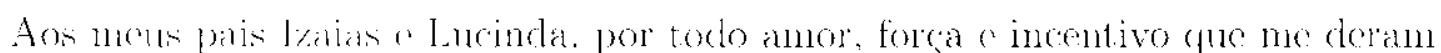

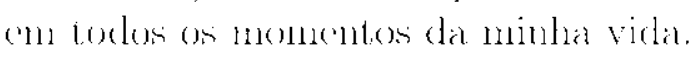

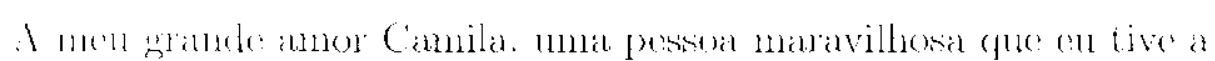
oportmidale de conlerer a me apaixonar.

(I can't live without anymone).

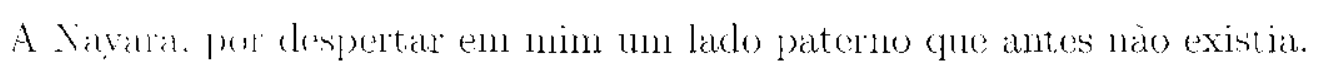

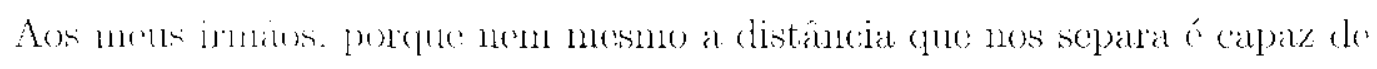

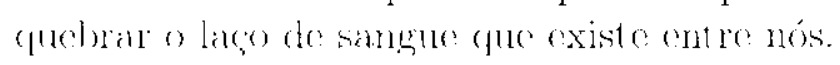

Amo muto wocess. Marcos Ouiles. 


\section{Agradecimentos}

Primerimance a minhar mais que orientiulora Resseli Aparecida Francelin Ro

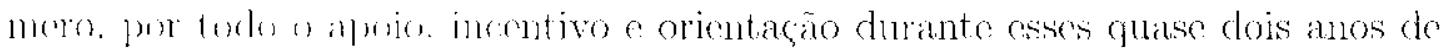

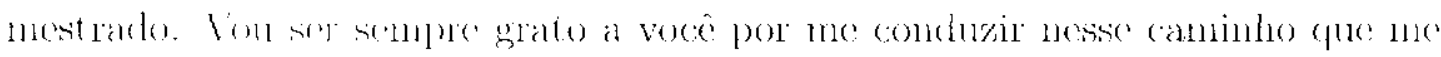

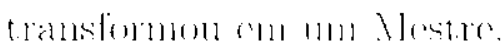

A rlois grantur professores e anigos, Eduardo Simöes e Alexandre Delbem.

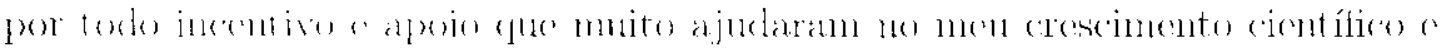
pessoal. " por tordis ats oportunidades a min concedidas.

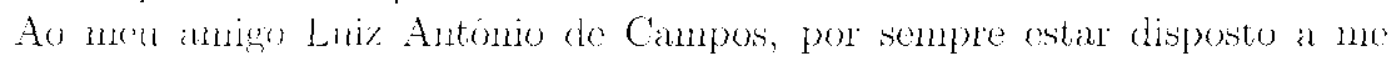
ajuclar (o)

Ao man mugo Alan (Gavioli, por toda amizade. companheirismo e pacioncia Hesses bilt intus allus

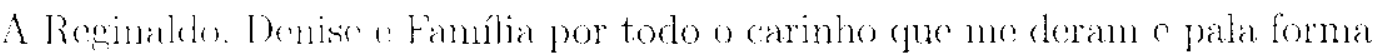

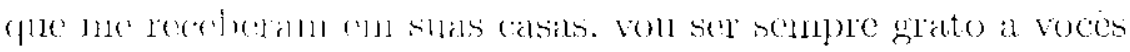

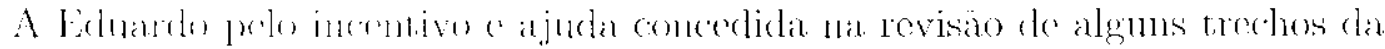
dissertacion

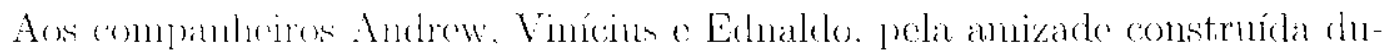

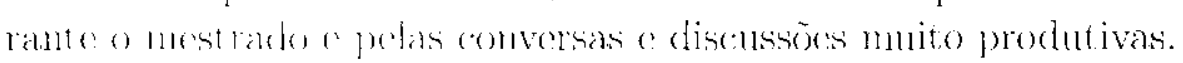

Ao Gretson. perla ajula com a parte de campos potenciais, pelas dicas sobreo

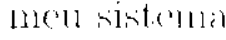

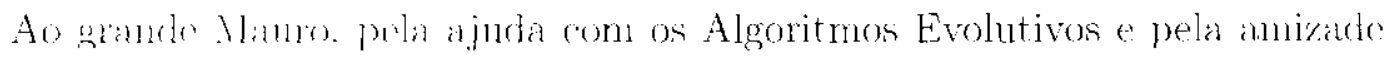

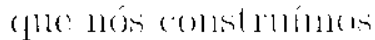

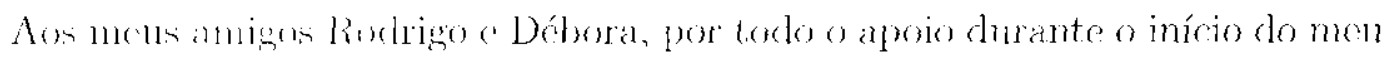
incstrados.

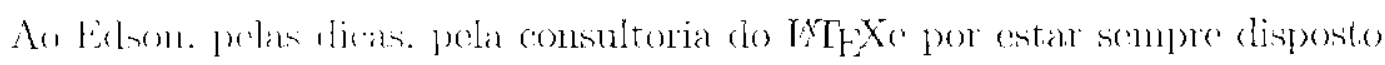
a me ajular.

A torkes con profersones que tive por toda a minha vida, pois, cada un de voces

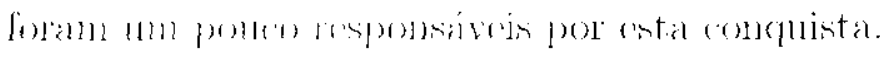

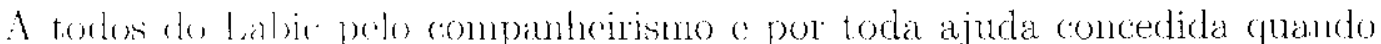
norecosiricis

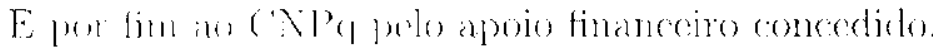




\section{Sumário}

2 Sistemas de Visão Computacional 4

2.1 Sistombe de Vinto Aplicados ao Controle de Robós Móveis . . . . 4

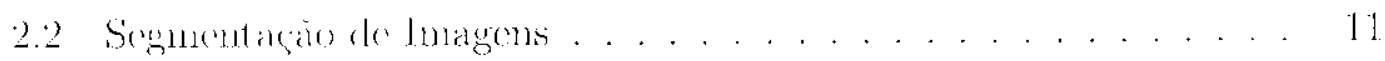

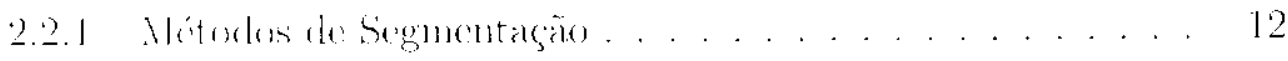

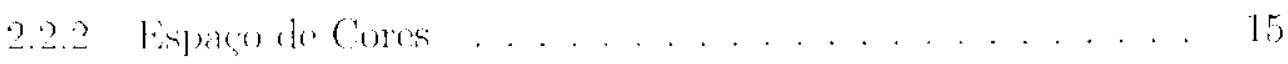

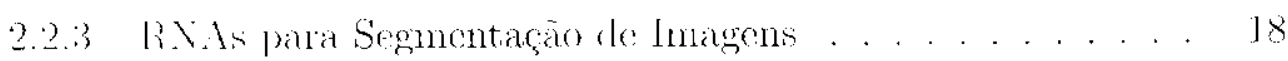

3 Técnicas do Computação Bioinspirada 24

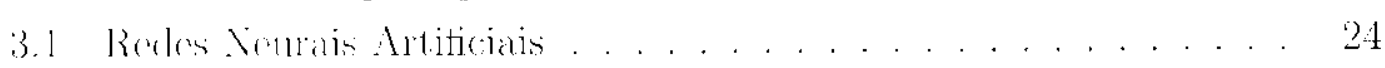

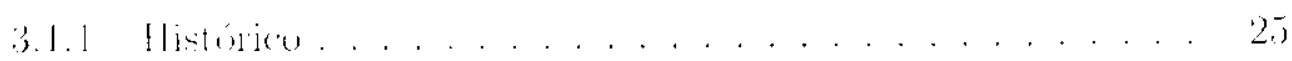

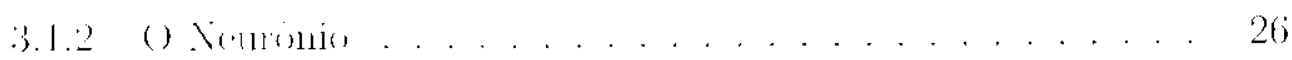

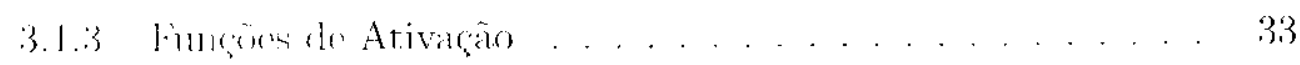

3.1 Clasifiracăo das Redes Veurais . . . . . . . . . 31

3.1 .5 I'eneretron Multi-camadas . . . . . . . . . . 39

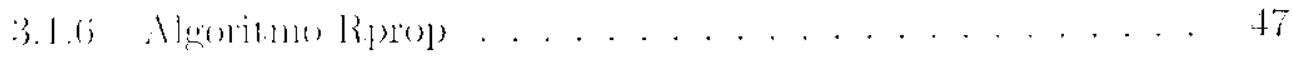

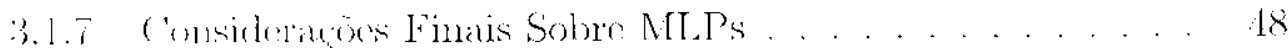

3.2 Alguritmos Evolutivos . . . . . . . . . . . . . . . 49

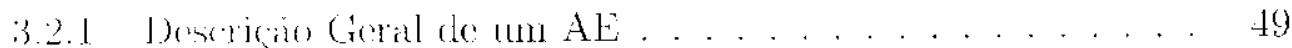

$3.2 .2 \quad 1$ lin Redes Veurais . . . . . . . . . . . 51

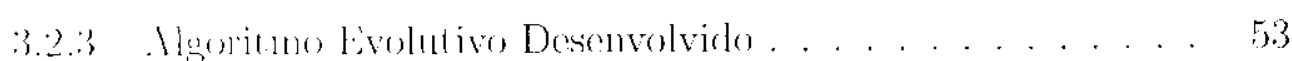

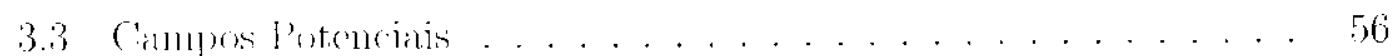

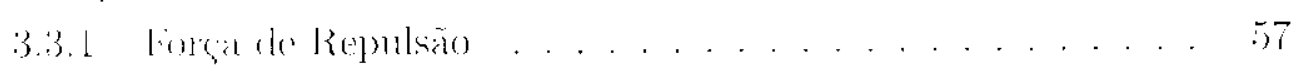

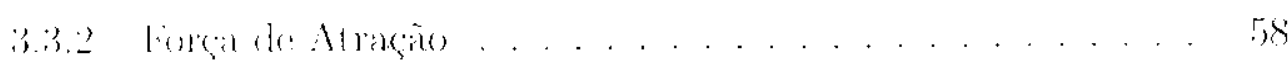

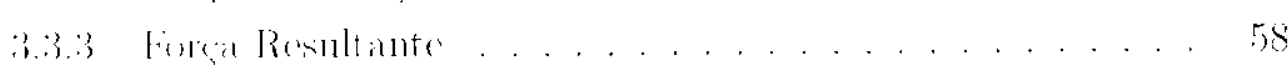

4 O Sistema Computacional Desenvolvido 60

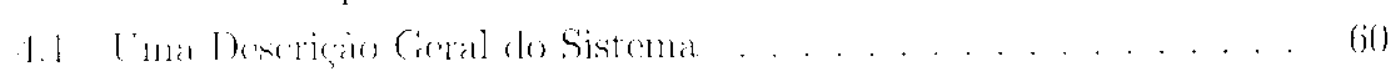

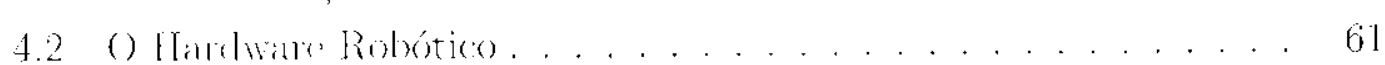




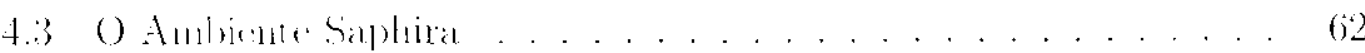

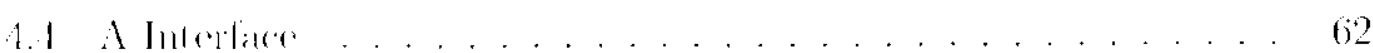

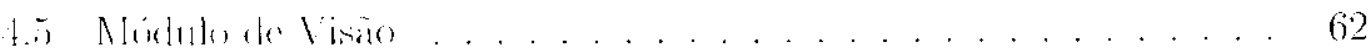

4.5 .1 Pre Promentmento . . . . . . . . . . . . 6.3

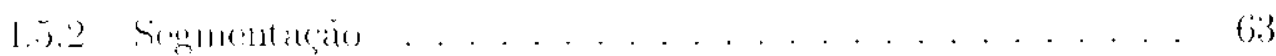

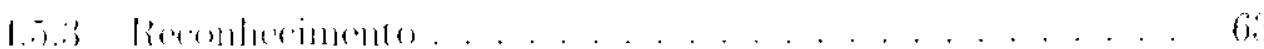

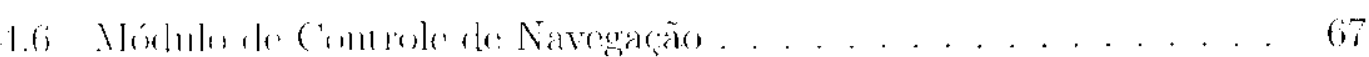

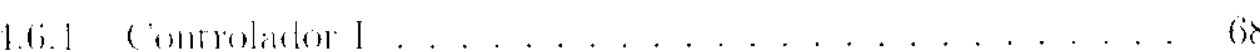

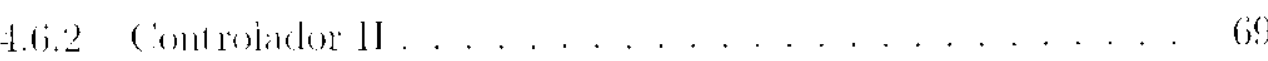

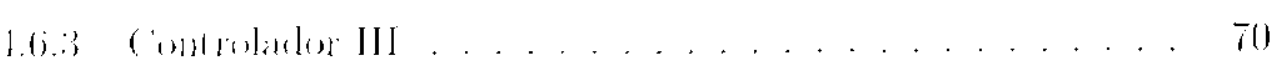

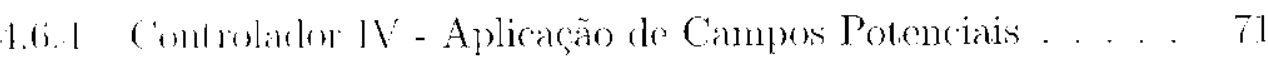

5 Experinchios

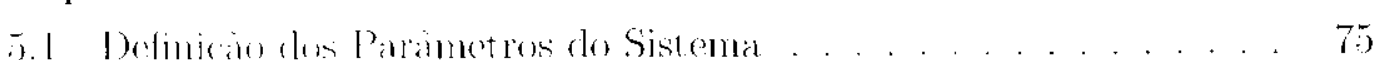

5.1 .1 R.VA para Segmentaçato . . . . . . . . . 76

5.1 .2 liNa para Reconhecimento da Posiçăo do Objeto .... . 83

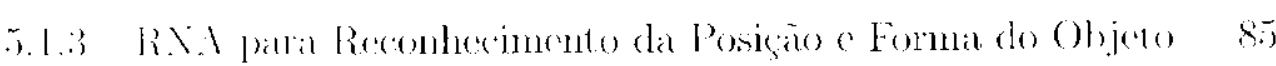

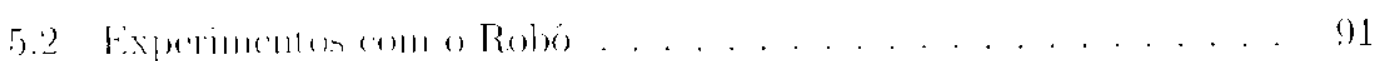

5.2.1 () Rolvi Perseguindo Cores . . . . . . . . . . . 92

5.2 () Rollo Perseguindo (ores o formas . . . . . . . . 93

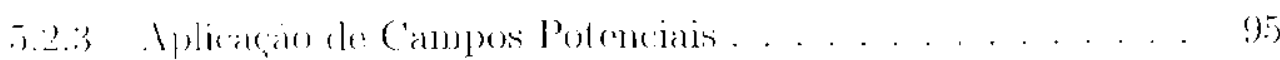

6 Conclusōes 96

Referências Bibliográficas $\quad 99$ 


\section{Lista de Figuras}

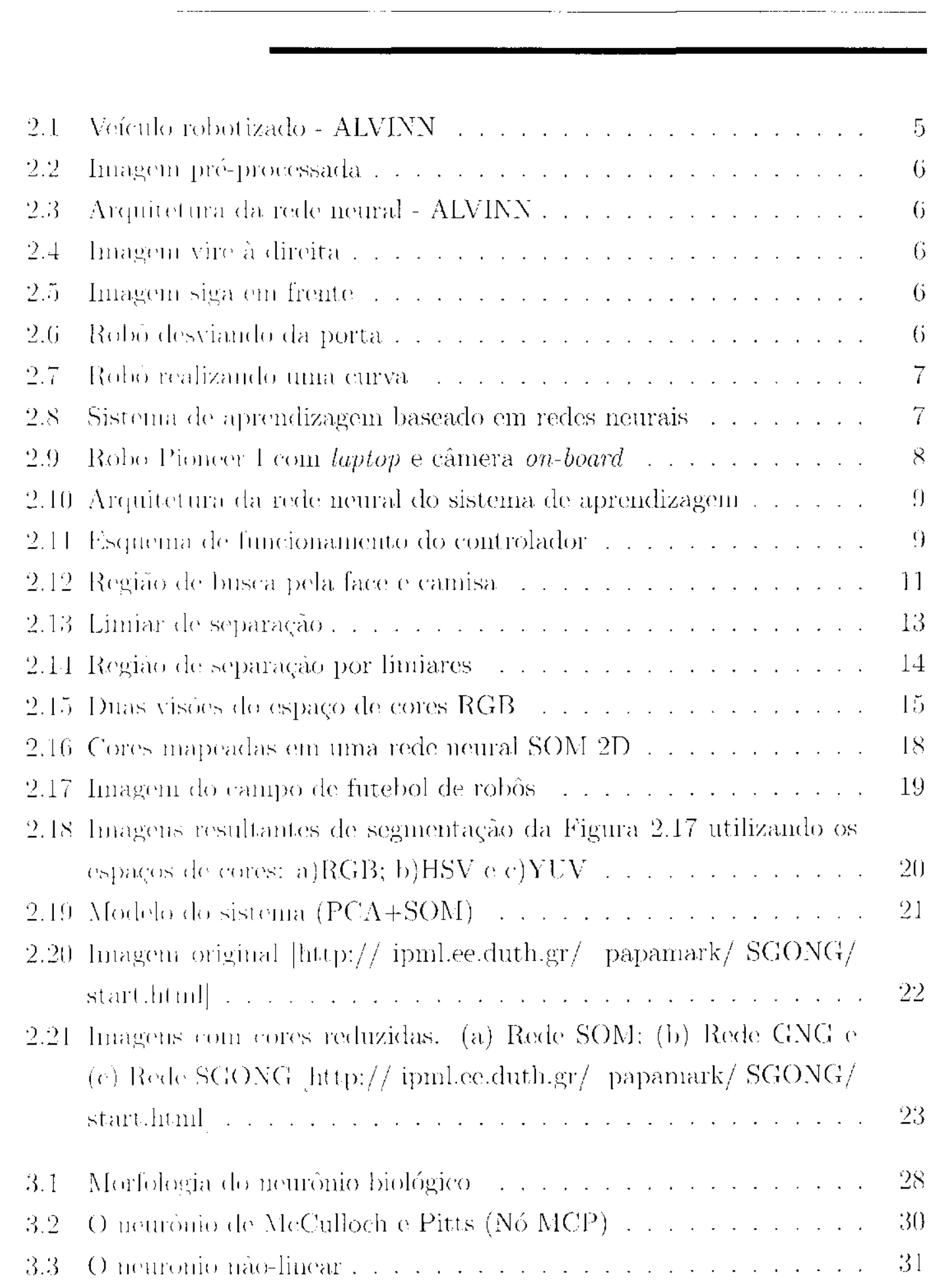




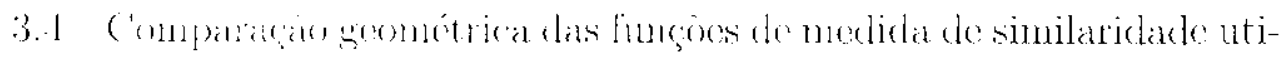

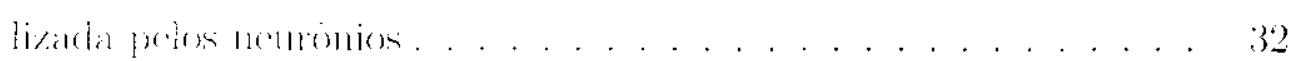

3.5 Dnas selucous (R.YA) para o problema XOR . . . . . . . . 333

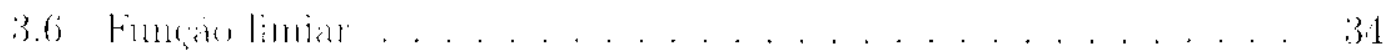

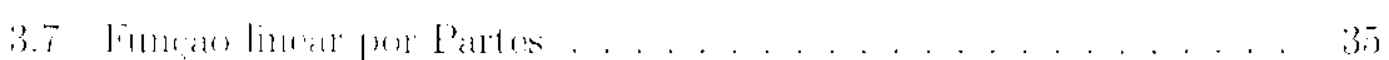

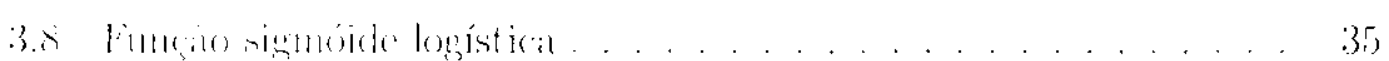

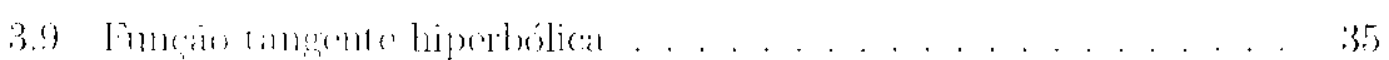

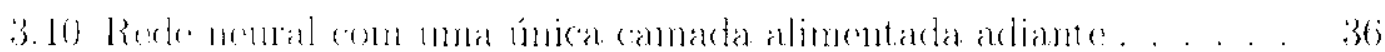

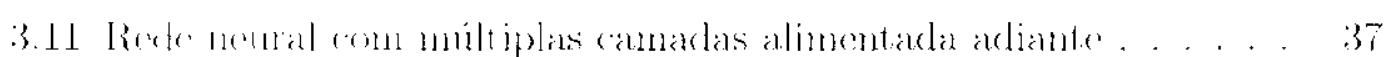

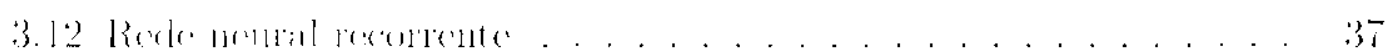

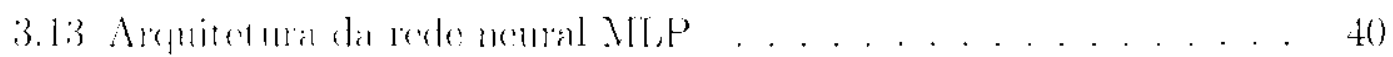

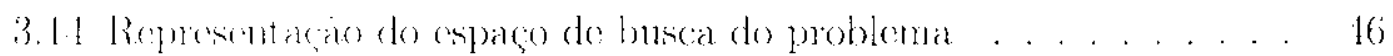

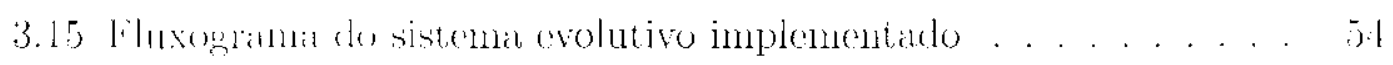

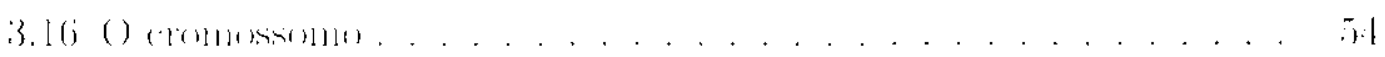

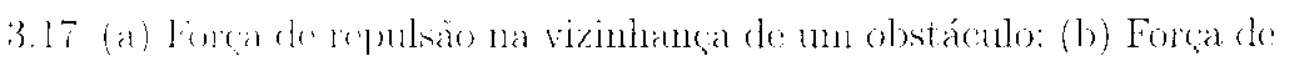
repulsan do ot joto () sobre un robo localizado em $R$. . . . . . 57

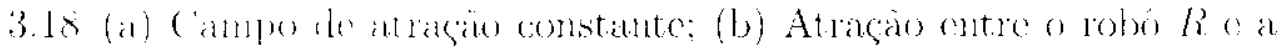

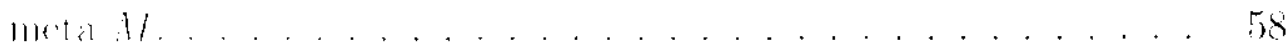

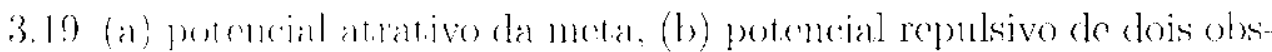

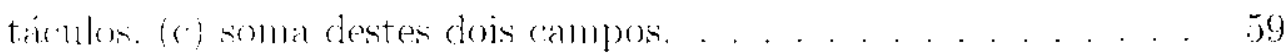

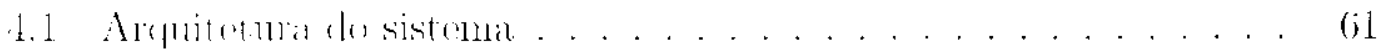

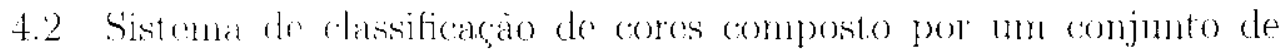

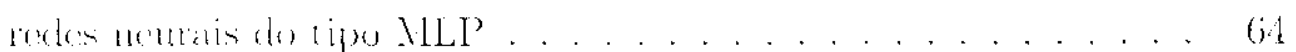

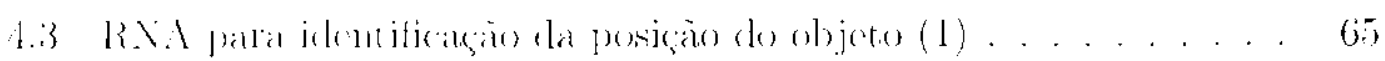

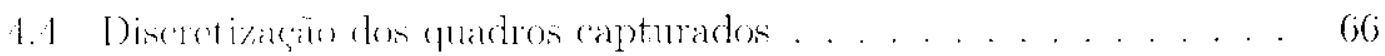

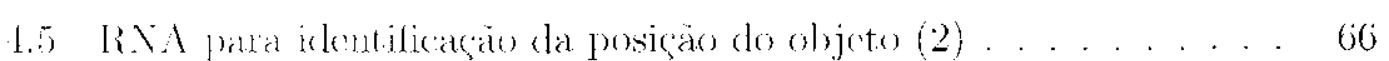

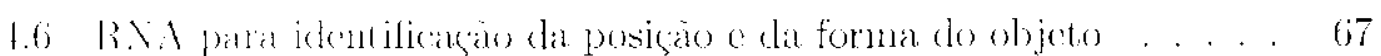

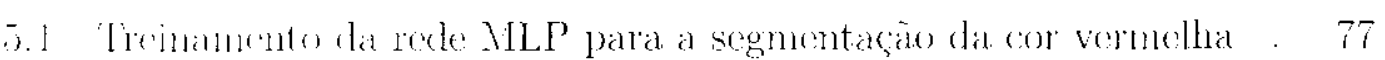

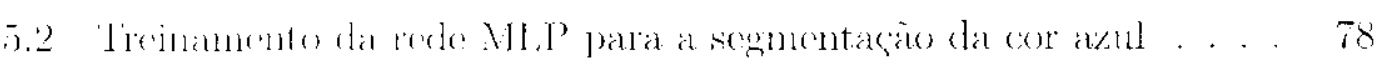

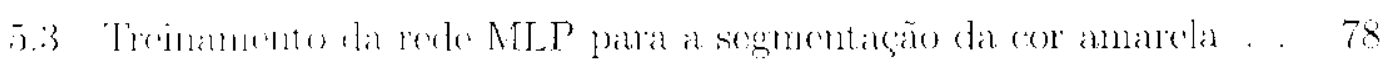

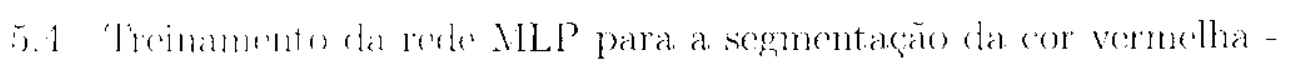

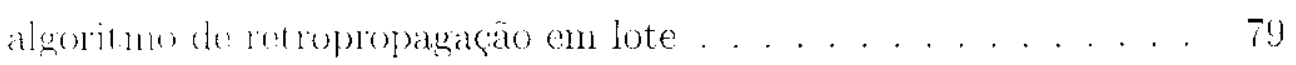

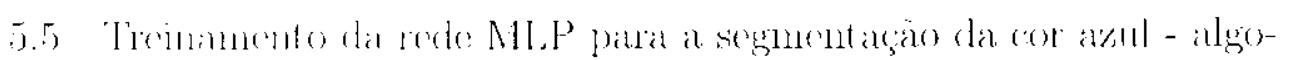

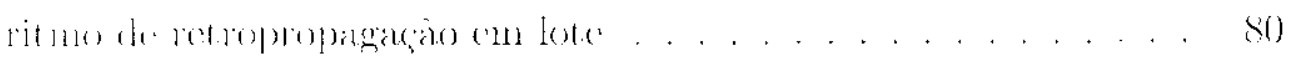

5.6 Troinamento da refo Mlep para a segmentayà da cor amarela -

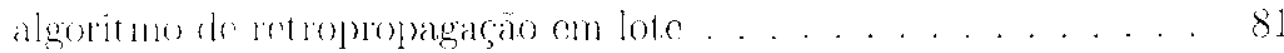




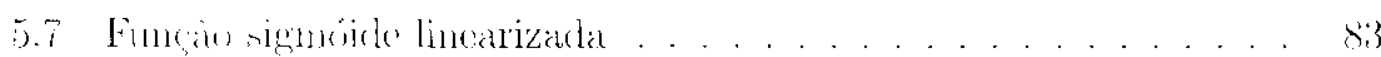

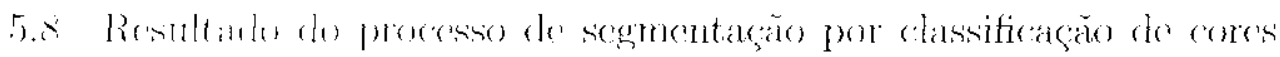

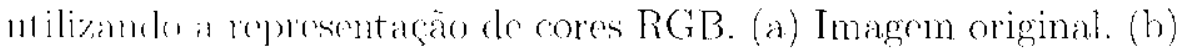

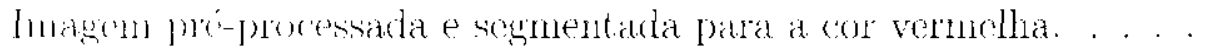

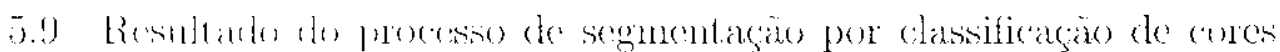

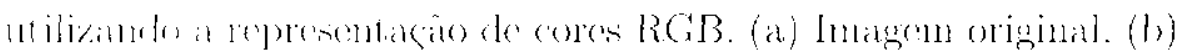

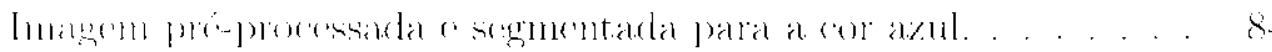

5.10 Resuldario do processo de segmentaça por classificaça do cores

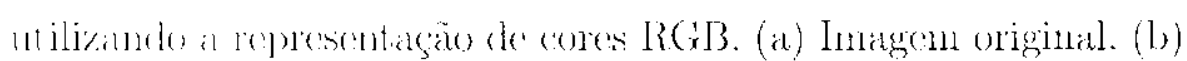

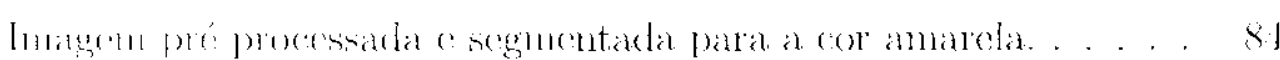

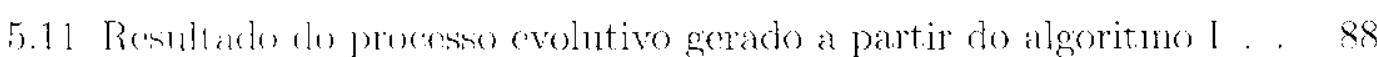

5.12 Fomultarlo do procenso evolutivo gerado a partir do algoritmo Il . 88

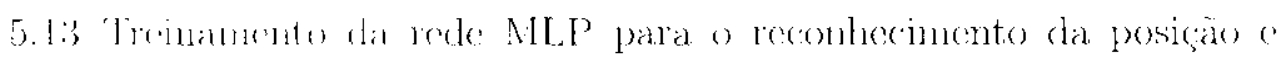

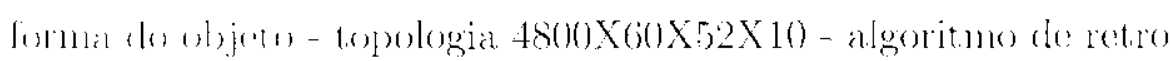

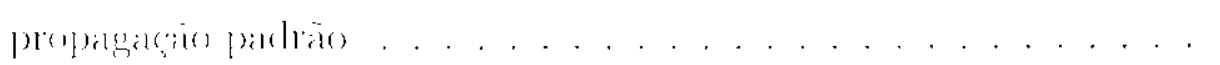

5.14 Trumannente da rede MLP para o reconhecimento da posiçăo "

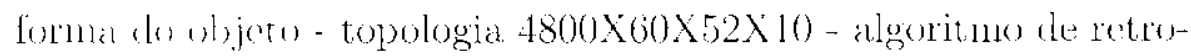

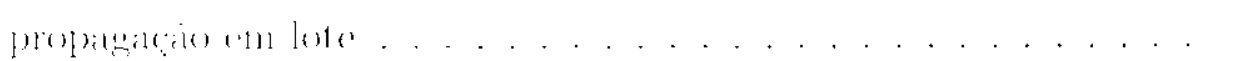

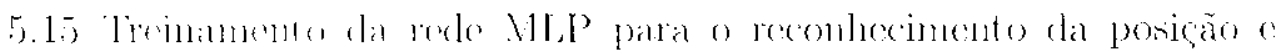

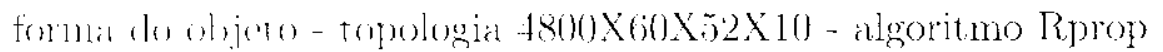

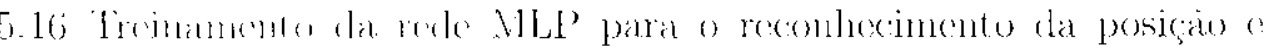
forma de abjete topologia $4800 \times 69 \times 43 \times 10$ - algeritmo de retro-

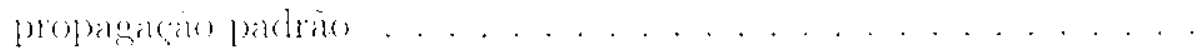

5.17 Treinamonto da rede MLP para o reconhecimento da posição o

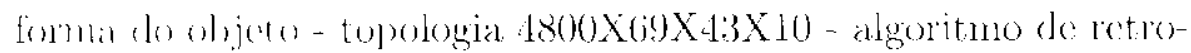

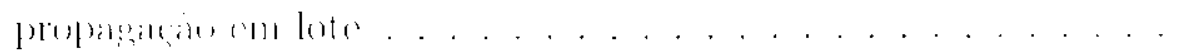

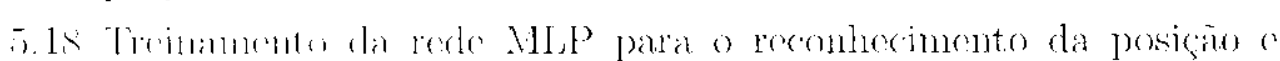

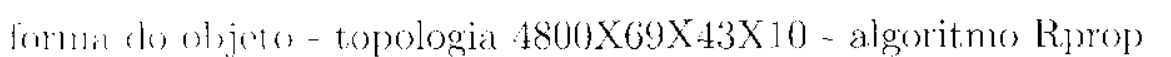




\section{Lista de Tabelas}

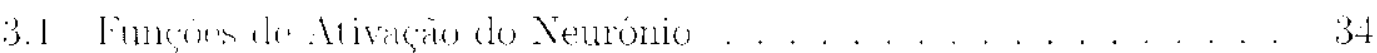

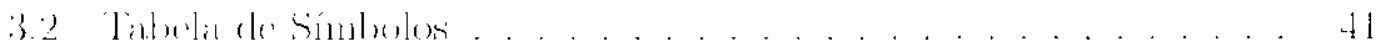

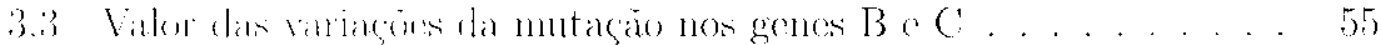

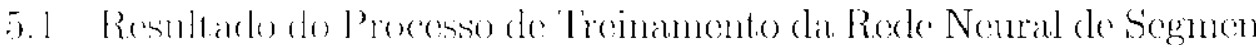

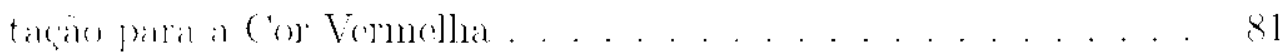

5.2 Remultarlu do l'ruesso de Treinamento da Rede Neural de Segmon-

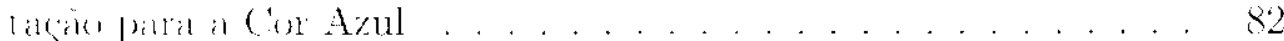

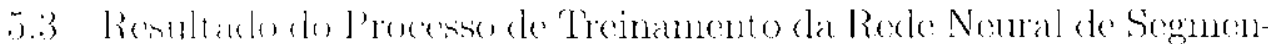

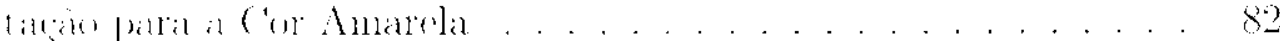

5.1 TRcullardo dk, Processo de Treinamento para a Rede Neural do Ro-

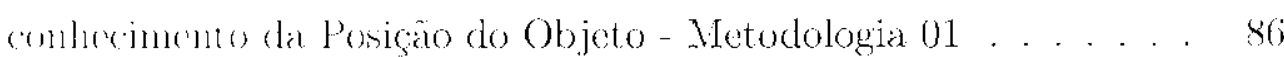

5.5 Resiltado do Prexesso de Tremamento para a Rede Neural de Re-

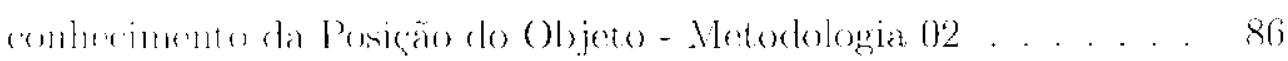

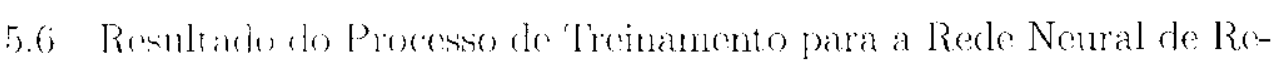

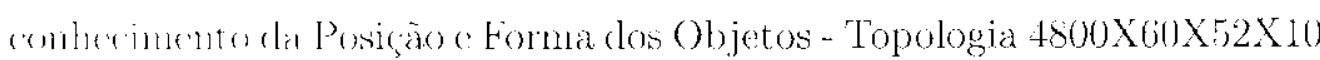
$(A \mathrm{~L}-1)$

5.T Rewaltario de Processo de Treinamento parta a Rede Neural de Reconlucinumen da Posicăo e Foma dos Objetos - Topologia 4800X69X43X10 (AE-II) 


\section{Lista de Algoritmos}

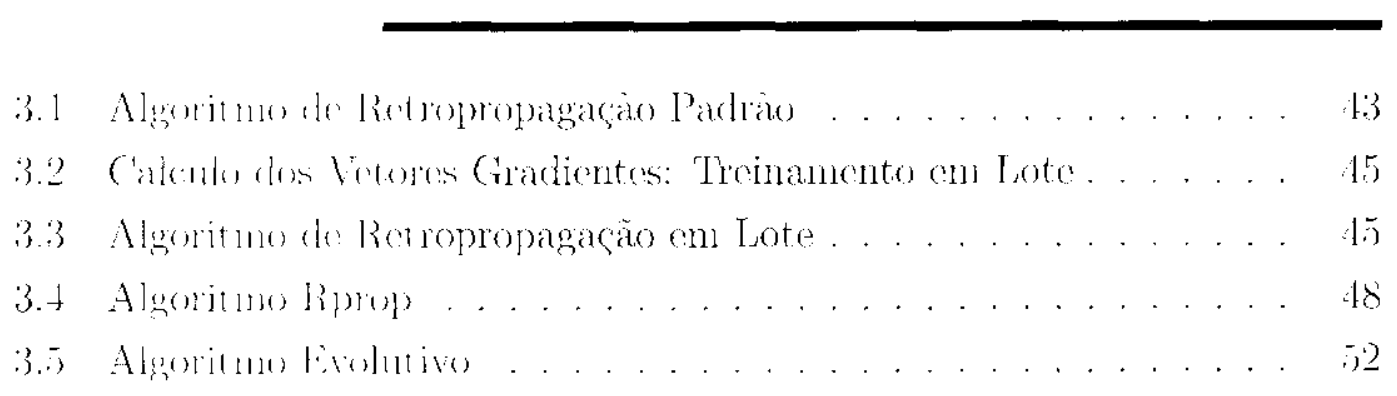




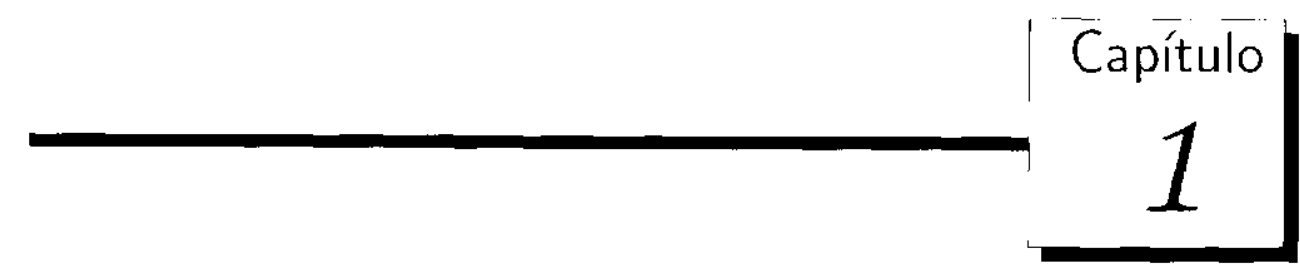

\section{Introdução}

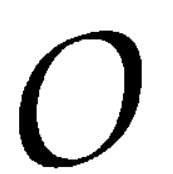

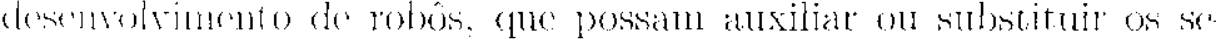

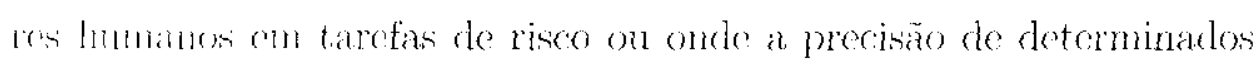

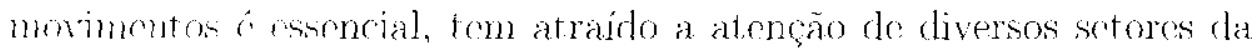

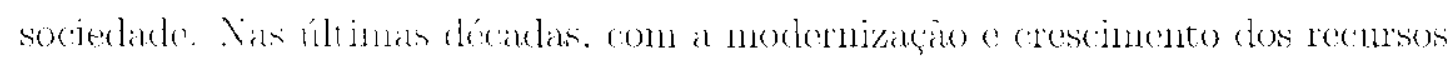

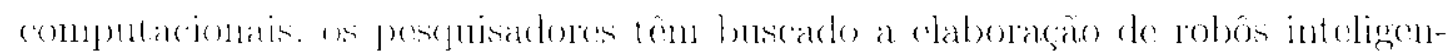

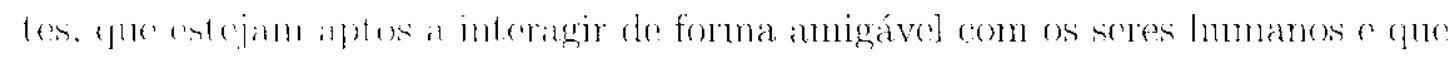

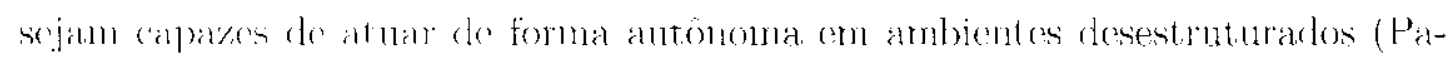

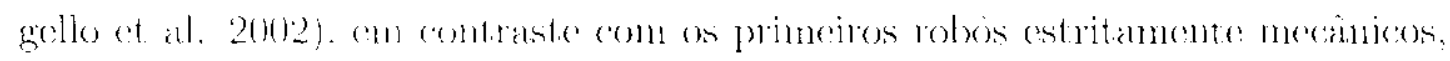

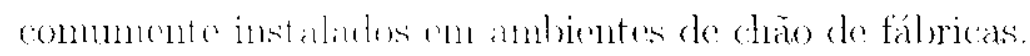

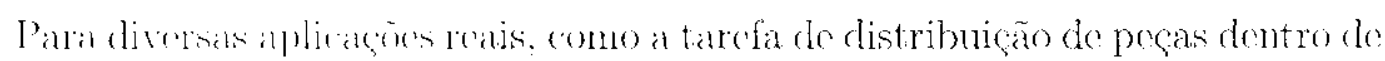

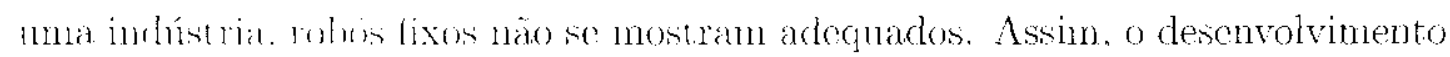

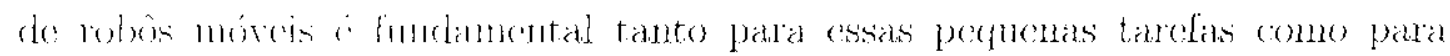

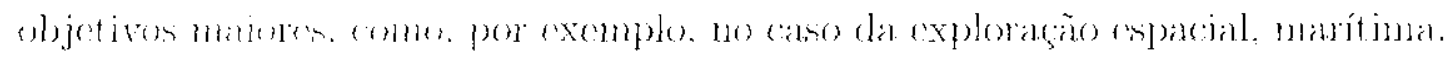

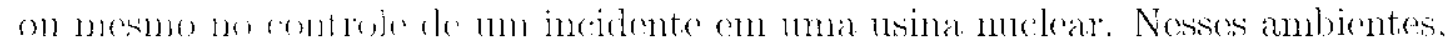

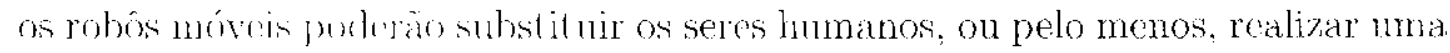

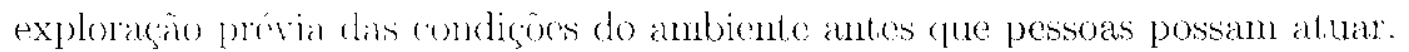

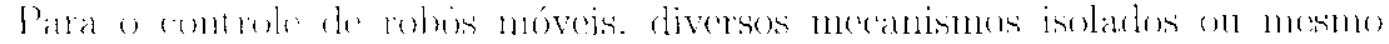

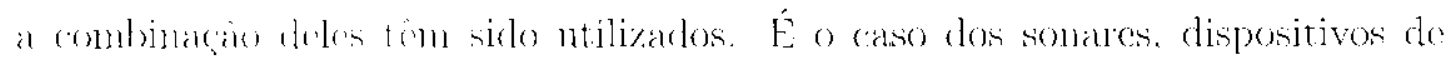

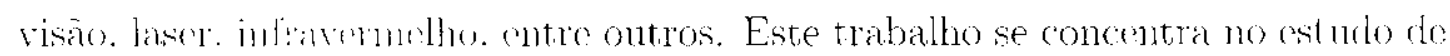

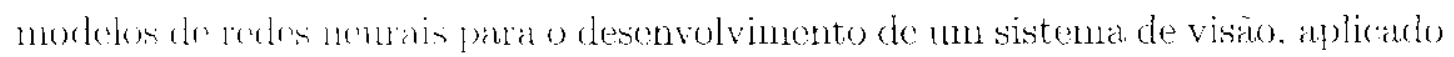

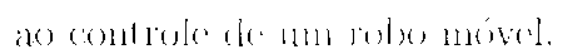

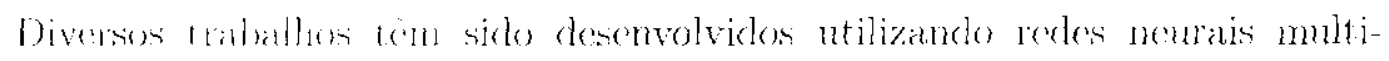

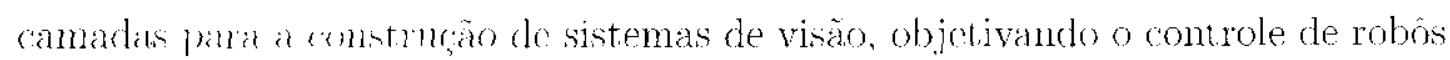

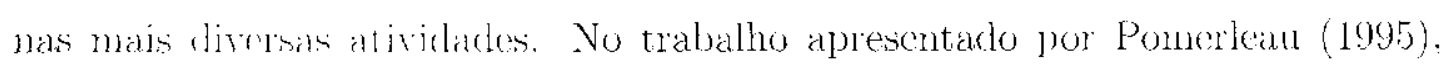

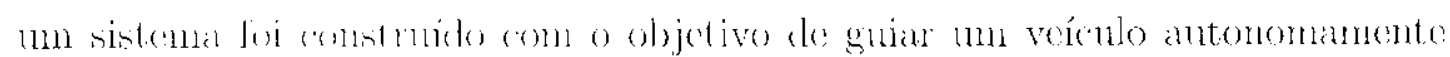

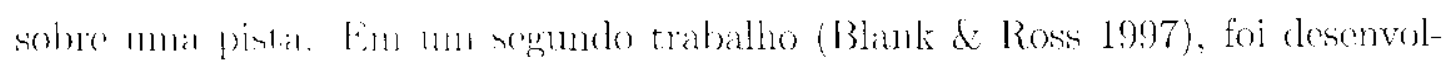




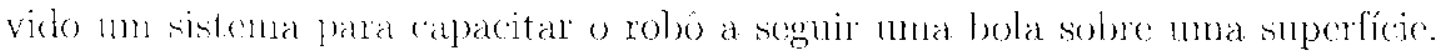

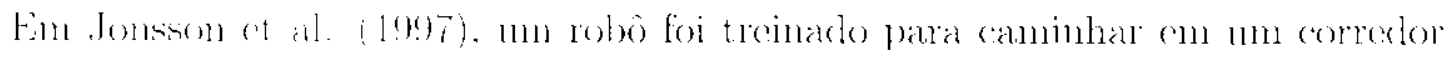

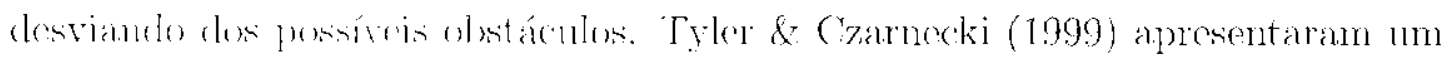

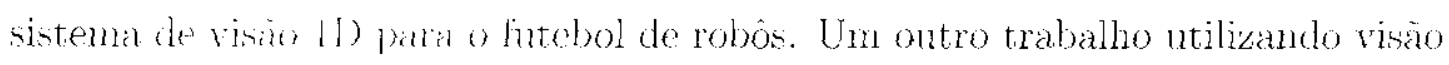

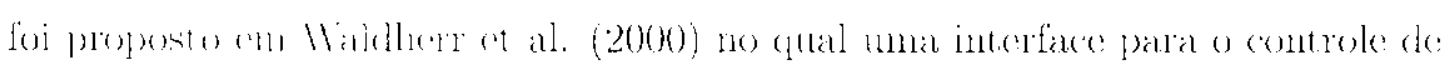

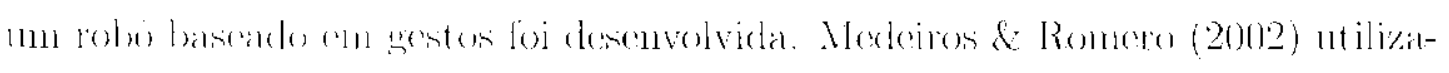

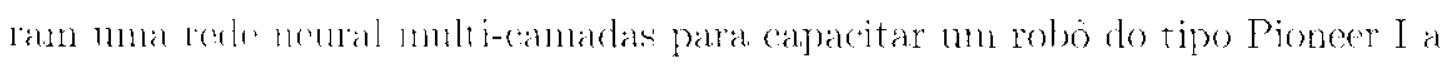

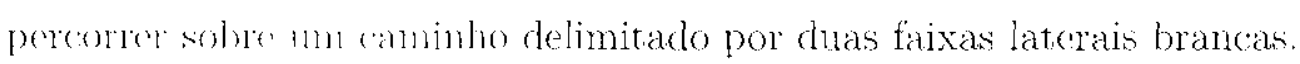

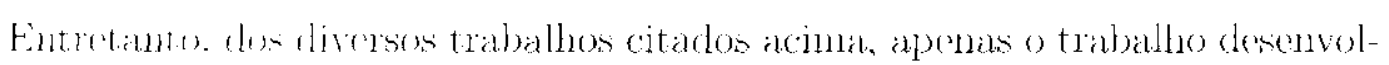

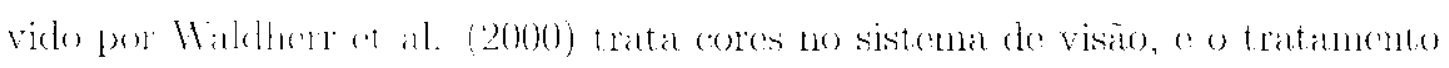

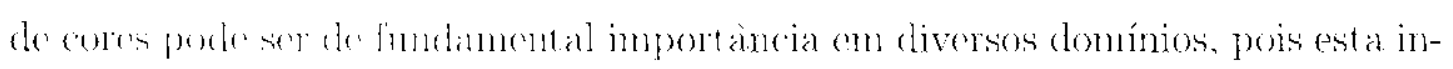

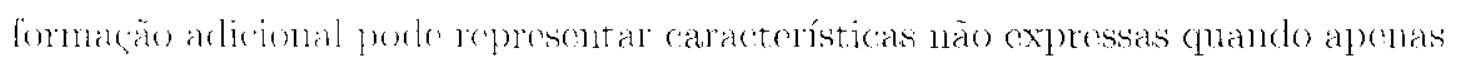

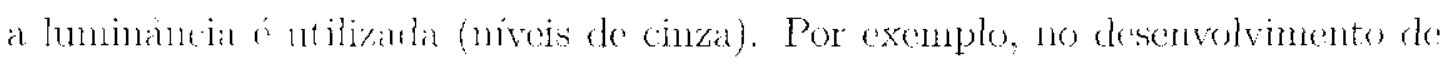

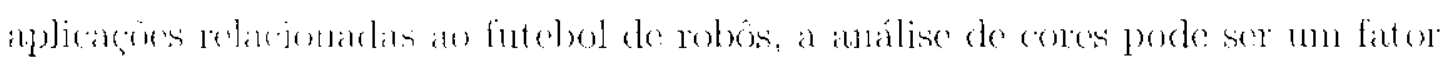

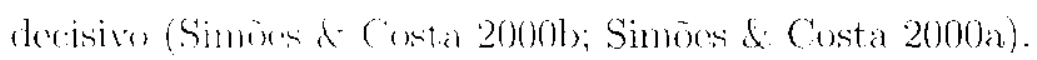

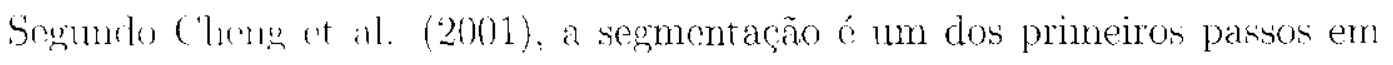

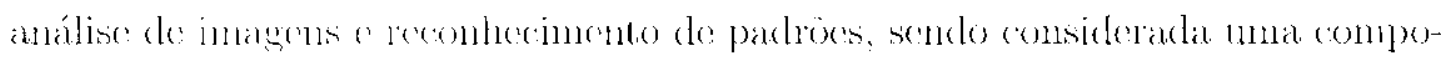

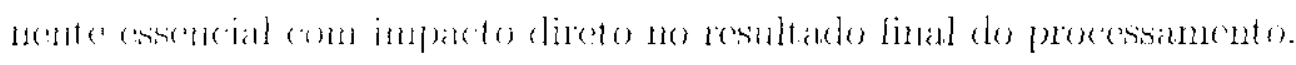

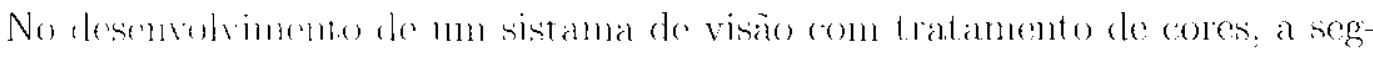

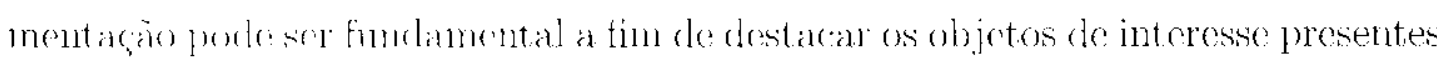

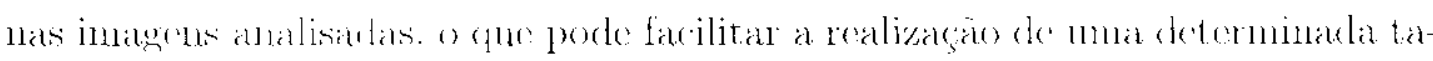

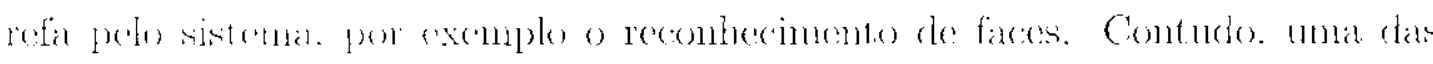

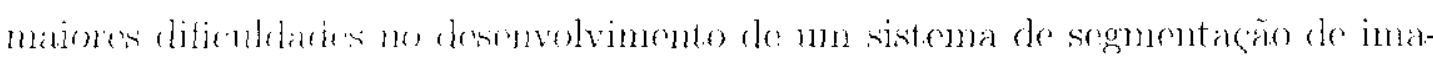

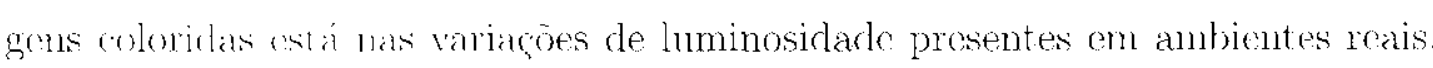

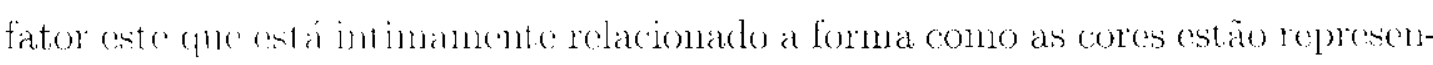

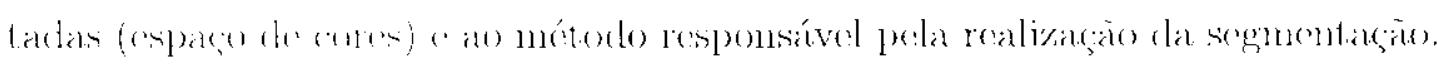

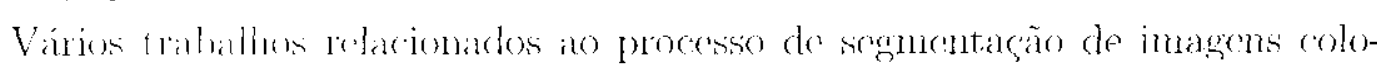

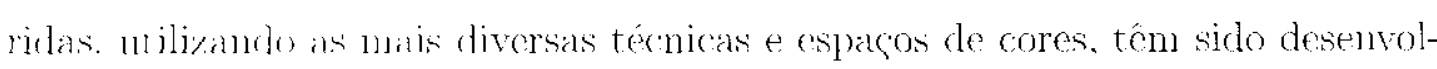

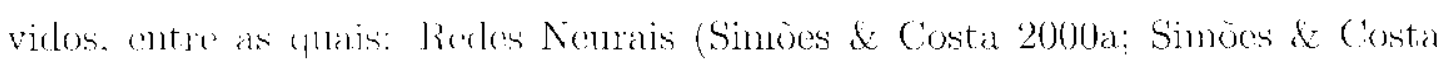

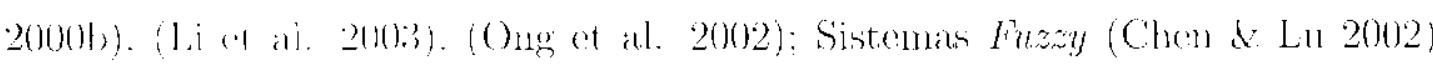

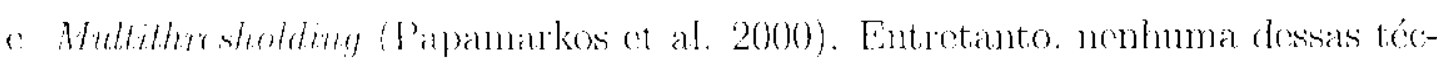

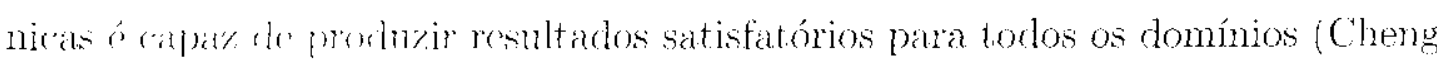

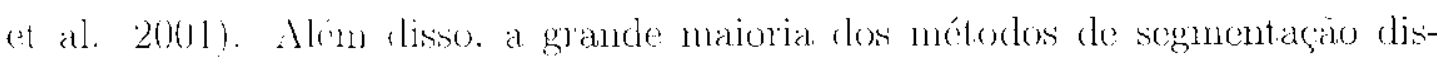

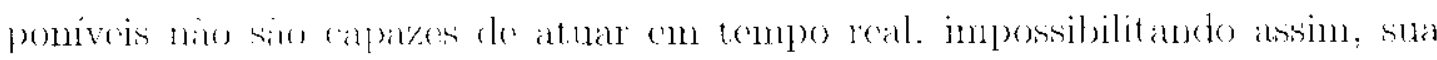

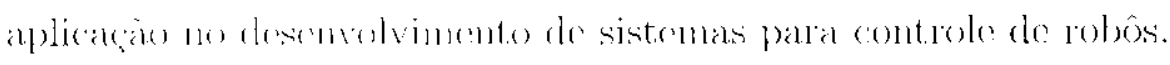

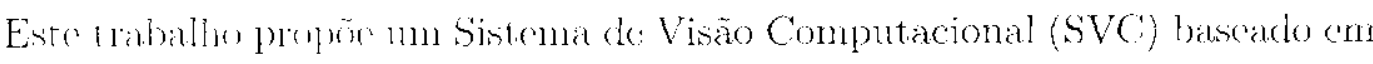
redes neurain para o controle de robós noveis com canera embarcada. Comos 


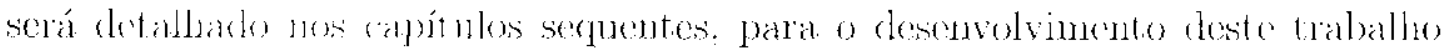

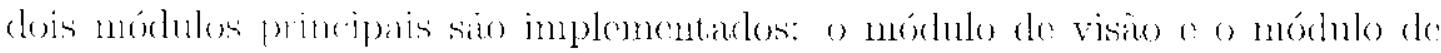
(ontirole.

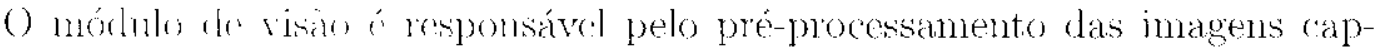

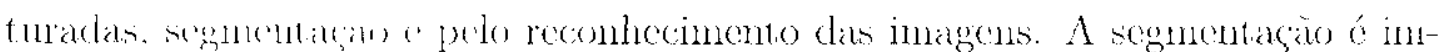

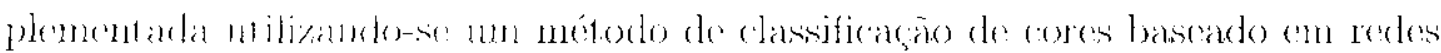

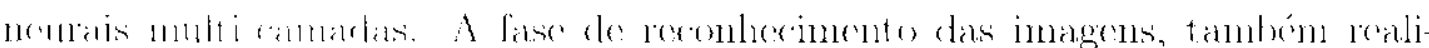

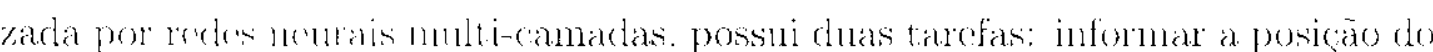

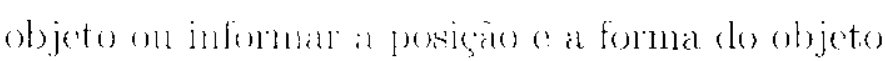

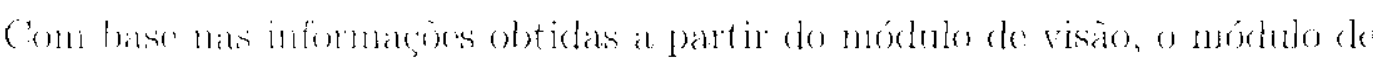

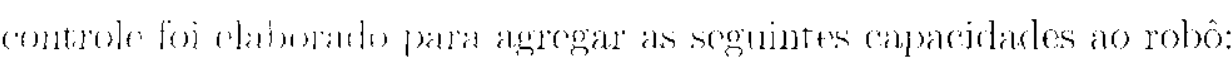

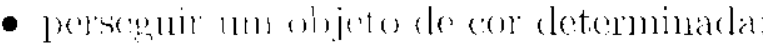

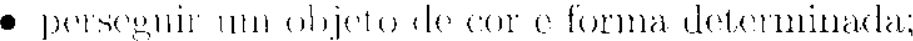

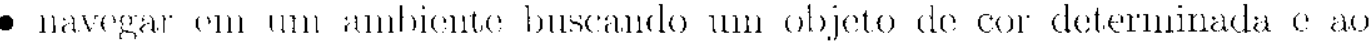

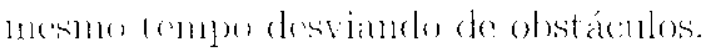

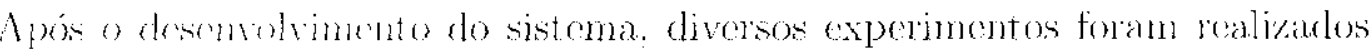

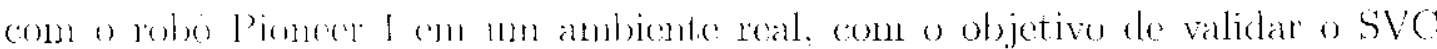
desemvelvide

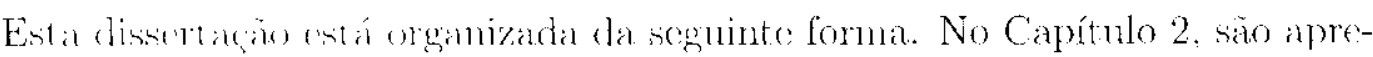

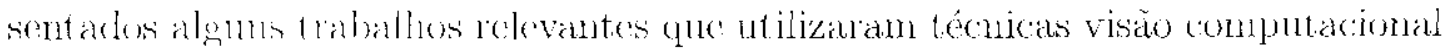

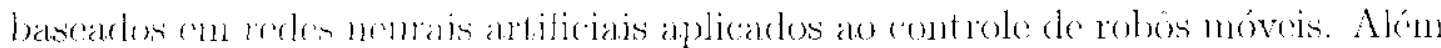

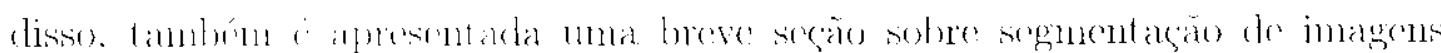

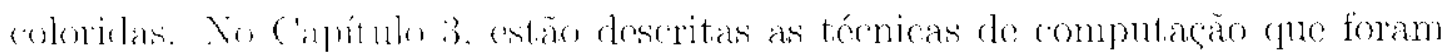
utilizatas na daturavio deste trabalho. O sisterna proposto é apresentado no

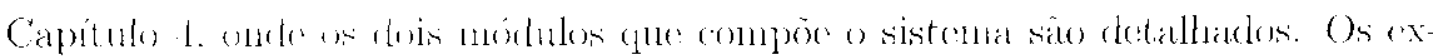

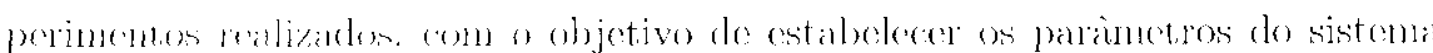
propesto. ben conne an multados obtirlos a pertip dos experimentos realizado

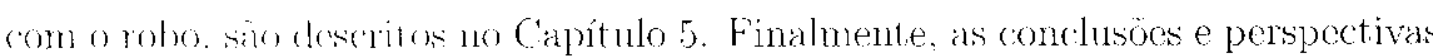

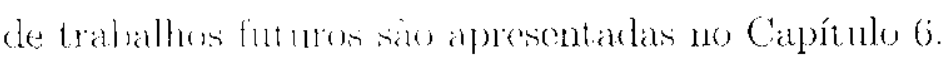




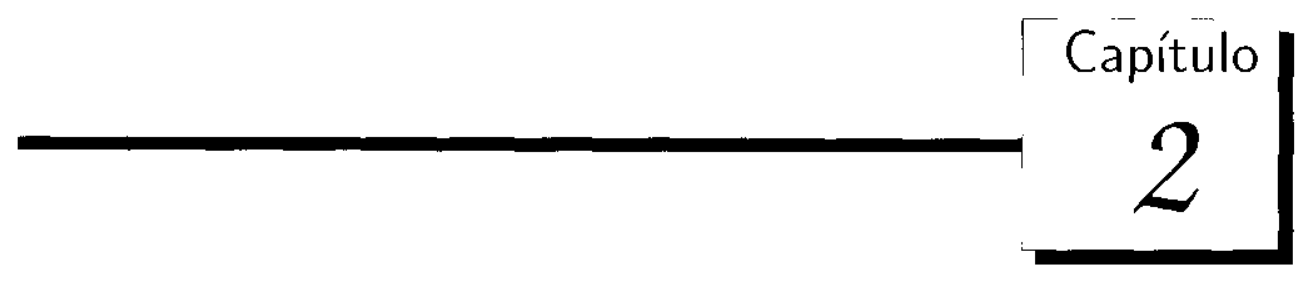

\section{Sistemas de Visão Computacional}

$\mathcal{A}$

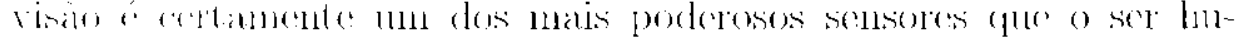

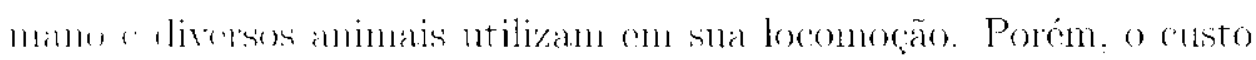

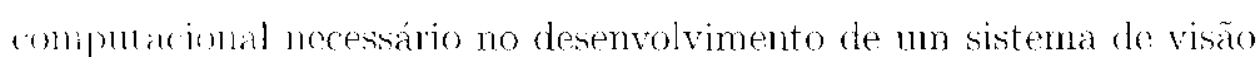

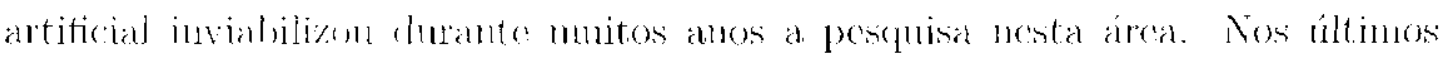

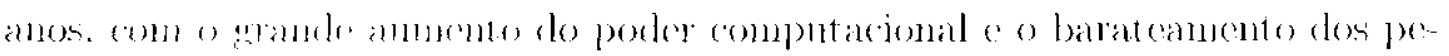

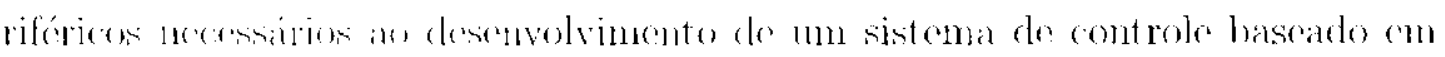

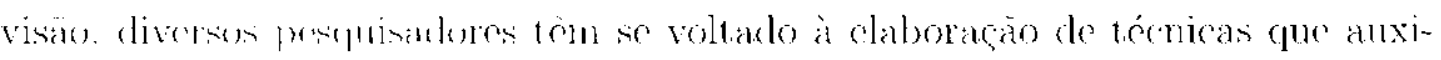

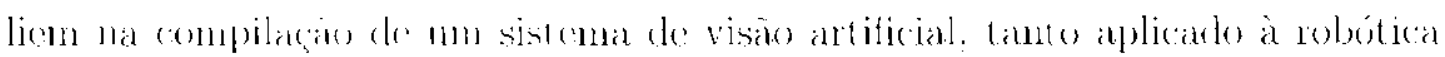

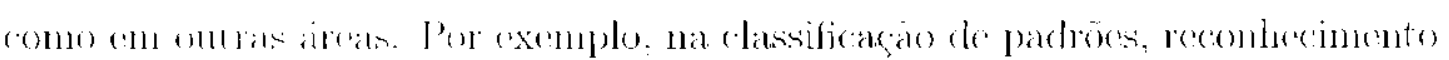

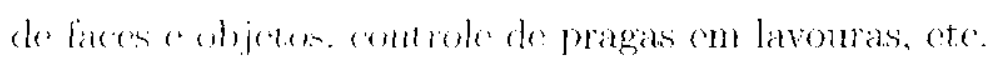

Segunde Vialwa ig9:3) o termo Visão Computacional pode ser definido (ollo:

"1 Vara cimputarional descrece automaticamente as estruturas $t$ as propradates de ama cena tridimensional do mundo a partir de uma

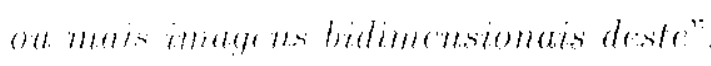

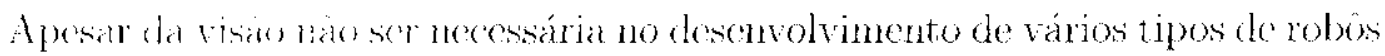

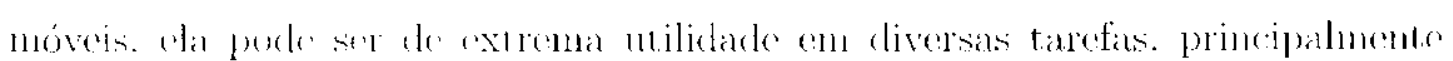

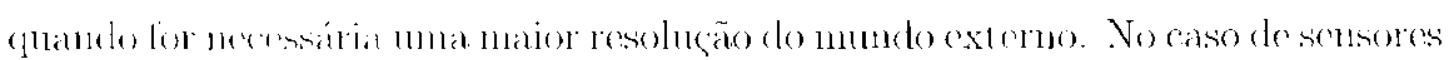
como o somat " "limer năo é possivel realizal a distinção de cores e texturas

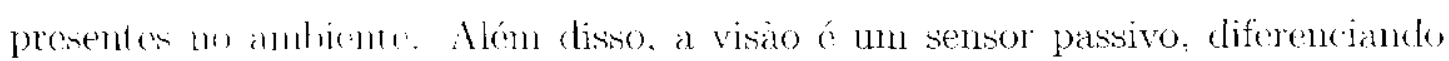

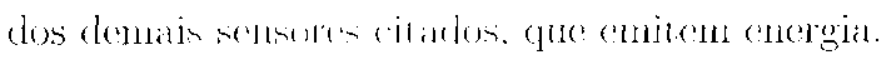




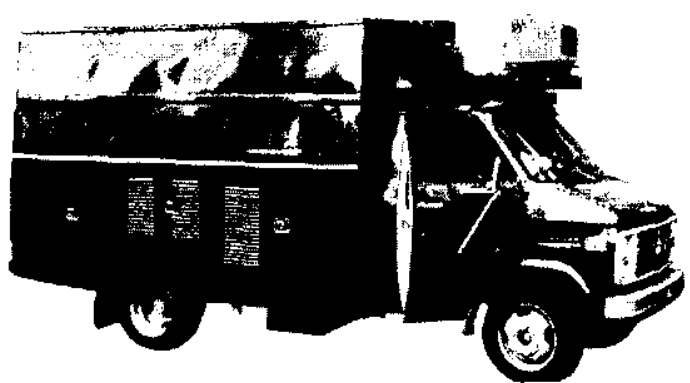

Fönum 2. 1: Vóculo robotizado - ALVINN (Poncrlean 1995)

\subsection{Sistemas de Visão Aplicados ao Controle de Robôs Mó- veis}

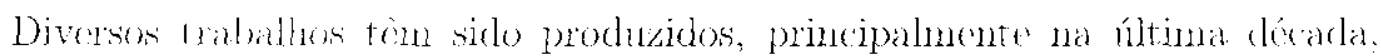
acoplando sistentate de visüu computakional an controle do robos.

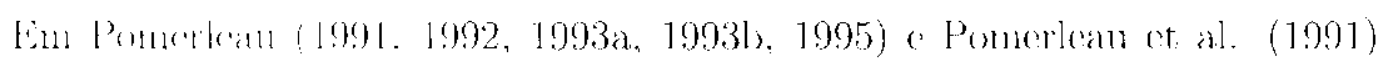

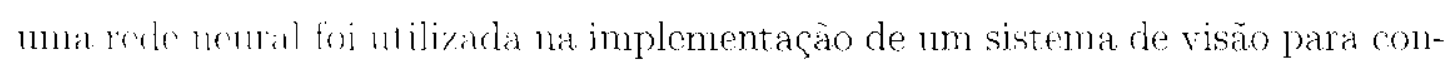

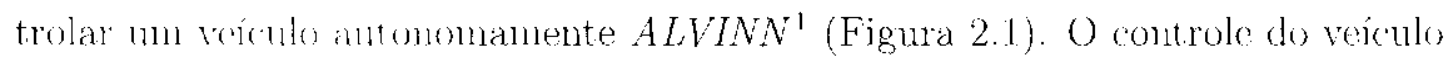

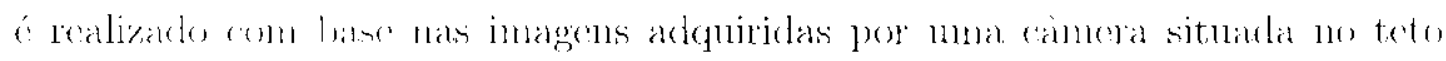

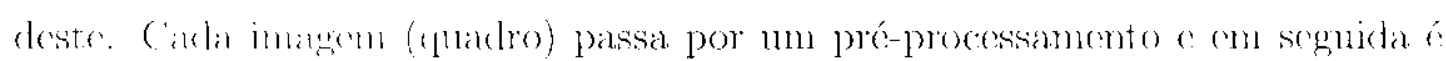
subneticla à verk wrural que desempenha o papel de controlar a trajctória do robô (antomórel) pula ustada, isto é, indicar ao robo qual a direça que esto

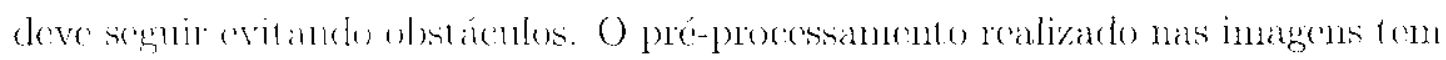

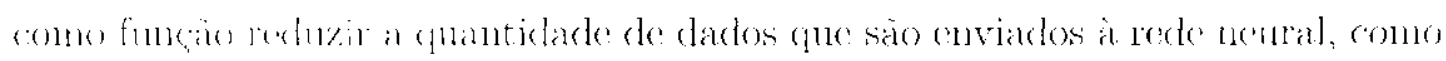

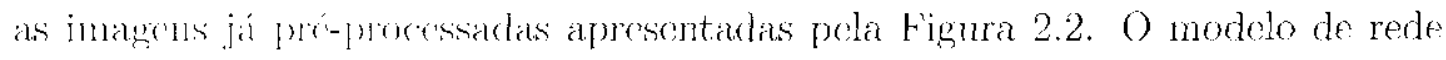
neurat utilizate neste trabatho foi uma MLP (Capitnlo 3. Seçäo 3.1.5) totalnente

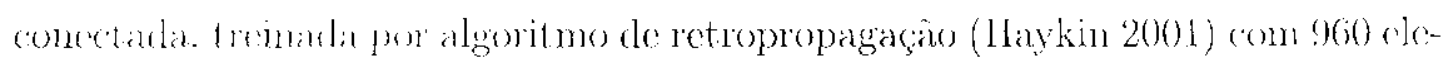

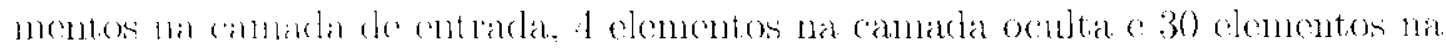

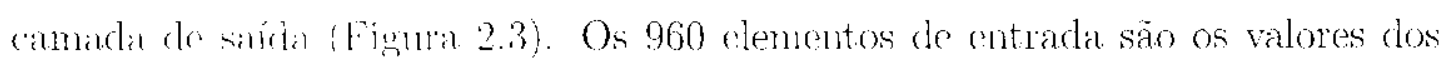
pontos da innacon já pré-processada (30X32) o os 30 clementos de sáda repre-

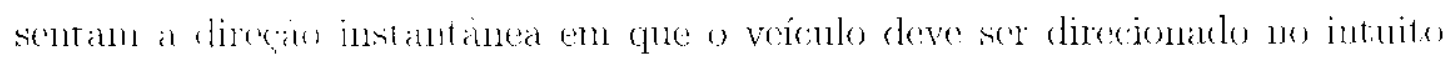

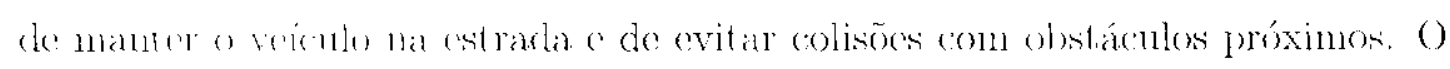

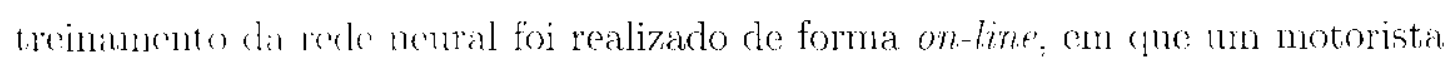
gruia o véfolo pelit estrada enquanto a rede neural aprende o comportamento

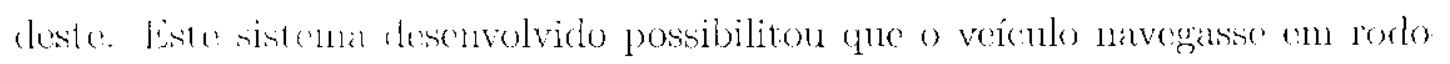

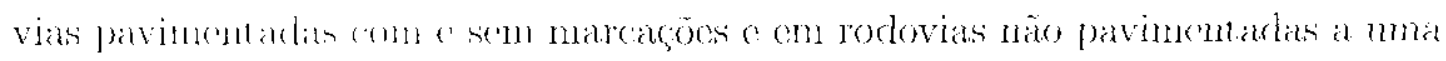

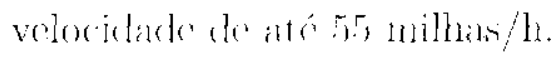

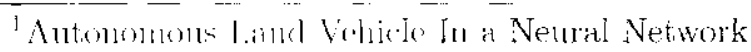




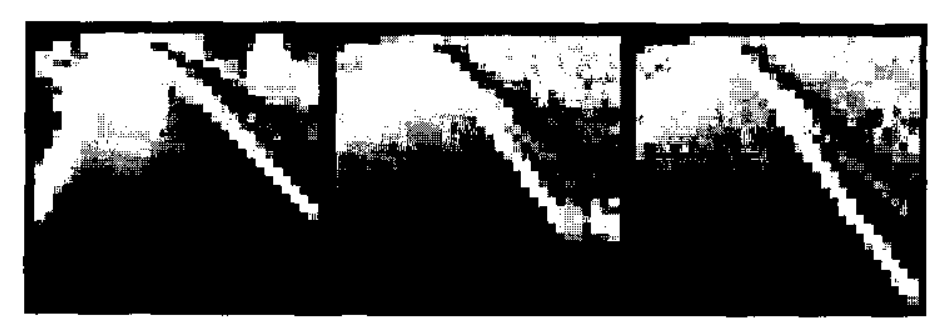

frignm 2.2: Inagem préprocessada (Pomerleau 1995)

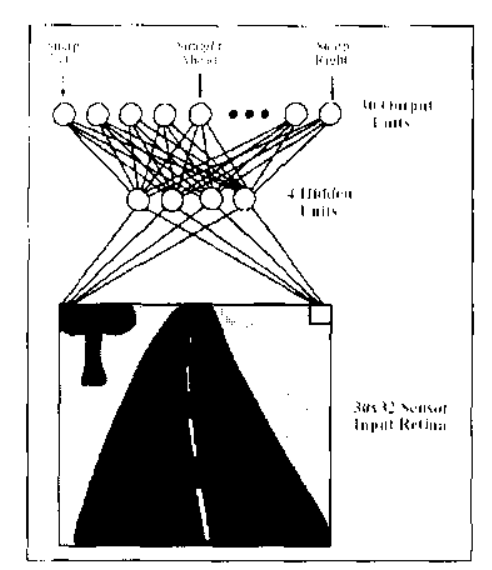

Fignua 2.3: Areuitetura da rede nenral - ALVINN (Pomerleau 1995)

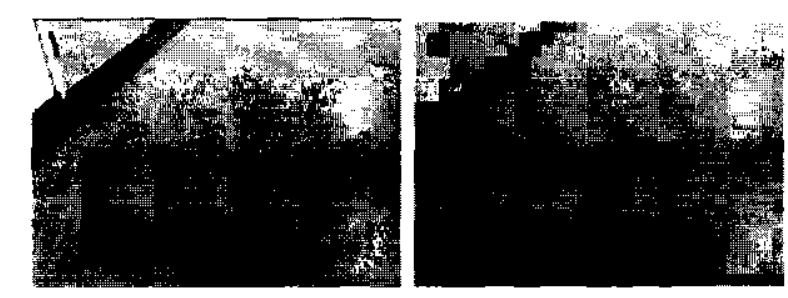

Fignura 2.4: Imagen vire à dircita (Jonsson at al. 1997)

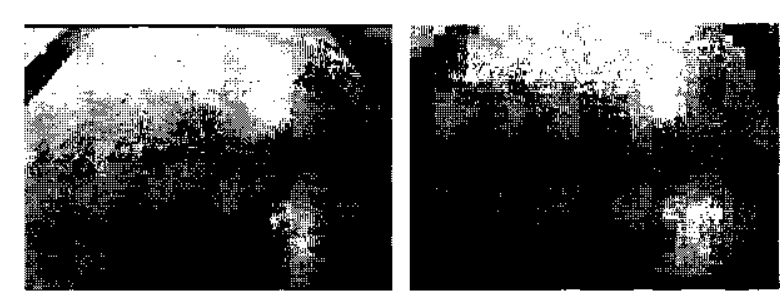

Figna 2.5: Imagen siga en frente (Jonsson et al. 1997)

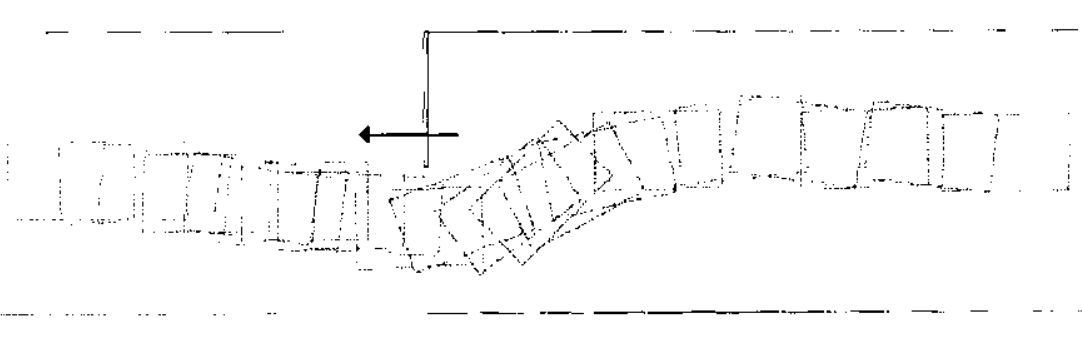

Fingura 2.6: Roho desviando da porta (Jonsson et al. 1997) 


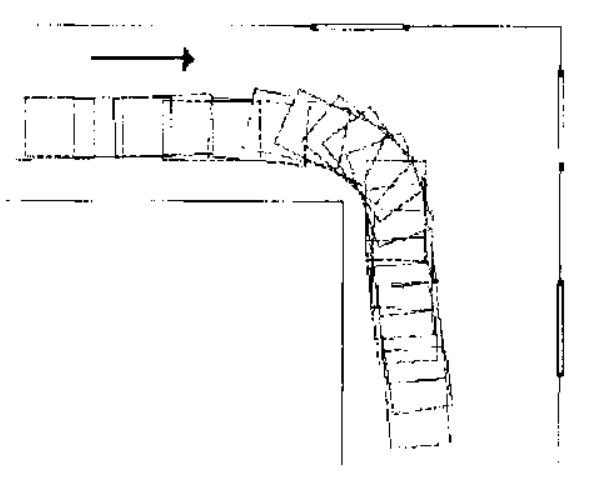

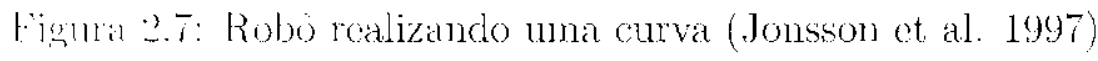

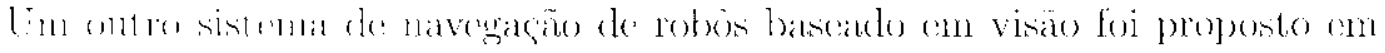
Jonson on al. (1997). () objectivo deste trabalho for capacitar um robo a caminhar

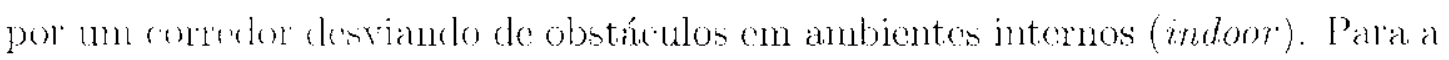

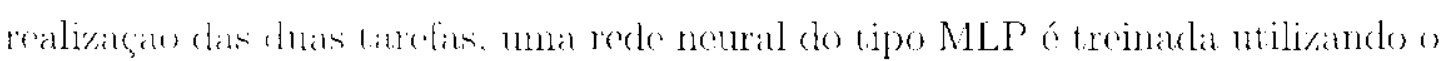

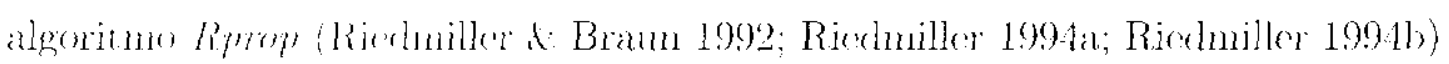

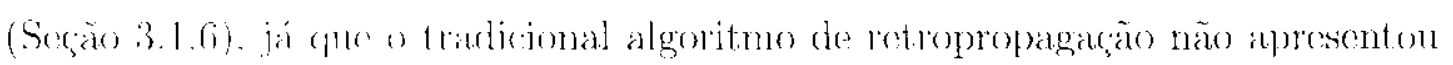
bons lesultatus. As imagens saio captadas à uma frequencia de 7 quadros/s por

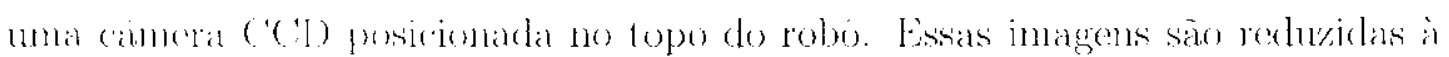

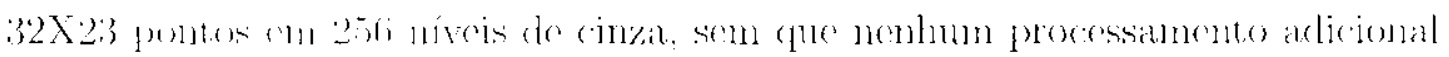

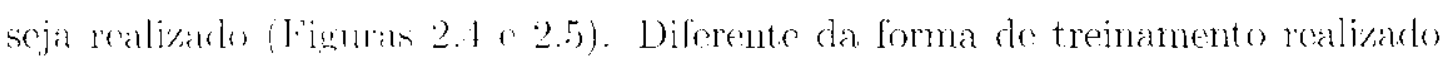
cm Ponnrlean (1995). neste traballow a rede neural foi treinada con ma base

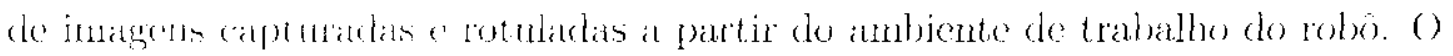

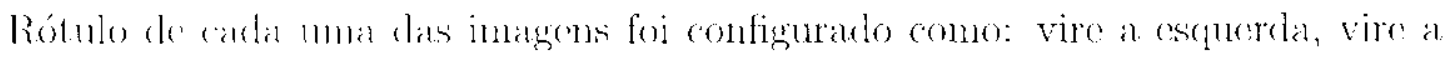
direitan ont sign end fireme.

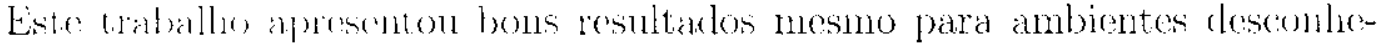

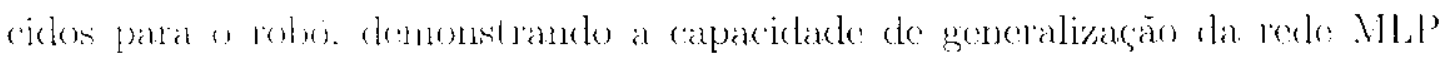

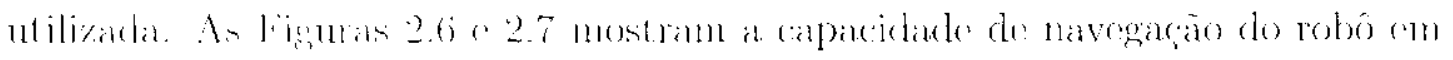

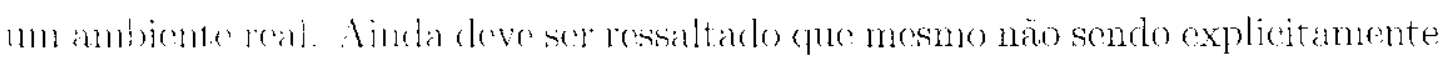

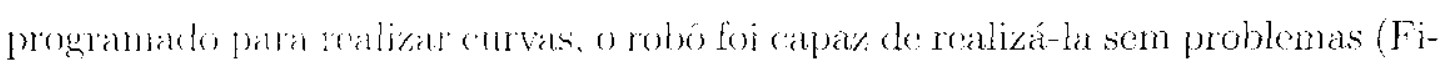

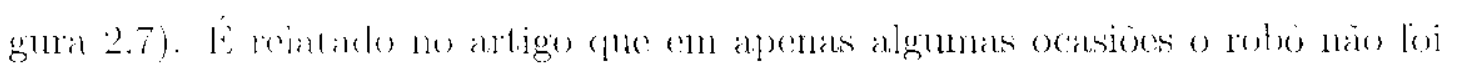

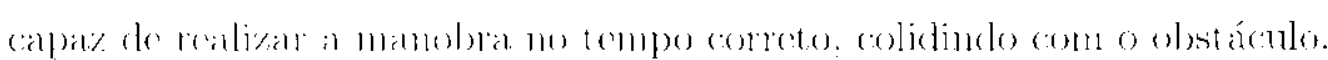

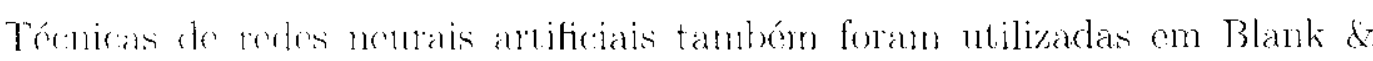

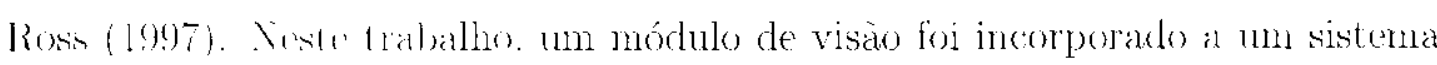

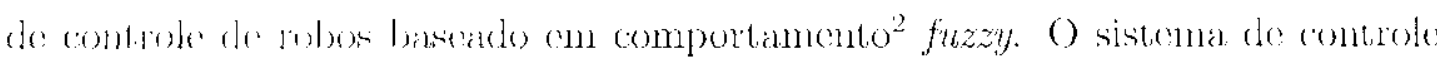
(1) robos funciona da seguinte forma: IF door-on-left THEN turn-left oncle

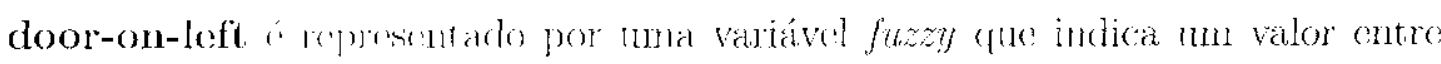

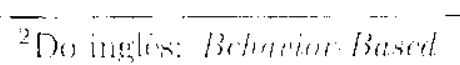




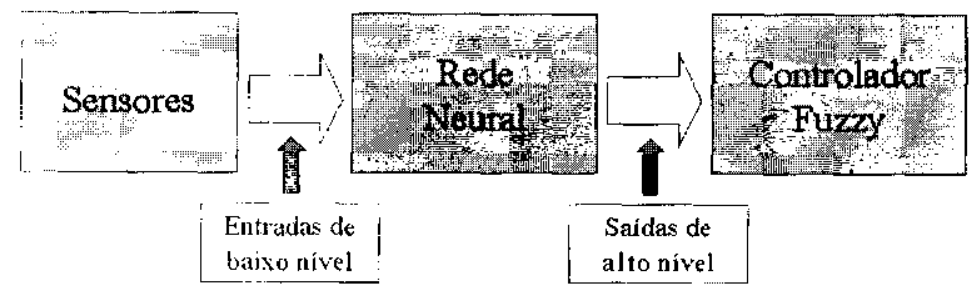

Finna 2.s: Sintema de aprondizagen bascado ent redes neurais

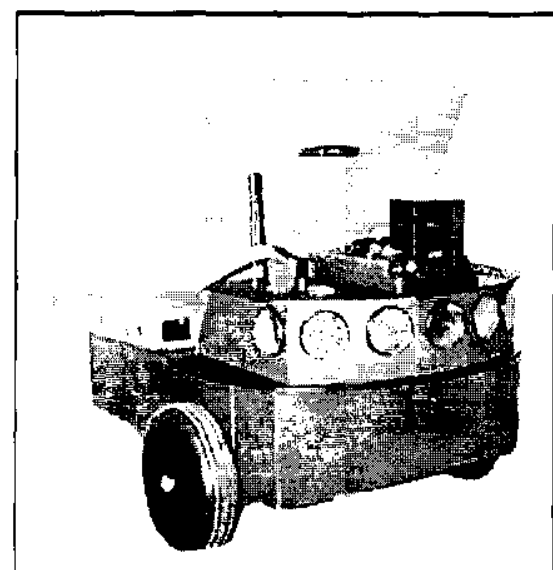

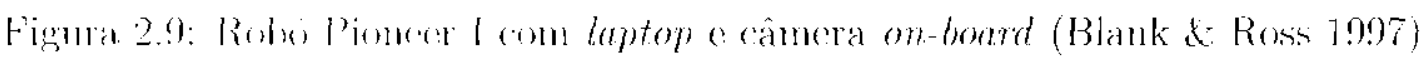

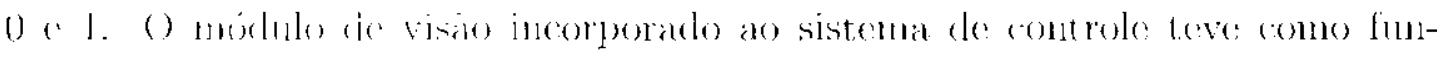

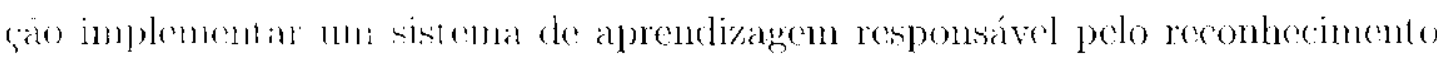

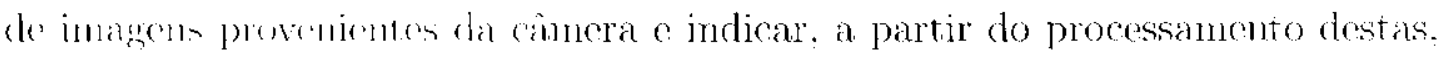
cual o niwh de at ivacion dias variáveis fuzzy que estäo incorporadlas aos comportannentos. Aswint. a rede neural que implement a o sistema de viño é responsivel

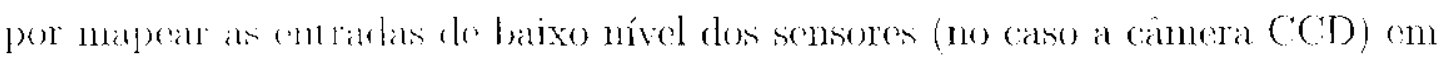

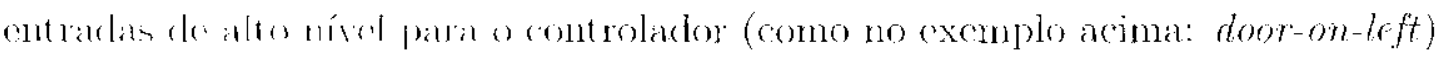
comó a indicarlo na Figura 2.8. Este sistema teve como objetivo capacitar o robo (Figura 2.9) a sechir ma bola sobre una deteminala superfície.

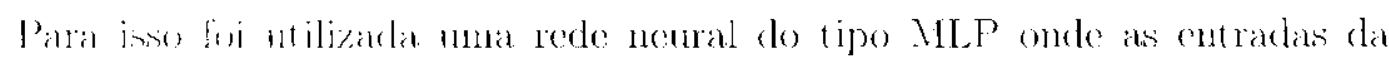

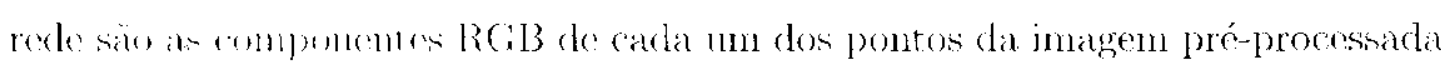
e as saldas da revle nemal ft clementos na camadda de saída) indicam em qual quadrante a bela se encentera (Figura 2.10). No préprocessannento, a imagem for redurida an tambulu de 14X18 pontes e as componentes R.GB foram binariza-

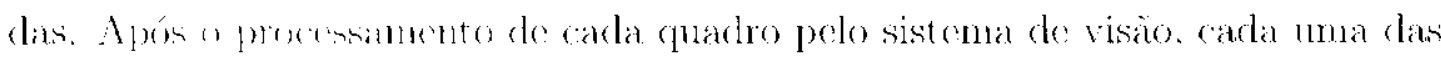
saídas da rede mentral. que representan os quadrantes da imagem. são submetidas aos comportaneentos inplementados no controlador. Os comportanentos foram

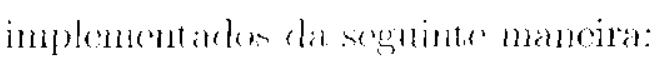




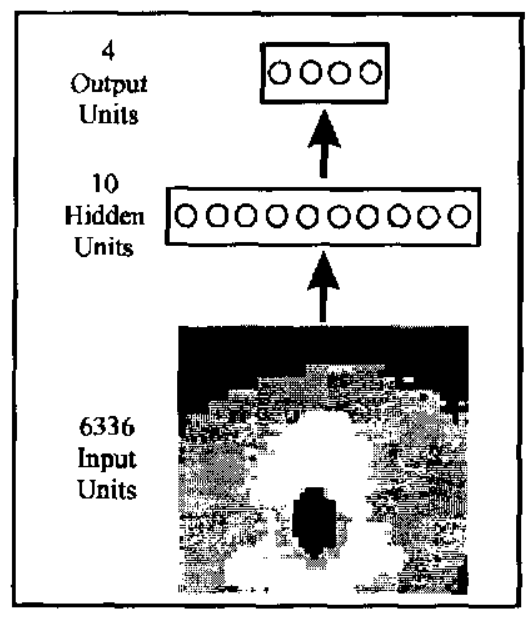

Figna 2.10: Aremitenura da rede nental do sistema de aprendizagem (Blank of Ross 1997)

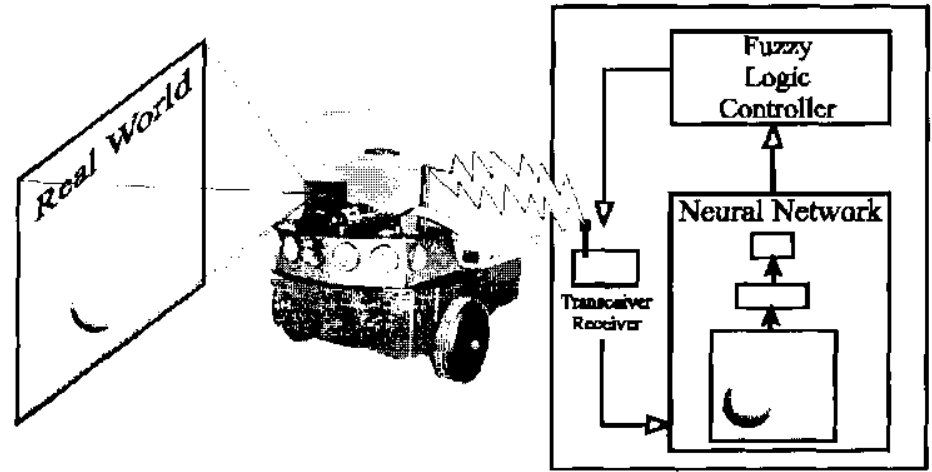

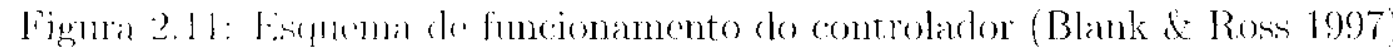

\section{IF (q1 OR q3) THEN Turn Left \\ IF (q2 OR q4) THEN Turn Right}

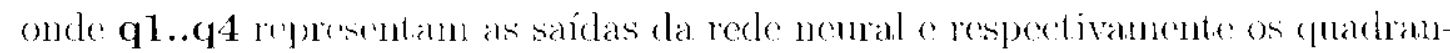

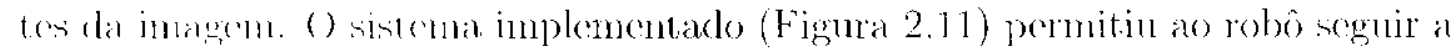

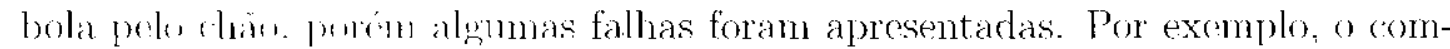
portamente do rebu quando a bola não se encontra en nenbum dos quadrantes

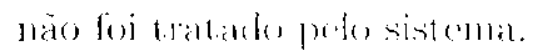

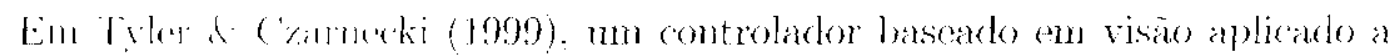
um robe jognder de futebel foi desenvolvido. Un robo Khepera foi utilizado nos experiunentos. A visio do robó consiste om un array $1 \mathrm{D}$ de 61 pontos en 256

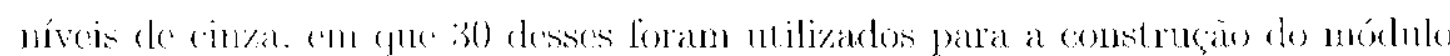

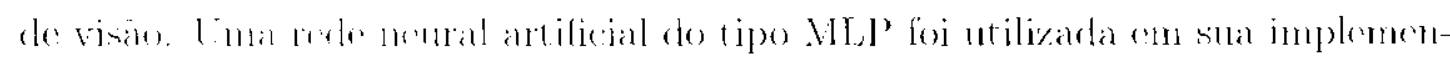
tacão. A rerti neural. constrúda com uma topologia 30-12-6 (30 elementos de chtrada. 12 na (anlada orulta e 6 na canada do sácla) tem cono funçäo indicar 


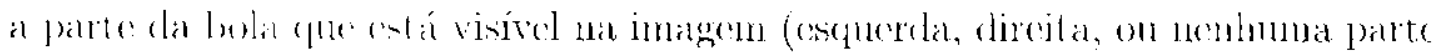

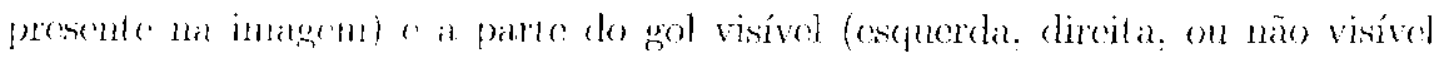

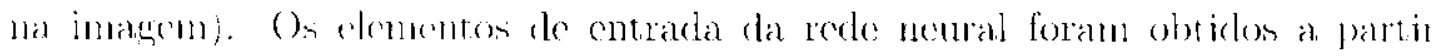

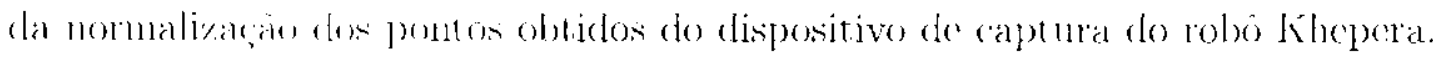

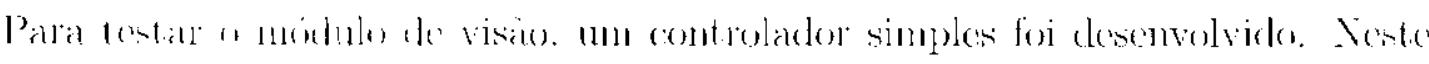

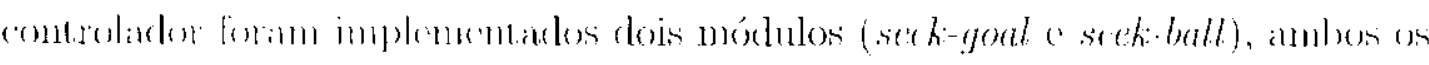

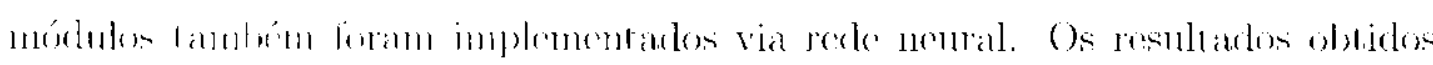

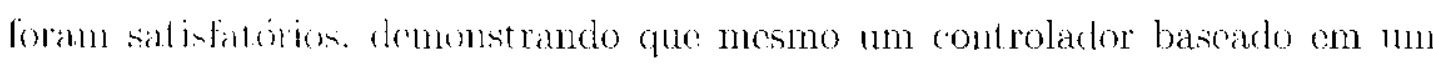

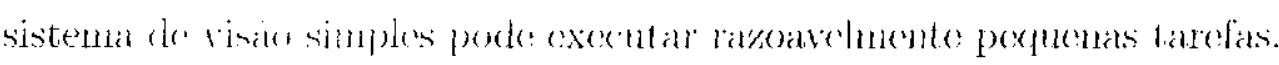

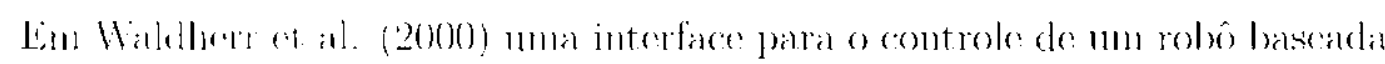

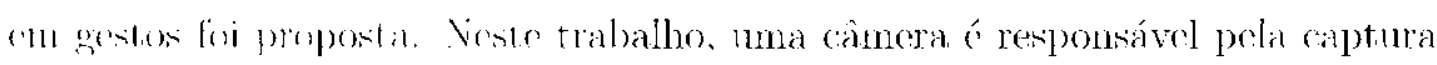

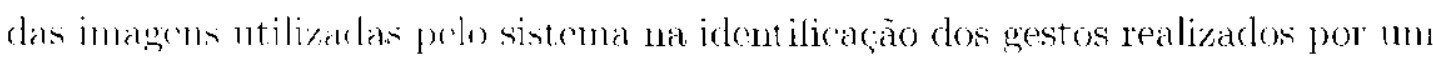

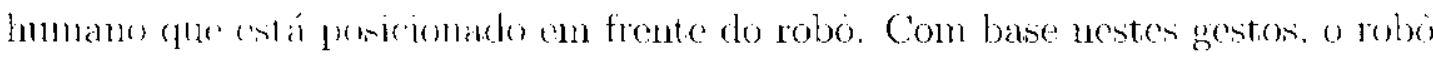

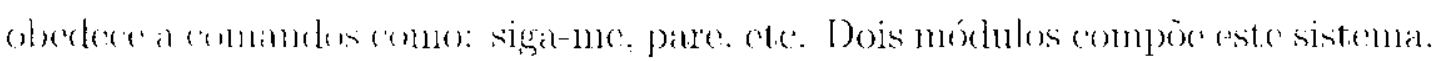

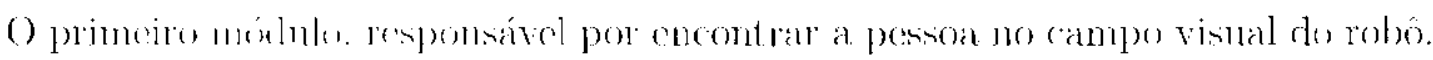

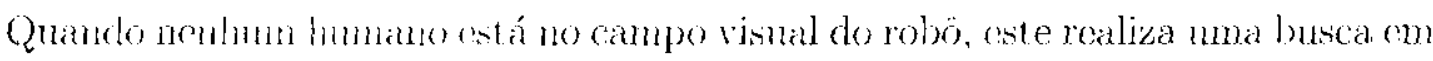

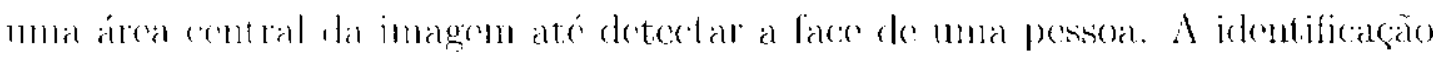

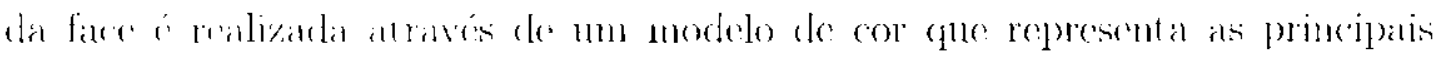

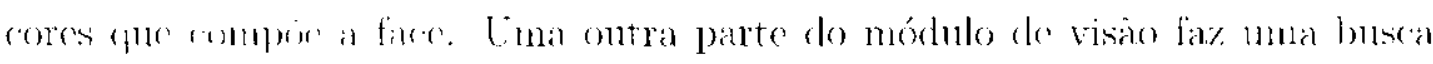
pela cor da caminis. Fista busca é realizada om nma regiäo retangular posicionada

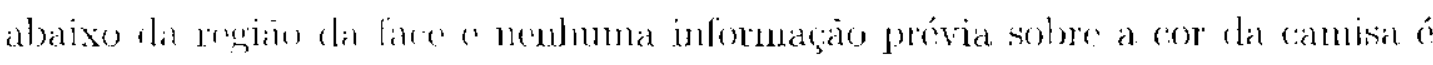

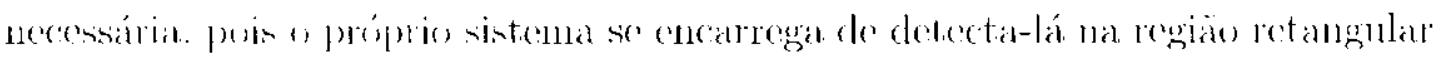

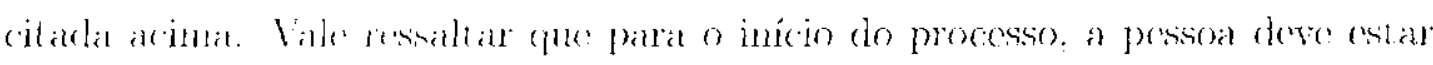

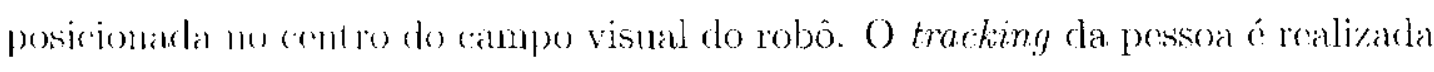

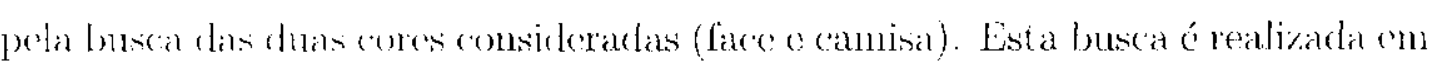

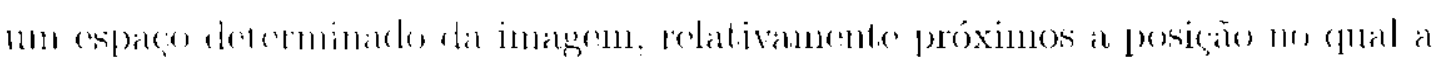

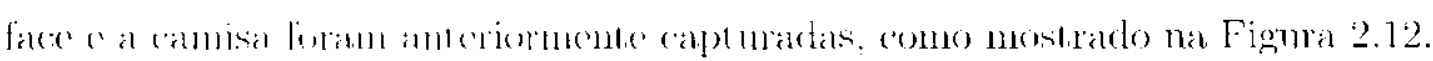

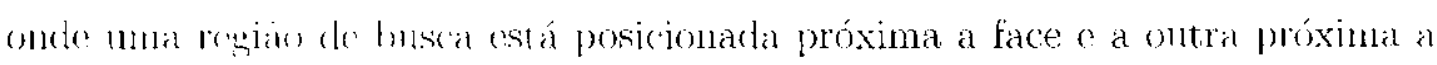
(a)lisisi.

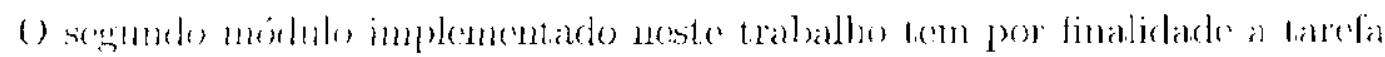

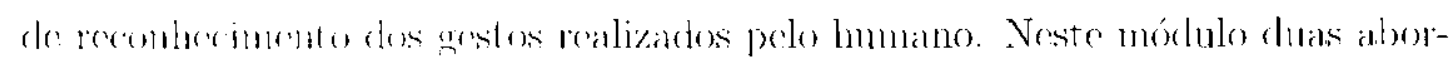

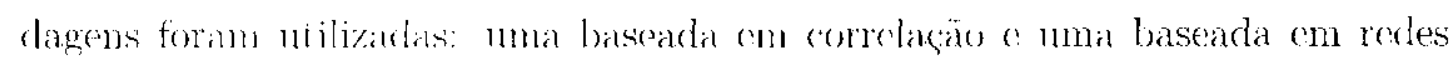
neurais. Ambar lonan combinadas com o algoritmo de Virtebi. alializado no pro-

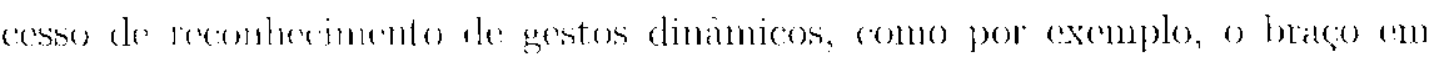
movimmentu.

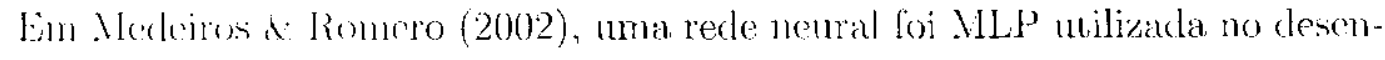

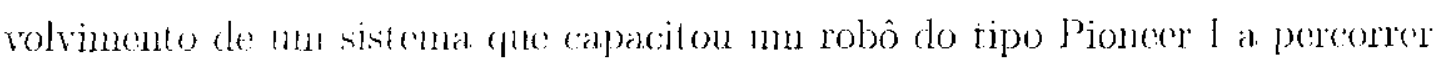




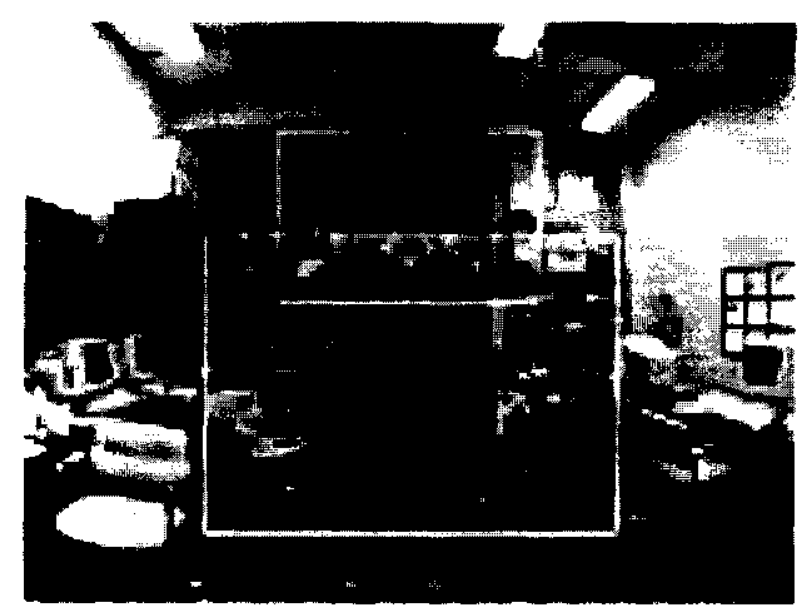

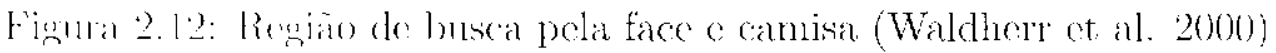

soble $m$ m (animho delinitado por duas faixas laterais brancas. As faixas săo

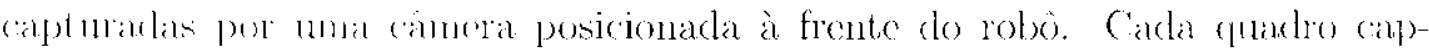

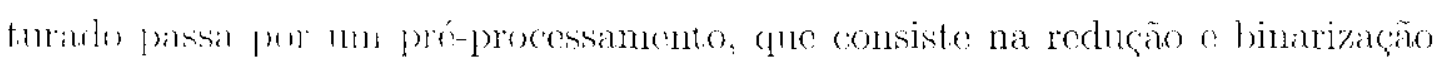

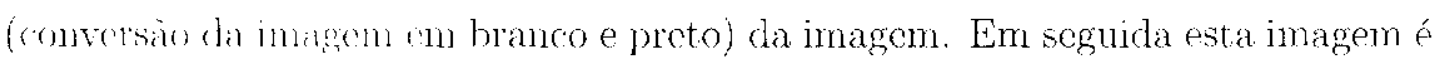

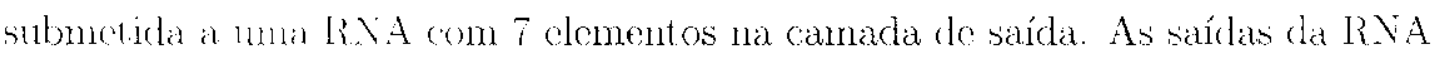

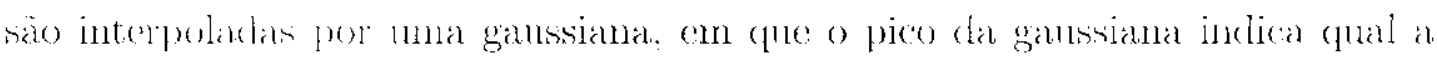

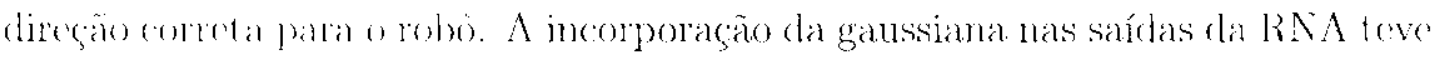
como ohjolivo slavizar a movimentação do robô dentro das faixas. Fste trabalho apresenton bons rewltarlos, entretanto. a resposta do sistema ainda compromote

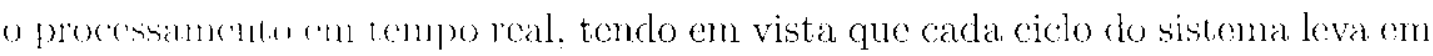
torno de 319 milisscrundes na plataforma em que o sistema foi implementado.

Os traballus apresintados acima relatam bons resultados para algumas tarefas. Entrelantu para a realização de tarefas mais complexas em visão conputaci-

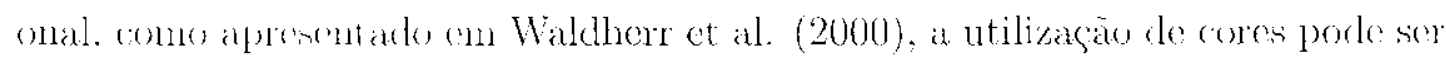

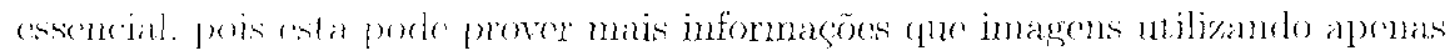

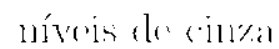

\subsection{Segmentação de Imagens}

Um dos pumeires passes que devem ser realizades na málise do imagens,

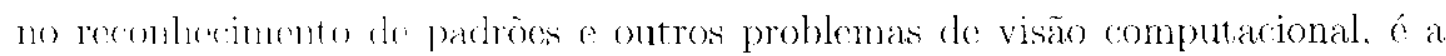
segmentacion. A segmentaçào é um componente crucial e cssencial no desen-

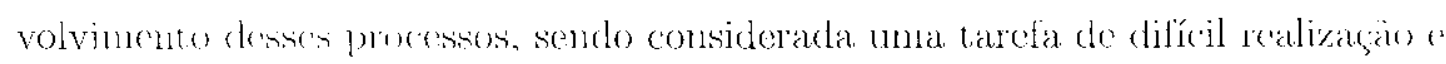

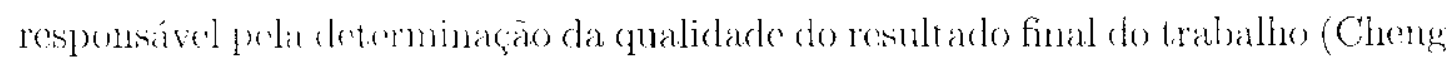
(ct. al. 2001$)$

A tardia de somentacào de imagens pode ser vista como um processo do 


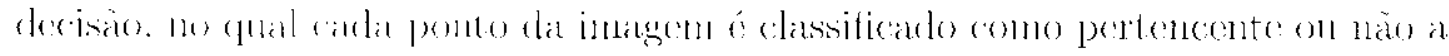

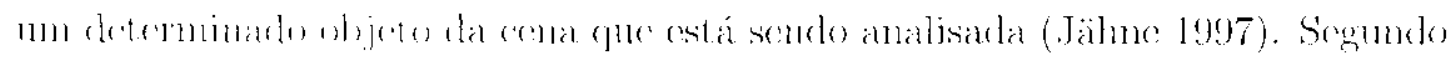

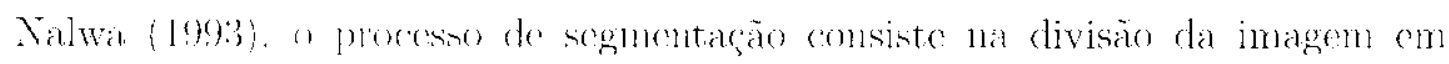
fragnuentos frommontos). onde as regiôes semelhantes säo homogenoizadas a fim

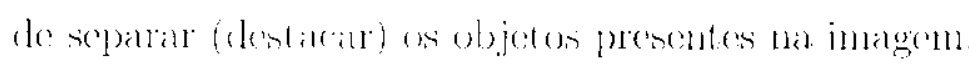

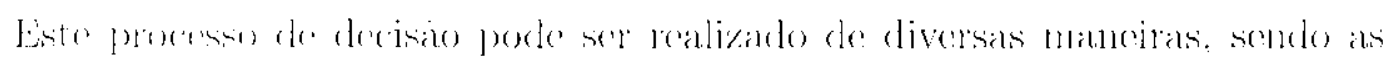

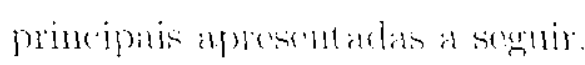

\subsubsection{Métodos de Segmentação}

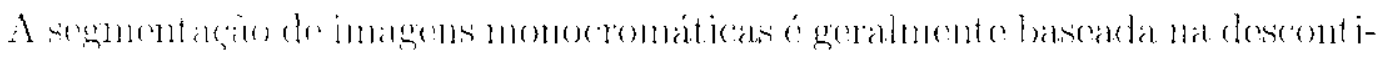

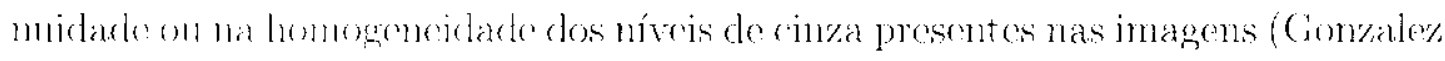
de Hoods $20(1) 0)$.

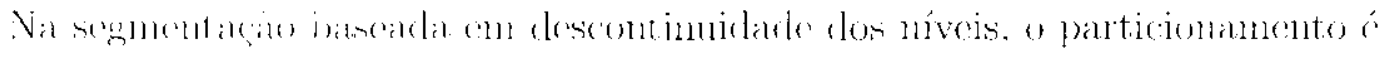

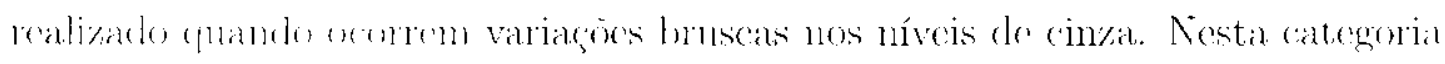

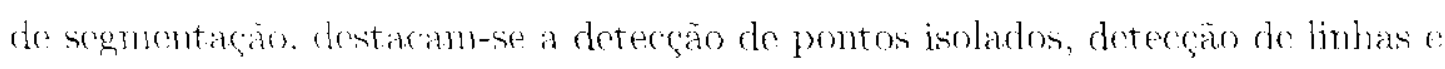

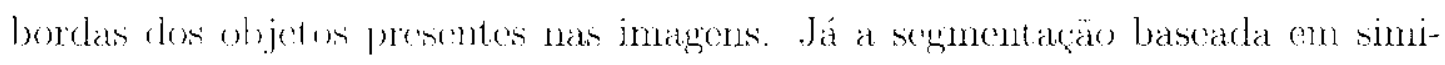

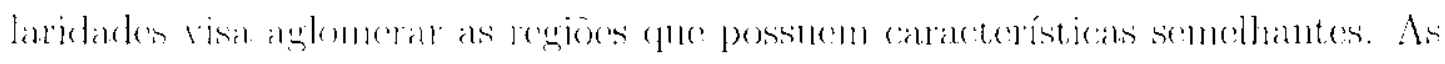

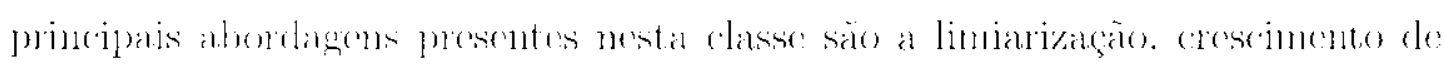

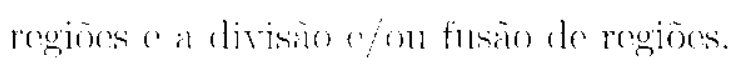

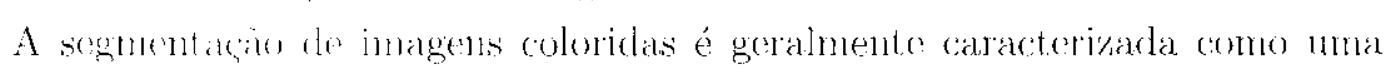

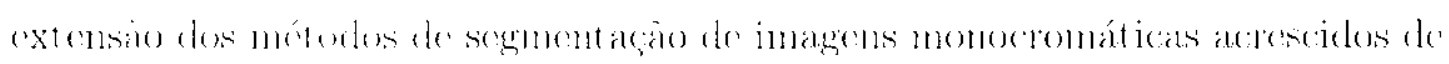

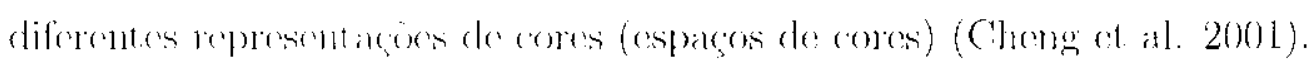

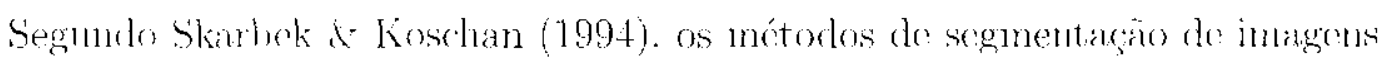

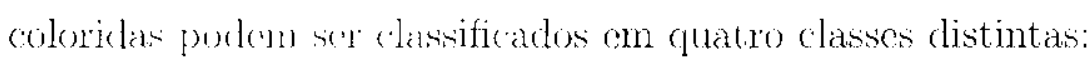

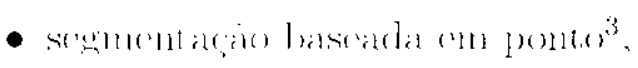

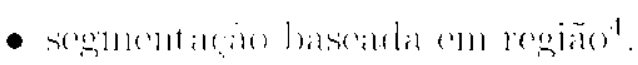

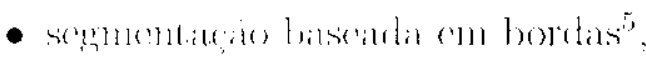

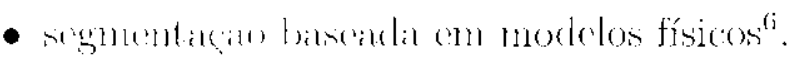

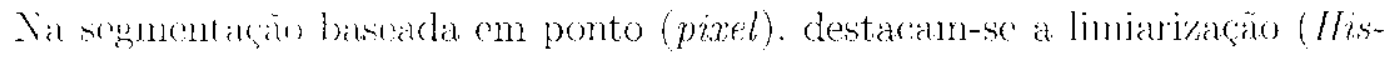

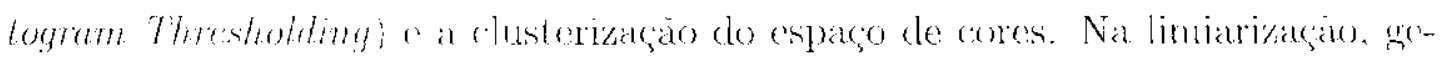

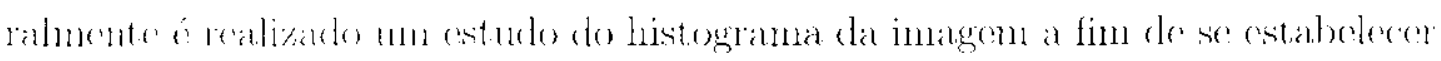

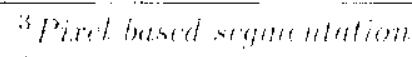

Area bascal segmientution,

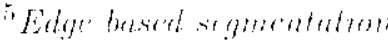

"Physics buset stgmentation
} 


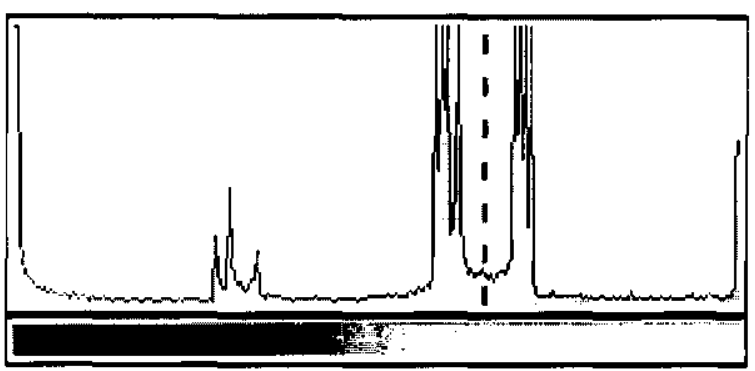

l"igura 2.13: Limiar de separagaio

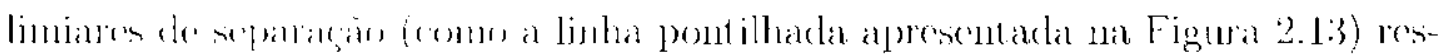

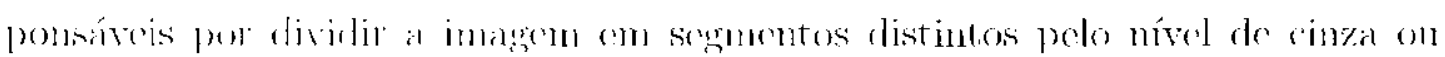

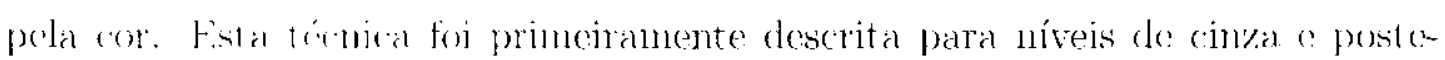

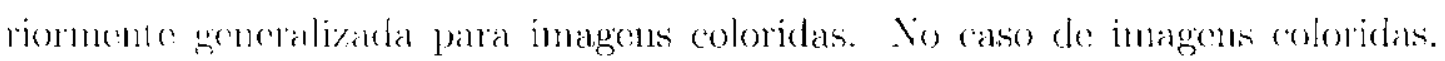

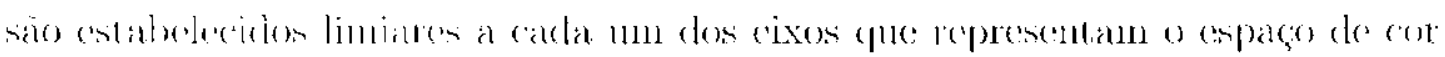

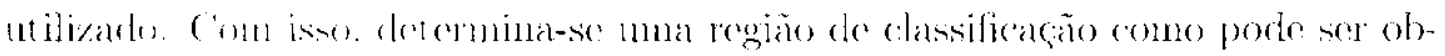

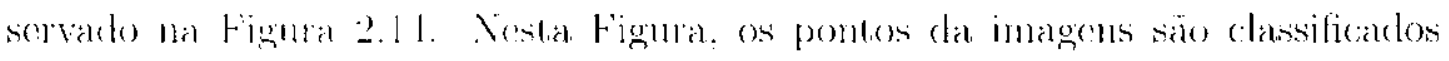

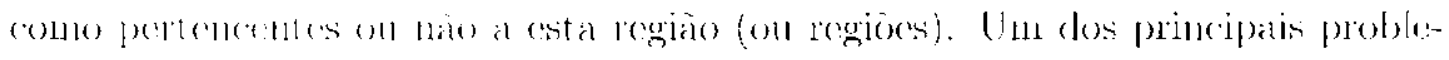

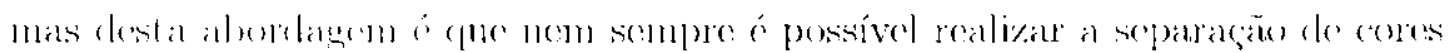

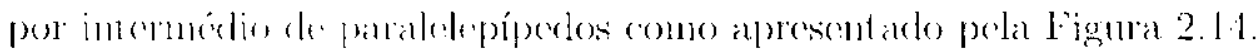

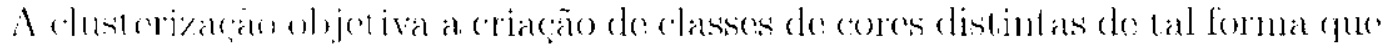

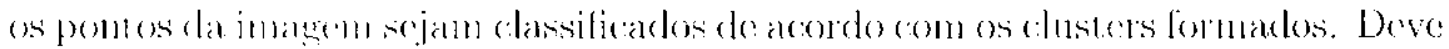

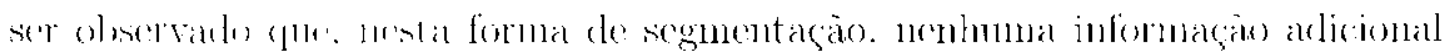

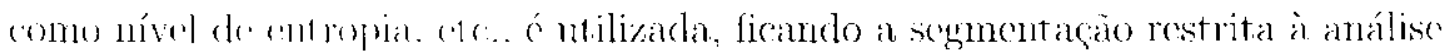

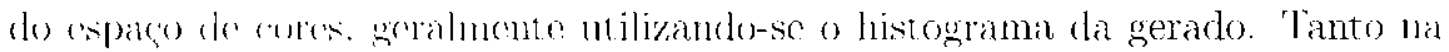

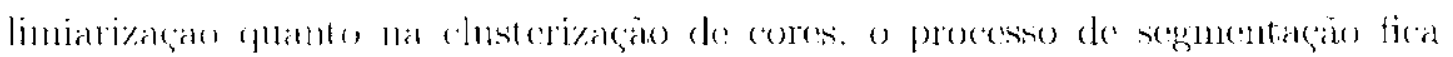

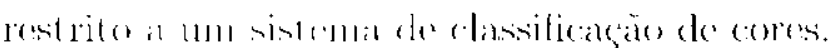

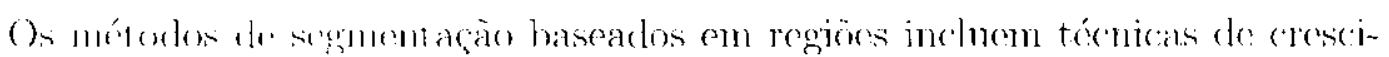

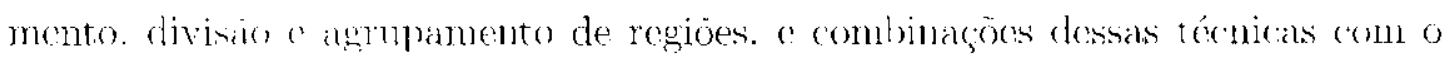

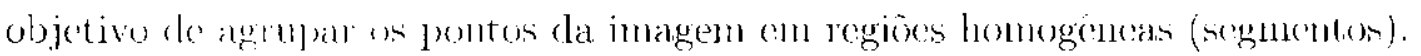

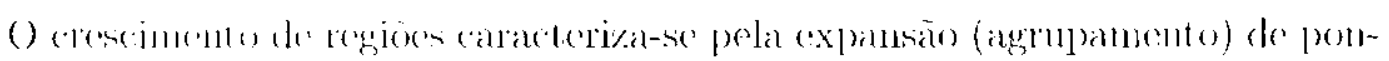

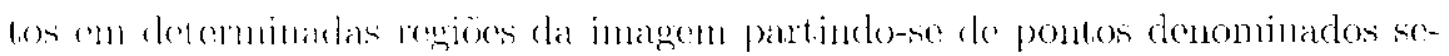

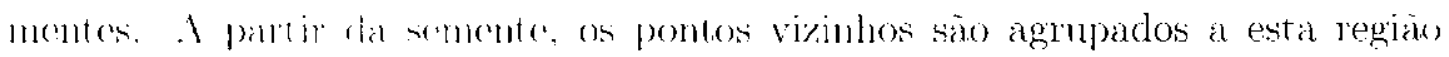

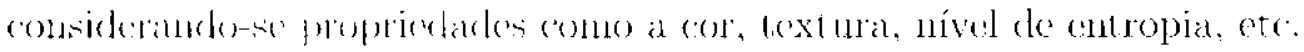

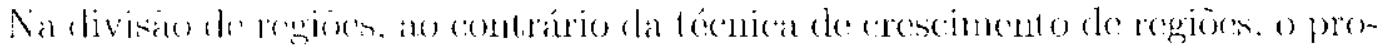

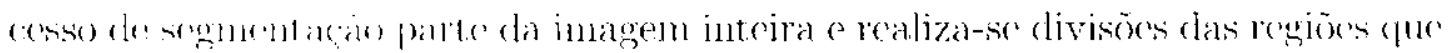

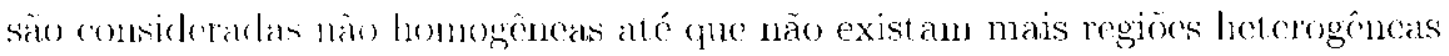
(comn base con algum critcíro de análise) 


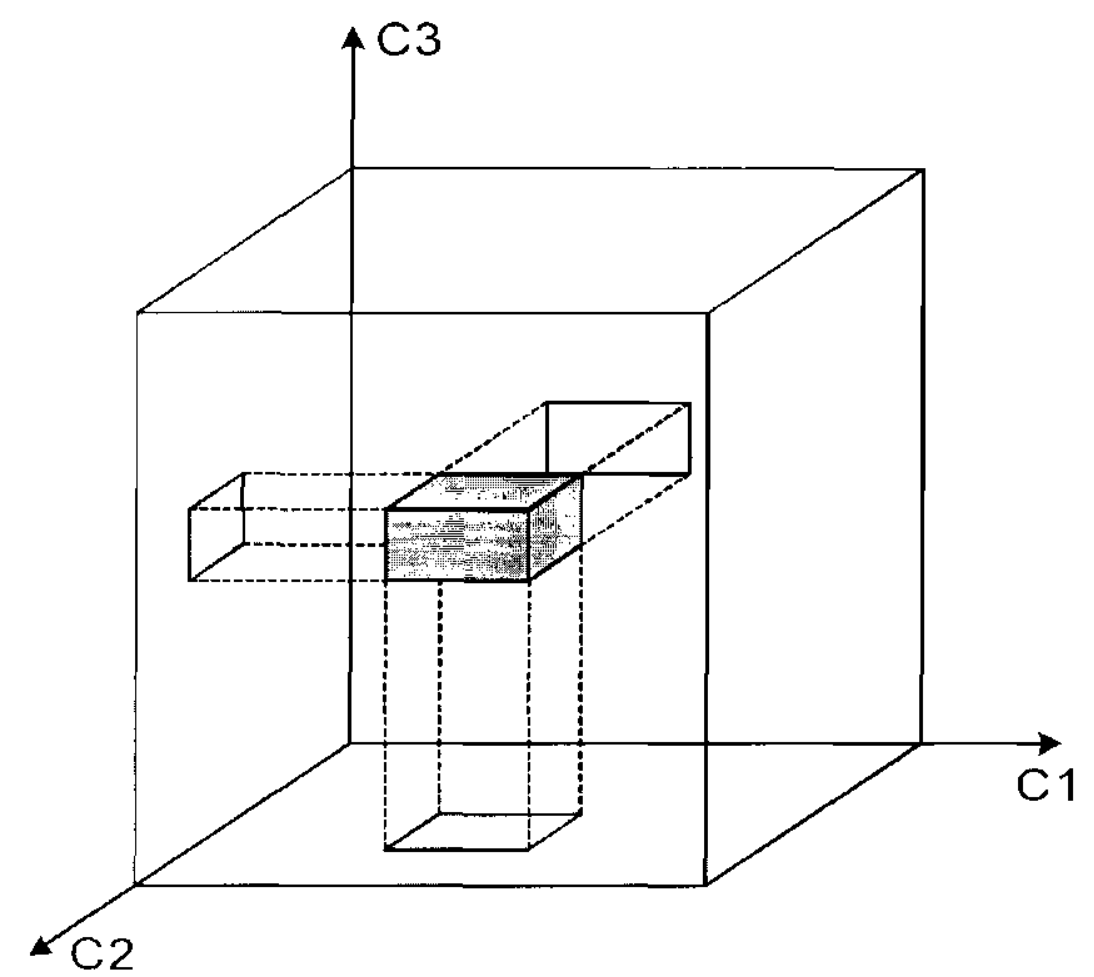

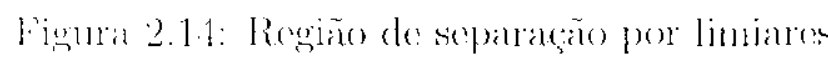

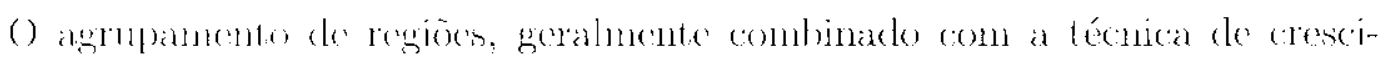

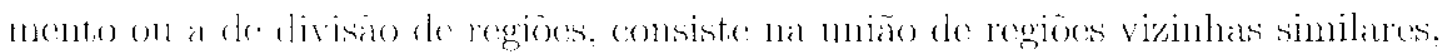

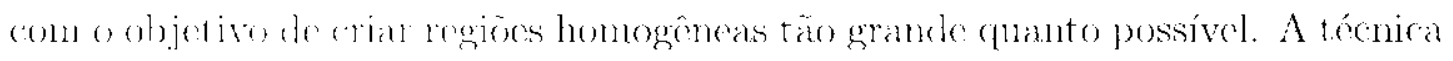

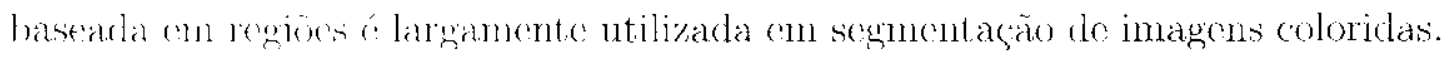

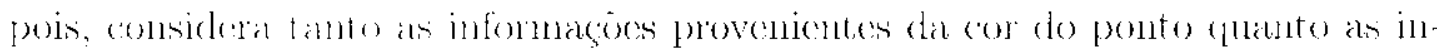

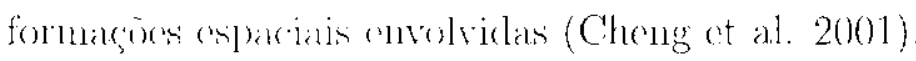

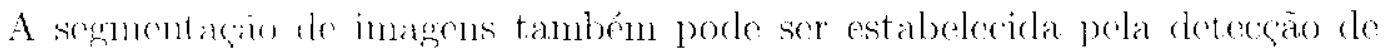
bordas entre as diversas regiōes que a compoe. A detecçào do bordas foi pri-

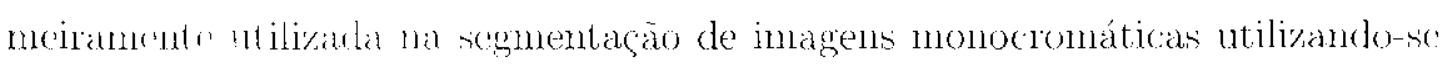

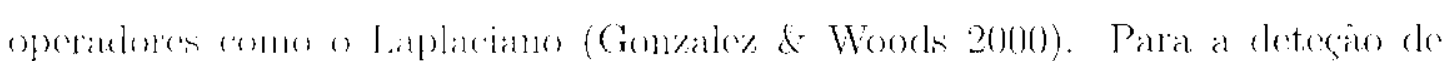

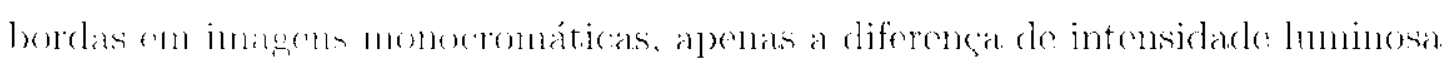
é utilizada. Futretanto. (me se tratando de inagens coloridas. mais informacócs

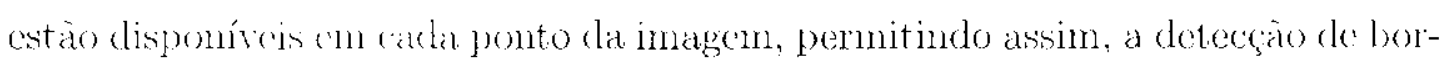

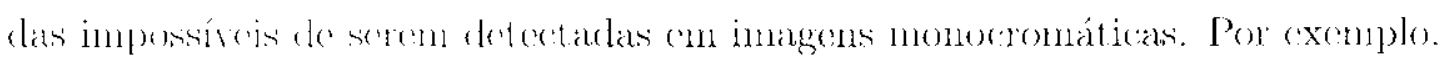

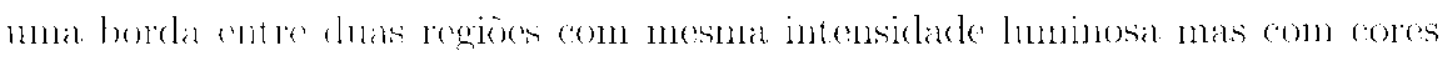
diferentos prorle ser cletectada cluando o processamentos considera a informaço proveniente dia cor (cheng et al. 2001).

Sima ontra técuica descrita na litcratura sobre segmentagäo de imagens ó

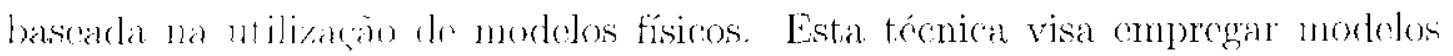



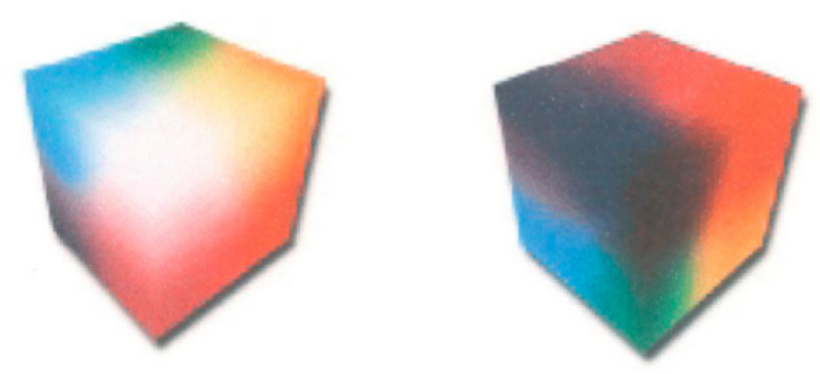

Figura 2.15: Duas visões do espaço de cores RGB

físicos que descrevem as propriedades de interação da luz com o material da superficie dos objetos presentes nas imagens. Isto possibilita o desenvolvimento de algoritmos de segmentação que solucionem problemas causados pelos reflexos luminosos, sombras, etc. (Lucchese \& Mitra 2001).

Contudo, segundo Cheng et al. (2001), esses algoritmos baseados em modelos físicos são eficientes apenas para a segmentação de imagens cujos objetos presentes possuem suas propriedades de reflexão conhecidas e de fácil modelagem, limitando, desta forma, a utilização de algoritmos de segmentação que utilizem essas técnicas.

Além da técnica de segmentação escolhida, um outro fator muito importante está relacionado em como as cores estão representadas (espaço de cores) (Cheng et al. 2001). Abaixo estão descritos alguns dos principais espaços de cores encontrados na literatura.

\subsubsection{Espaço de Cores}

A percepção das cores pelos humanos é resultado da combinação de três estímulos de cores básicas: vermelho (Red), verde (Green) e azul (Blue). A partir do espaço de cores RGB, iniciais dos três estímulos, diversos outros espaços (representações de cores) podem ser derivados pelo uso de transformações lineares e não-lineares. A revisão bibliográfica apresentada por Cheng et al. (2001) mostra que na literatura são encontrados diversos espaços de cores utilizados em segmentação de imagens, tais como RGB, HSI, YUV, L* $\mathrm{u}^{*} \mathrm{v}^{*}, \mathrm{Nrgb}$, dentre outros. Porém, nenhum deles é consagradamente o melhor, sendo sua escolha muito dependente da aplicação e do método de segmentação escolhido.

O RGB não é considerado um bom espaço de cores para realização do processo de segmentação, devido à alta correlação existente entre os componentes $\mathrm{R}, \mathrm{G}$ e $\mathrm{B}$, o que torna difícil a criação de limiares que permitam a separação das cores nessa forma de representação (o cubo RGB é apresentado na Figura 2.15). Essa 


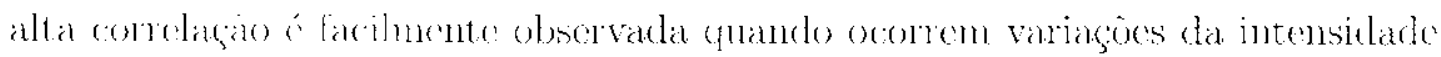

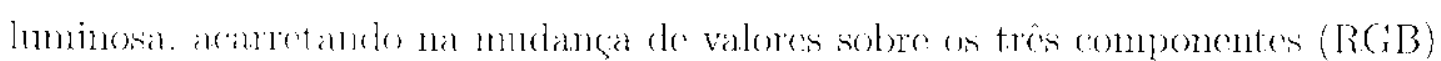

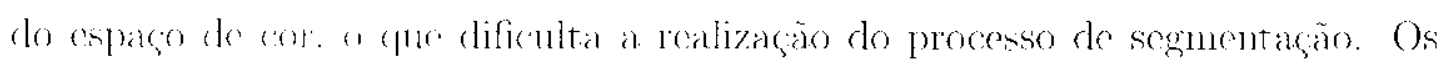

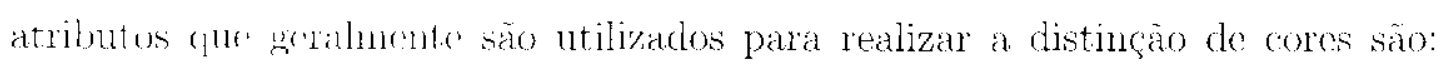

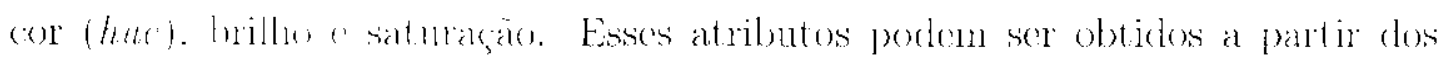
elementos R. (is 13

\section{Transformações Lineares}

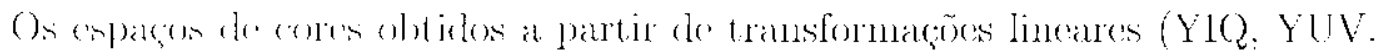
dentre ontros) persuen geralmente un custo computacional reduzido. podendo

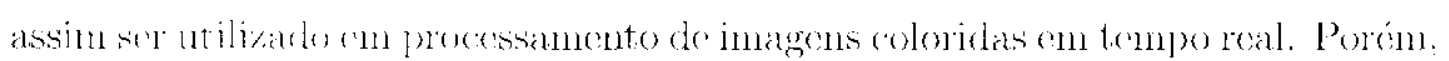

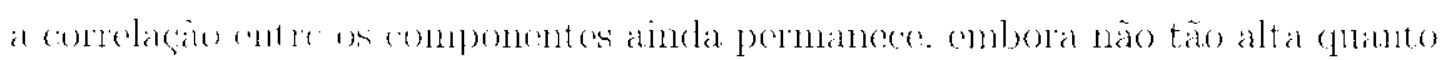

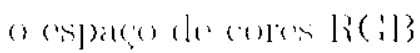

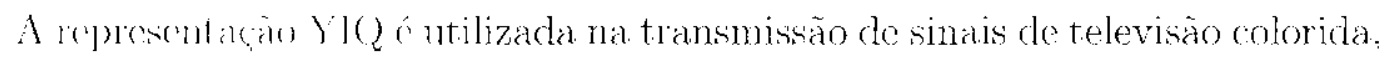

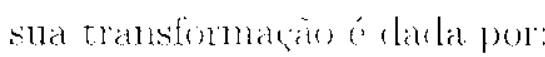

$$
\left(\begin{array}{c}
Y \\
I \\
\zeta
\end{array}\right)-\left(\begin{array}{ccc}
0.299 & 0.587 & 0.114 \\
0.596 & -0.275 & \ldots 0.321 \\
0.212 & -0.523 & 0.311
\end{array}\right)\left(\begin{array}{c}
R \\
G \\
B
\end{array}\right)
$$

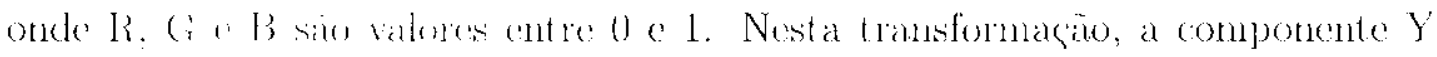

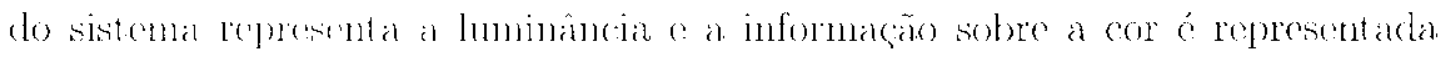

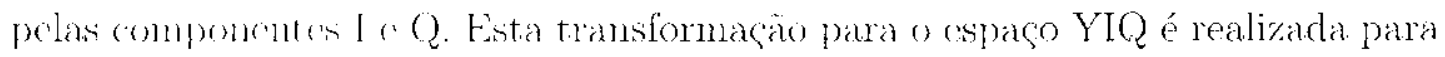

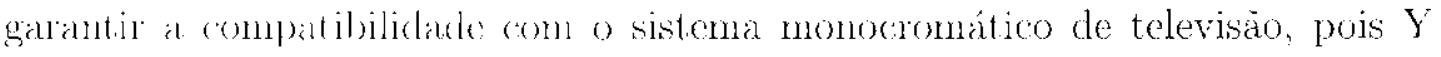

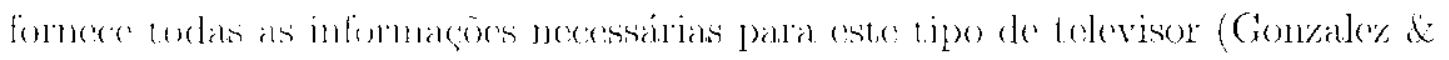
Woorts $200(0)$.

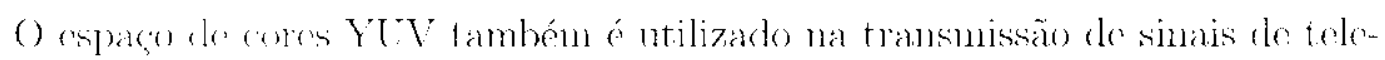

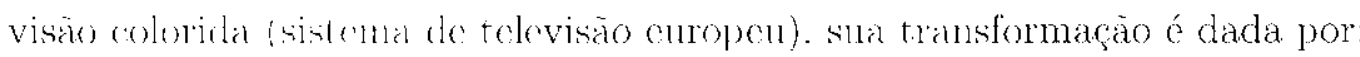

$$
\left(\begin{array}{l}
Y \\
l \\
1
\end{array}\right) \cdots\left(\begin{array}{ccc}
0.299 & 0.587 & 0.114 \\
-0.147 & -0.289 & 0.437 \\
0.615 & 0.515 & 0.100
\end{array}\right)\left(\begin{array}{c}
R \\
G \\
B
\end{array}\right)
$$

mide R. (t)

\section{Transformações Não-Lineares}

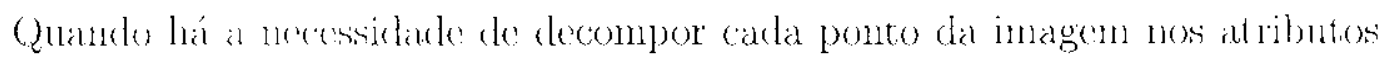

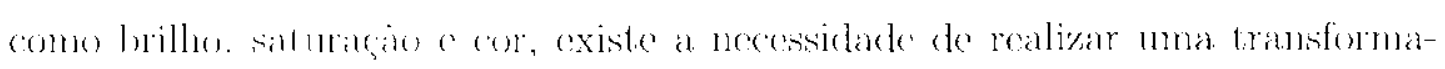

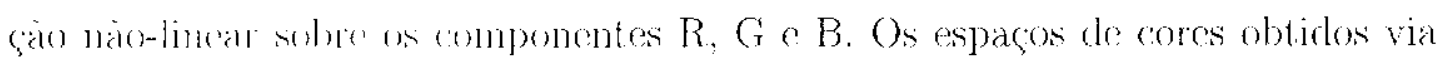

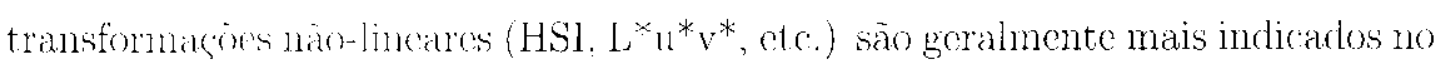




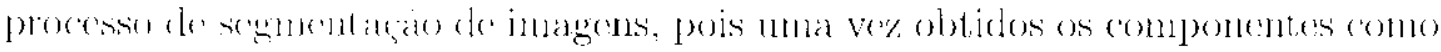

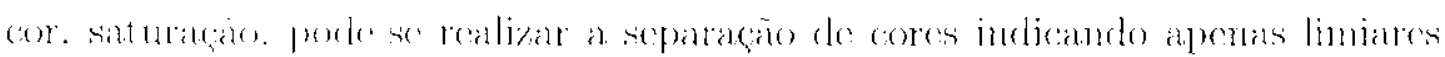

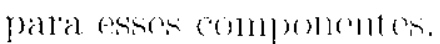

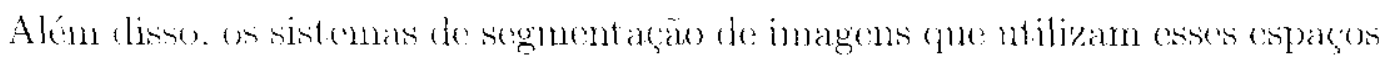

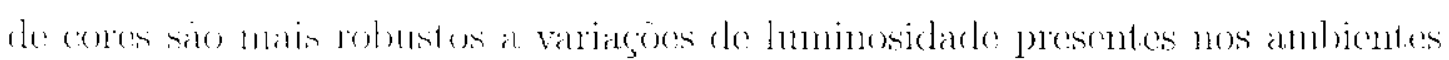

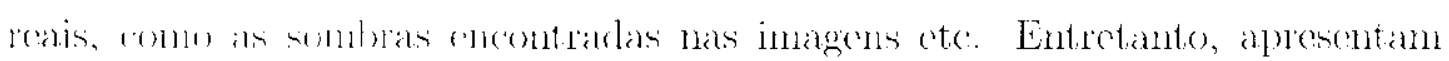

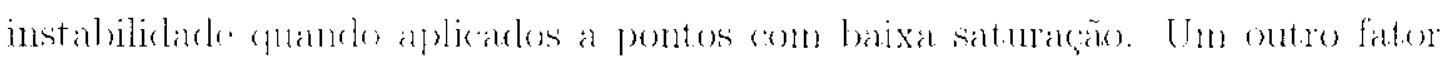

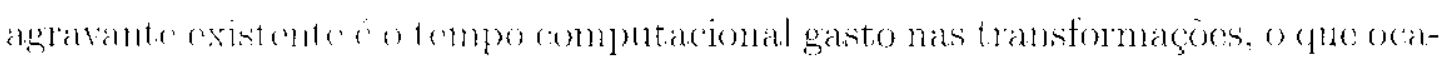

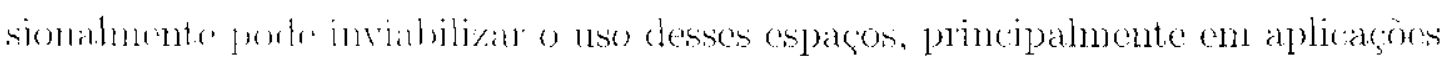

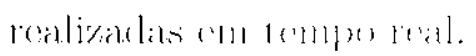

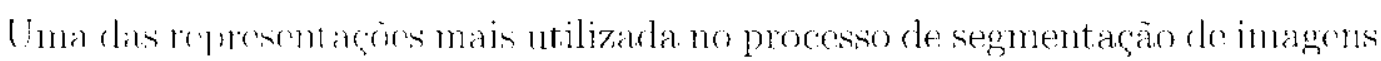

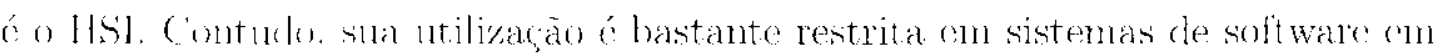

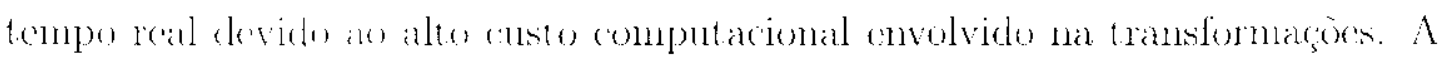

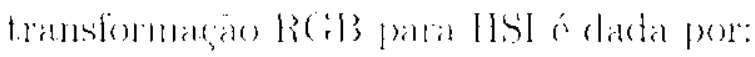

$$
\begin{aligned}
& I \cdots \frac{1}{3}(R+G+B) \\
& s-1 \frac{3}{(R+C+B)} \min (R,(x, B) \mid
\end{aligned}
$$

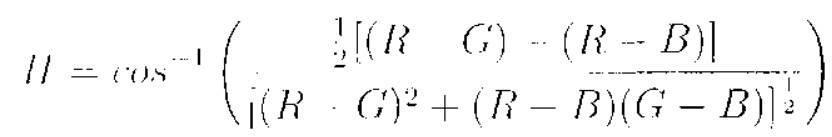

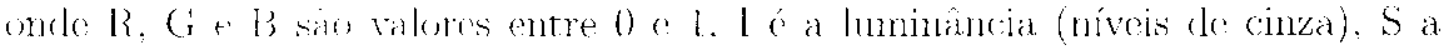

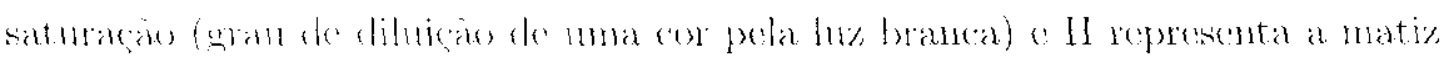

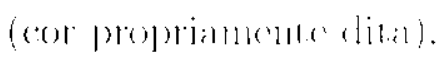

\section{Espaços Hibridos}

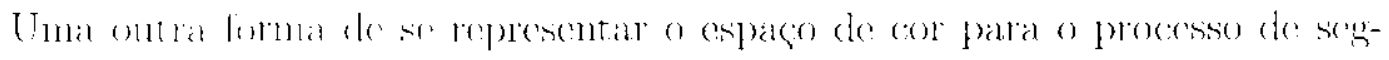

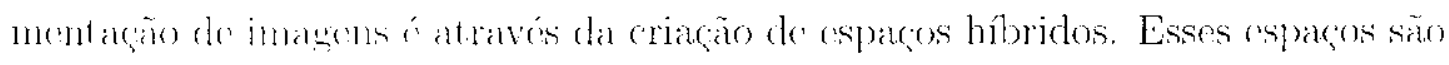
compostos por mu comjunto de clementos (como o R. G e B). obtidos a partir

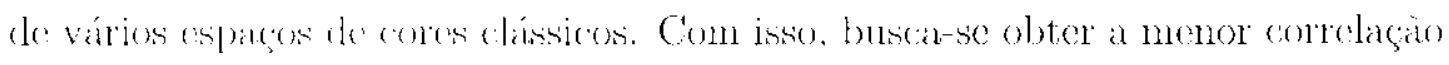

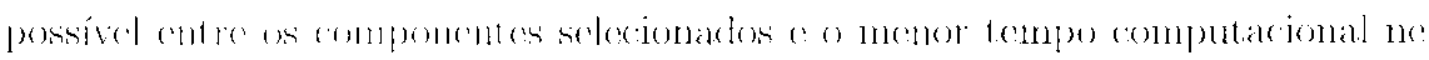

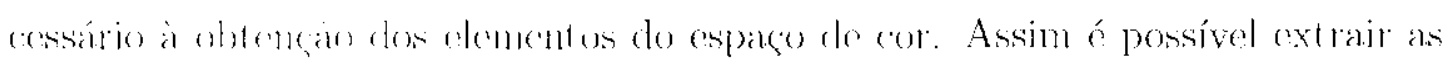

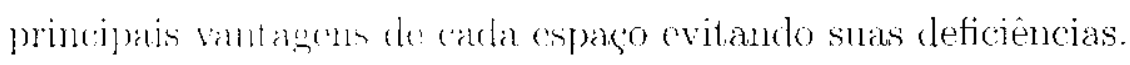

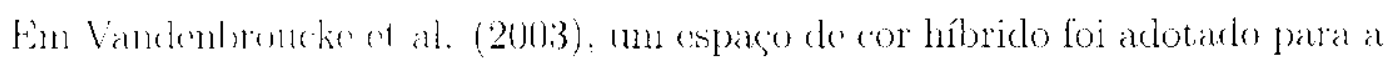

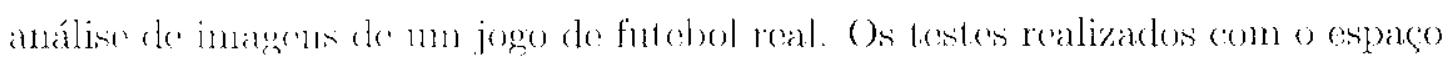

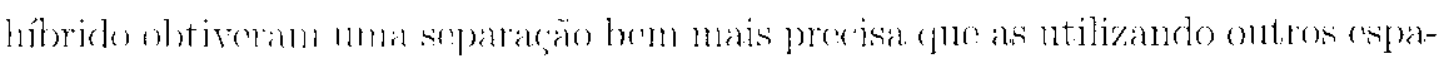

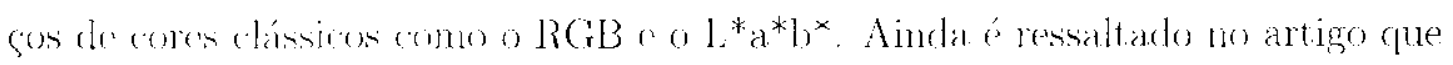




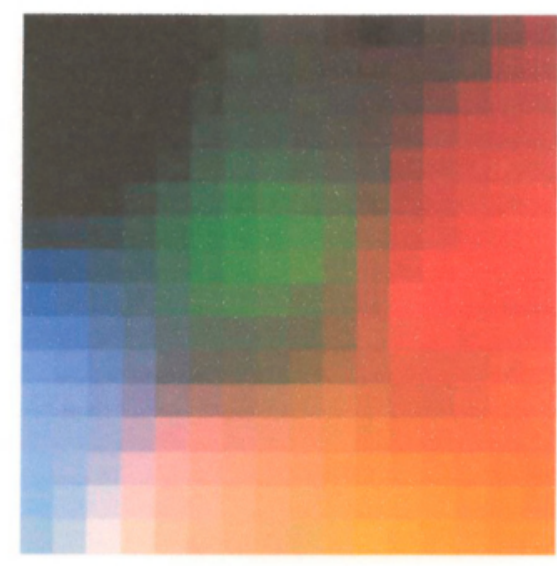

Figura 2.16: Cores mapeadas em uma rede neural SOM 2D (Ong et al. 2002)

nenhum espaço de cor clássico provê resultados satisfatórios para todos os tipos de imagens. Assim a construção de espaços híbridos pode ser uma boa alternativa para alguns domínios onde são encontradas deficiências com os espaços clássicos.

\subsubsection{RNAs para Segmentação de Imagens}

Para o desenvolvimento deste projeto, foi realizada uma busca de trabalhos que utilizaram redes neurais artificiais na implementação de sistemas de segmentação de imagens coloridas, ou mesmo trabalhos que utilizaram as RNAs no desenvolvimento de técnicas de classificação e/ou redução de cores. Essa busca teve por objetivo encontrar uma metodologia que pudesse ser ajustada ao sistema proposto por este projeto de mestrado.

Diversos trabalhos têm utilizado redes neurais artificiais no processamento de imagens (Egmont-Petersen et al. 2002). Para o processo de segmentação de imagens coloridas, as redes neurais têm sido aplicadas diretamente no processo de segmentação ou como ferramenta auxiliar.

A seguir, são apresentados os principais trabalhos estudados.

Em Ong et al. (2002) um método de segmentação de imagens coloridas, baseado em classificação de cores, foi proposto utilizando dois estágios de redes neurais auto-organizáveis (SOM - Self-Organizing Maps). No primeiro estágio, uma rede neural 2D foi utilizada para fazer um mapeamento das cores presentes nas imagens de treinamento formando clusters dessas cores. Na Figura 2.16 pode ser visto que a rede apresenta a formação de clusters de cores bem definidos. Já no segundo estágio foi utilizada uma rede 1D que tem como finalidade extrair elementos que representem os clusters formados na primeira rede. Assim, de uma forma não supervisionada, a quantidade de cores significativas nas imagens são obtidas. O tamanho da rede do segundo estágio não é fixo, podendo sofre 


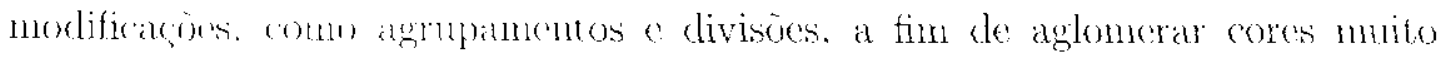

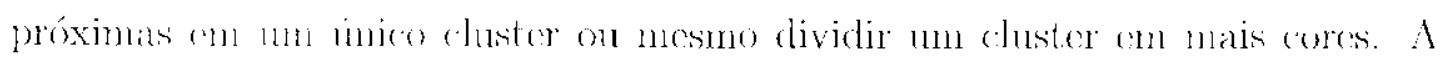
distancia culdidenat for ntilizada para medir a distancia entre duas cores. () espaco de coure utilizado no processo de segmentaçăo foi o $\mathrm{L}^{*} \mathrm{u}^{*} \mathrm{v}^{*}$. obtides a

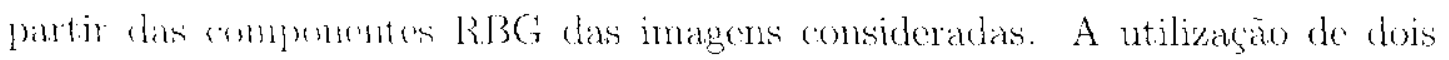

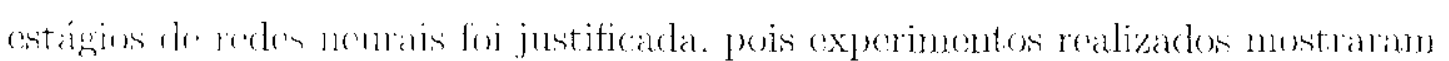

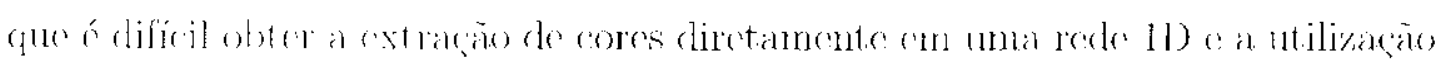
direta dr una huica redo 2D não seria adequada para o controle do número de

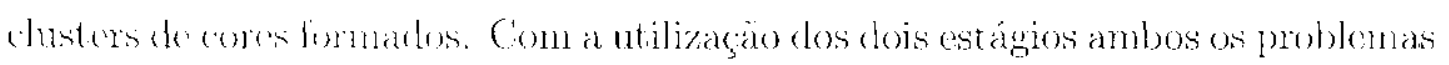
ritades foram mesolvides. Apesal deste trabalho apresentar bons resultades no processo de sem imagens con ternpo real. weensitando assim de modificaçes para adaptá-lo à usta finalielade.

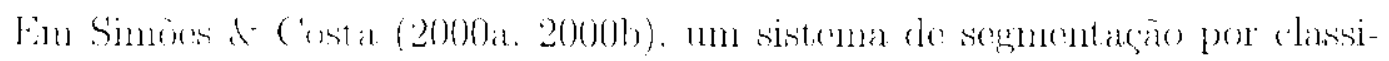

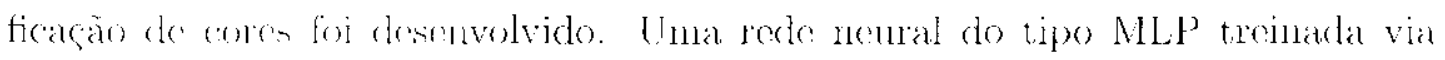

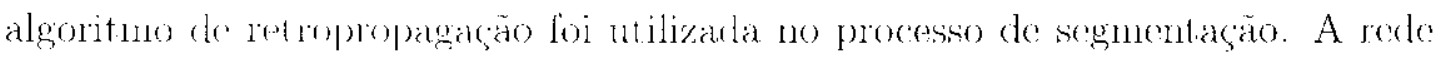

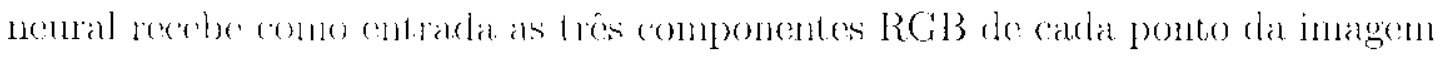

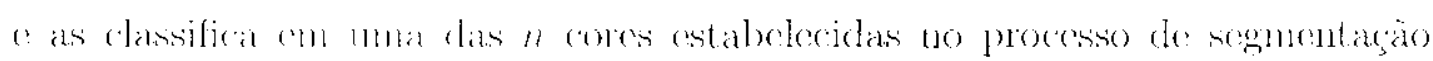
Para a dominino do futchol de robôs. 7 clisses cores foran estabeleciclas: laranja, rosa, verdo analedr. branco. cinza o preto, podendo também ser definidas outras classes de comen conlonme: a necensidate do problema em estudo.

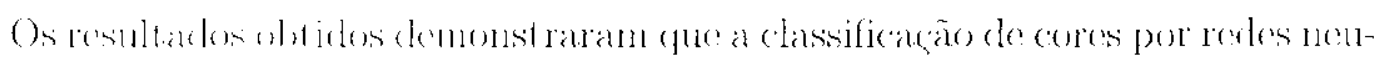

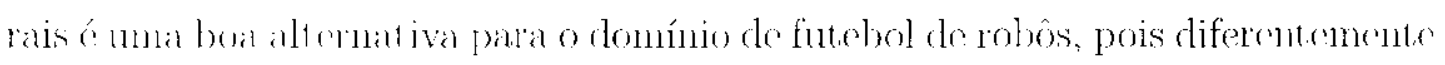
da técnim de liniarizacion para a separaçăo de cores, cm que paralelepípedos de

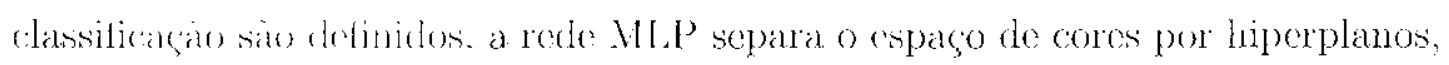

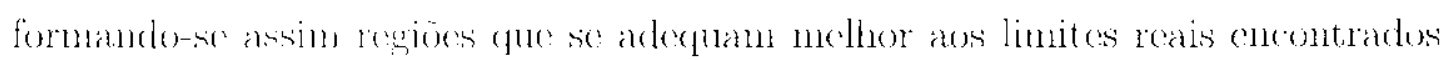

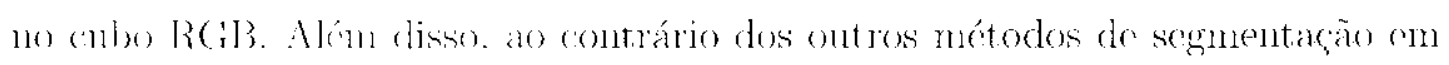

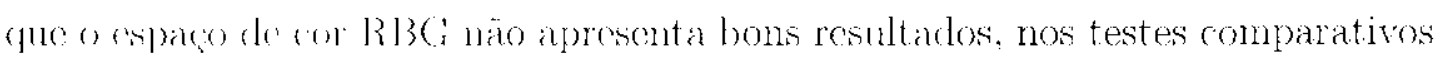

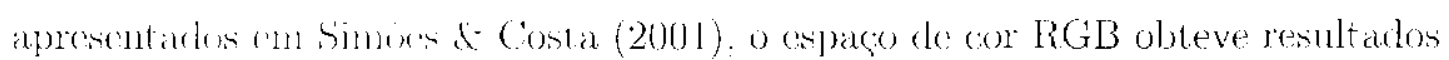

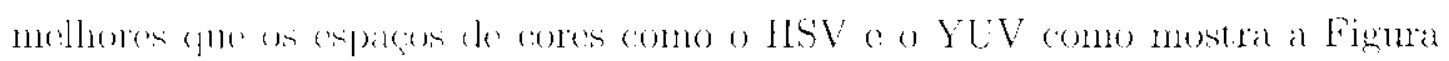

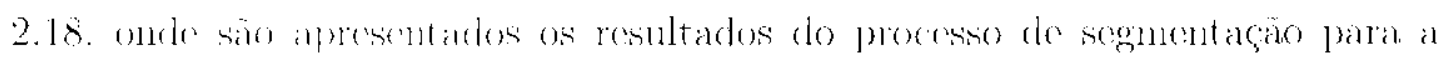
inagem da Fignta 2.17.

Entretanto esse método apresentado foi utilizado na segmentação de imagens obtidats por una samera situada no teto do campo de futebol de robos, diferen-

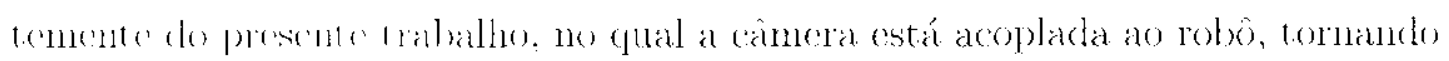
as imagents adquiridits mais expostas a variaçones de luminosidade o sombras presentes nor and inenter. 


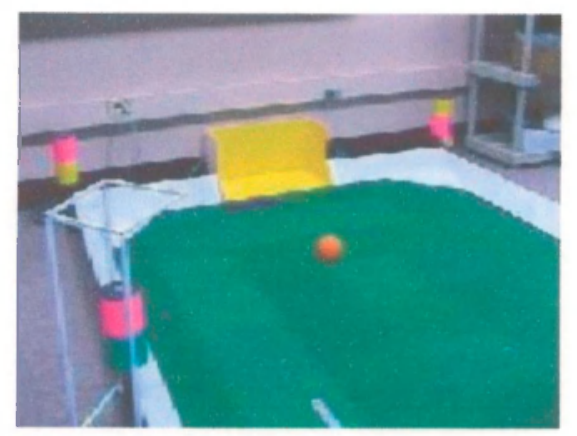

Figura 2.17: Imagem do campo de futebol de robôs (Simões \& Costa 2001)

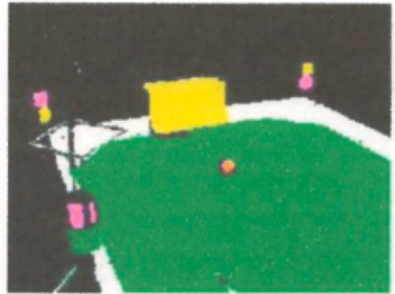

(a)

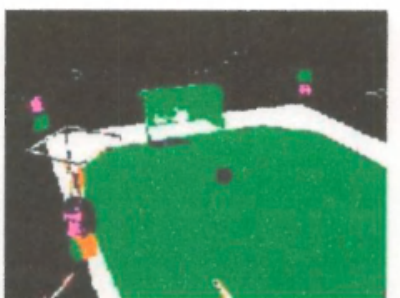

(b)

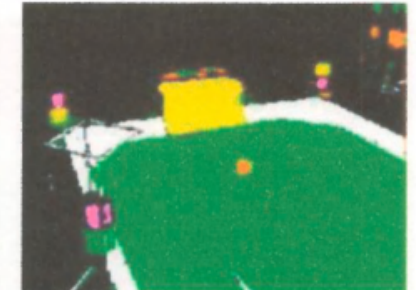

(c)

Figura 2.18: Imagens resultantes de segmentação da Figura 2.17 utilizando os espaços de cores: a)RGB; b)HSV e c)YUV (Simões \& Costa 2001)

Em Papamarkos (1999), um sistema para redução de cores em imagens foi proposto. Uma rede neural do tipo SOM foi utilizada para agrupar as classes de cores mais significativas da imagem. Ao contrário do trabalho proposto por Ong et al. (2002), este utiliza apenas uma rede SOM. No modelo apresentado, além das três componentes do espaço de cor, um maior conjunto de características podem ser utilizados na formação das entradas da rede neural. Por exemplo, algumas características da vizinhança do ponto, como média da vizinhança, entropia, etc. podem ser utilizadas. Em Papamarkos et al. (2002), foi proposto uma nova técnica adaptativa de redução de cores. Um sistema de clusterização adaptativo baseado em uma estrutura de árvore foi implementado onde cada nó da árvore possui um NNC (Neural Network Classifier) semelhante ao modelo utilizado em Papamarkos (1999). Contudo, uma rede do tipo PCA (Principal Component Analysis) (Haykin 2001) foi acrescentada ao modelo com o objetivo de diminuir a correlação entre as $n$ características (entradas) que são apresentadas a rede SOM (Figura 2.19). Em cada nível da árvore um conjunto adicional de características são utilizadas de tal forma que novas classes de cores possam ser vistas (separadas). A técnica de redução de cores em cada nó da árvore é aplicada aos pontos da imagem inicial, contudo, diferentes característcias obtidas da imagem são utilizadas. Ao final, os componentes extraídos da imagem são 


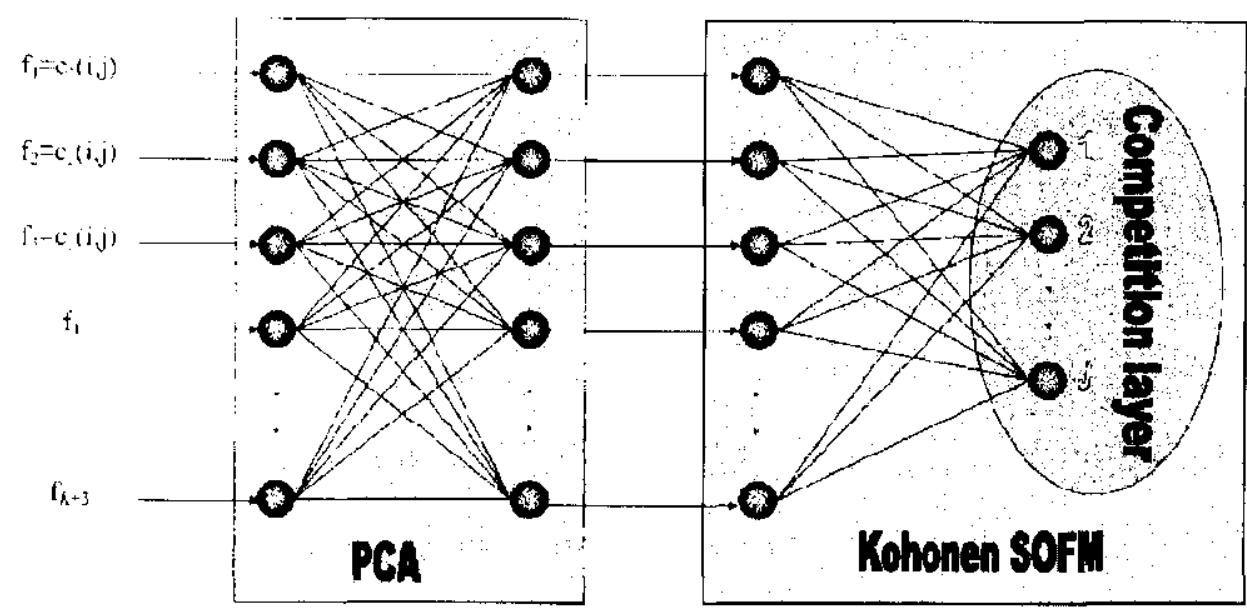

Finn: 2.19: Hodelo do sistema (PCA/SOA)

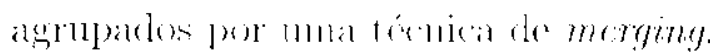

Anbos os trabalhom propostos por Papamarkos apresentan bons resultados no processo de reducio do cores utilizando o espayo de cor RGI3. Entretanto, as

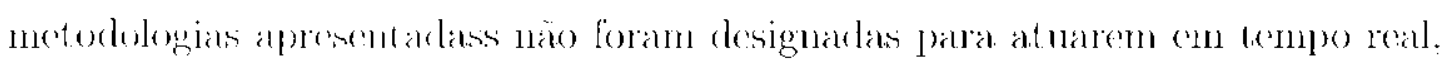

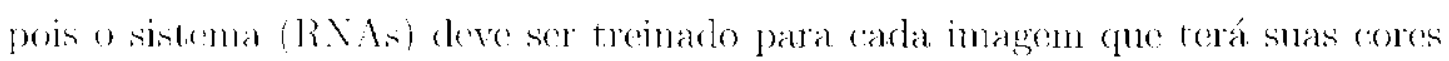
reduzidas. limitando assim. a utilizaçăo destas metodologias para o propósito deste mabalho at mestrater.

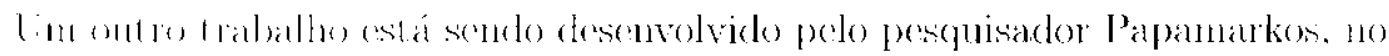

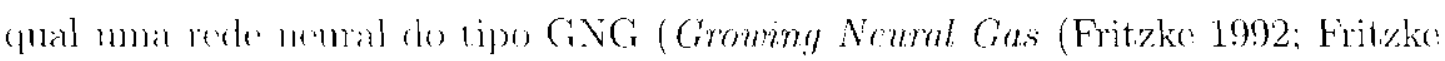
1995) ( Ima redia dorivada da G.NG denominada SGONG (Self-Growing Organized Nurul (irss) (ntaio sendo utilizadas no processo de reduçäo de cores en imagens. ()s primures resultarlos apresentades em (http:// ipml.ceduth.gr/ pat-

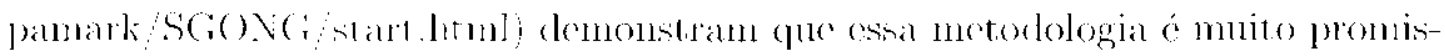
sora guando companada com os resultados apresentados pelas redes do tipo SOM. A Figura 2.21 apronenta a resultado do processo de reduça de cores para a ind-

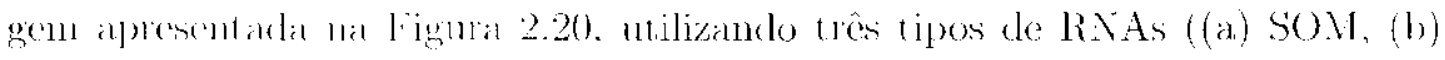

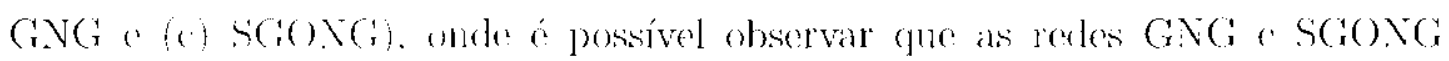
apresentaram un multado superior ao obtido pela rede SO.M.

Nestes trabalhos a RAA näo foi utilizada diretamente no processo de segnen-

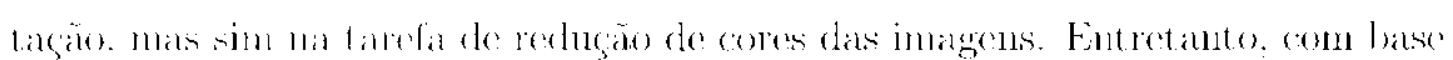

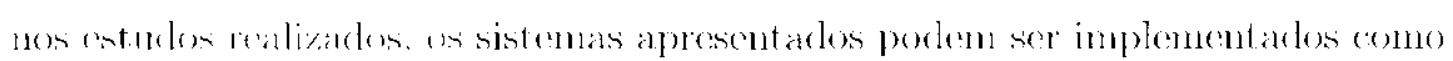

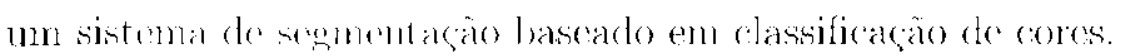

Com base In lovantamento bibliográfico realizado e en alguns experimentos

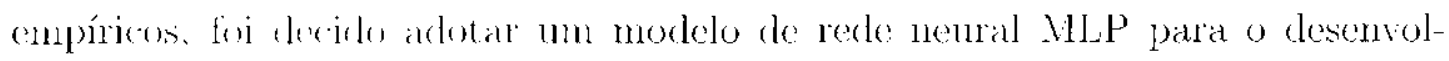
vimento do sistema de segmentagão desenvolvido. Dentre os principais motivos 


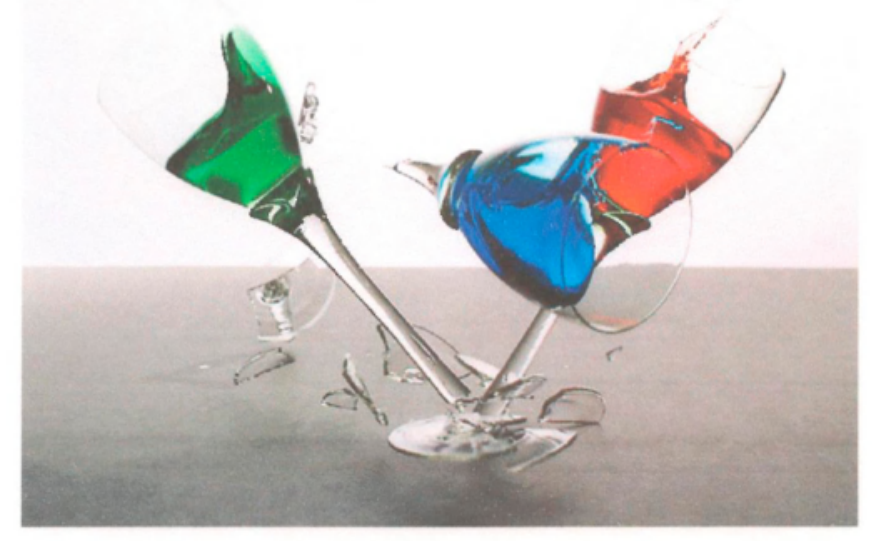

Figura 2.20: Imagem original [http:// ipml.ee.duth.gr/ papamark/ SGONG/ start.html]

para esta escolha podem ser destacados:

- A rede MLP se mostrou mais adequada ao processo de classificação de cores, principalmente no desenvolvimento de um sistema de binarização das imagens;

- Por se tratar de um sistema onde a base de dados pode ser facilmente rotulada (classificação das cores por um humano), o sistema de aprendizagem supervisionado se mostrou mais adequado.

- A rede MLP se mostrou adequada para realização do processo de classificação de cores utilizando-se o espaço de cor RGB;

- A rede MLP é reconhecida por ser capaz de lidar com dados ruidosos, o que é uma grande vantagem quando se trabalha com imagens;

- A rede neural MLP já está implementada em FPGAs pelo grupo de computação reconfigurável do ICMC, o que pode facilitar a implementação deste sistema em um hardware embarcado.

O sistama de segmentação proposto no presente trabalho será apresentado no Capítulo 4. 


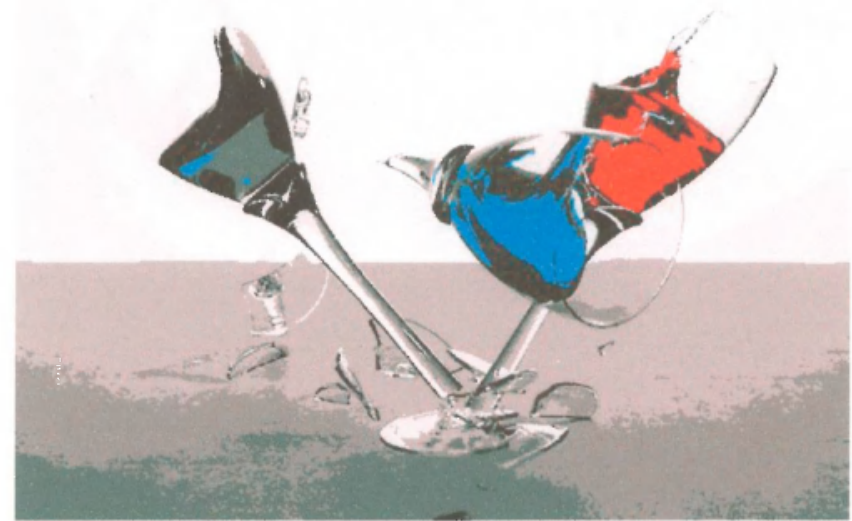

(a)

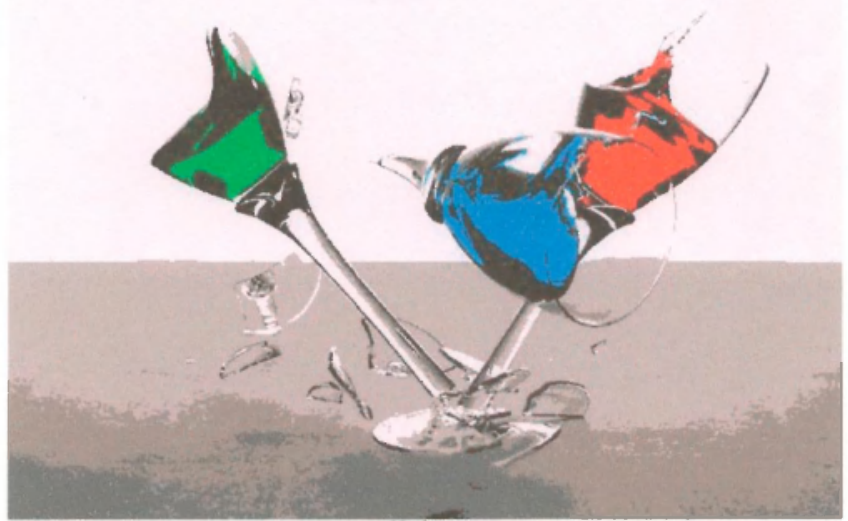

(b)

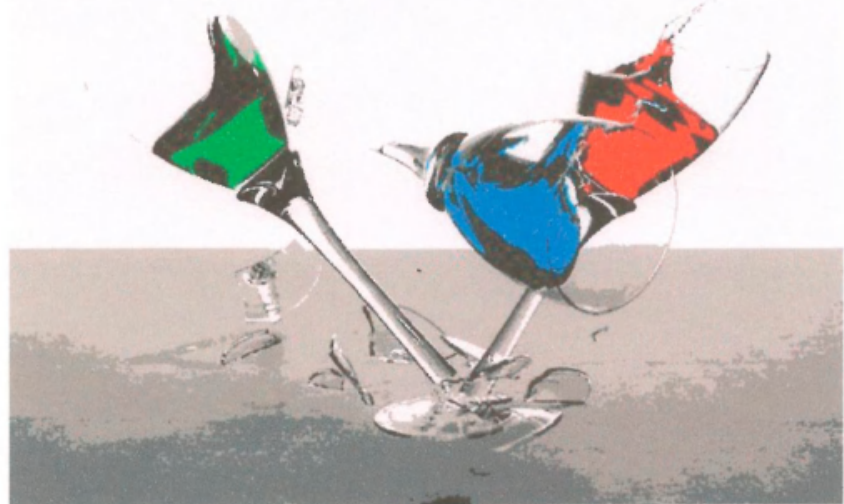

(c)

Figura 2.21: Imagens com cores reduzidas. (a) Rede SOM; (b) Rede GNG e (c) Rede SGONG [http:// ipml.ee.duth.gr/ papamark/ SGONG/ start.html] 


\section{Técnicas de Computação Bioinspirada}

$\mathcal{D}$

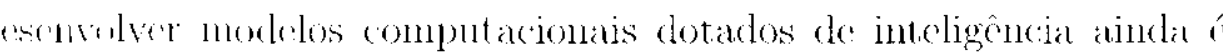

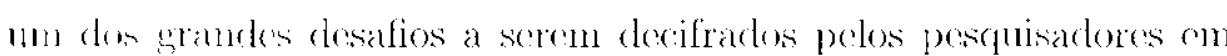

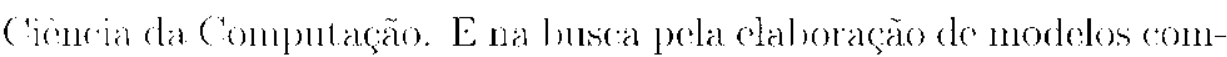

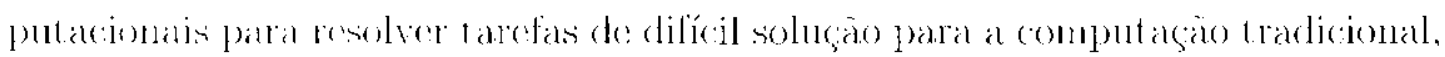

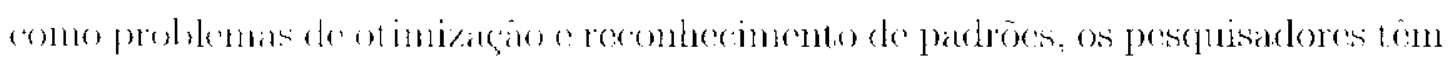

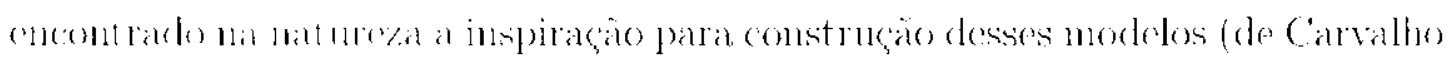
(it al. $200+1)$

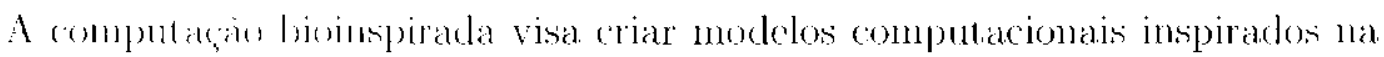

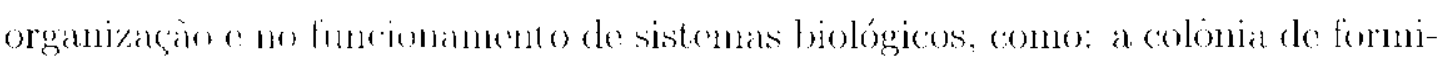

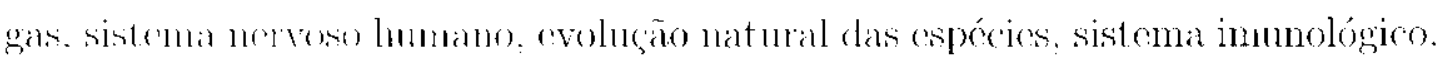

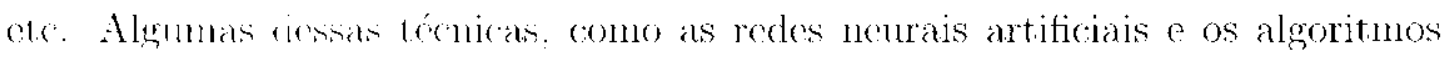

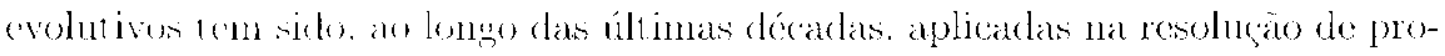

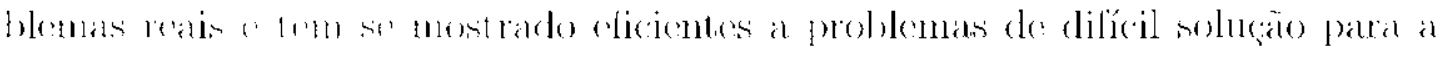

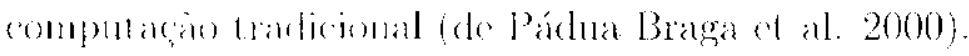

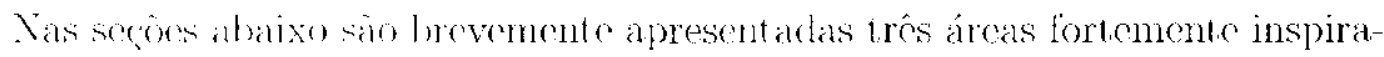

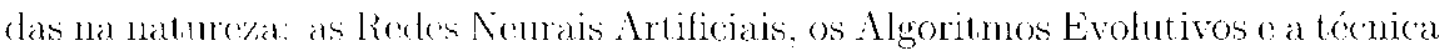

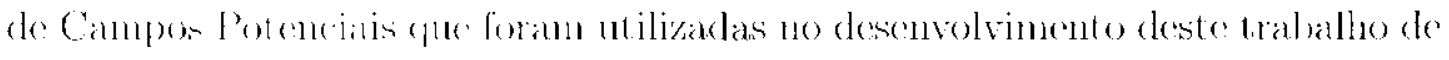
incestrator).

\subsection{Redes Neurais Artificiais}

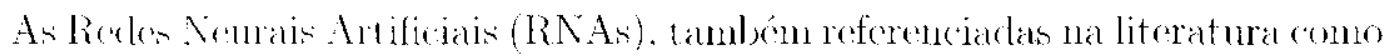

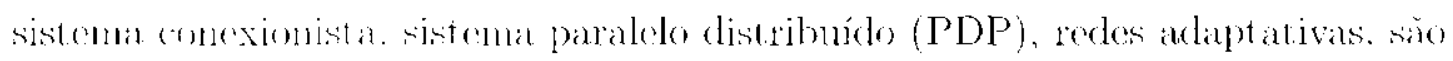
modelos compulationain iuspirados na estrutura o no funcionamento do córebro.

Segmede kinulel ot al. (1997), a principal semelhanga ontre as RNAs o os

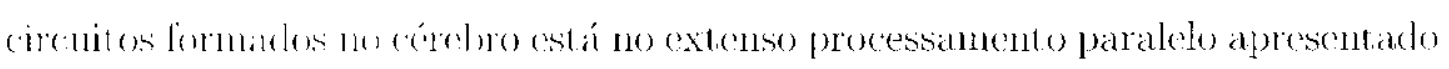

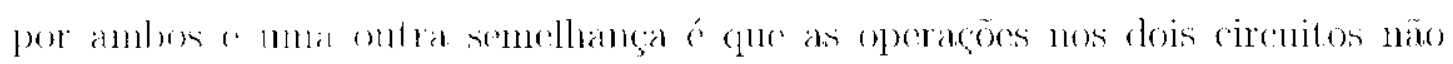




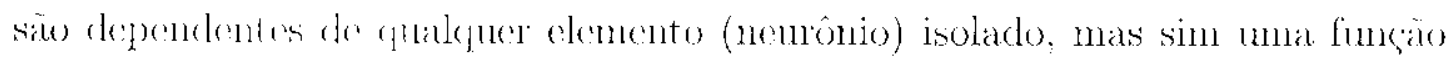

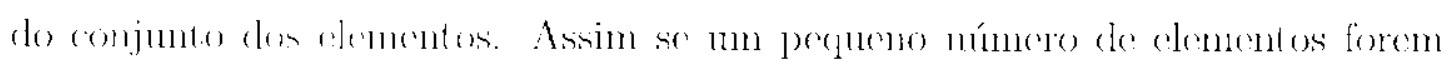

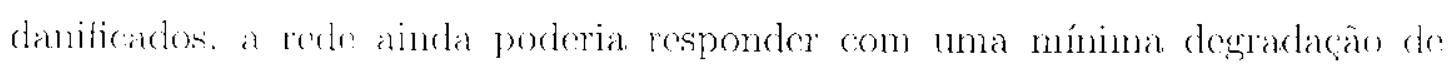
(lesempernlos.

\subsubsection{Histórico}

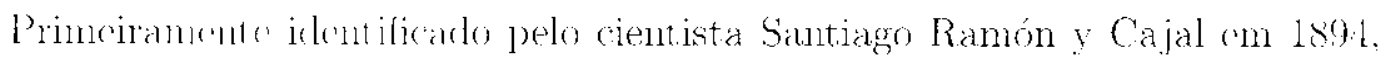
o nemonio ankitui a bame do sistema nervoso (Kandel et al. 1997).

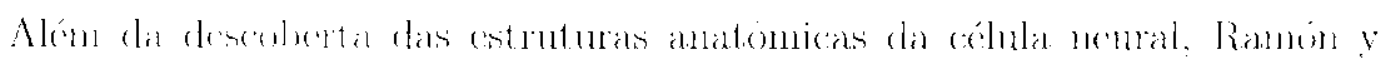

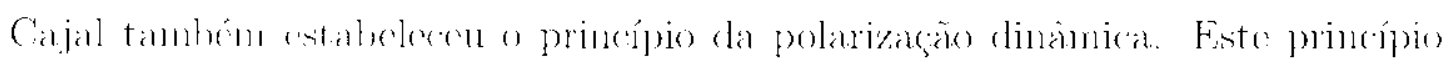

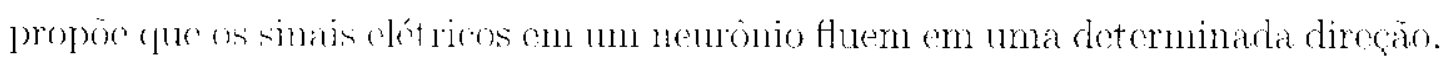

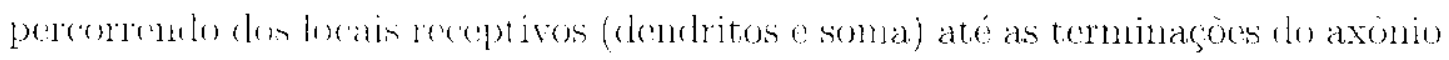

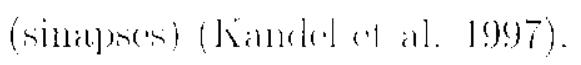

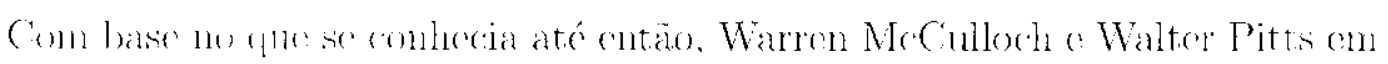
1913 propuscrinn o primoiro nourònio artificial (matenático) que pode ser visto (ono nma simpliticaucio do que já havia sido descoberto a respeito do neuronio

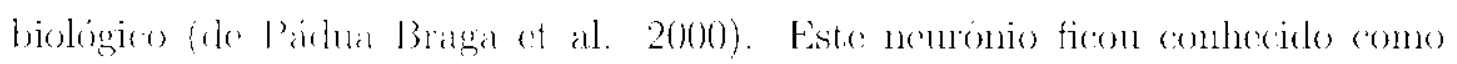

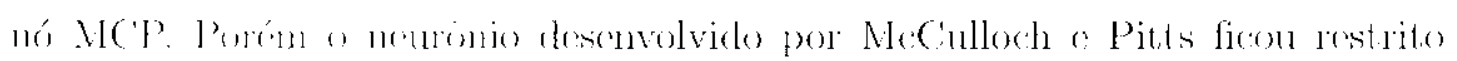

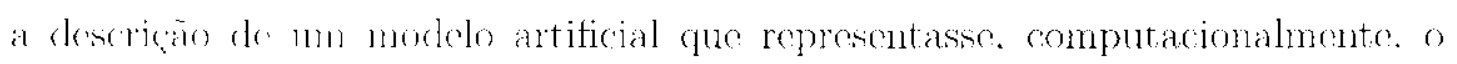

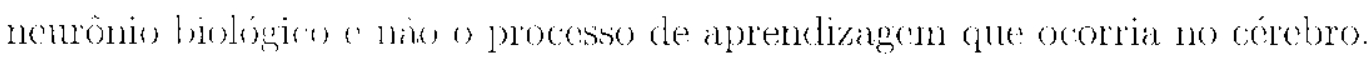

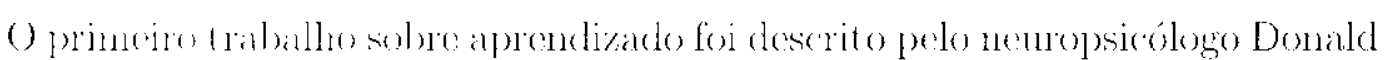

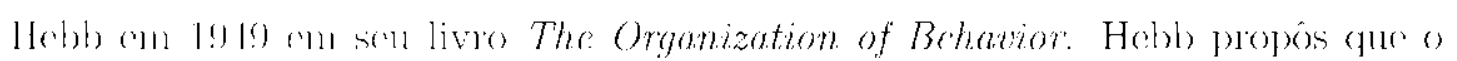

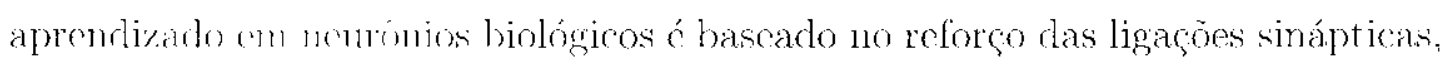

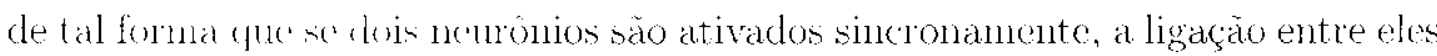

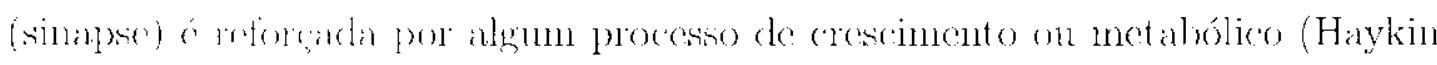
$2001)$

Rosenblatt an 1958. apresentou um modelo do rede denominada perceptrom.

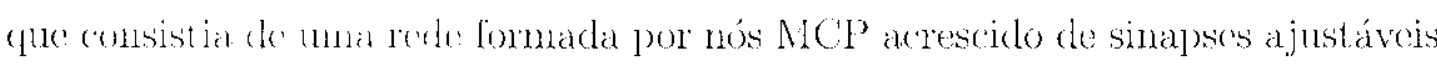

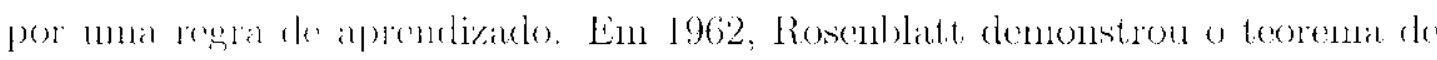

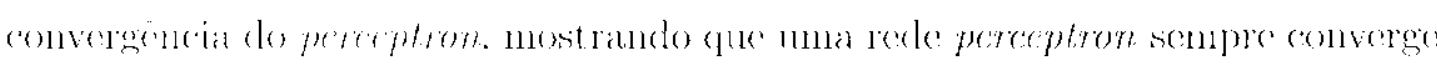

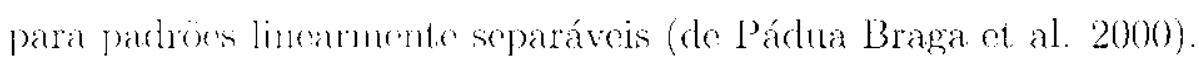

Quase ('m patalelu conn Rosenblate, ('m 1960. Widrow e Hoff aptesentaram

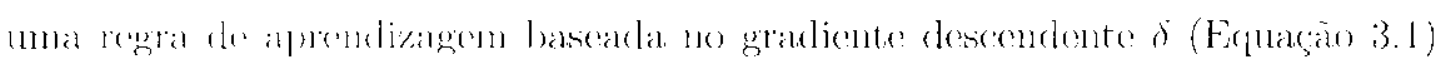

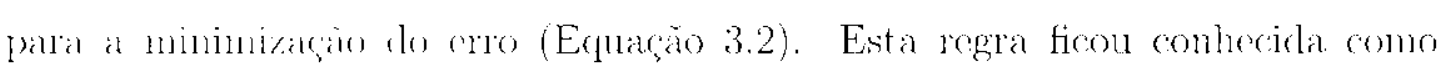
regra dellu. semelo esta milizada na formulagao do modelo nemal lincar ADALINE (Adaptatime linnot tilment). Porteriormonte, Widrow e seus alunos, em

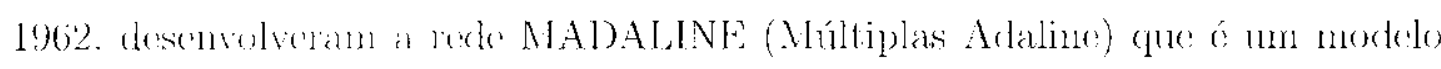
multidimemsionali da MI) MIJNE (Haykin 2001). 


$$
\begin{aligned}
& \delta=-\frac{\partial L}{\partial \omega} \\
& E-\frac{1}{2} \sum(d+\operatorname{sc} j a d o-(d) \text { hato })^{2}
\end{aligned}
$$

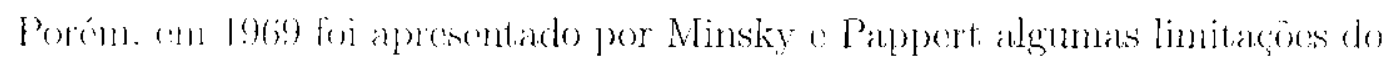

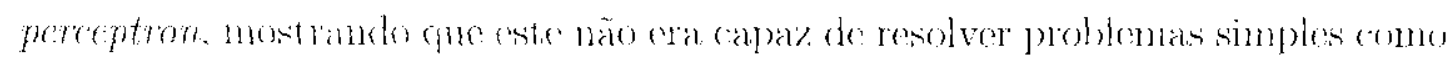

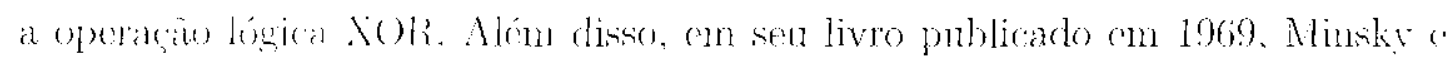

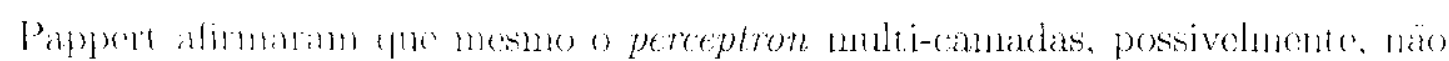

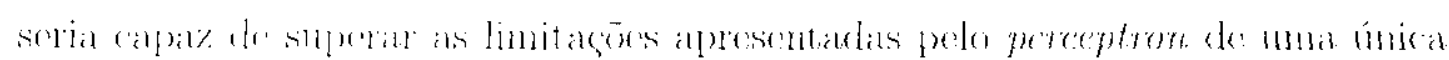

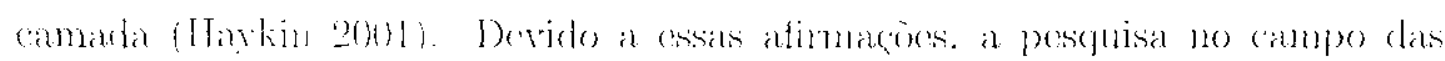

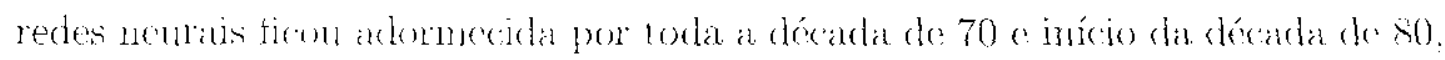

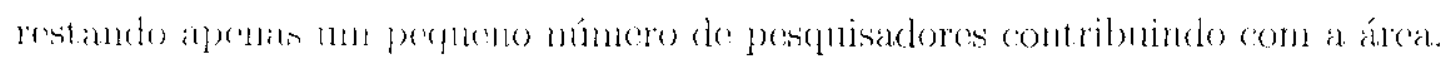

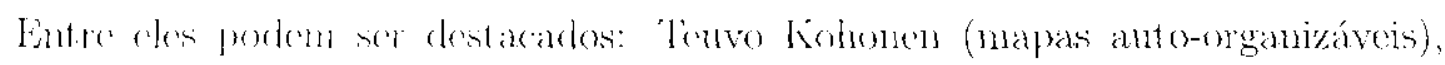

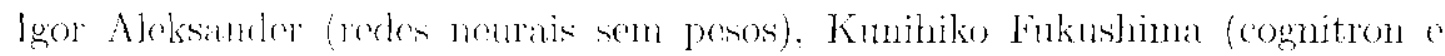
neocogniturn) "Steven Crossberg (sistomas anto-adaptativos) (do Pádula Braga (ct al. $2(0)(0)$

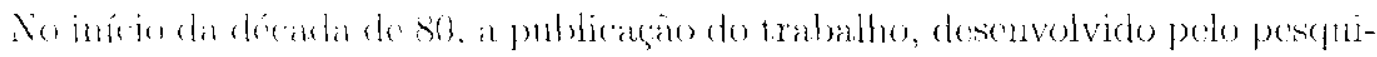

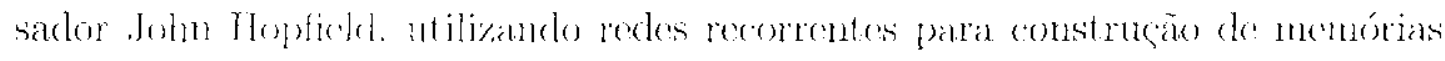

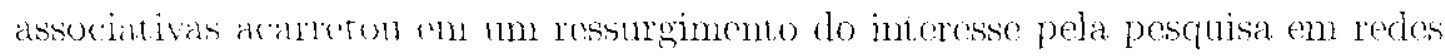

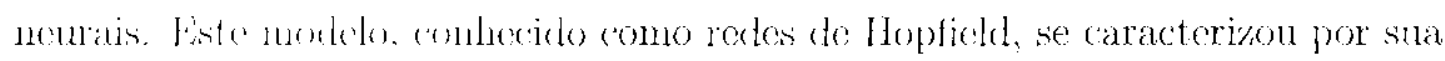

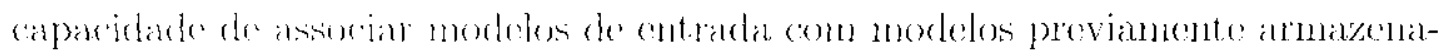
dos lar memória da rede (1laykin 2001).

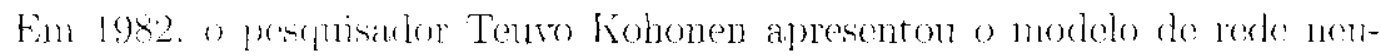

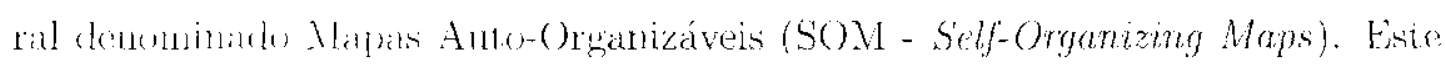

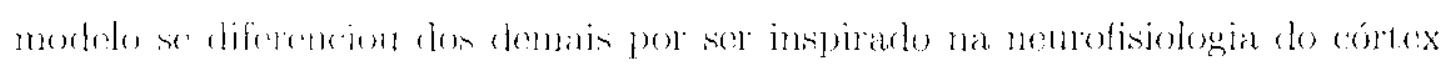

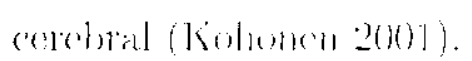

Porém. apenas enu 1986 com o desenvolvimento do algoritno de retropropagal-

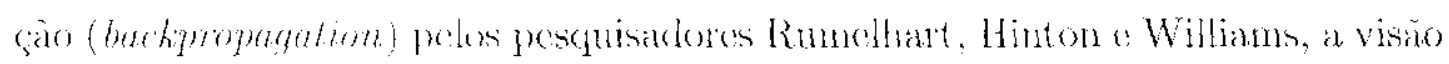

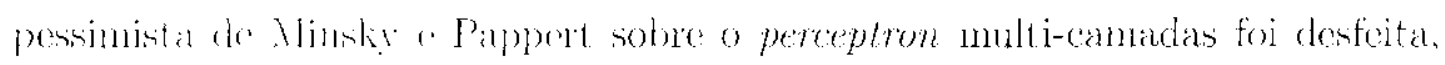

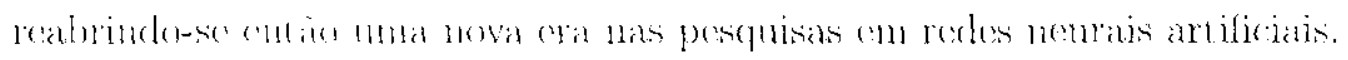

\subsubsection{O Neurônio}

\section{O Neurônio Biológico}

O sistema mevese í composte por duas classes distintats de cólulas. A pri-

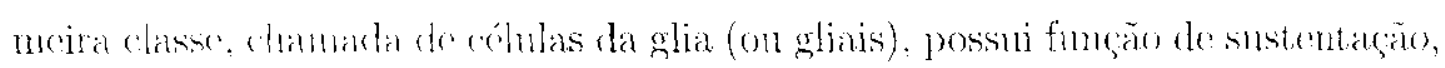
isolanmento. morlularano da at ividade neural e defesa (Machado 2000). A segunda 


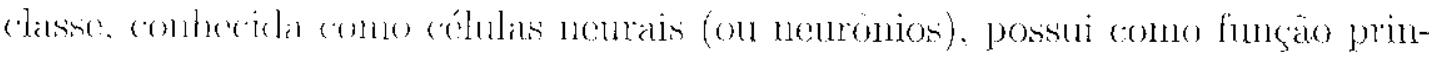

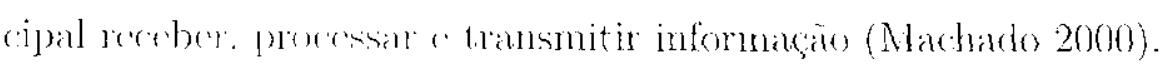

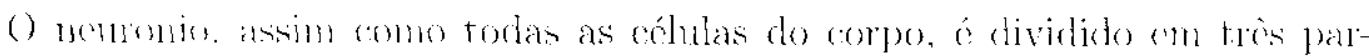

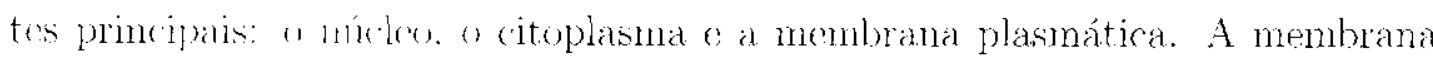

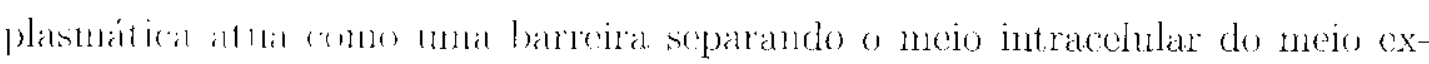

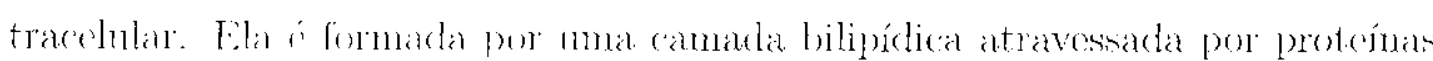

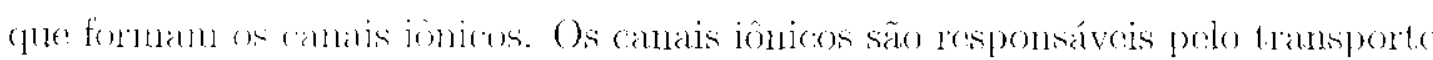

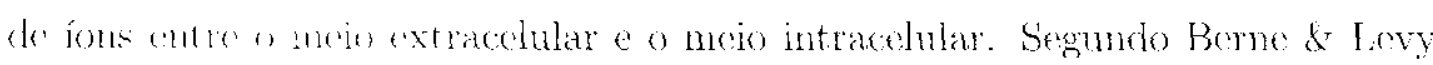

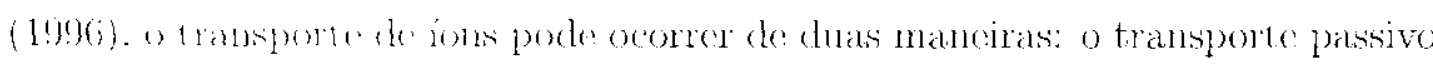

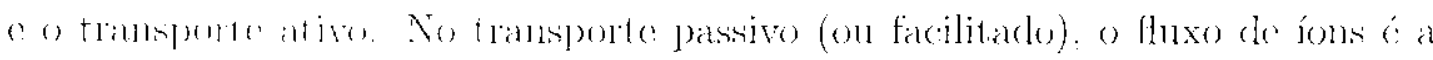

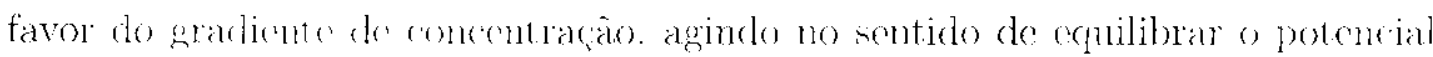

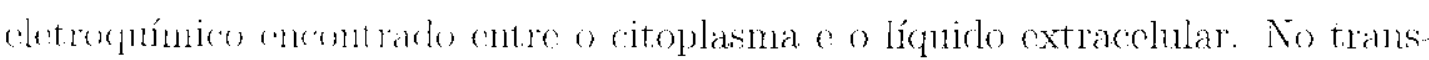

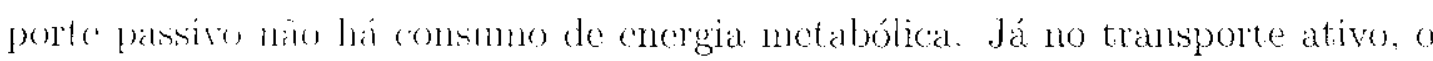

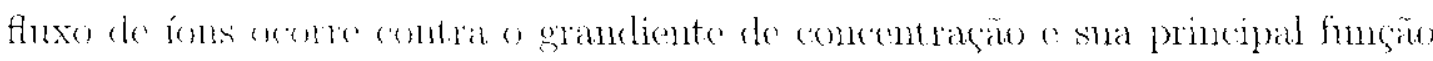

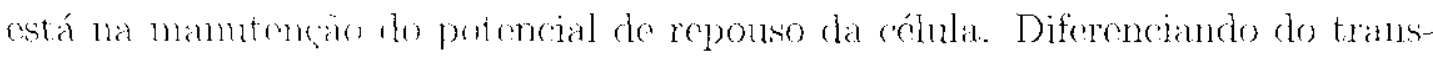
porte passive " trangente ativo consome energia motabólica e devido a ossal

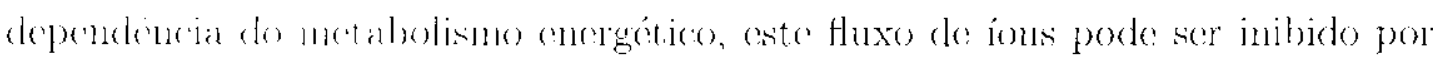

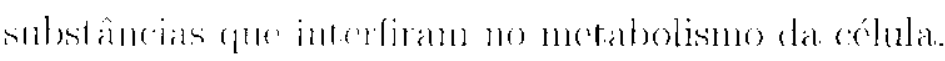

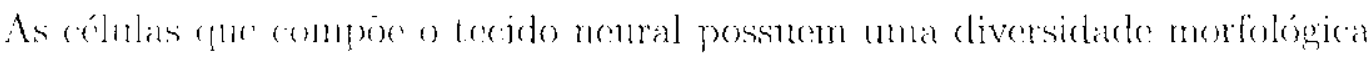

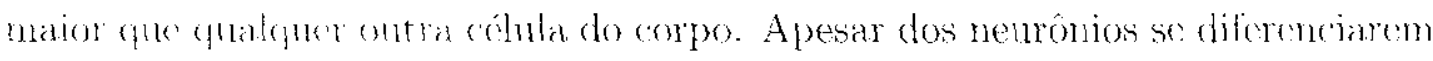

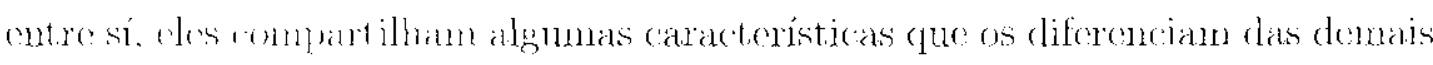

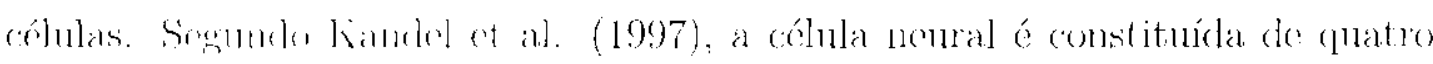

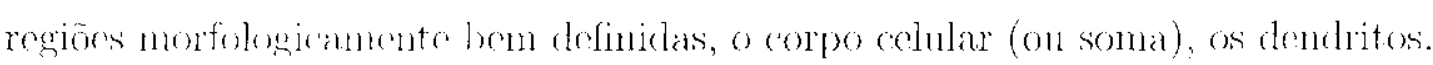

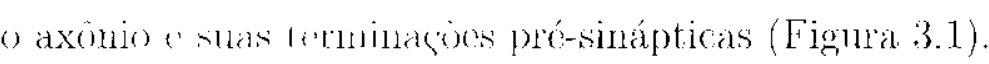

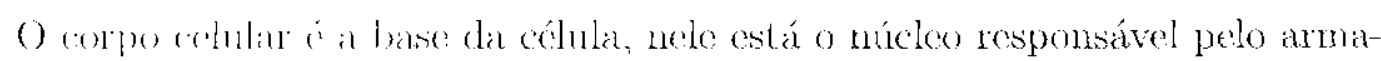

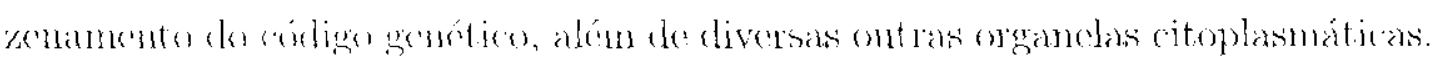

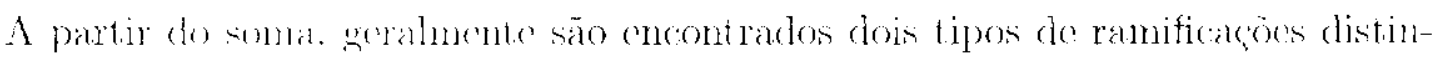
las. o axonio o de demdritos. Na maionia das cólulas neurais, são encontrados

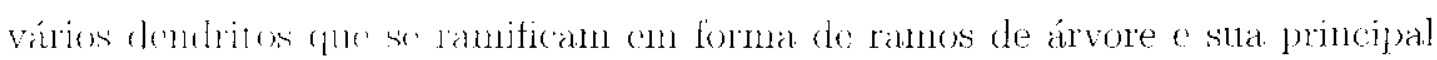

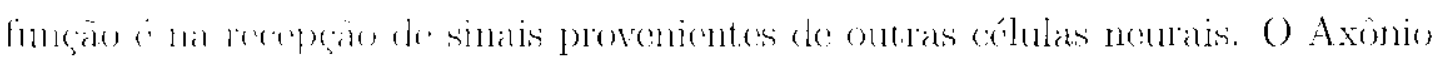

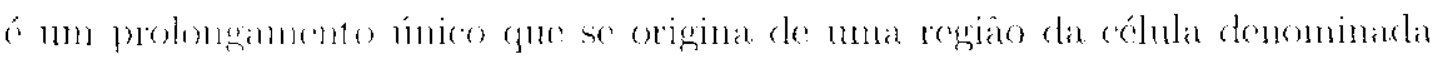

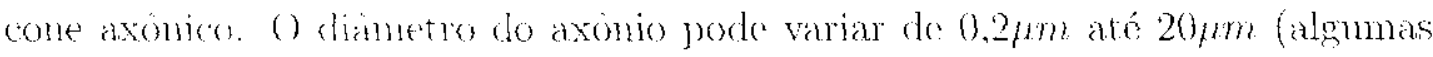

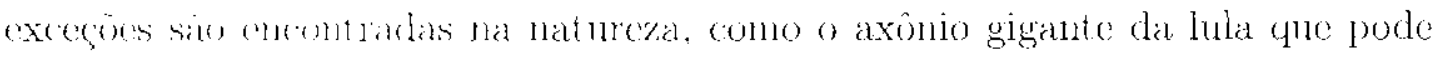

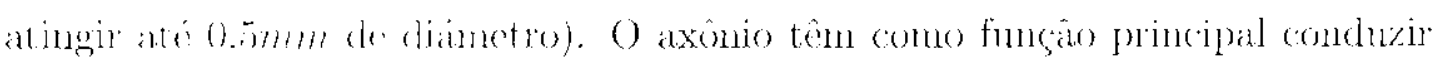

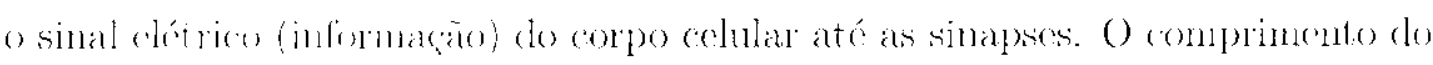
axonio pode variar de comprimentos de 0.1 mm ate $2 \mathrm{~m}$. A maioria dos axônios se

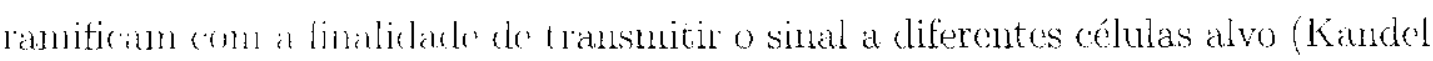




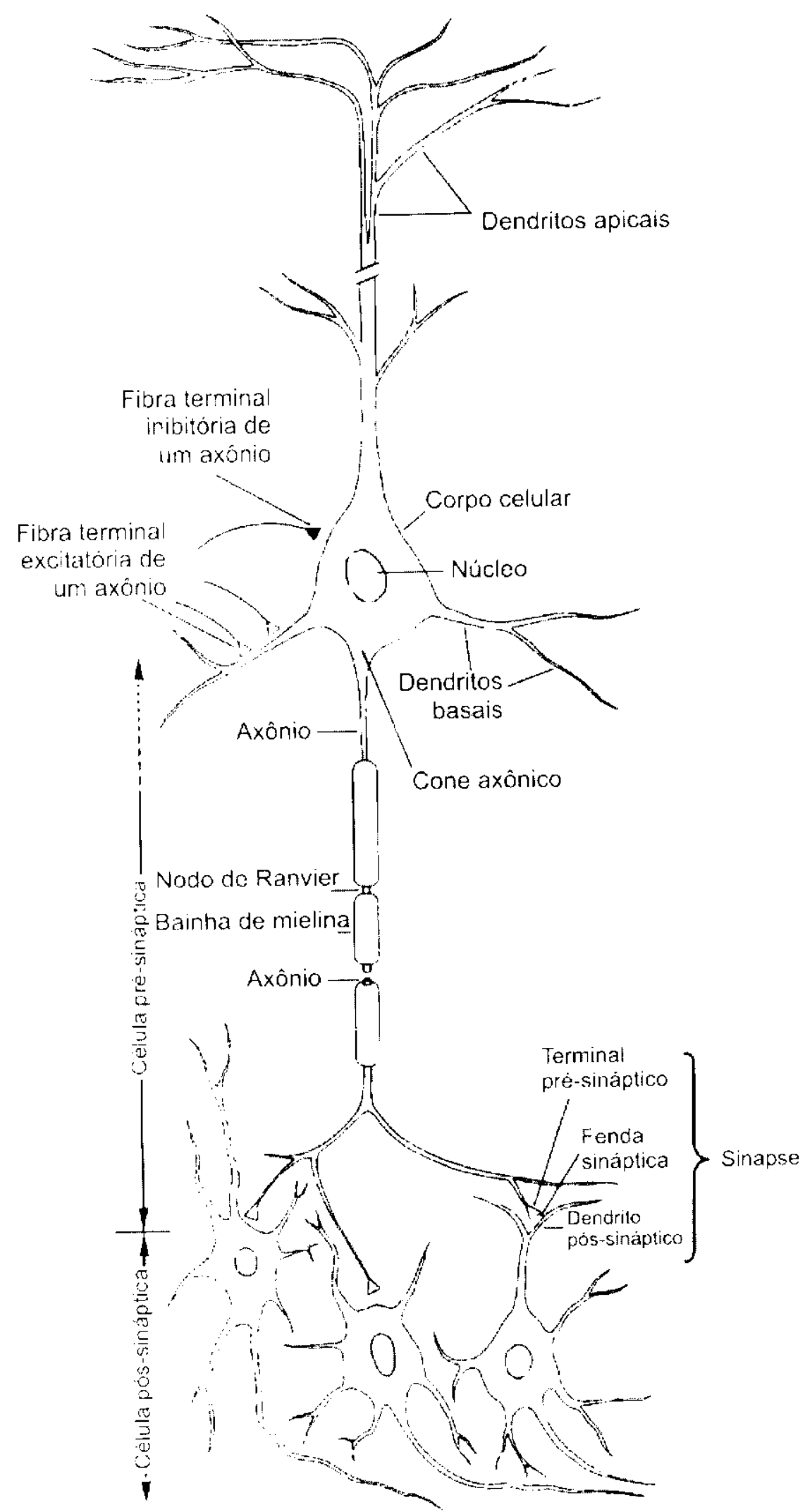

Fignura 3.1: Morfologia do neuronio biológico (Kandel ot al. 1997) 
(1. ial. 1997 )

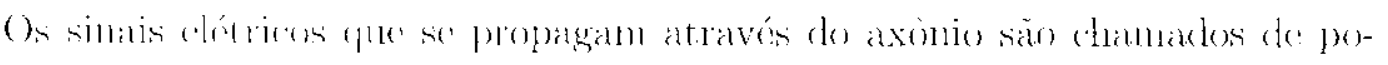

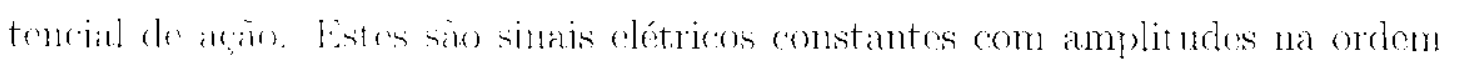

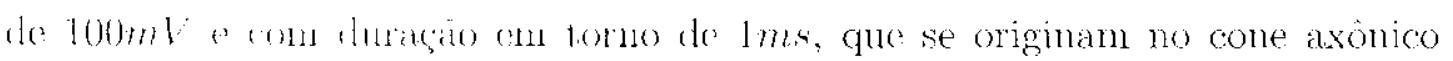

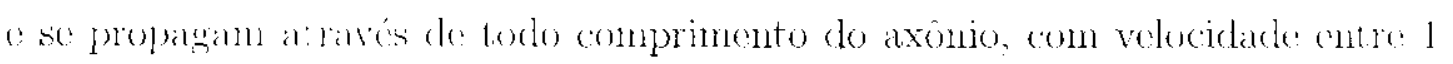

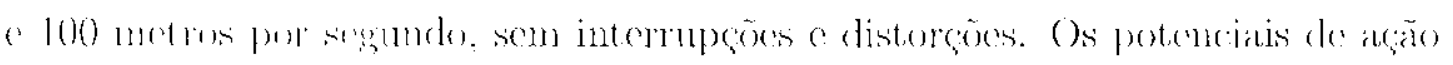

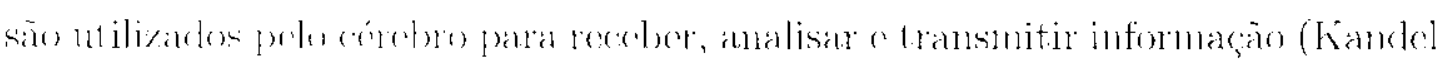
ct al. $199 \%$ )

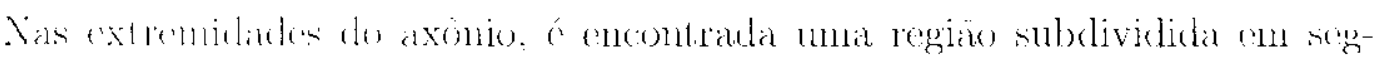
mentos lones qu

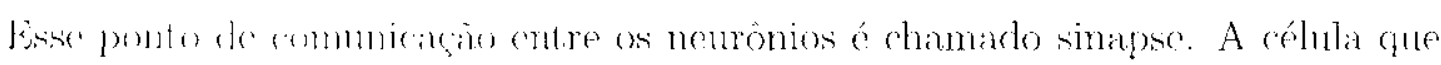

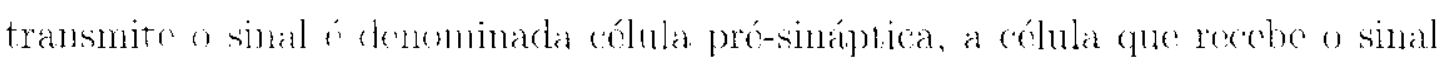

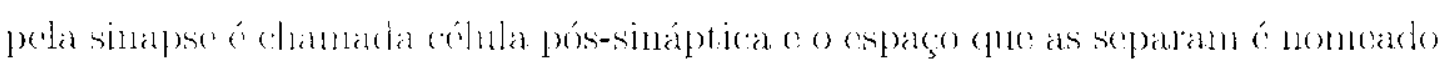

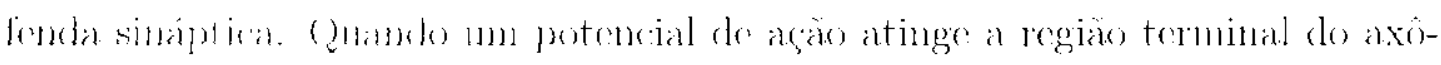

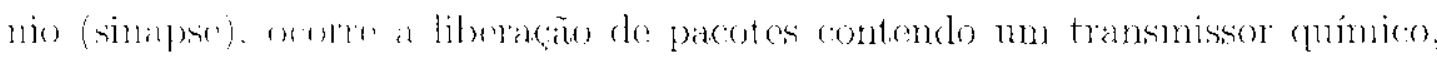
também dhanake de nenotransmissor. Existem diversos tipos de nenotrans-

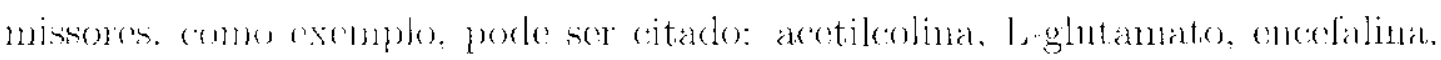

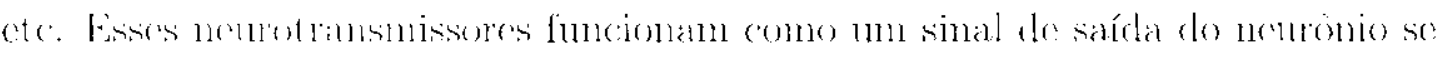

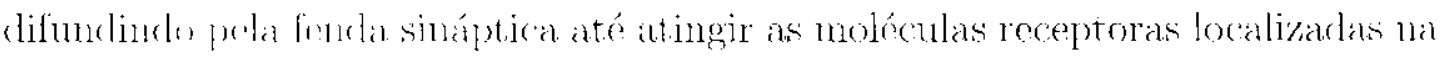

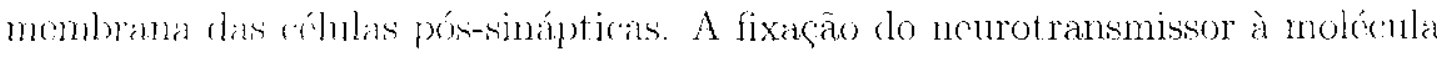

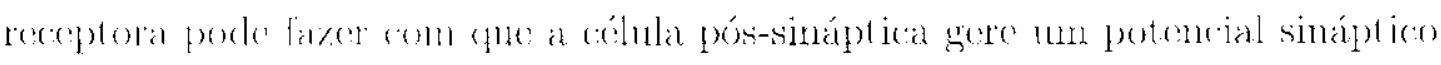

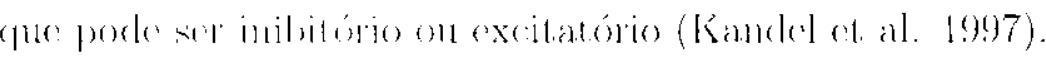

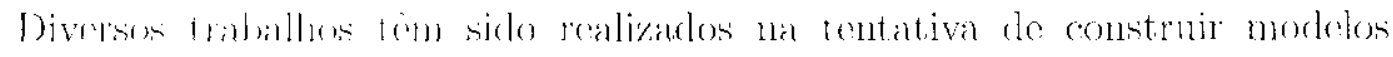

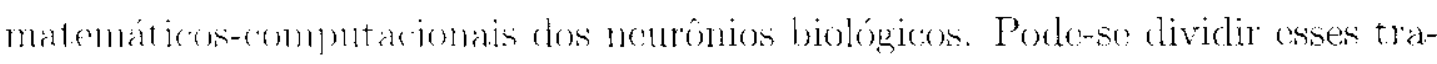

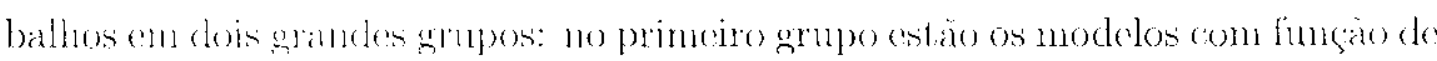

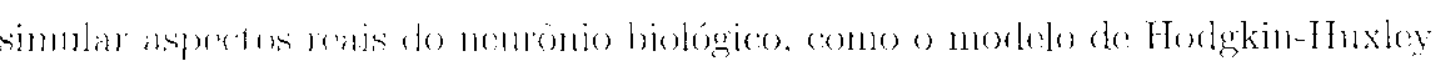

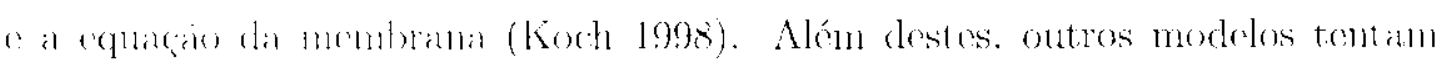

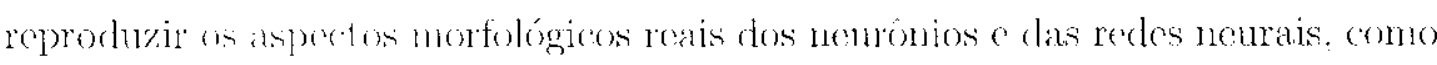

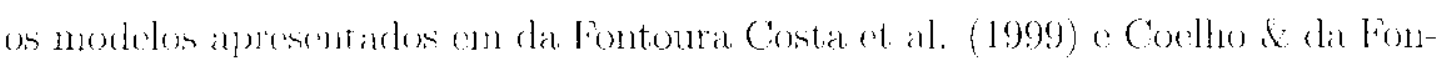

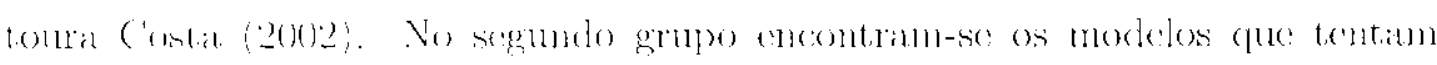

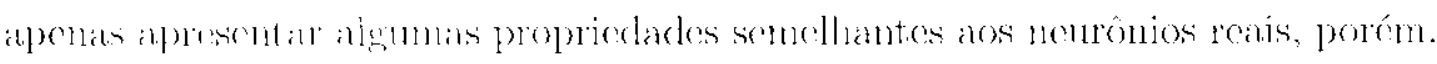
scon so prousupar come a plansibilidade biológica.

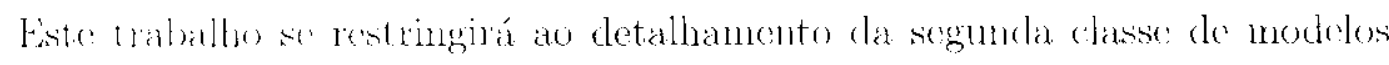

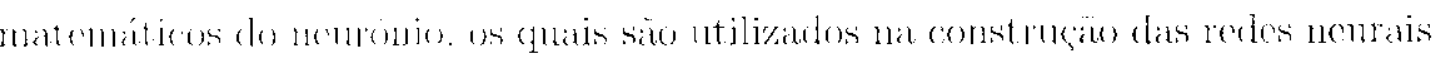
artiliciaris. 


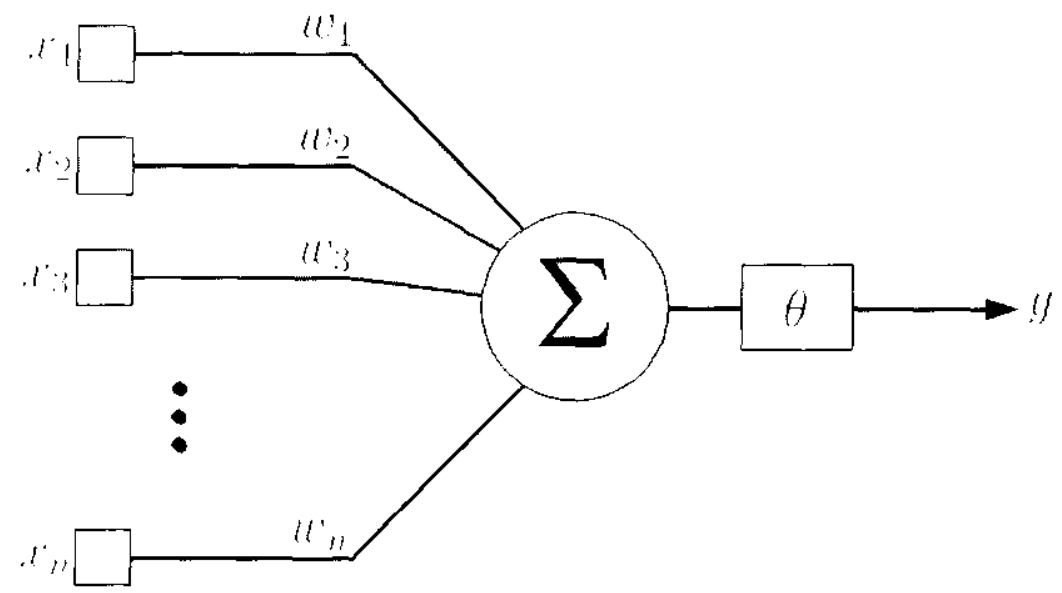

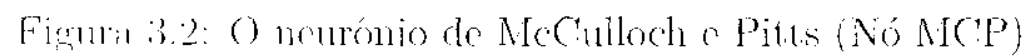

\section{O Neurònio Artificial}

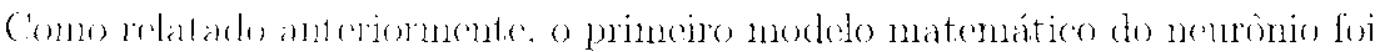

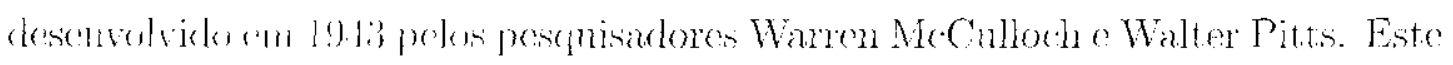

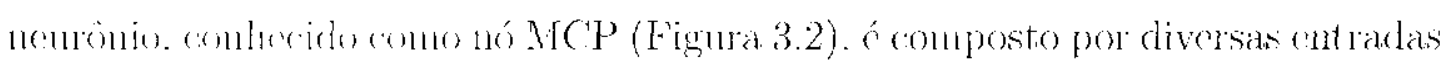

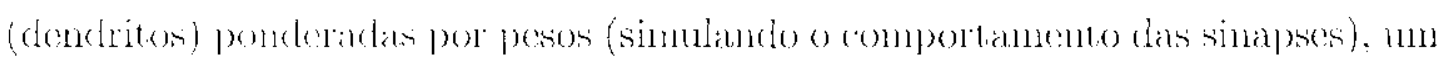

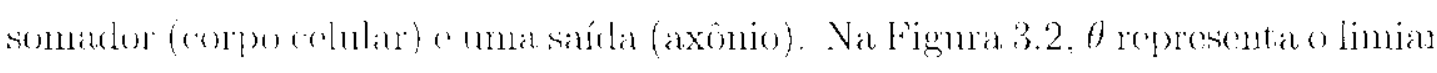

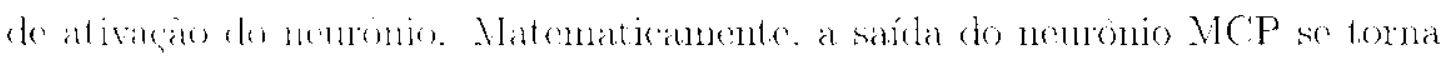
atival cluatulo:

$$
\sum_{i=1}^{n}\left(x_{i}\left(c_{i}\right) \geq 0\right.
$$

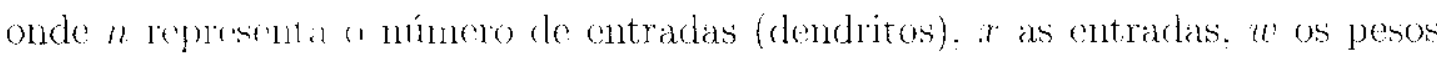

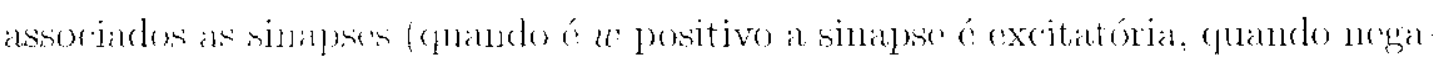

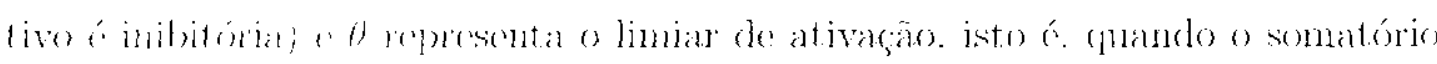
atingir o limial 0. " memonto se toma ativo. Matematicannente a Equaça 3.3

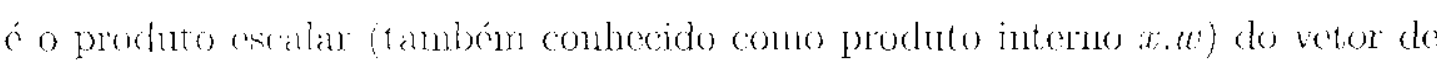

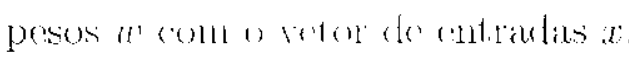

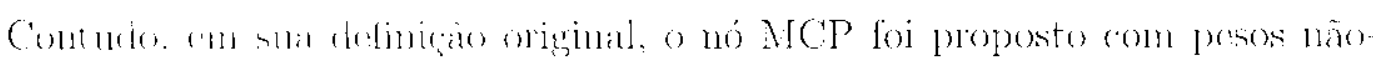

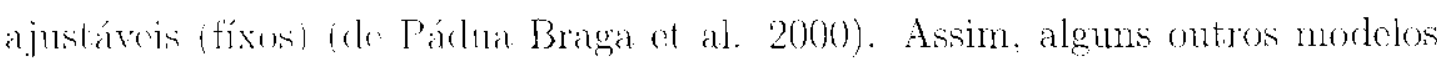

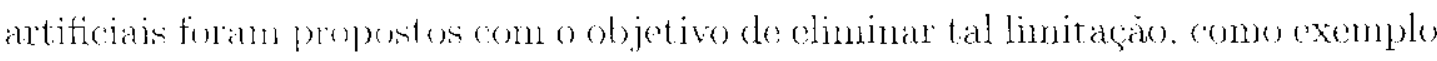

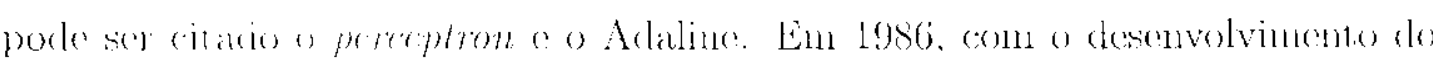

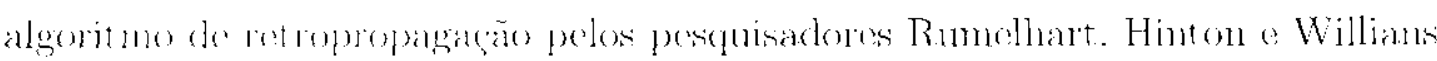

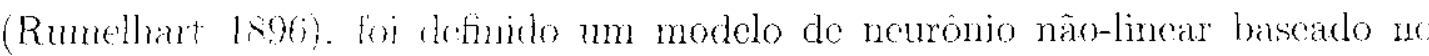
perceptron. Este nenoonio, é atualmente o mais utilizado pola comunidade do 


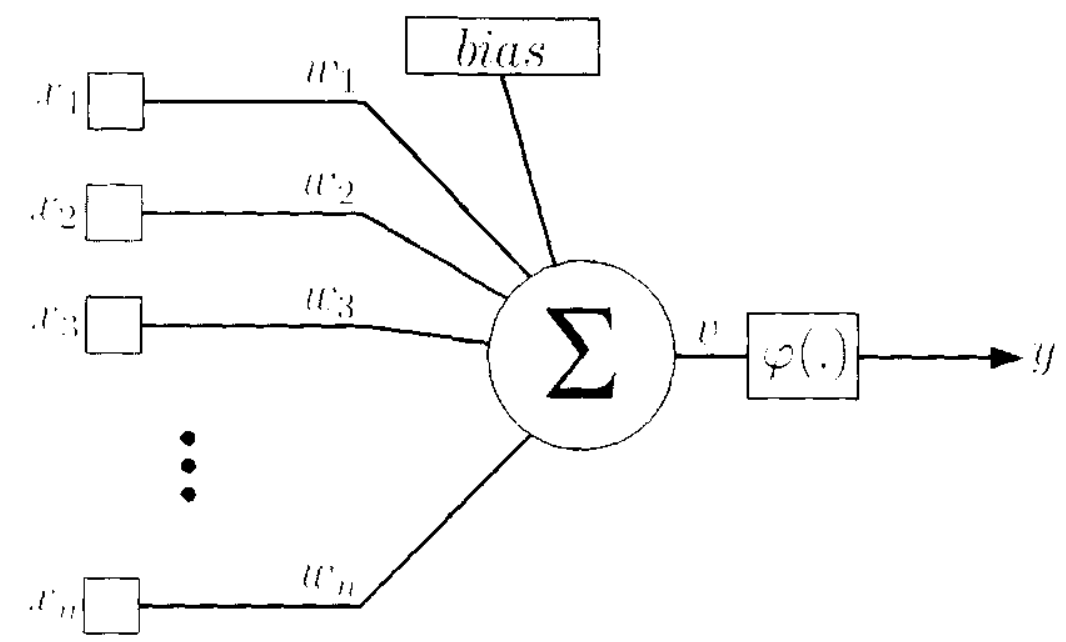

Fignเa 3.3: () neuronio năo-linear

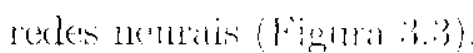

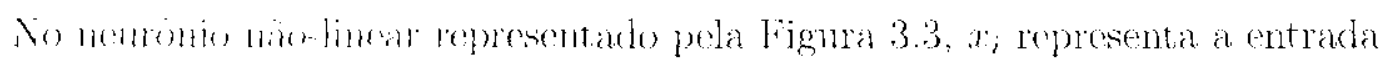

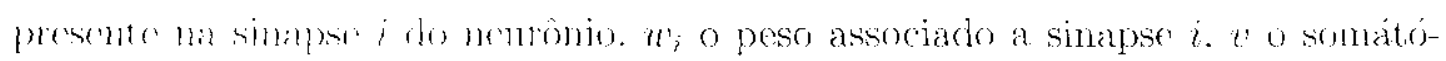

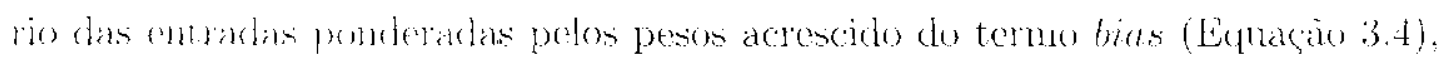

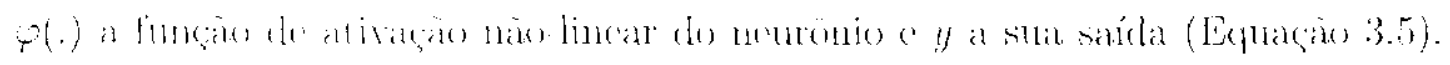

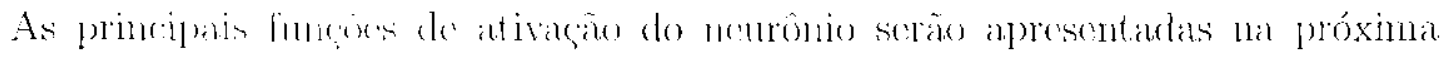
Subsecian).

$$
\begin{gathered}
n=\left(\sum_{i=1}^{n} x_{i}\left(w_{i}\right)+b \operatorname{bit} t s .\right. \\
y-\phi(n)
\end{gathered}
$$

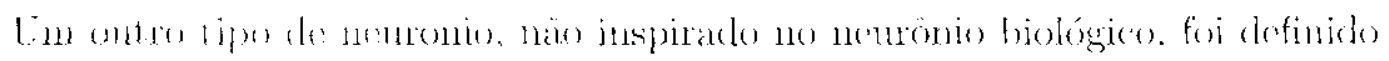

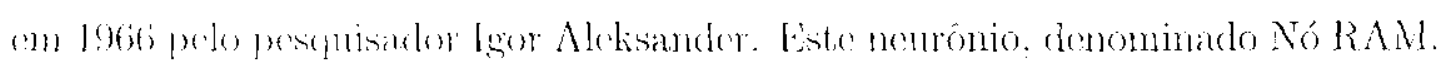

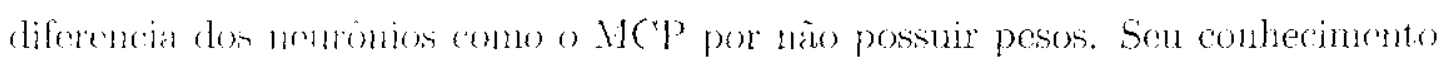

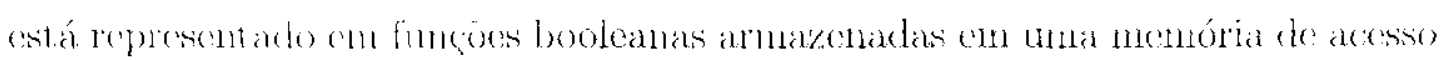

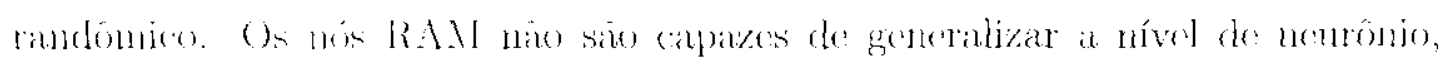

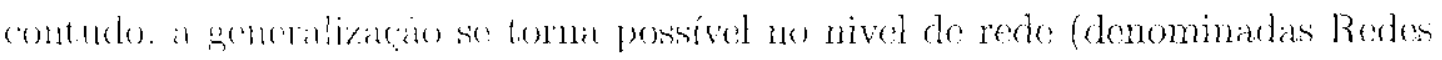

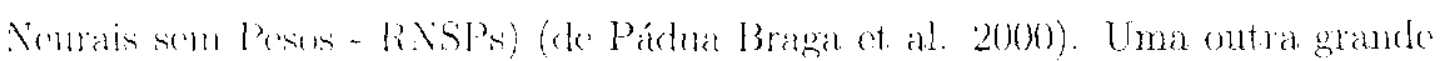

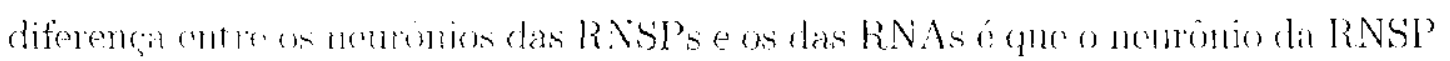

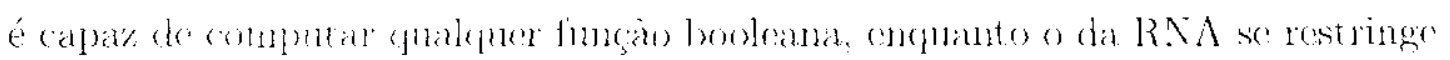

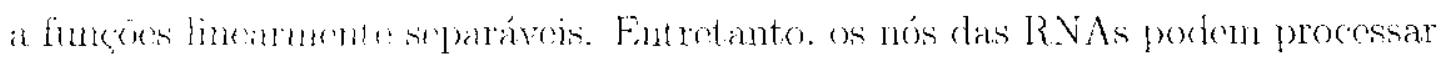

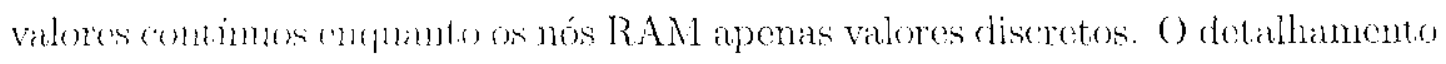

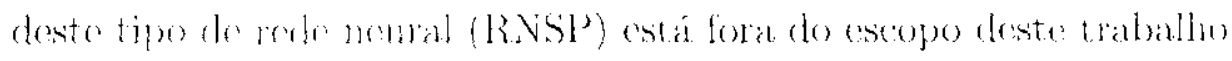




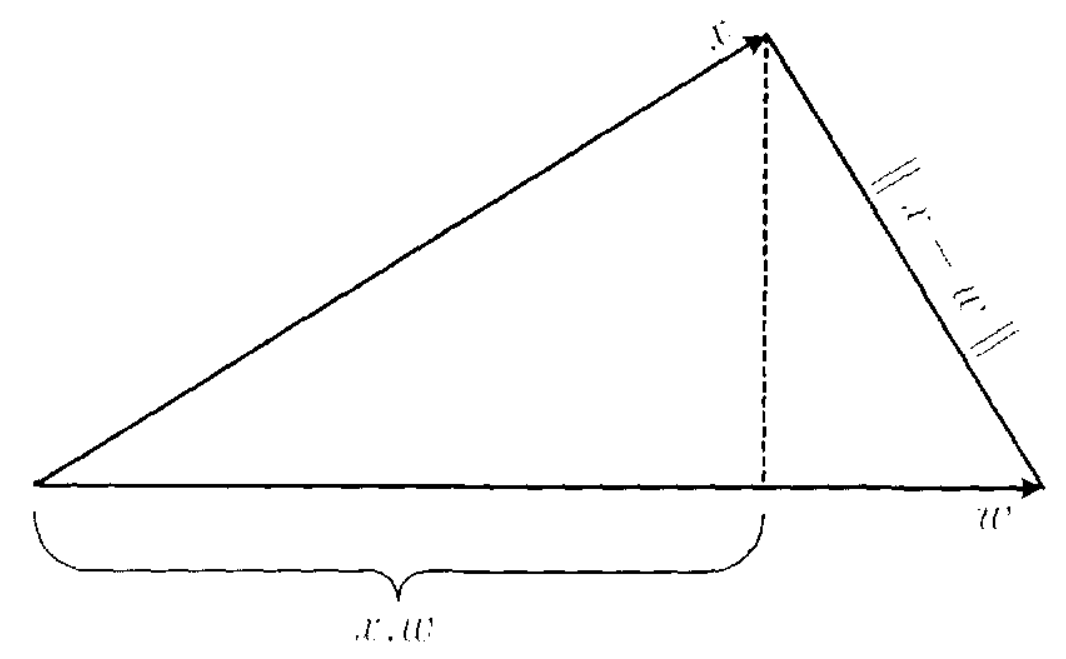

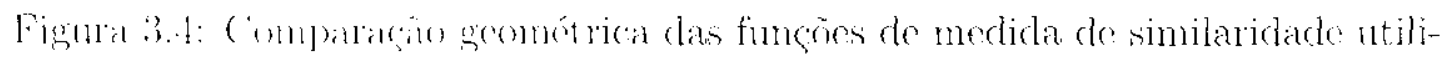
zarda pelos nemonion

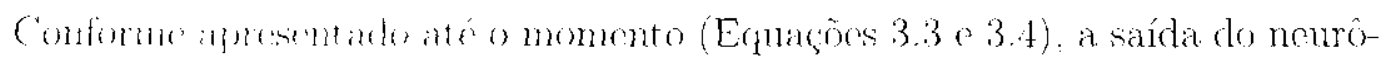

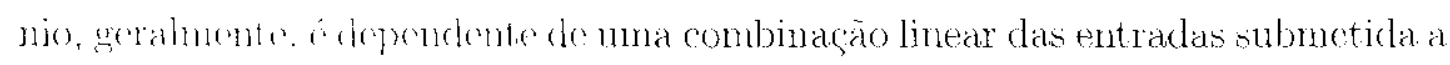

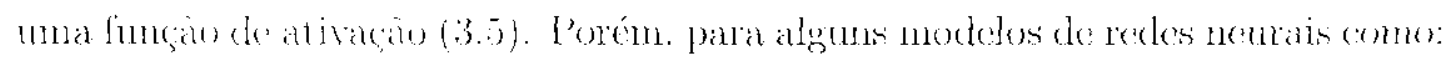

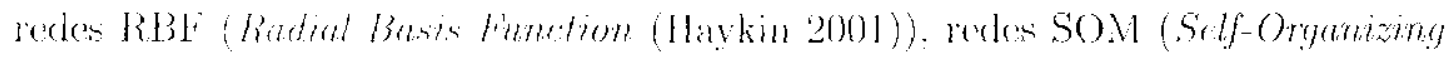

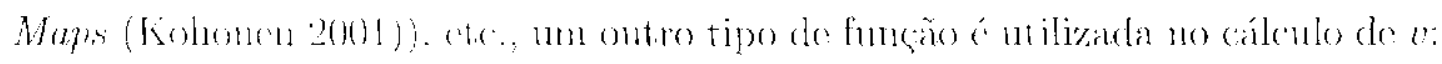

$$
v=\sum_{i=1}^{n}\left(x_{i}-w_{i}\right)^{2}
$$

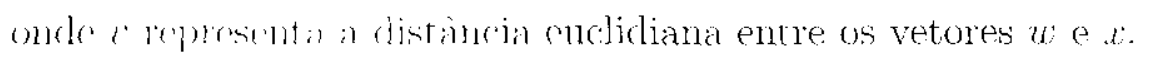

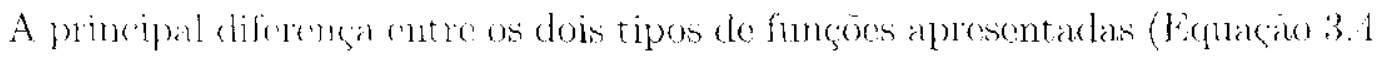

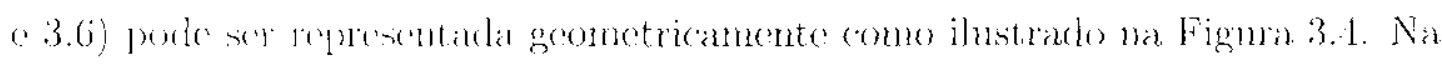

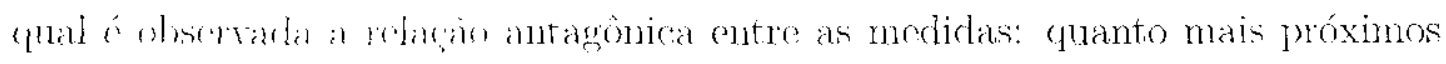

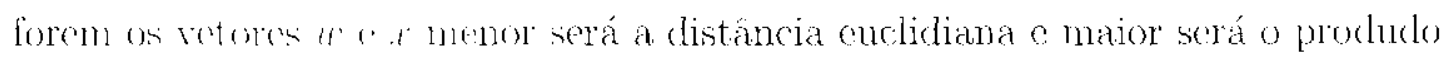
intermo entere ders.

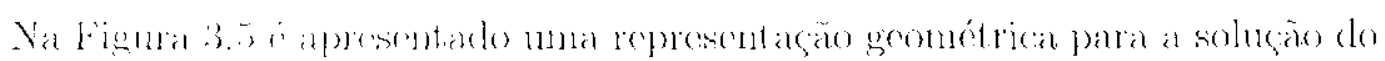

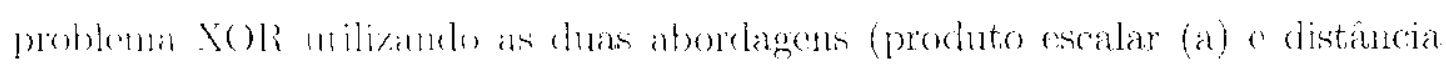
curdidian (b). Va prineina ahordagem (a) os pesos dos remonios da camada

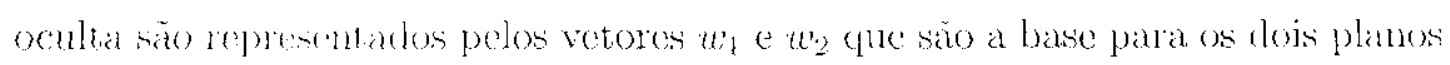

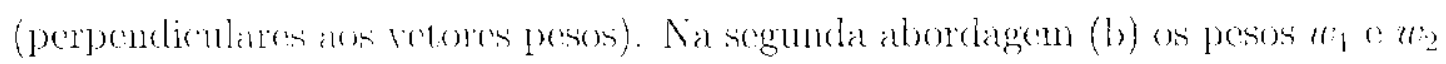

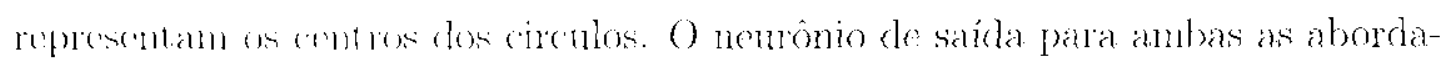
gens pork ser mu pereptron. sabendo-se que a funçäo deste último neuronio é a

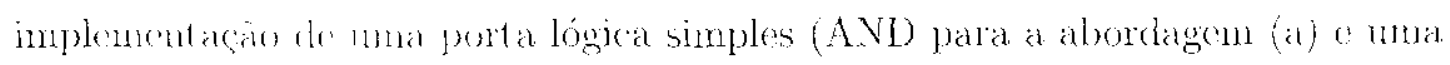
porta ()R para at aberdigen (b)). 

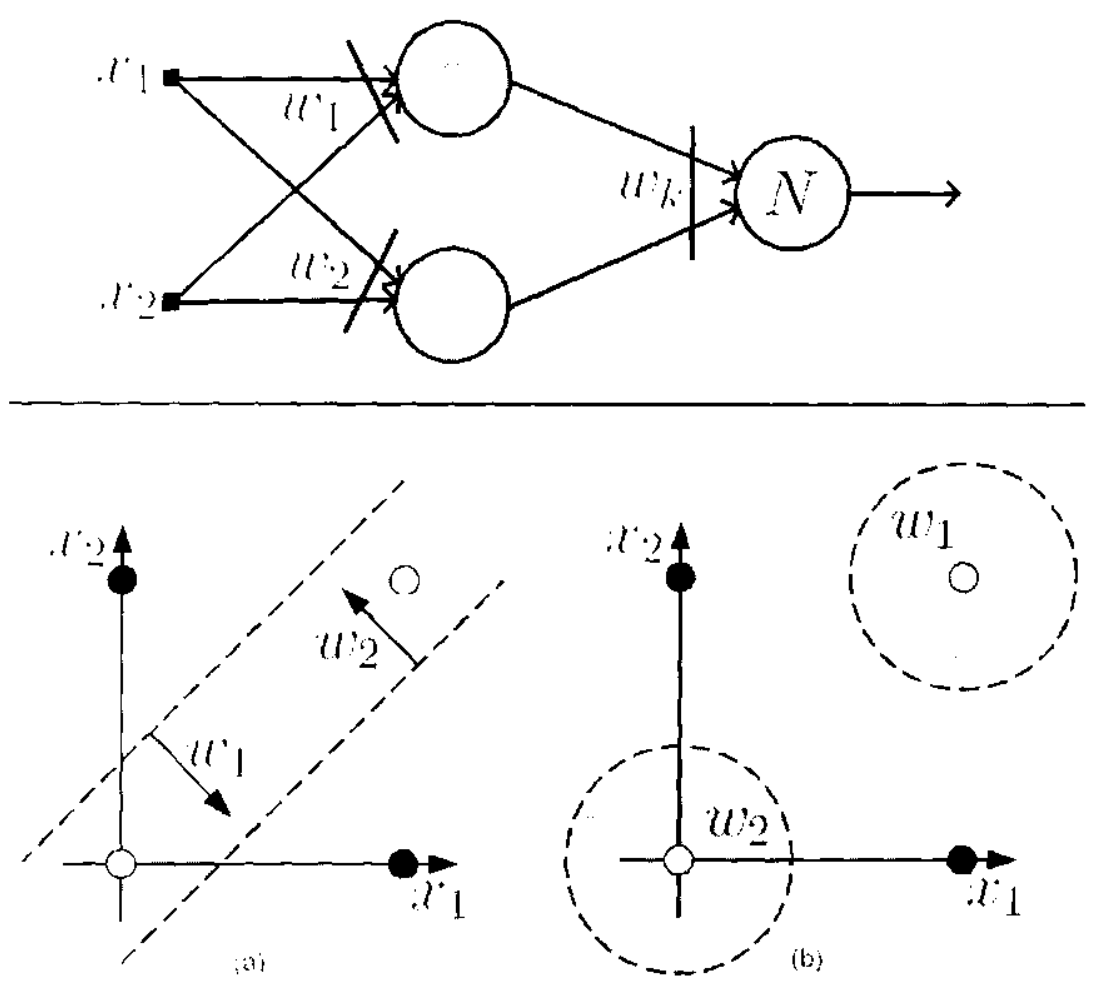

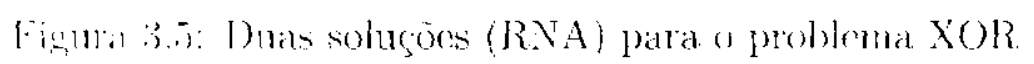

\subsubsection{Funções de Ativação}

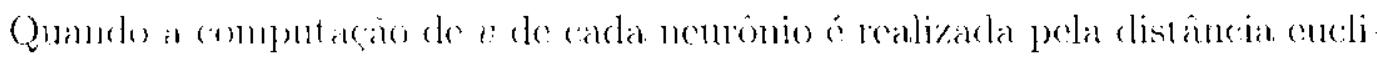

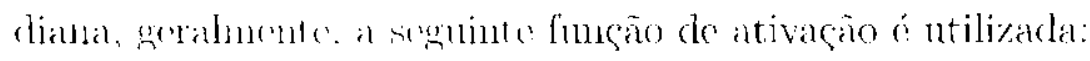

$$
y^{-}-(\operatorname{cop})(-i)
$$

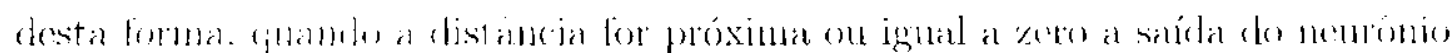

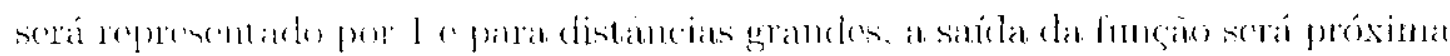
il $x$ (i)

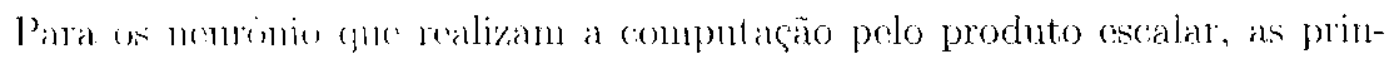

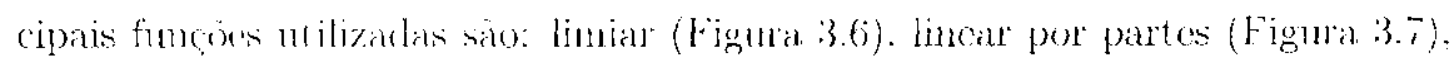

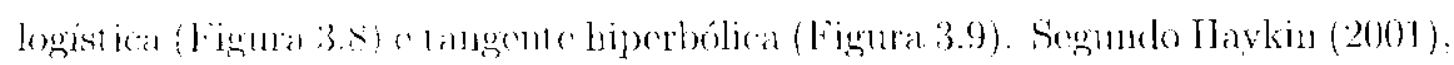

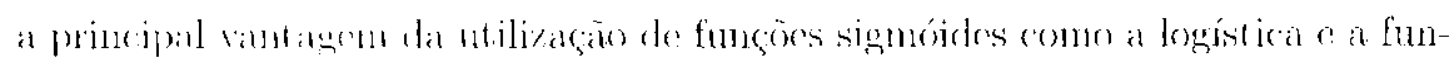

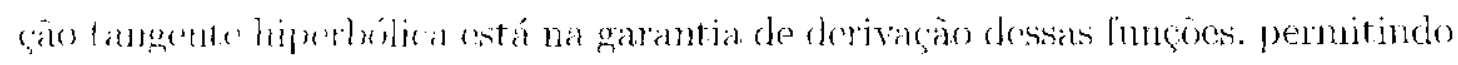

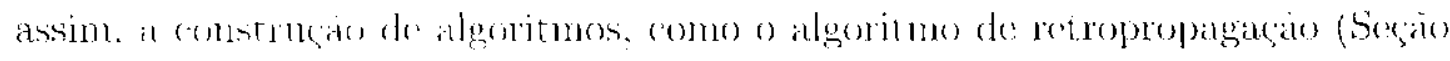

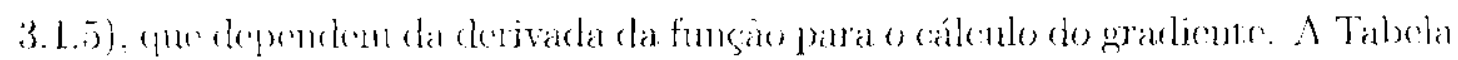

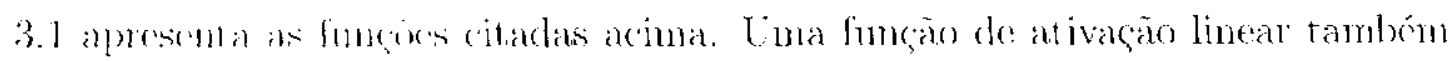

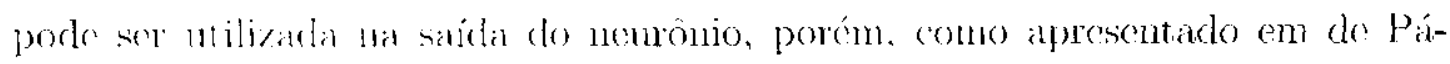

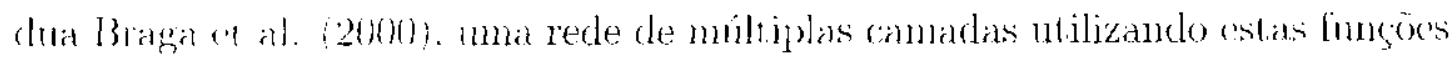




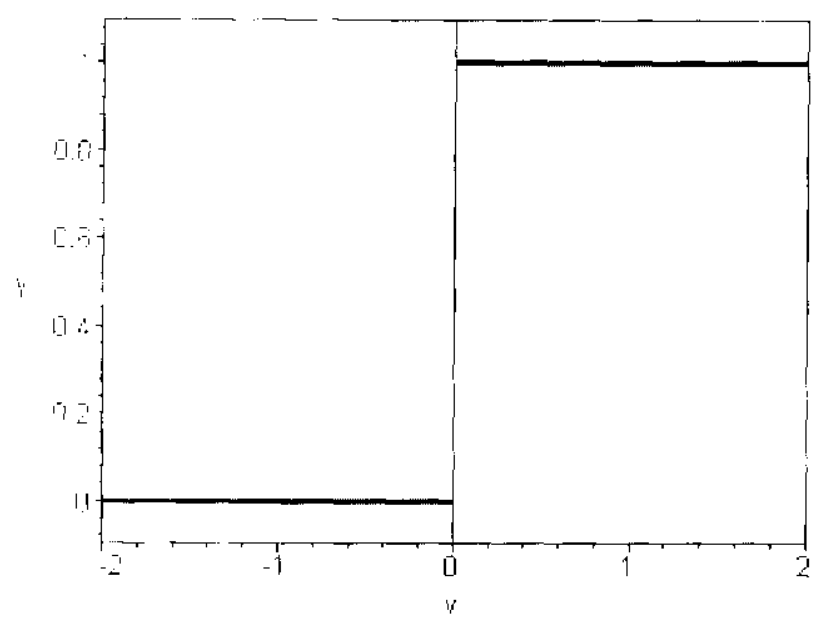

Fignua 3.6: Funçón limian

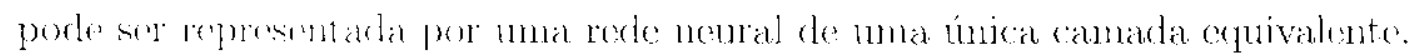

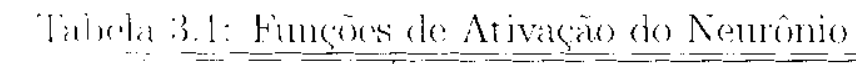

\begin{tabular}{|c|c|}
\hline T'ipo de Função & Funçào \\
\hline Liminar & 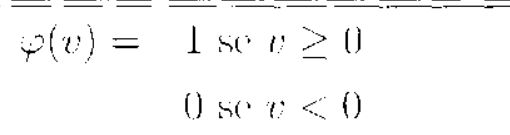 \\
\hline lintrat por Partes & $\begin{aligned} \varphi(v)= & 1 \text { sis } v \geq \frac{1}{2} \\
& v \text { se }-\frac{1}{2}<v<\frac{1}{2} \\
& 0 \text { se } v \leq-\frac{1}{2}\end{aligned}$ \\
\hline Signnido Logristica & $\varphi(v)=(1+c u(-a v))^{-1}$ \\
\hline Timponto 1lipserbólica & $\varphi(0)=\tanh (0)$ \\
\hline
\end{tabular}

\subsubsection{Classificação das Redes Neurais}

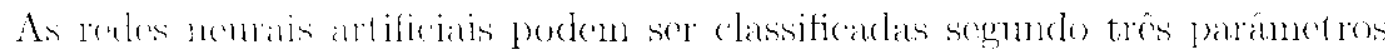

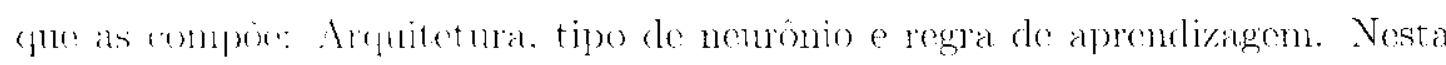

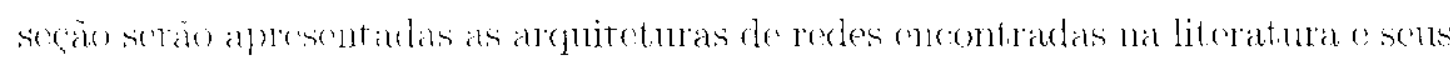
patadignats de: annerdiragem.

Arquitetura das RNAs

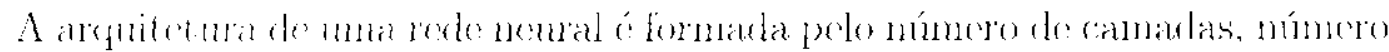

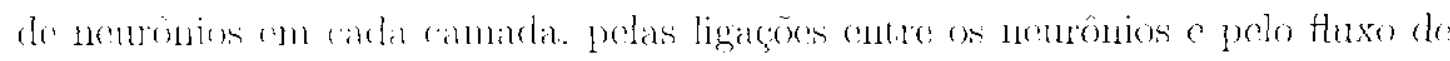

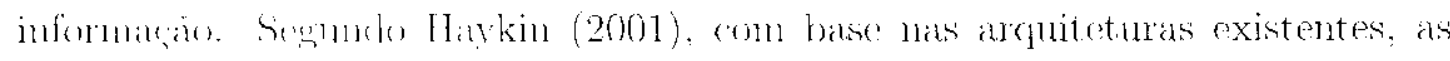
redes nomais potom ser divididas en thes classes principais: Redes fectforward

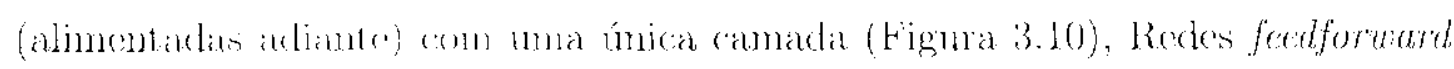

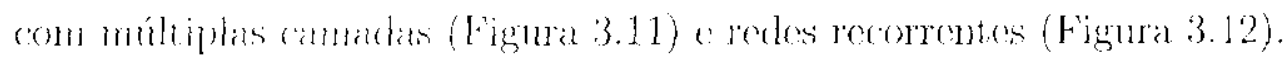




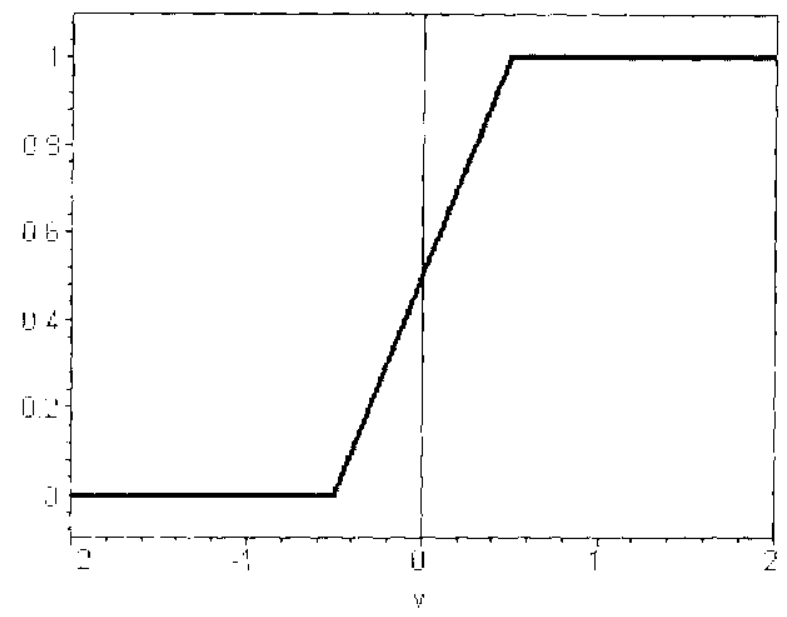

linulu 3.7: Fungăo lincal por Partes

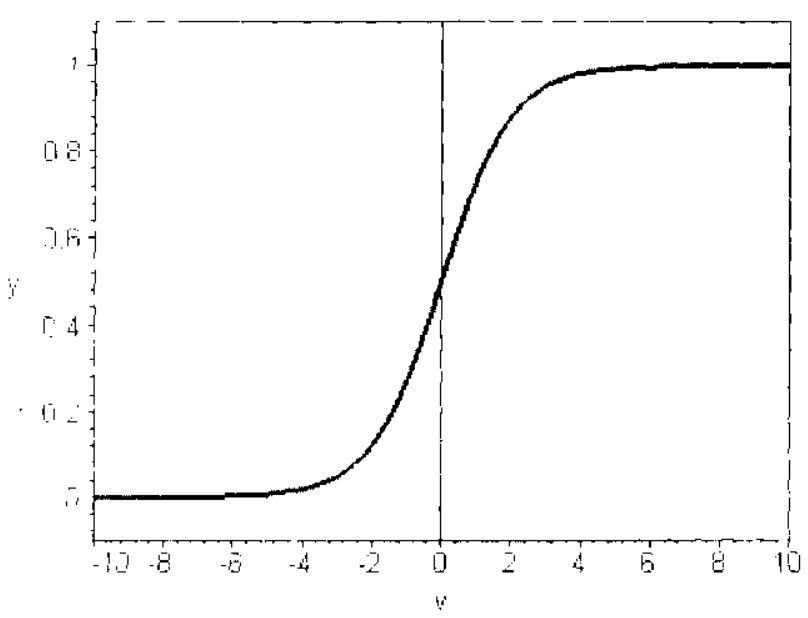

Figna 3.s: Funcion signóide logistica

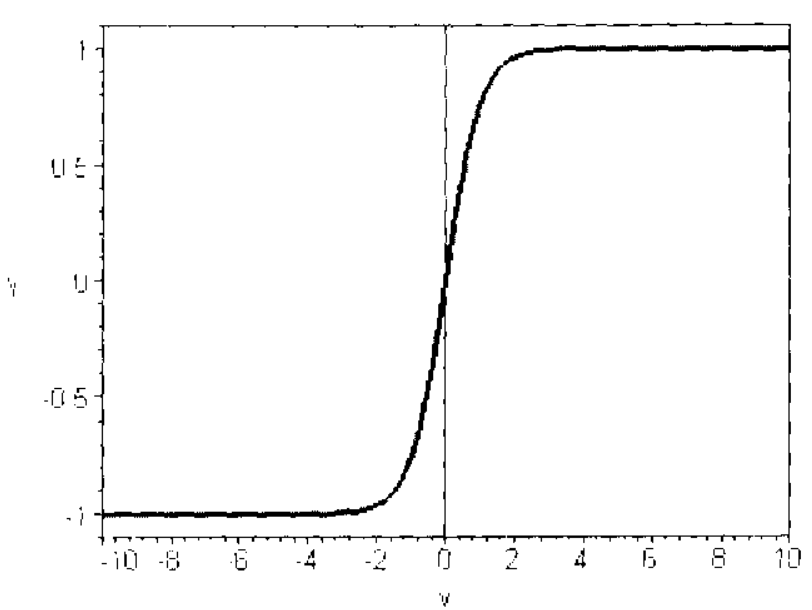

Fignura 3.9: Função tangente hiperbólica 


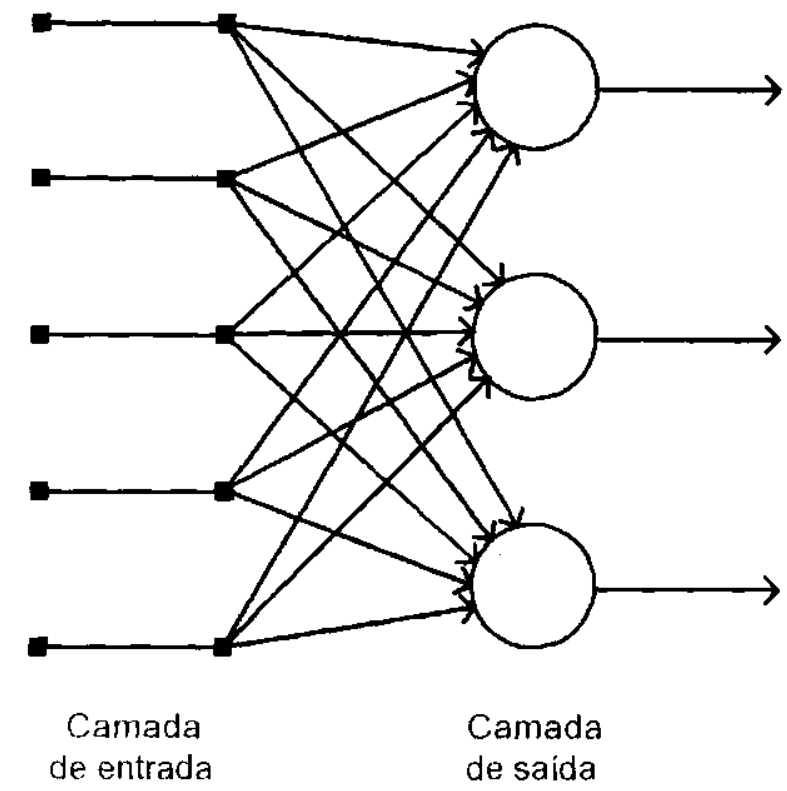

Fïnura 3.10: Rorde nerubal eom una única camada alinentada acliante

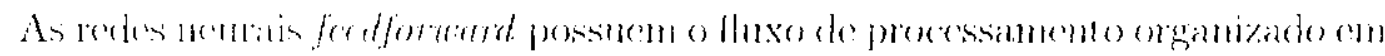

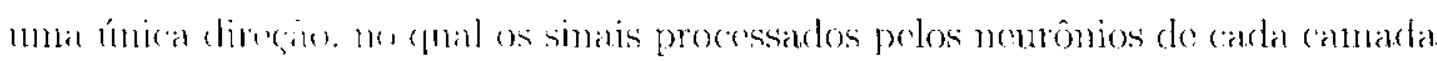

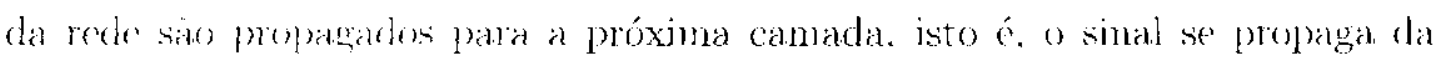

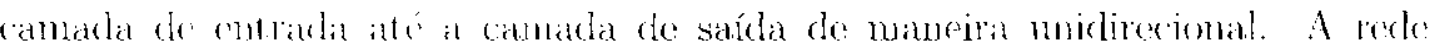

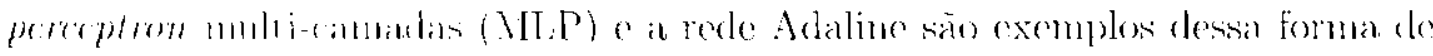
arcuntertin:m.

As roder nemais recorrentes possuem laços de realimentaça responsáveis por

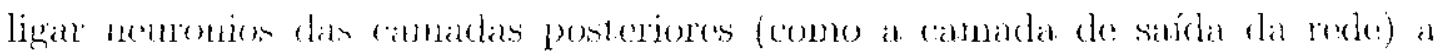

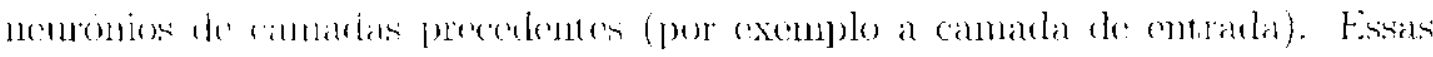

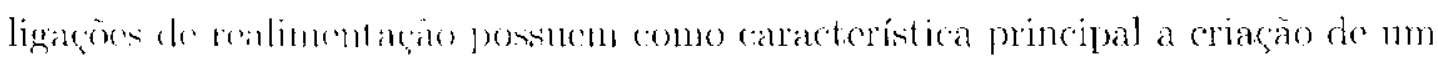

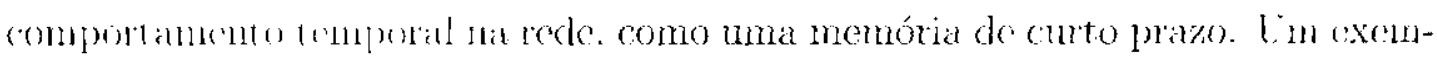

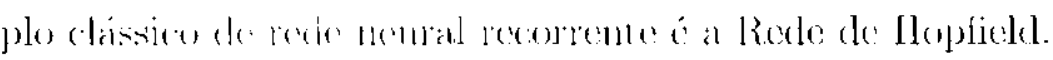

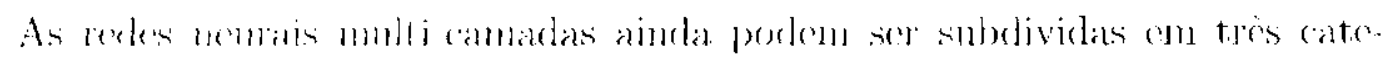

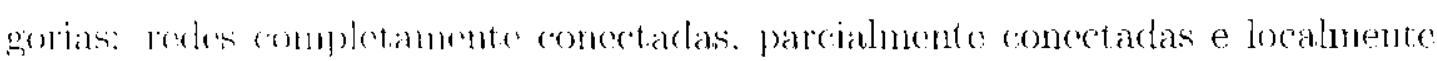
ronererialias.

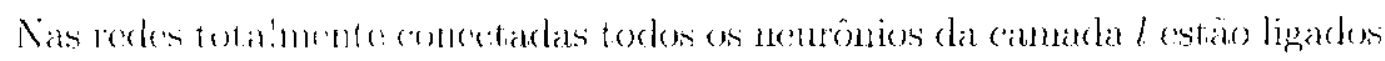

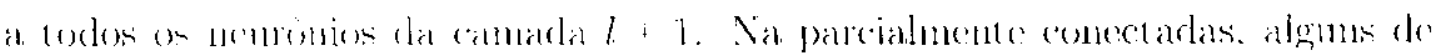

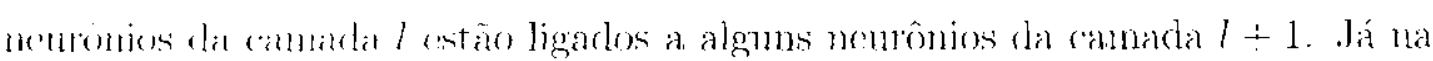

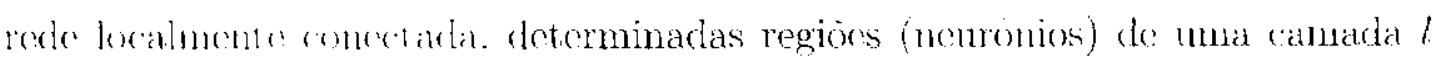

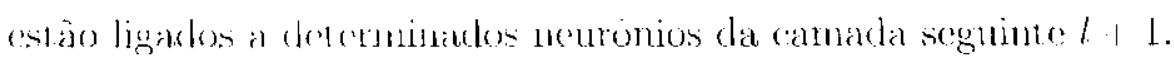




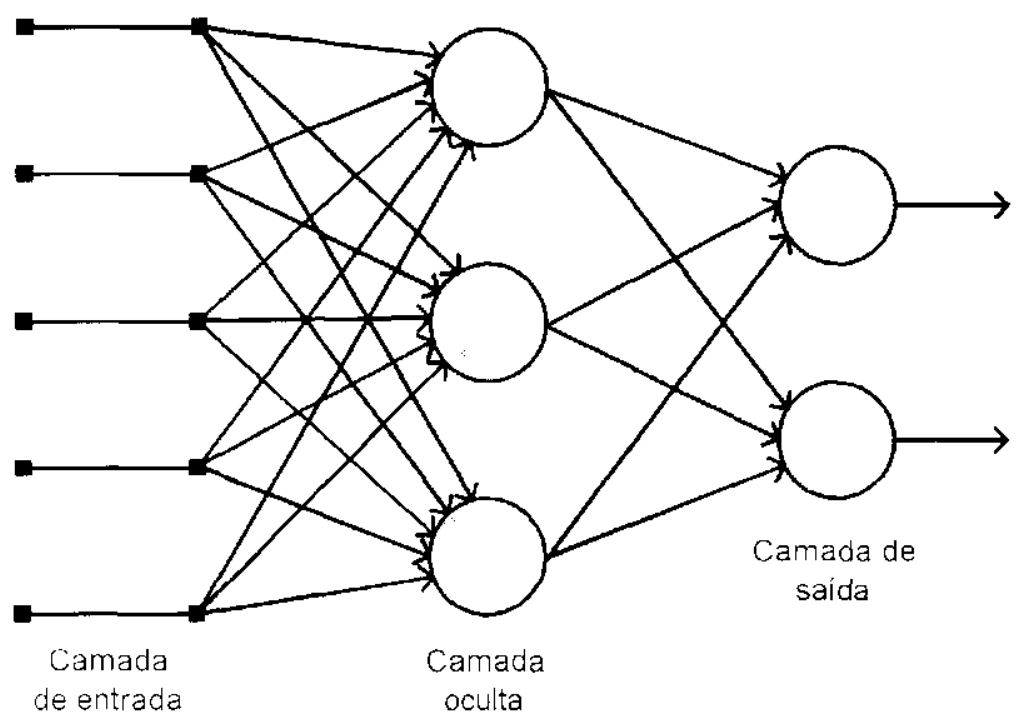

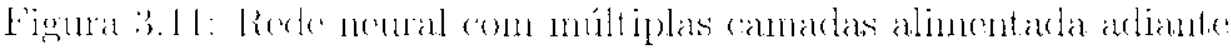

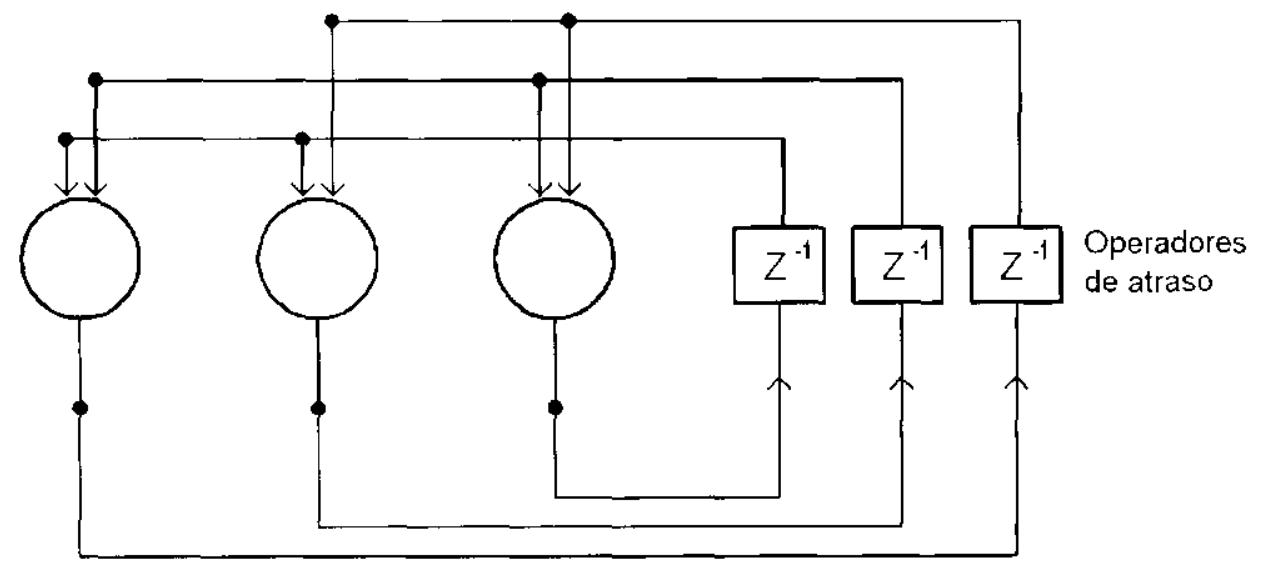

Figna 3.12: Rede neural recorrente 


\section{Tipos de Aprendizagem}

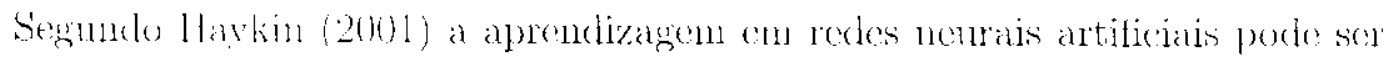
definictal comb:

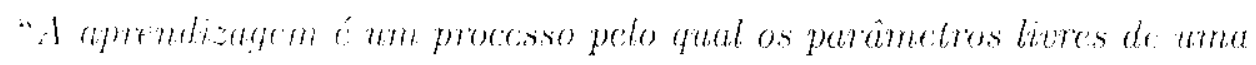

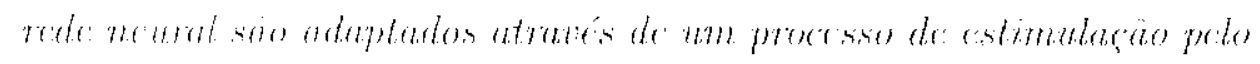

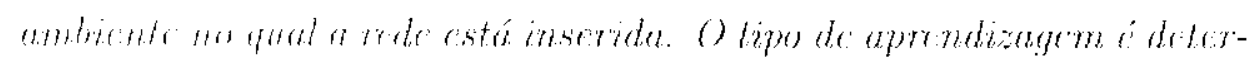

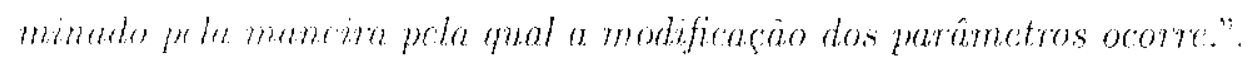

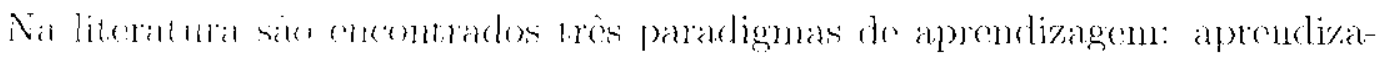
grm supervisionarta. anmondizagem näo-supervisionada e aprendizagem por reforco. Vale ressaliar fure alguns autores nà consideran a aprendizagem por

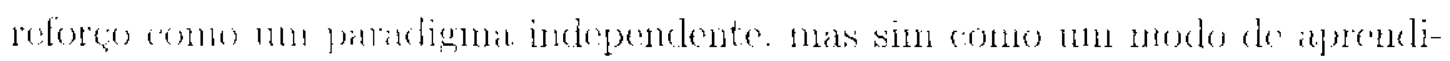

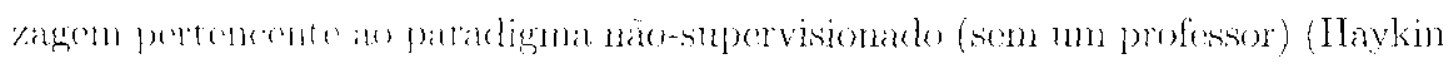

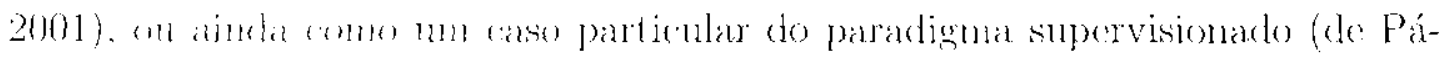

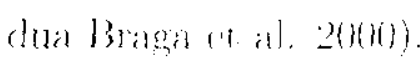

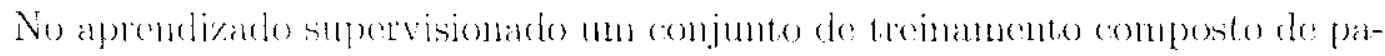

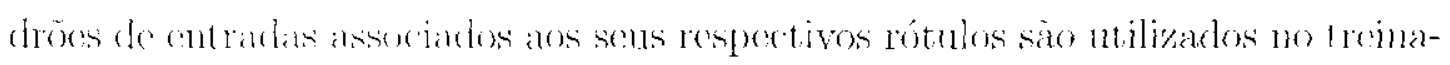

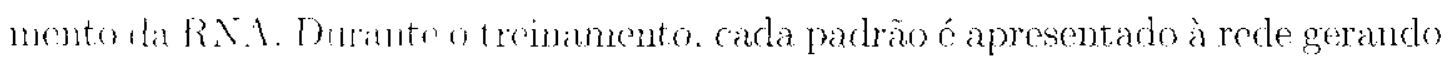
um sinal de satida. Lism sinal gerado é comparado ao valor correspondente an pa-

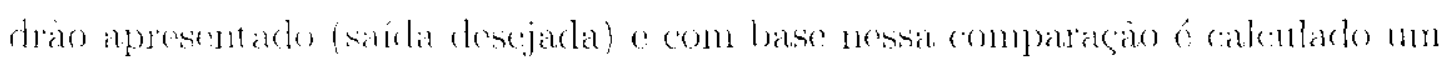

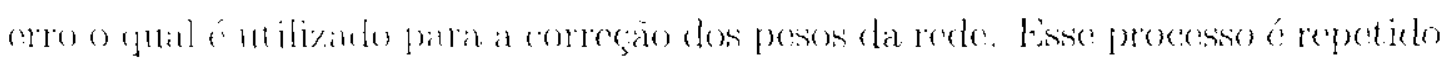

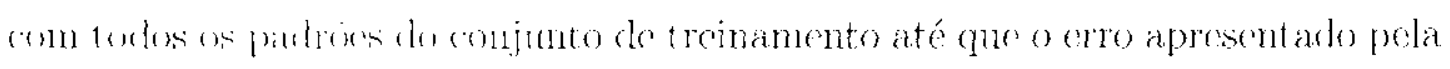

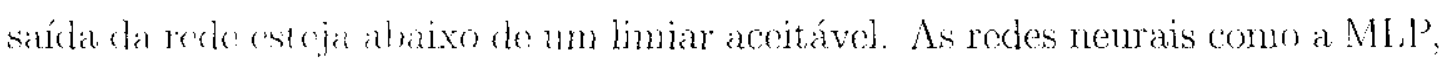

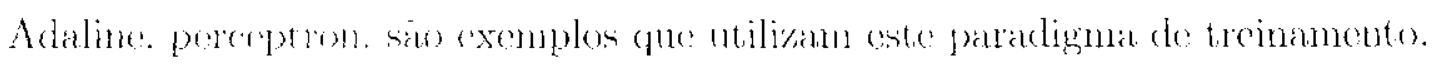

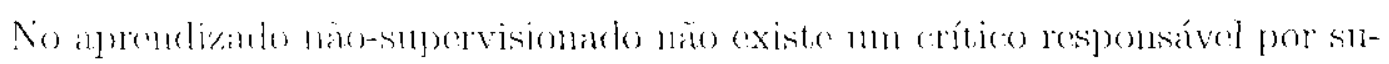

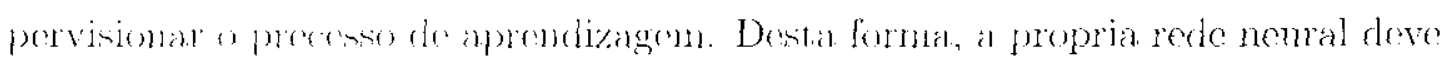

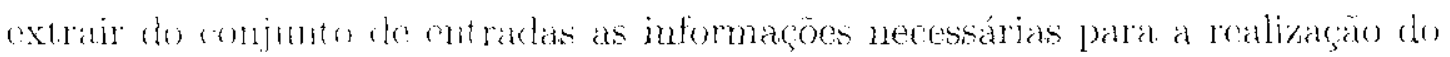

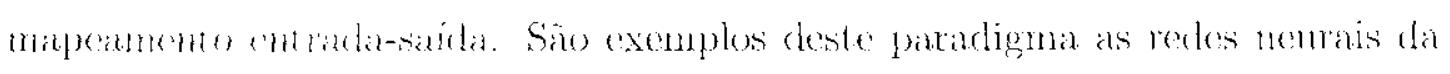

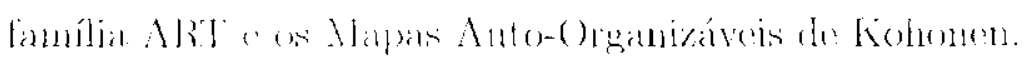

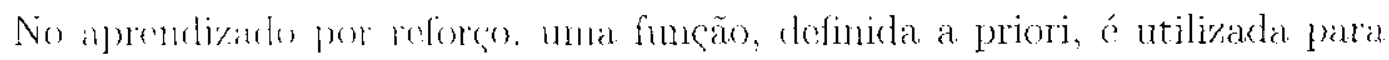
indicar so a salda gerarla pela rede é boa ou ruinn. getrando assim un processo

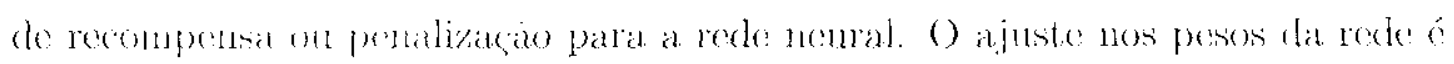

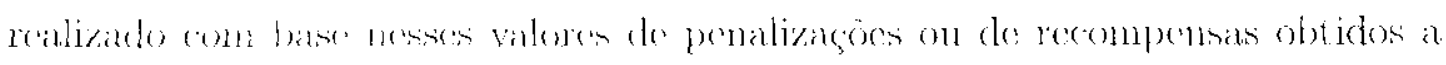

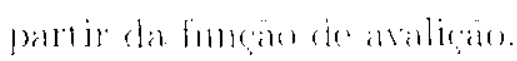




\subsubsection{Perceptron Multi-camadas}

\section{Considerações Iniciais}

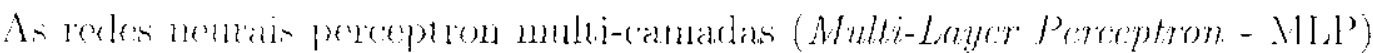

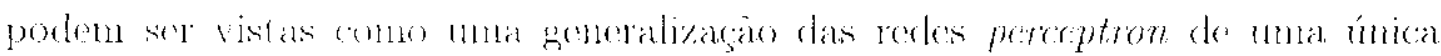

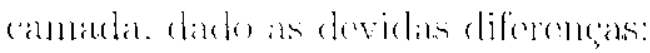

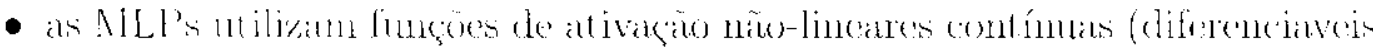

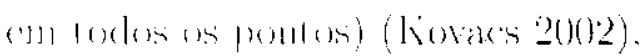

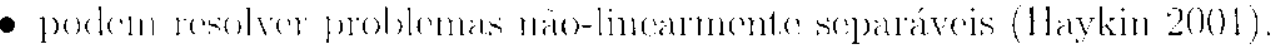

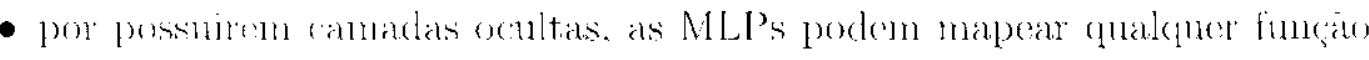
matemátina (cy)enko 1988: (ybonko 1989).

- dentire ontrias.

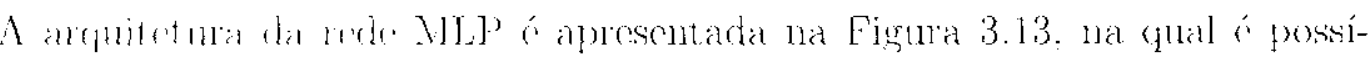

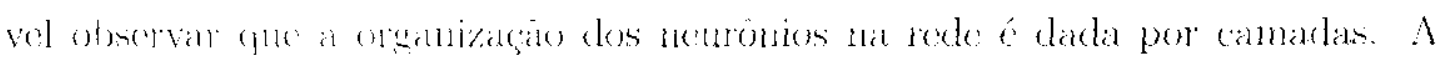

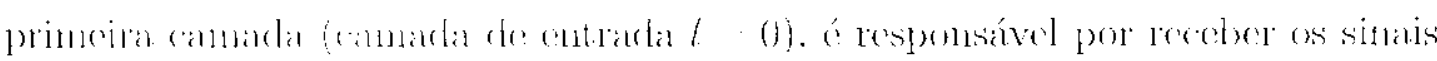

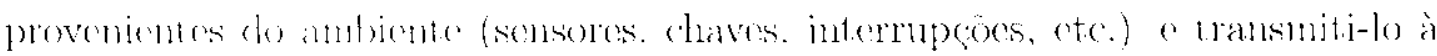
próxima cantada (t - - 1). Aquela näo é propriamente uma camada da RNA, jois.

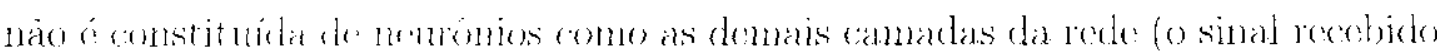

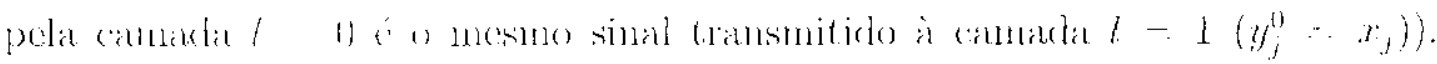

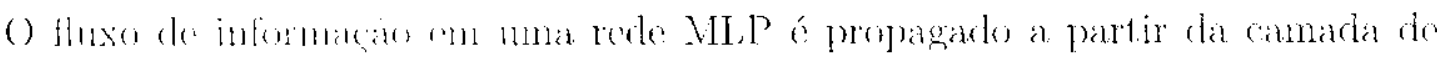

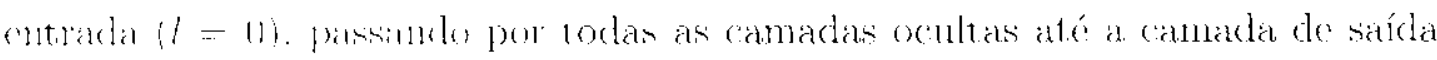

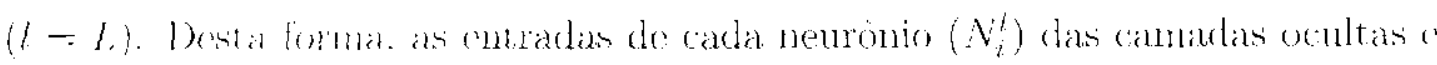

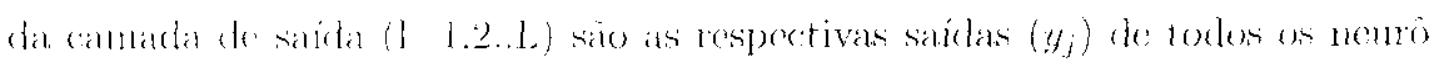

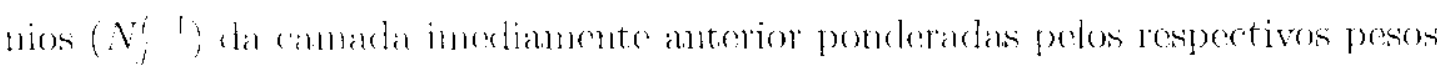
sináptios $\left(w_{j, j}\right)$. A sombin de todas as entradas $\left(y_{j}\right)$ ponderadas pelos peos $\left(w_{i j}\right)$ 6 chamada de rampo local induzido (e). representado pela cquacio 3.8.

$$
r_{i}^{l}-\left(\sum_{i=1}^{m} u_{i}^{\prime} y_{i}^{l}\right)+\operatorname{bichs}_{j}^{\prime}
$$

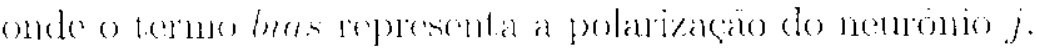

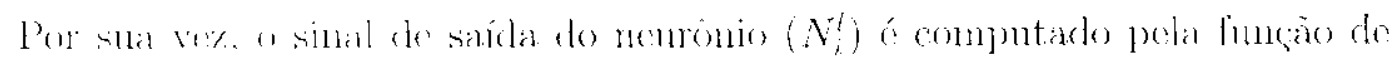

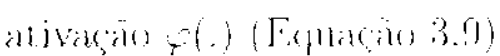

$$
y_{j}^{l}-p\left(y_{j}^{l}\right)
$$




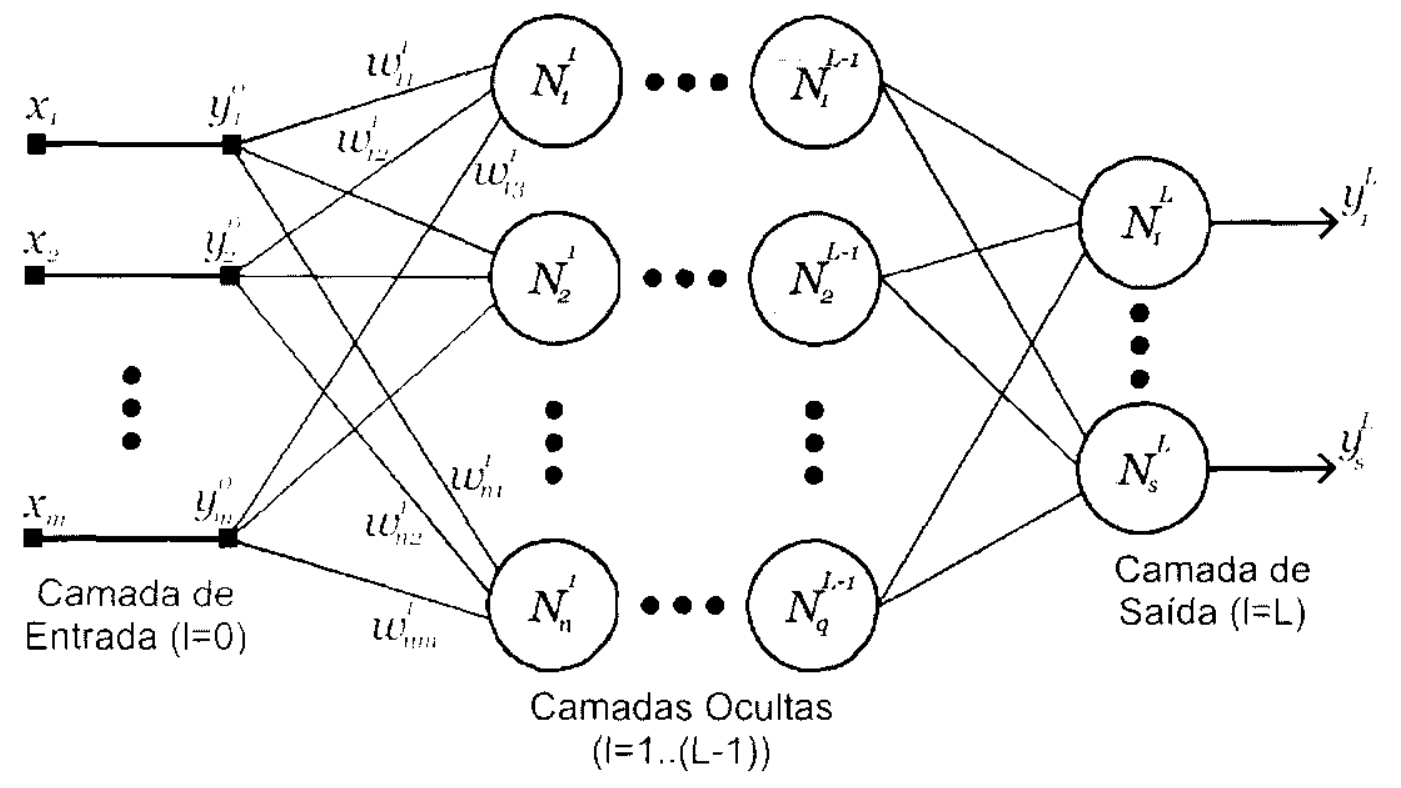

Fignaria 3.13: Arepuitetura da rede neural MLe

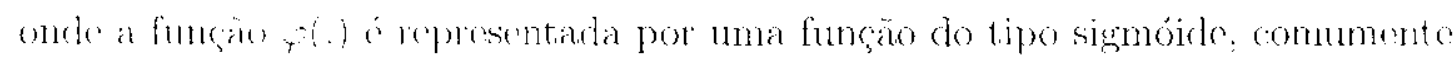
a funcino logínt icar on a funçân tangente hiperbólica ó utilizada (Tabela 3.1).

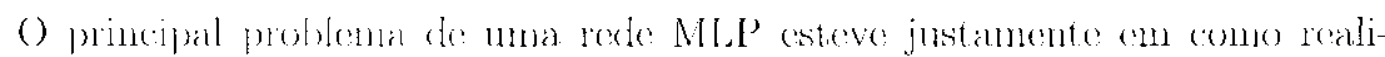

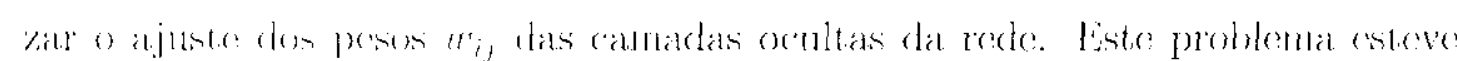

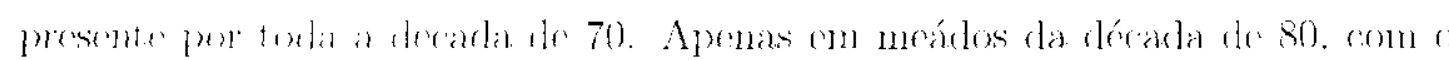
drsemvolvinoute du alyoritmo de retropropagação do erro (backpropagation) pe-

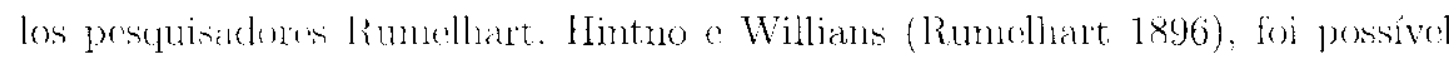

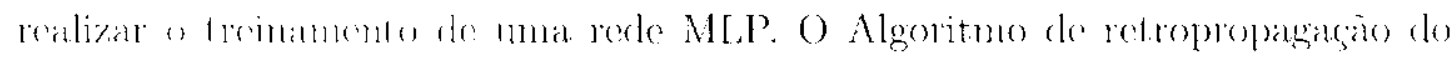

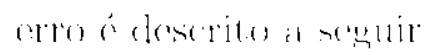

\section{O Algoritmo de Retropropagação do Erro}

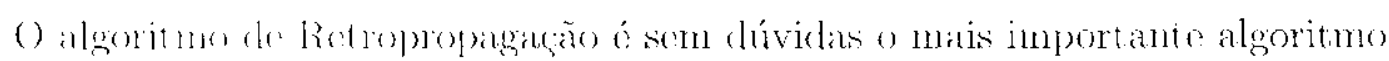
desemvolvide atr hoje para o treinanento de redes neurais, tanto por fatores

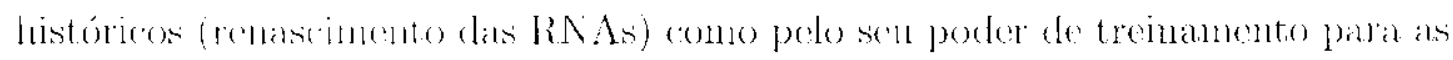
redes . Mllis

Tamben conberato amo regra delta generalizada, o algoritmo de retropropa-

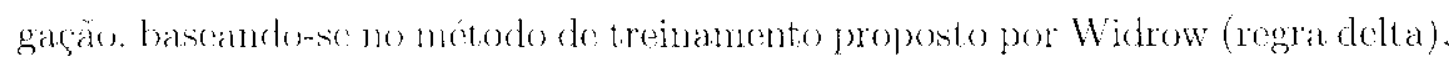

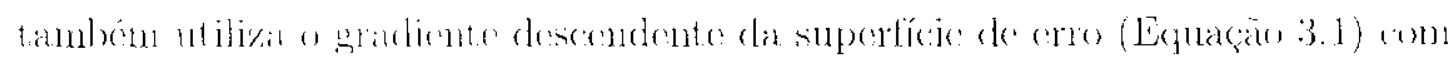

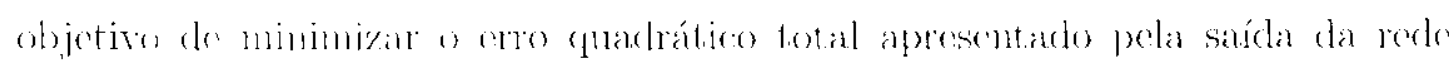
(Equarano 3.2). Complomontando a regra delta, por isso denominado regra delta genetalizada. Rummelhatt "sta equipe desenvolveran una forma de caleular o

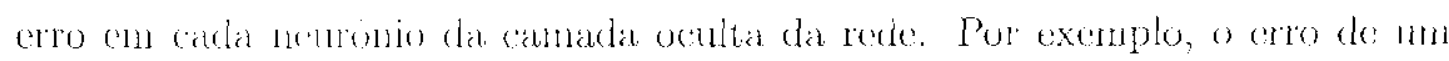




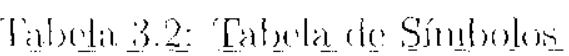

\begin{tabular}{|c|c|c|}
\hline & Inulice. & Descrisanto \\
\hline & $111.11 .1 \% \cdot$ & 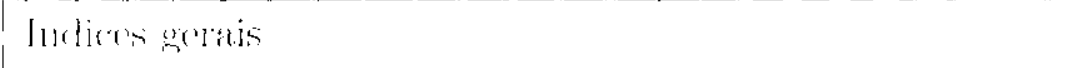 \\
\hline & 1 & Indien dias camadas da rede: \\
\hline & $L$ & I Intien la cambada de saíla da rede \\
\hline & 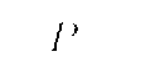 & 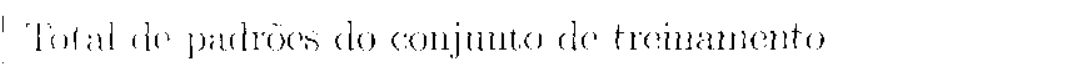 \\
\hline & !r & Iuclien do un padrão de entrada $X(p)$ \\
\hline & 1 & Indiere de itcração \\
\hline & $\mathrm{N}_{j}$ & Nemrinio da rede \\
\hline & $x(p)$ & l'andras (velor) de contada \\
\hline & $i_{i}$ & 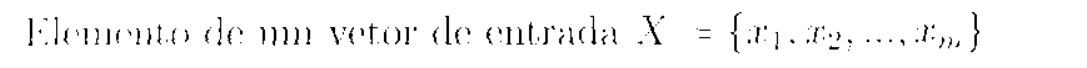 \\
\hline & $\gamma^{\prime}(b)$ & Sinal (votor) rle sáda da camada / da redo para o padrão " \\
\hline & $y_{i}$ & i-rime elemento do vetor $Y=\left\{y_{1}, y_{2}, \ldots, y_{n}\right\}$ \\
\hline & D)(p) & Sarikla descjada para o padrãon \\
\hline & $d$ & 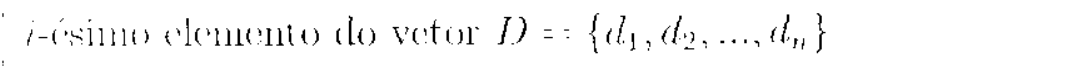 \\
\hline & $m !$ & Peso da j-́mina cutrada do neuronio $i$ da camadal \\
\hline & $\because$ & Campo lowal incluzido do nemonio i da canadal $(\mathrm{Eq}, 3.8)$ \\
\hline & $r(0)$ & Finçario de ativação do neuronio (Täbela 3.1) \\
\hline & 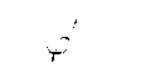 & Derivala da função de ativagào \\
\hline
\end{tabular}




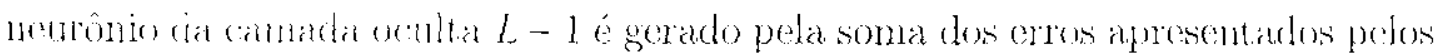

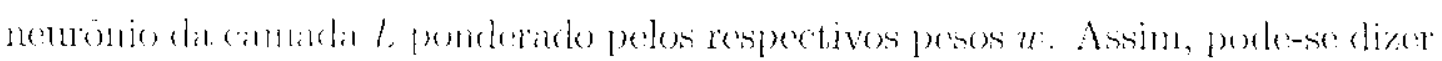

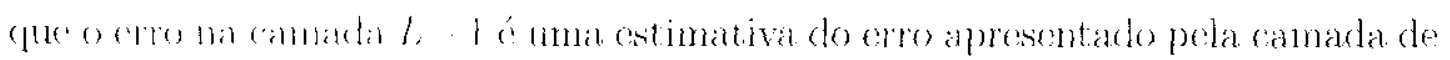

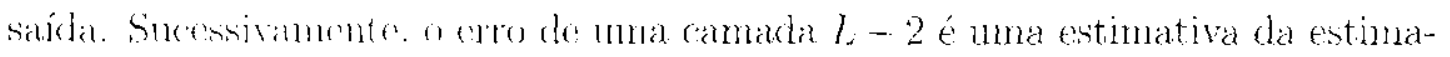

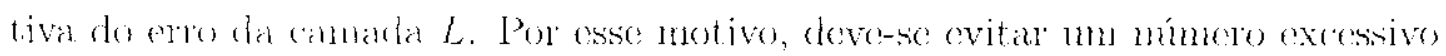

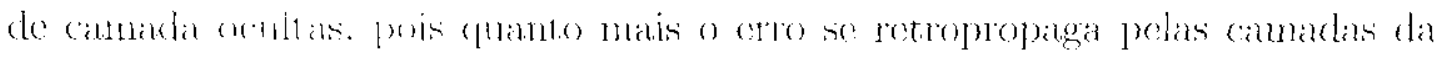

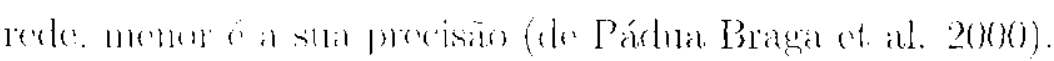

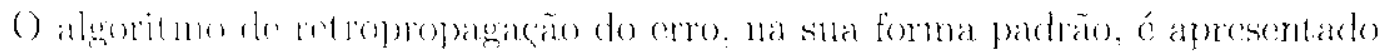

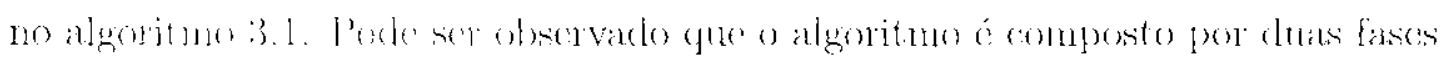

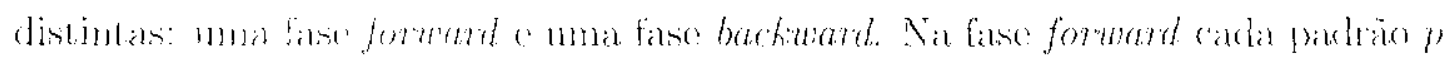

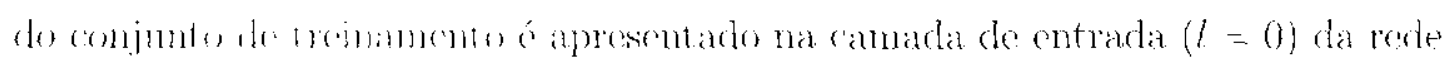

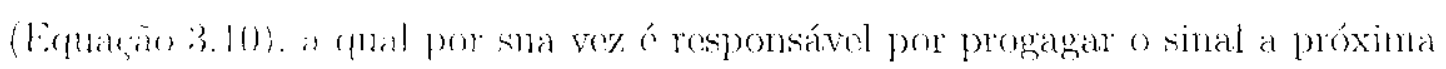

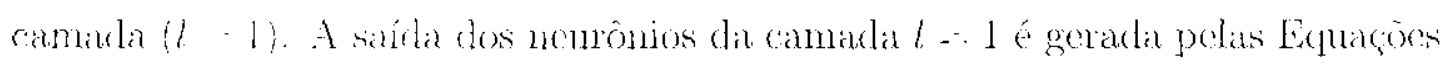

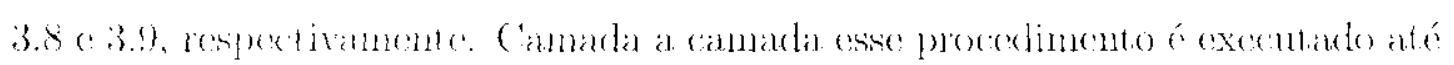

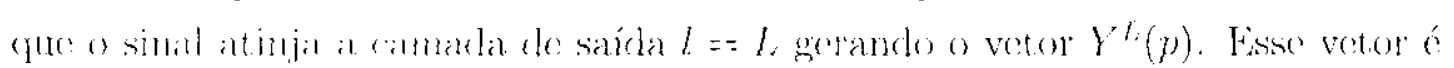

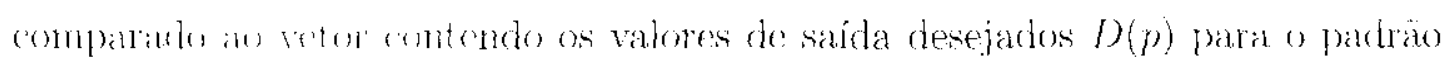

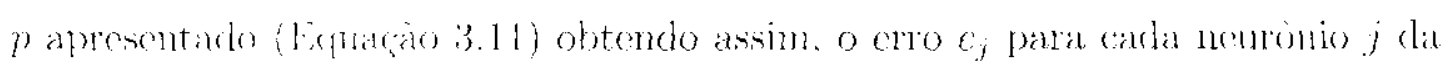

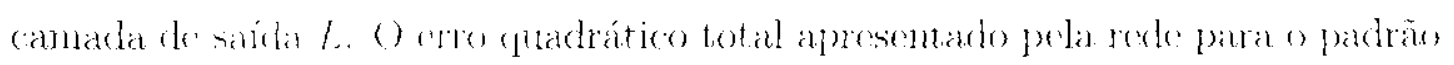

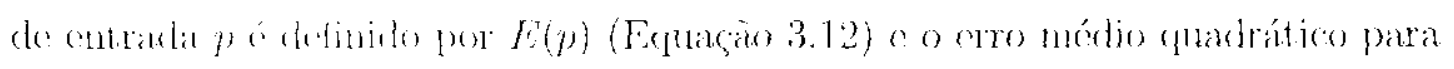

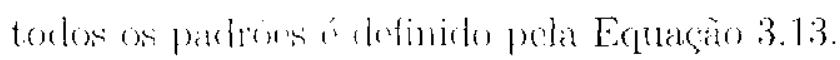

$$
\begin{aligned}
& y_{j}^{0}=-x_{j} \\
& r_{j}(p)-d_{j}(p)-y_{j}(p) \\
& l(z)=\frac{1}{2} \sum_{j \in i} r_{j}^{2}(p) \\
& E_{\text {tuct }}=\frac{1}{I^{\prime}} \sum_{p^{\prime}=1}^{l} E(p)
\end{aligned}
$$

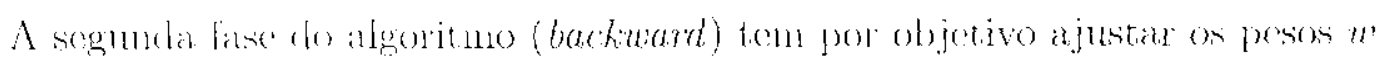

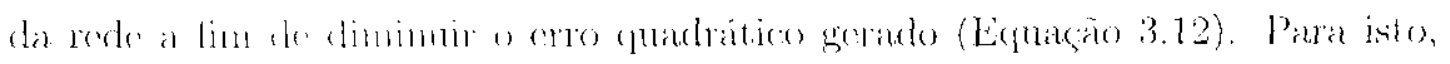

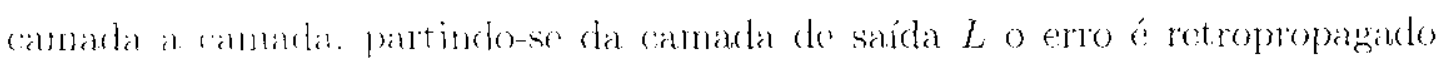

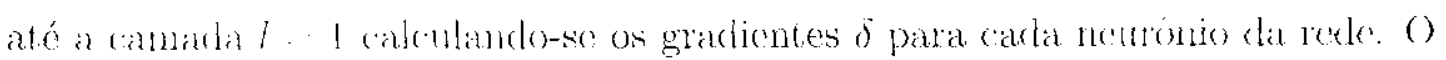

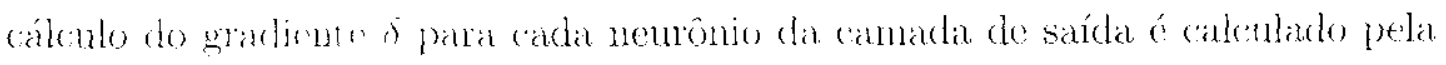
Equacios:311: 


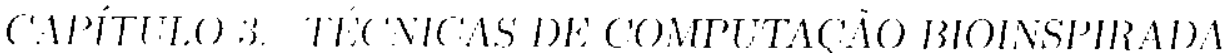

$$
\delta_{j}^{l}-c_{j}^{l}\left(r_{j}^{l}\right)
$$

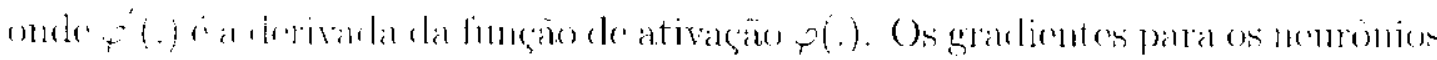

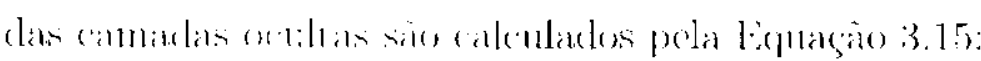

$$
d_{j}^{\prime}-\varphi_{j}^{\prime}\left(u_{j}^{\prime}\right) \sum_{k} d_{k}^{l-1} u_{k j}^{l \cdot 1}
$$

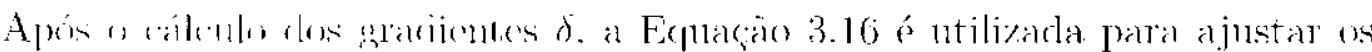
pesos dia recke.

$$
u_{i i}^{l}(l+1)-w_{j i}^{l}(l)+w_{j}^{l} y_{i}^{l-1}
$$

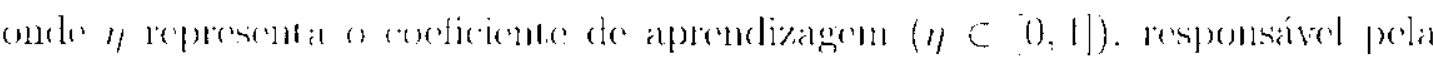

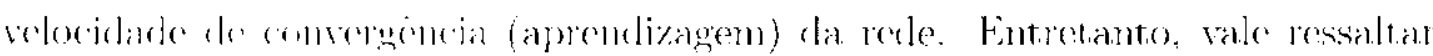

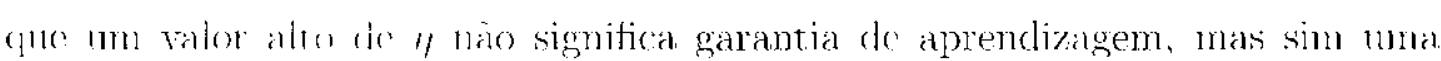

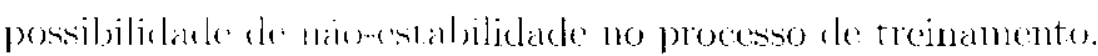

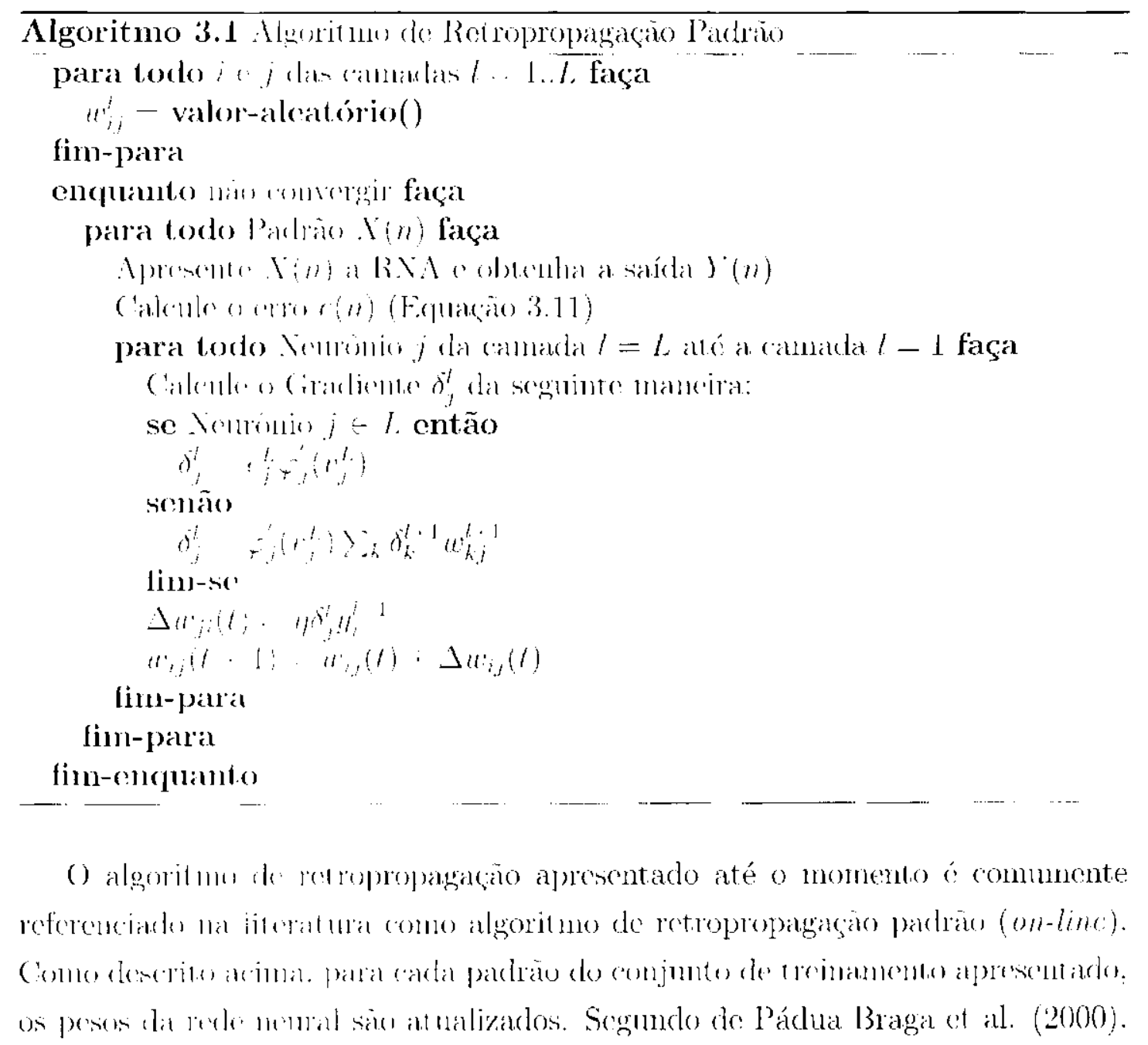




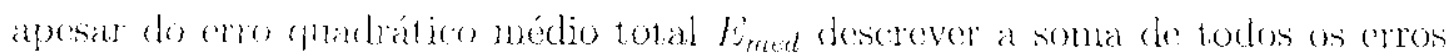

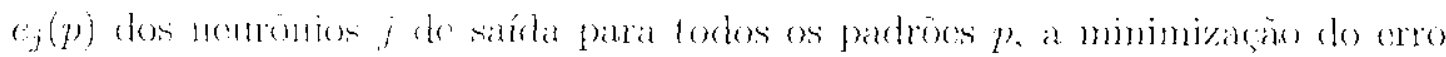

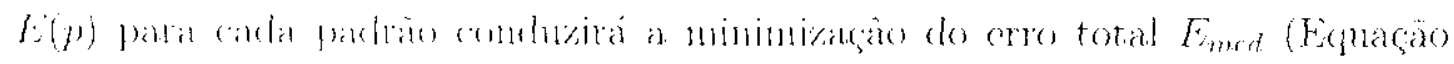
$3.13)$

\section{O Algoritmo de Retropropagação em Lote}

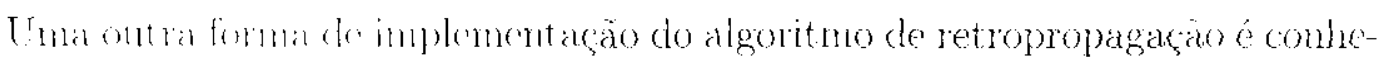

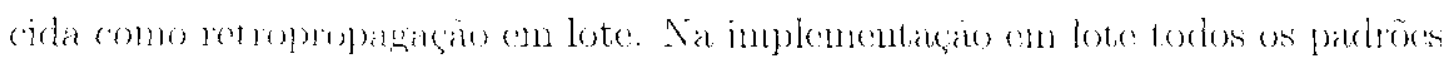

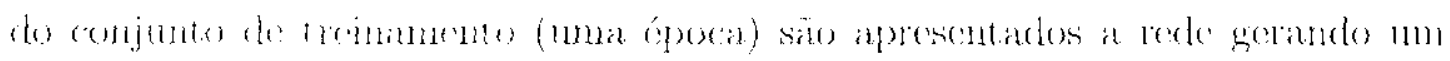

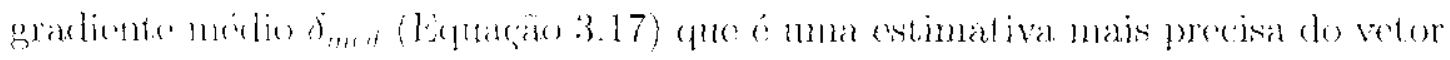

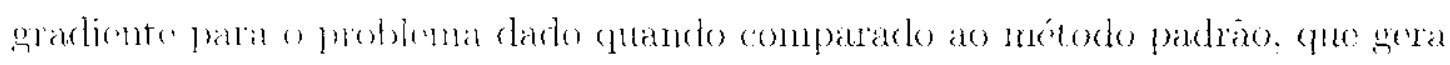

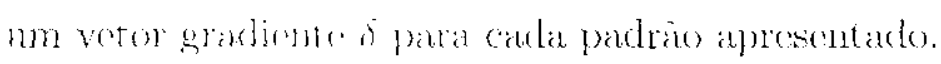

$$
\delta_{i m+d, j}=\frac{1}{P} \sum_{p=1}^{P} \delta_{j}(p)
$$

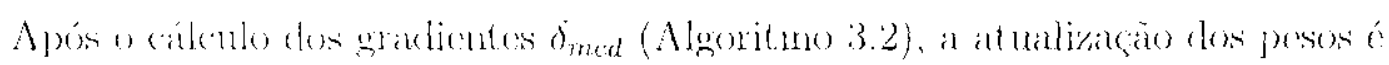

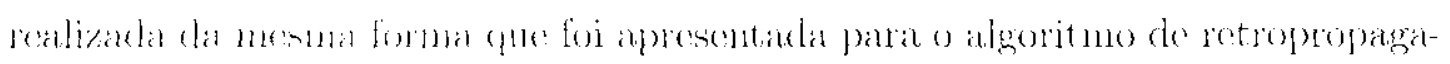

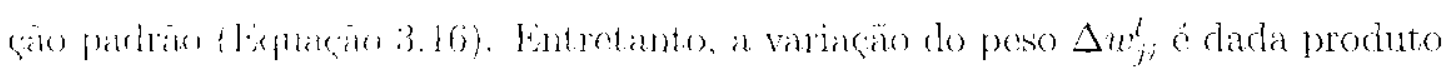

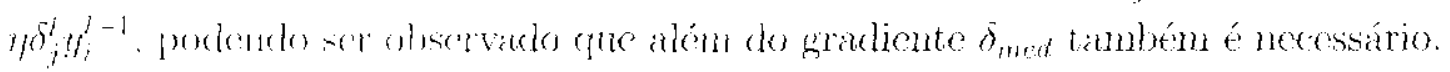

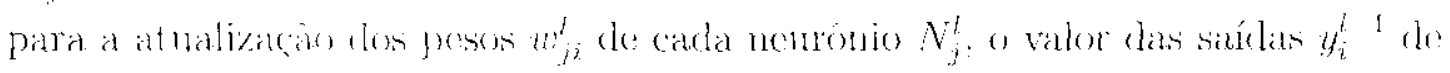

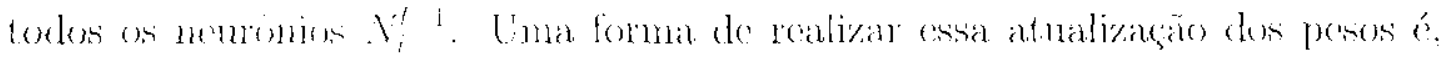

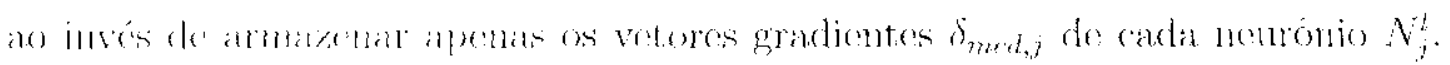

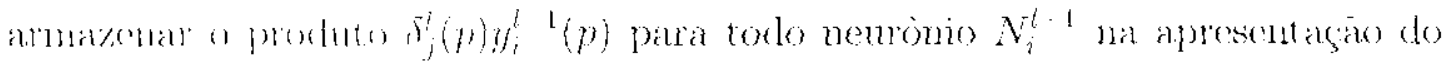

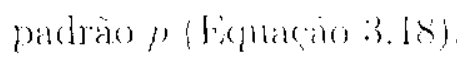

$$
f_{j i}^{l}:=\sum_{p \in l^{\prime}} \delta_{j}^{l}(p) y_{i}^{l} \quad l(p)
$$

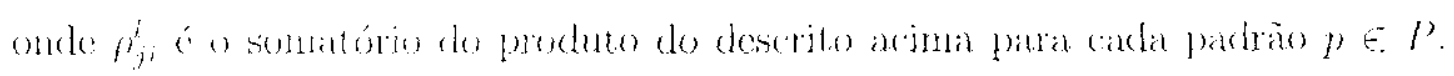

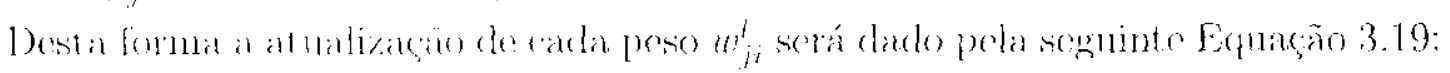

$$
w_{j i}^{l}(t+1)=w_{j i}^{l}(t)+\eta \rho_{j i}^{l}
$$

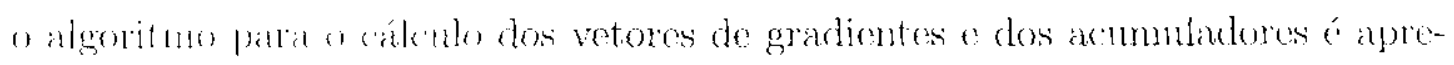

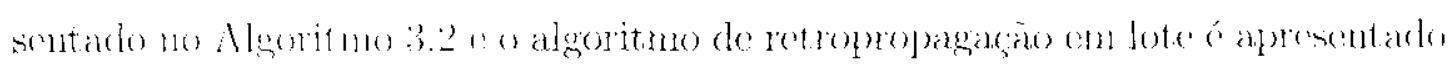
(10) Algoritinu, :3:?.

\section{Adição do Termo Momentum}

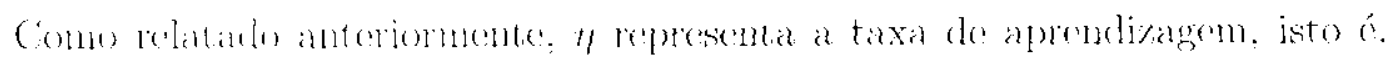

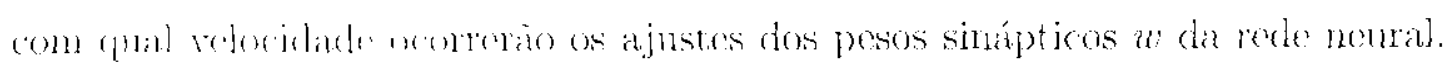



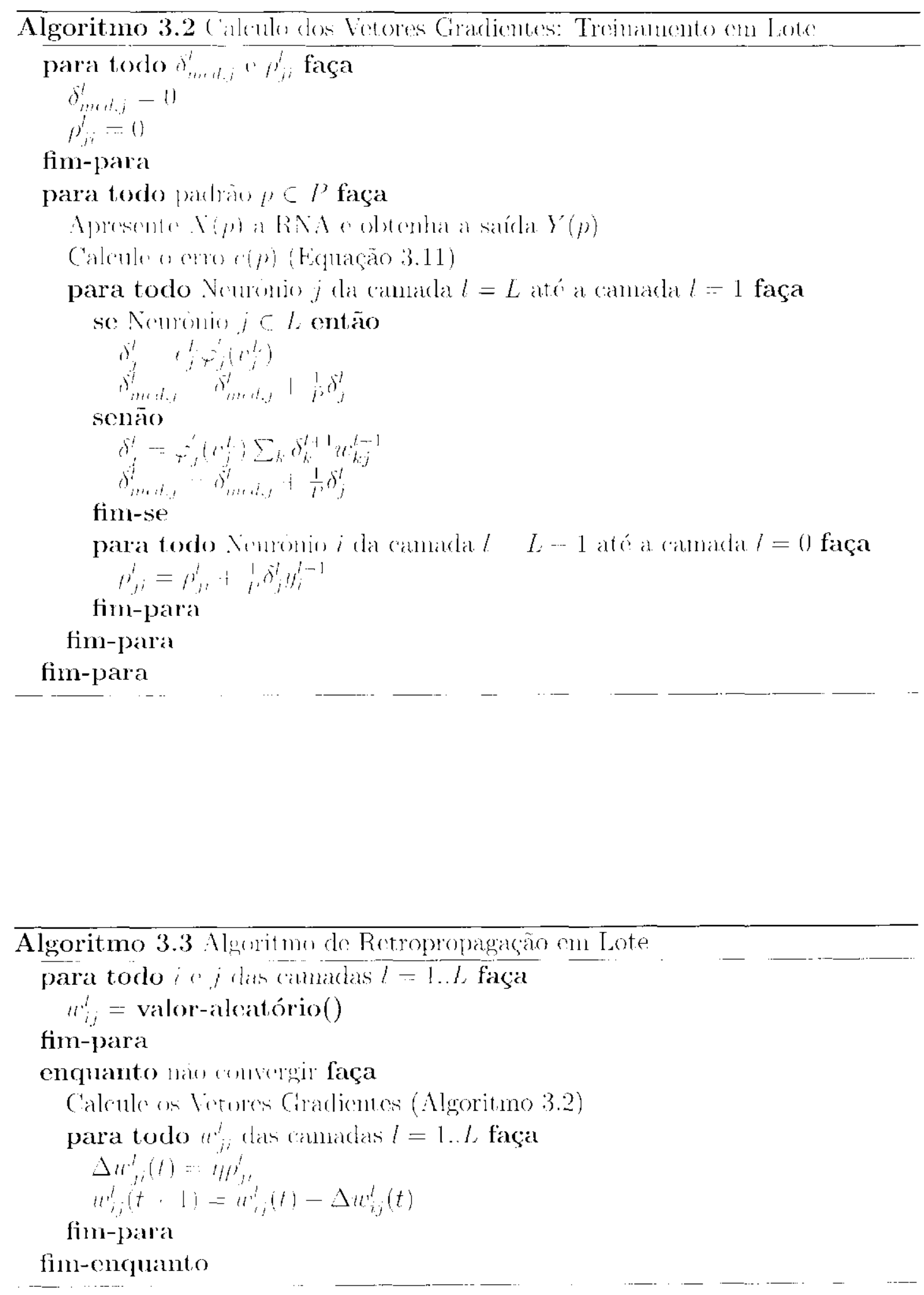


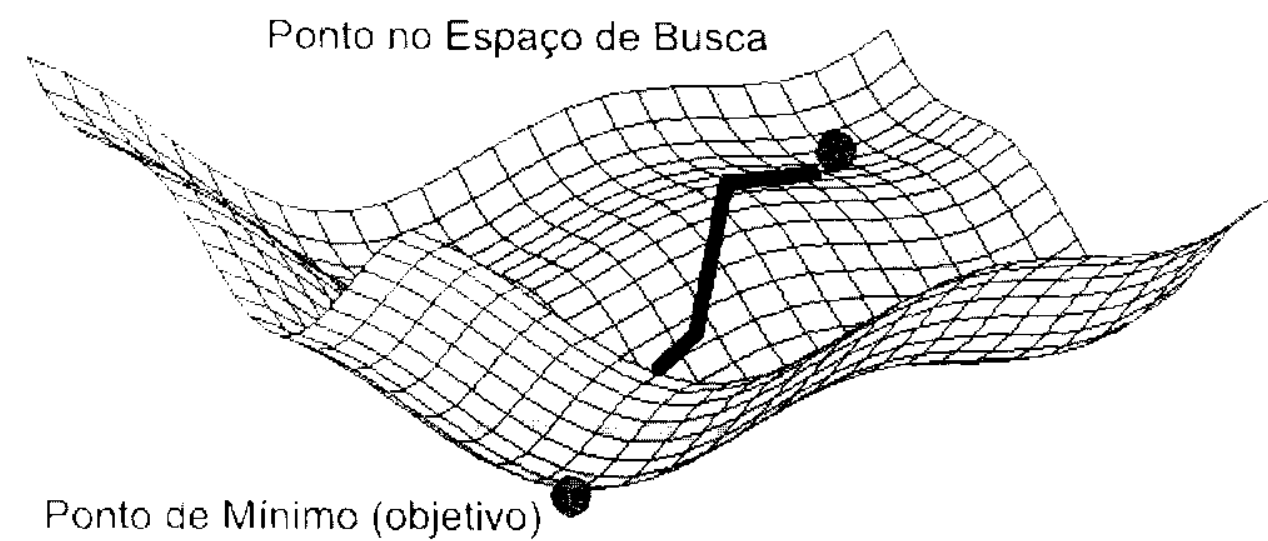

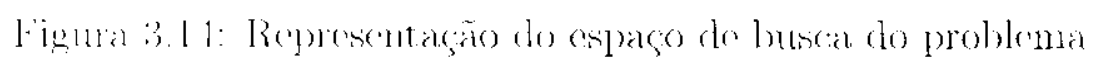

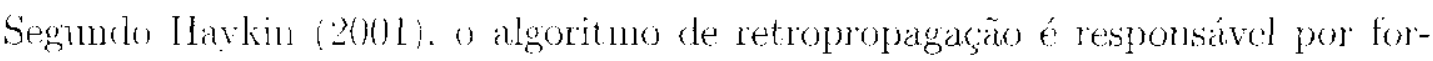

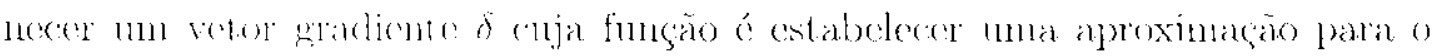

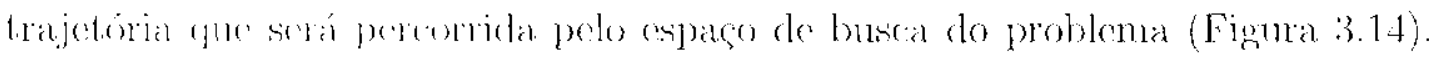

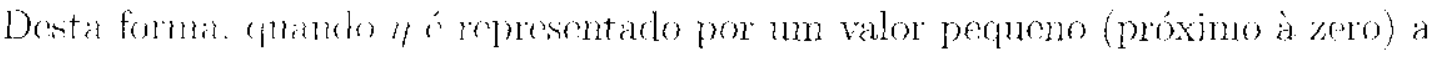

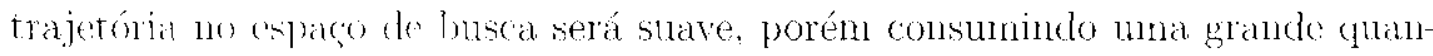

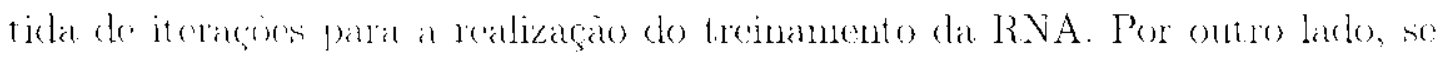

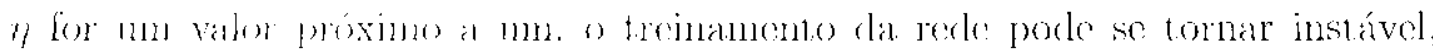

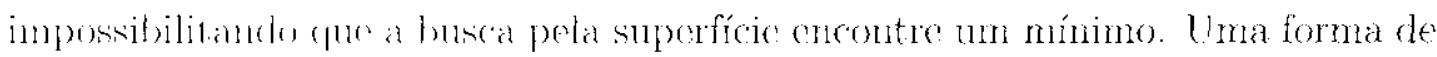
aceleme o proceno de treinamento de mula MLP reduzindo o perigo de instabi-

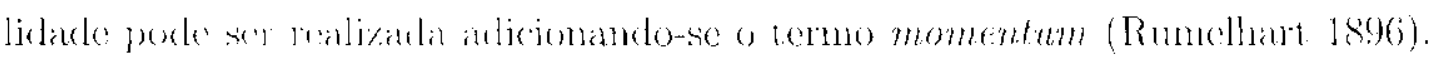

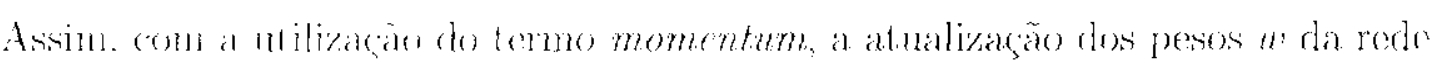
MLP í dislia por:

$$
u_{j}^{\prime}(t+1)-w_{j i}^{l}(l)+m b_{j}^{l} y_{i}^{l-1}+a \Delta u_{j i}^{l}(t-1)
$$

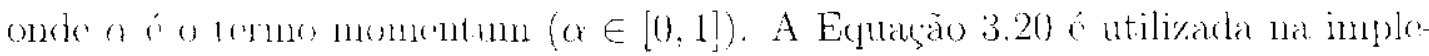

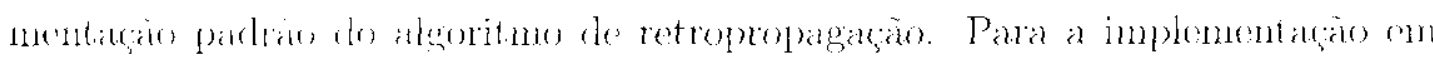

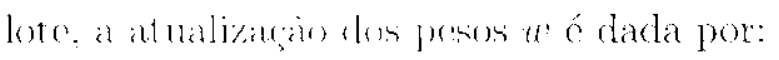

$$
w_{j i}^{l}(l+1)=w_{j i}^{l}(t)+m p_{j i}^{l}+\alpha \Delta w_{j k}^{l}(t-1)
$$

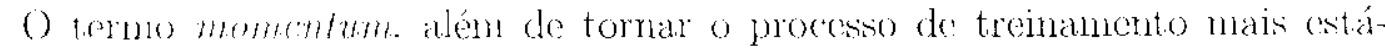

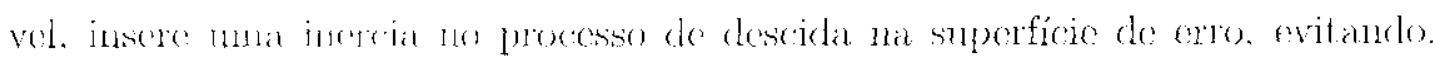

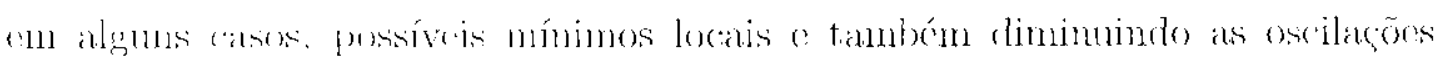
observalas quander a rede está em tomo de unn mínimo local. 


\subsubsection{Algoritmo Rprop}

Um grande moblema cneontrado no algoritmo de retropropagacano esta na

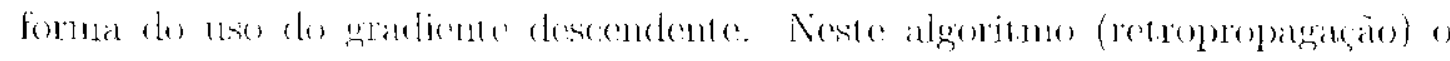

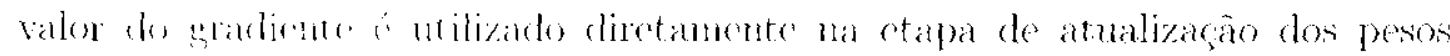

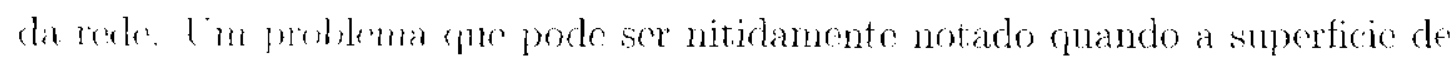

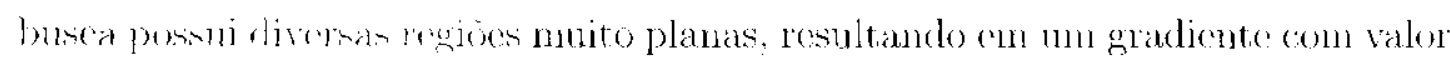
próximutat a $a(1)$

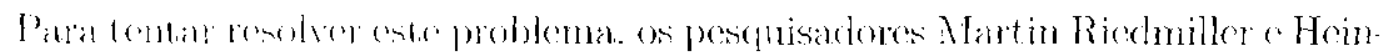

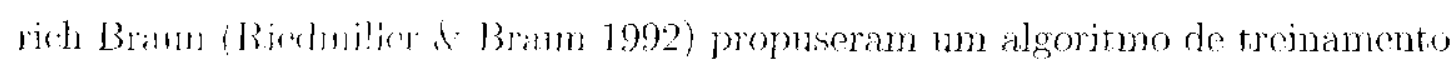
denominato Rarop (Resticnt backpropagation).

O aleritmo Rprop a rum algoritmo supervisionado de treinamento en lote e.

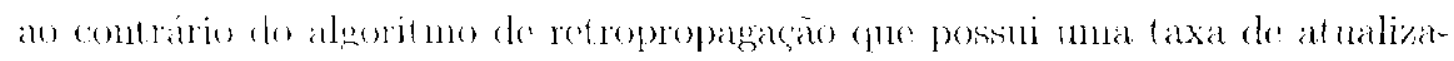

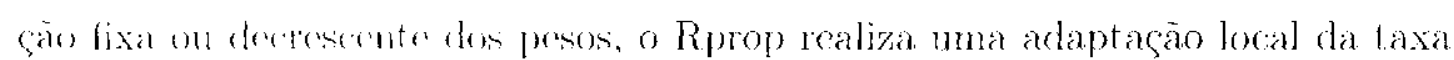

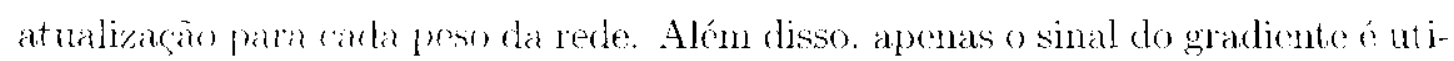

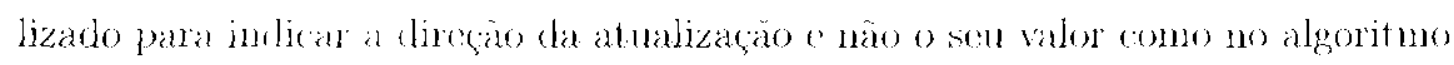

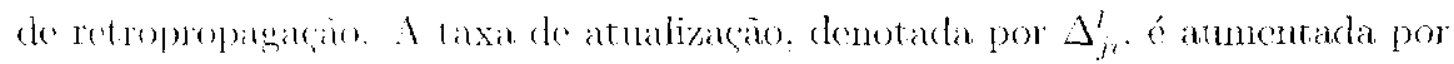

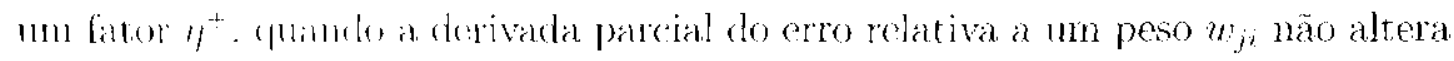

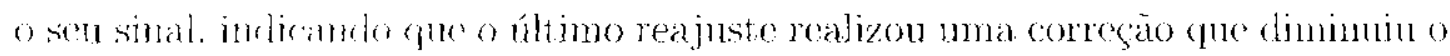

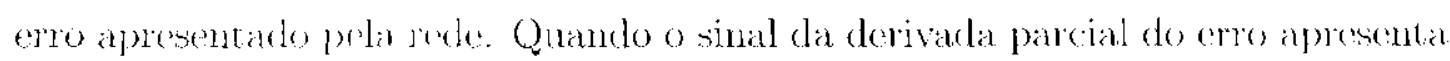

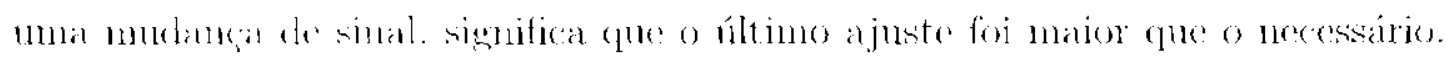

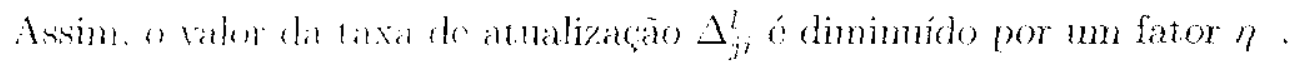

An taxals of " 17 wate dadas por:

$$
0<\eta_{-}<1<\eta_{+}
$$

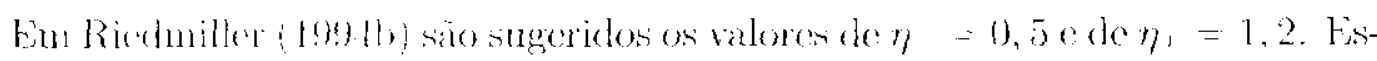

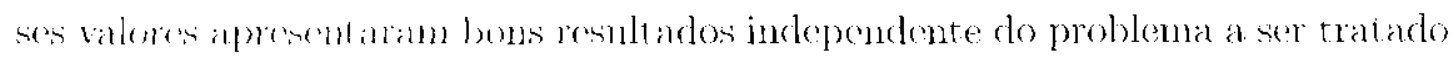
pela RXil.

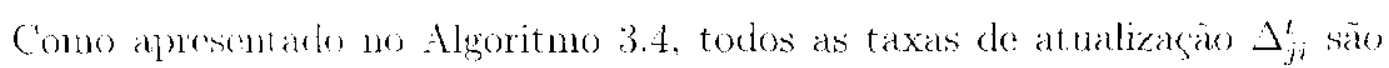

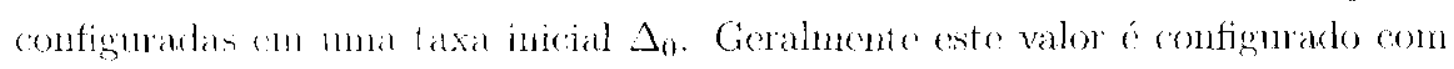

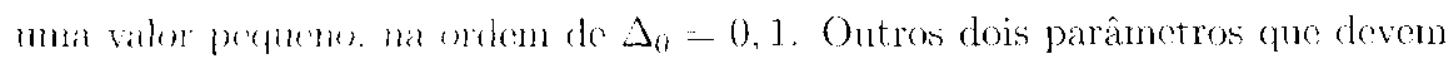

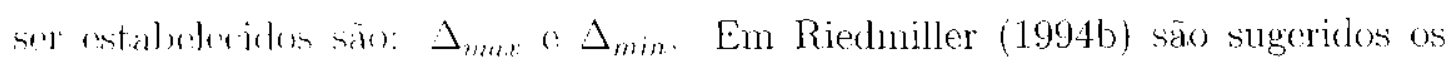

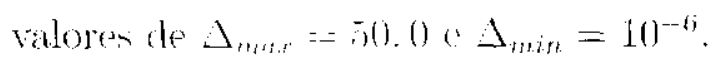

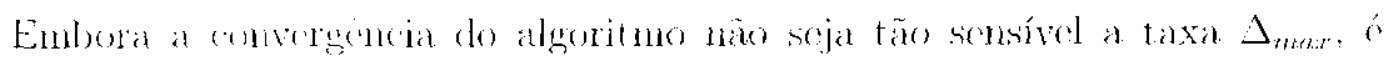

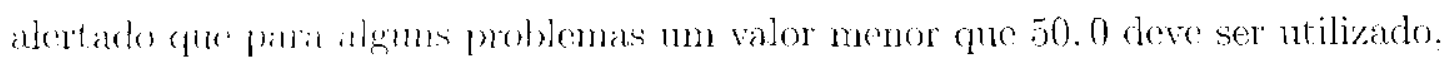
evitando asimn mona ronvergencia prematura para un mínimo local subótimo.

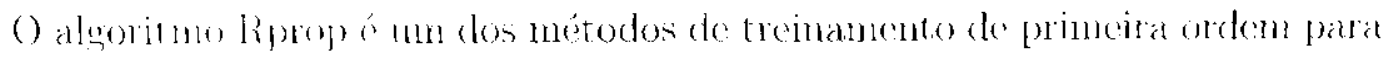




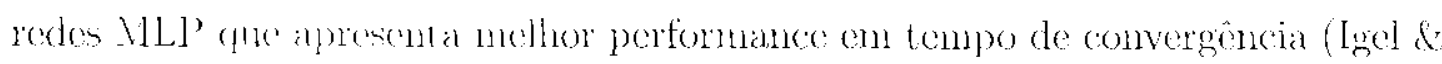

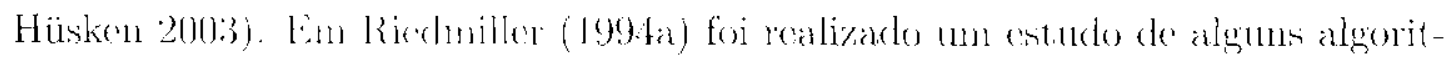

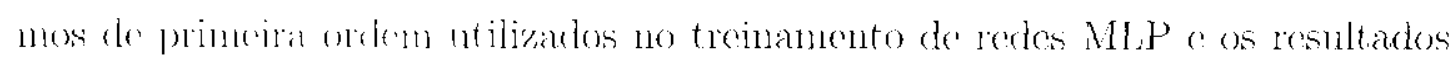

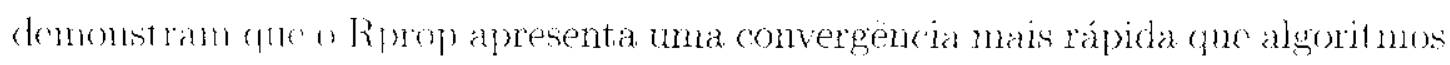

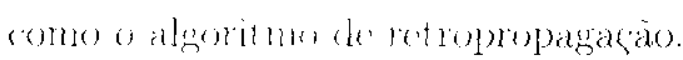

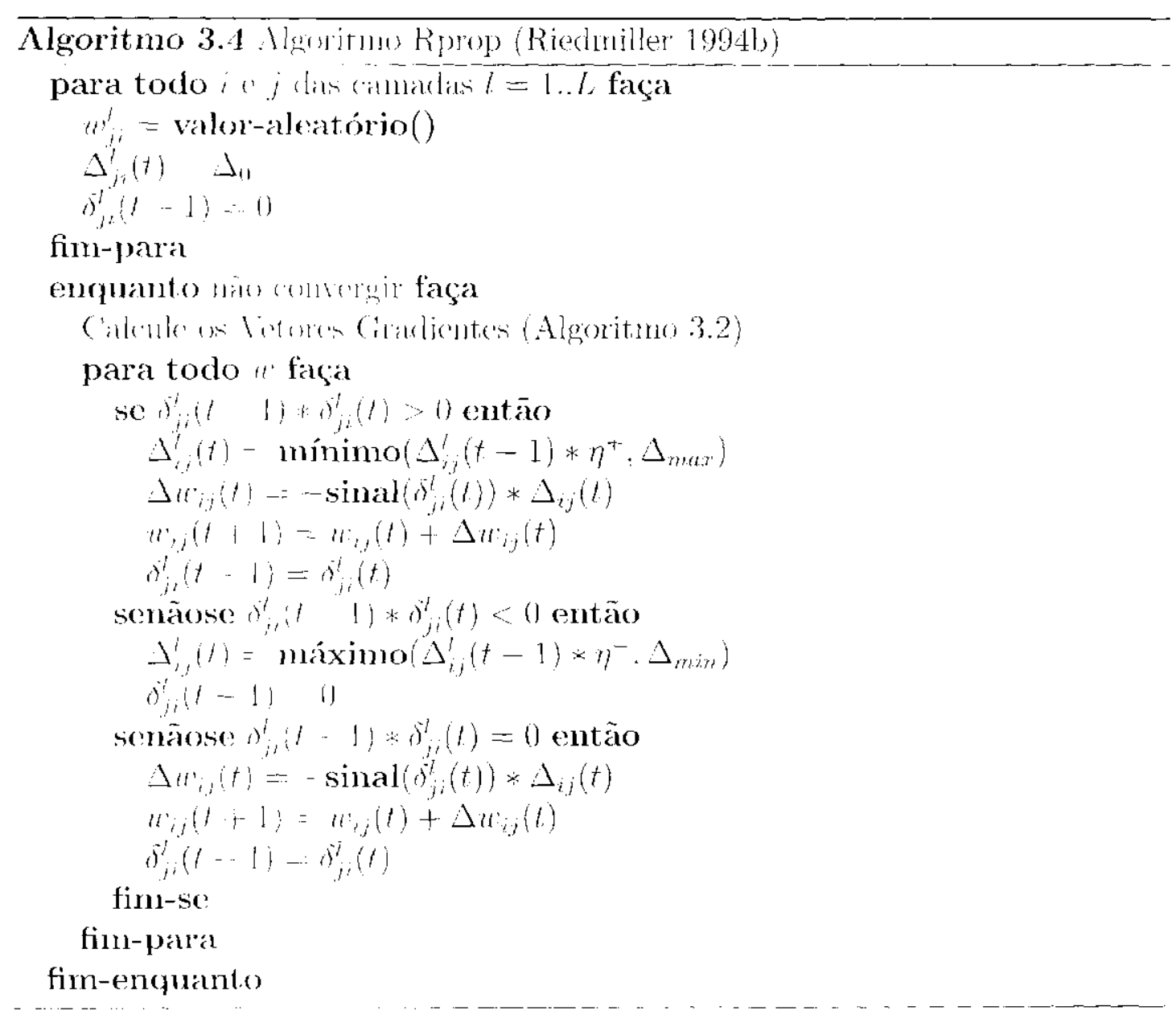

\subsubsection{Considerações Finais Sobre MLPS}

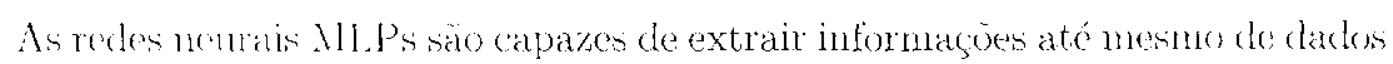

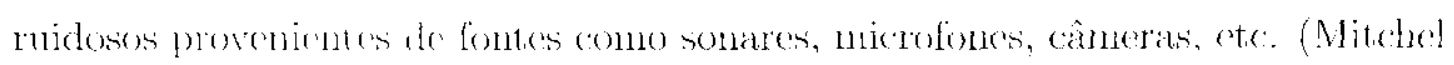
$1997)$.

Apesare do tompe de minamento de uma rede neural MLP ser relativamente

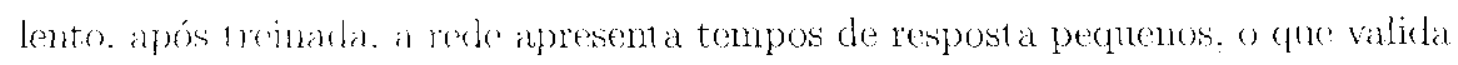

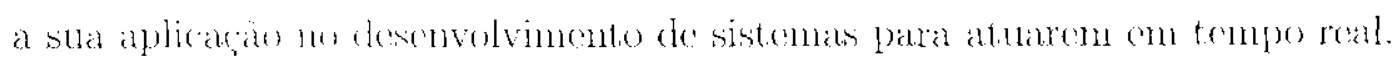

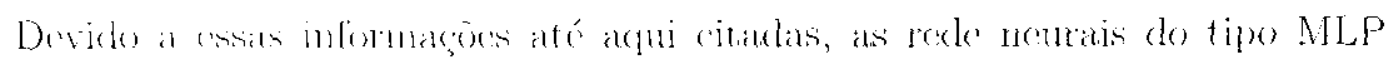
foran alotinlits bara o descmvolvinento deste trabalho de mestrado. 


\subsection{Algoritmos Evolutivos}

Primcimmente propesto por Holland (1975) (Algoritmos Genćticos) na Lni-

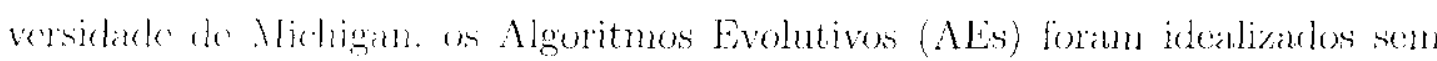

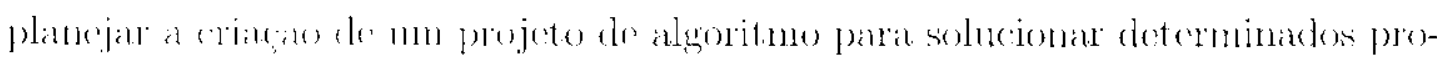

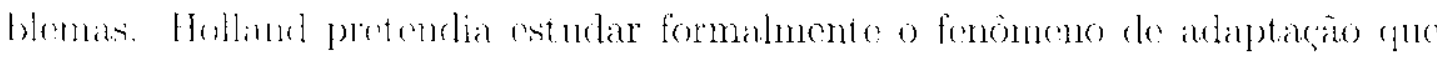

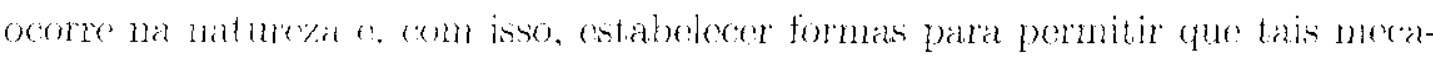

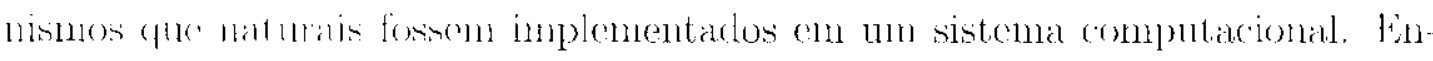

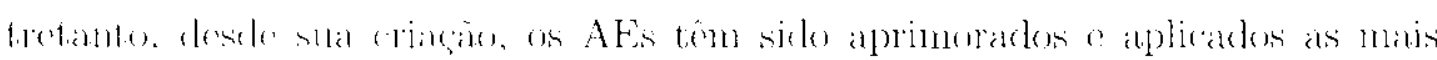

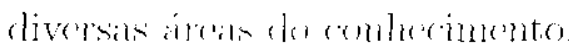

() Alis nion mun interessaute estratégia computacional devido à sua habili-

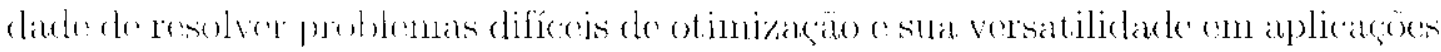

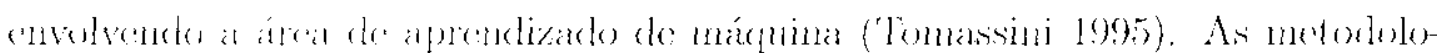

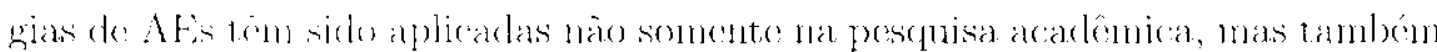

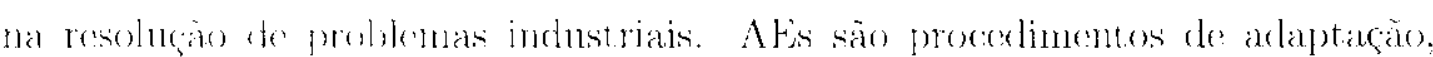

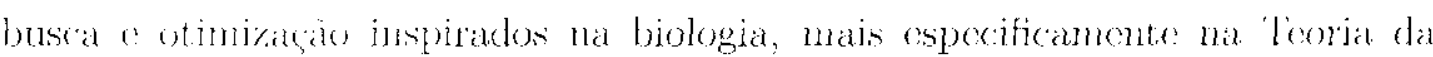

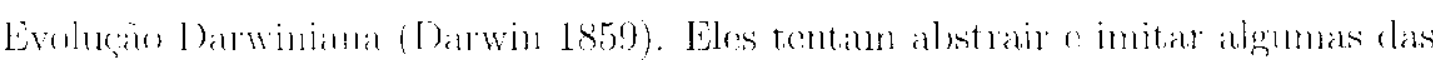

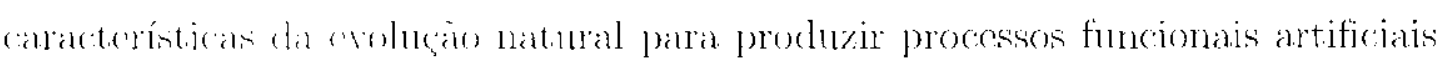

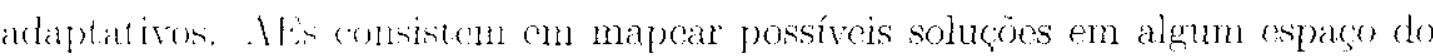

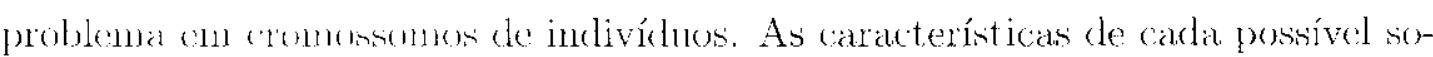

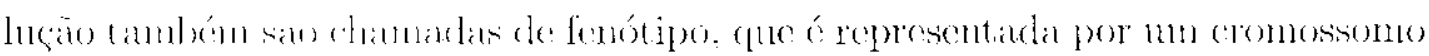

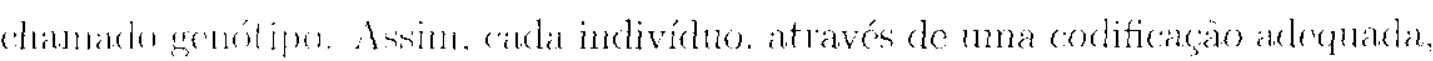
represonta $10 n$ ponto (uma possível soluçäo) eln um espaço de busca do un dado problemis.

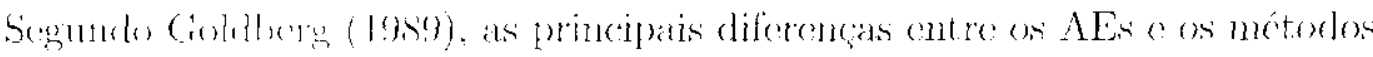

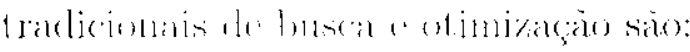

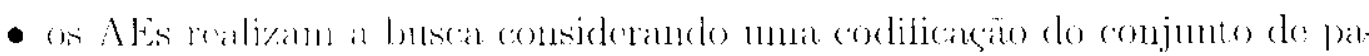

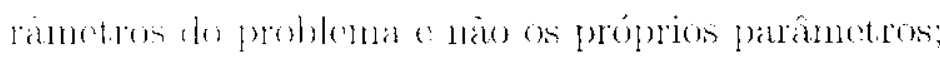

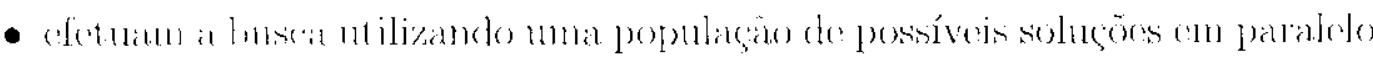

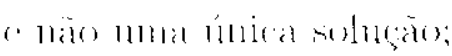

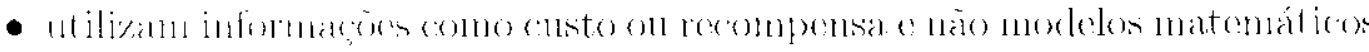

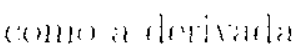

\subsubsection{Descrição Geral de um $A E$}

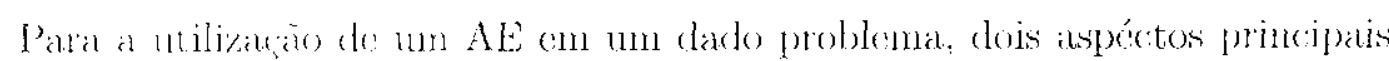

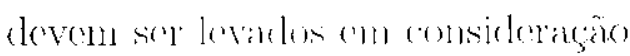




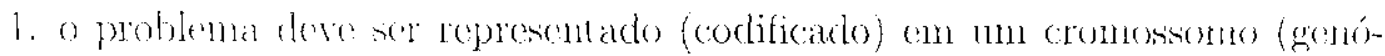

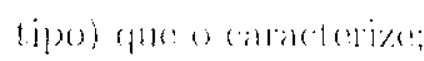

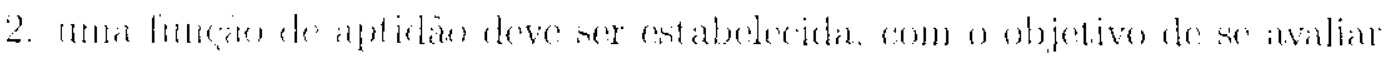

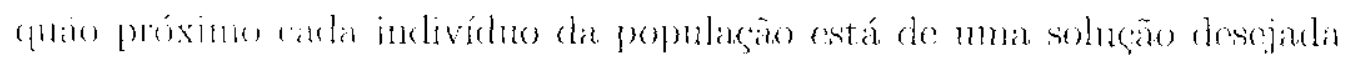
(oll satiofationia.

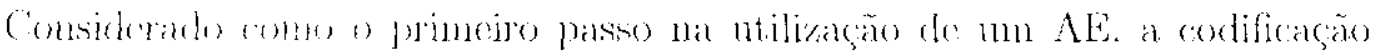

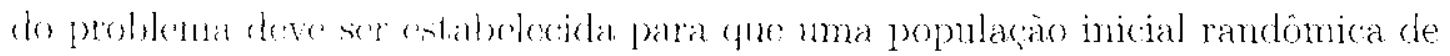

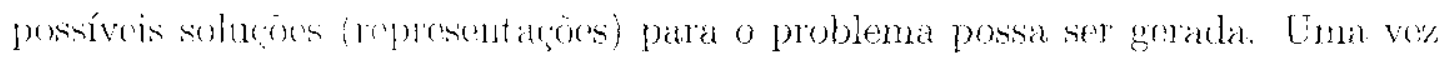

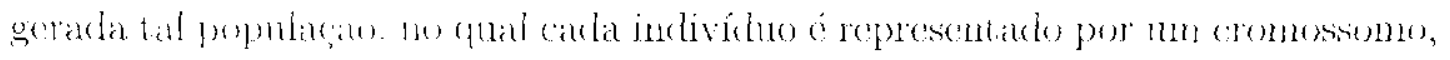

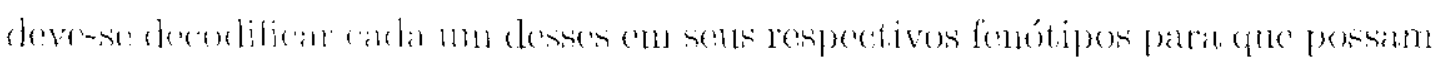

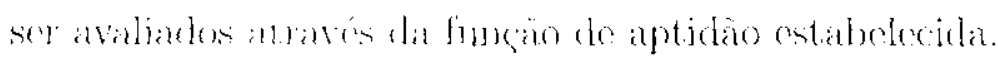

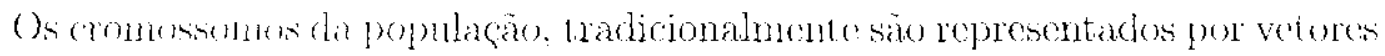

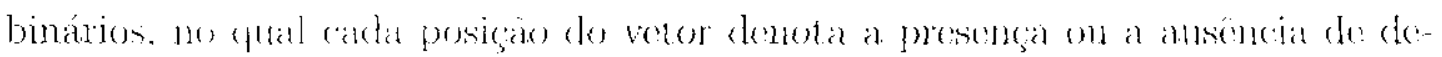

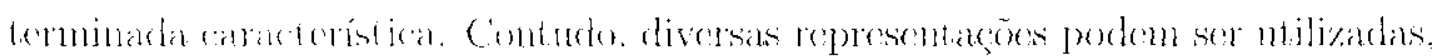

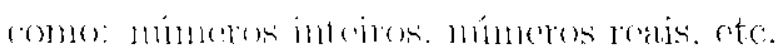

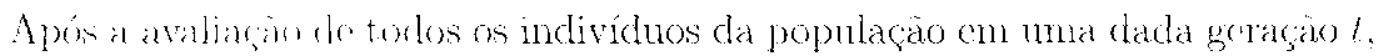

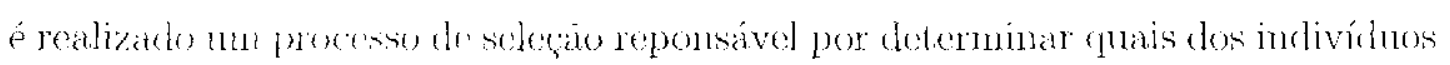

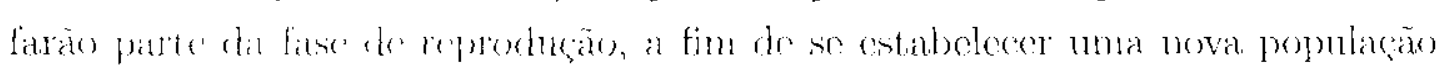
para as equatel / 1 .

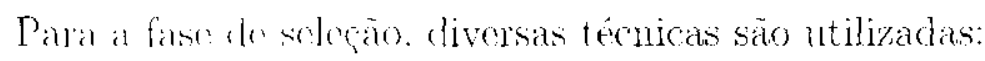

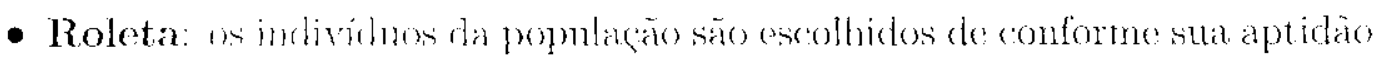

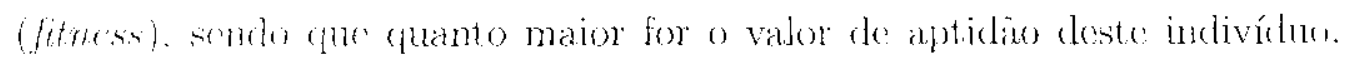

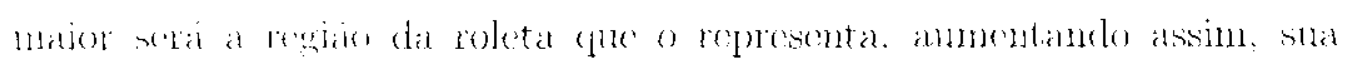

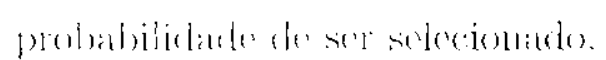

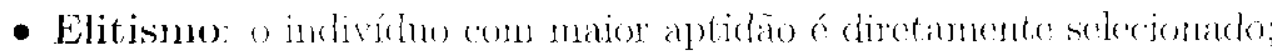

- Soleção por Truncamento: os $t$ indivíduces com on maiores valores de

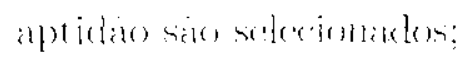

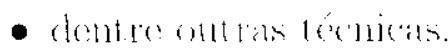

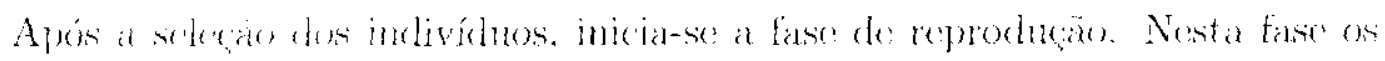

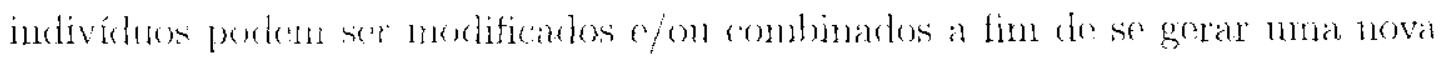
pojulatian.

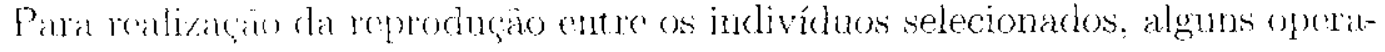

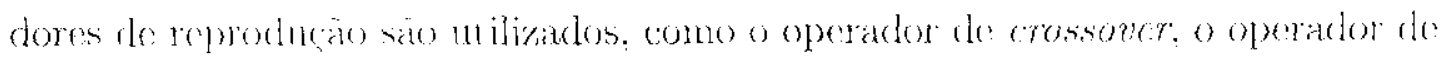
muicion. etr. 


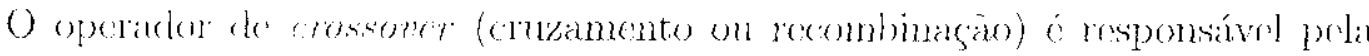

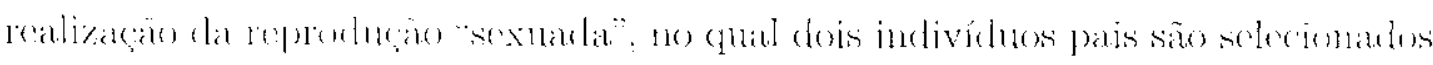

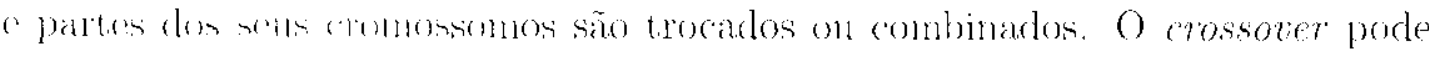

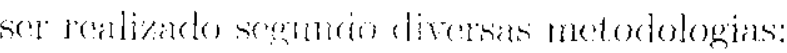

- Um ponto: ástaluelecida mu porto de cruzamento e. a partir deste as

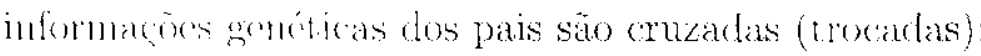

- Multi-pontos: da mesma forma que o aossoverde um ponto, porón, neste

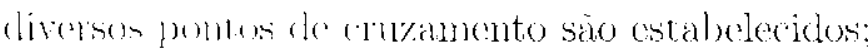

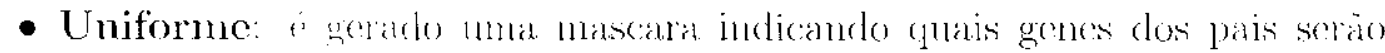

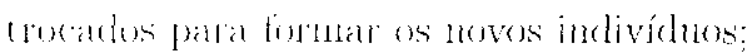

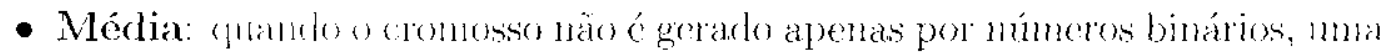

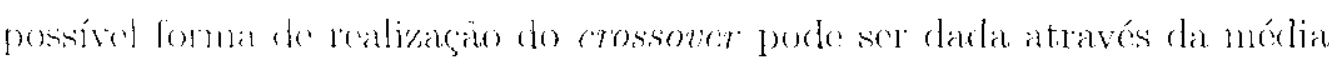

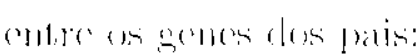

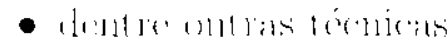

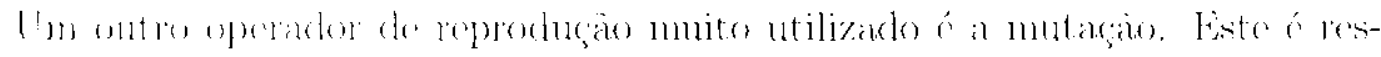

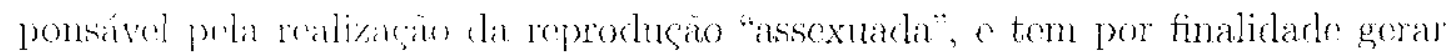

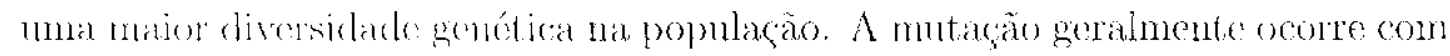

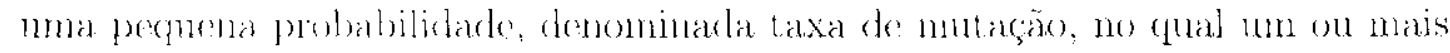

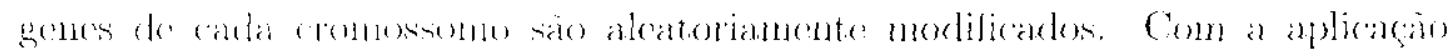

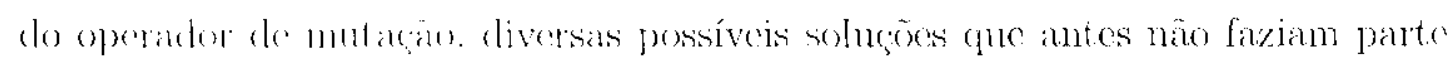

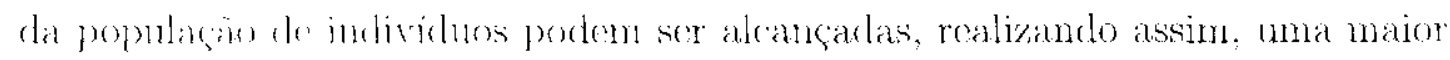

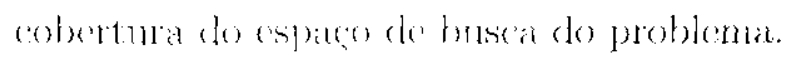

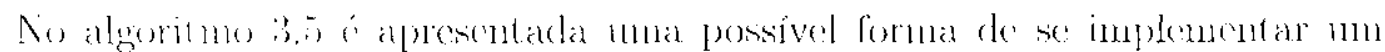

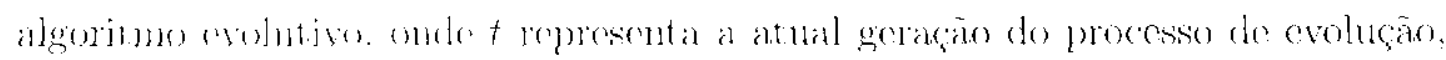

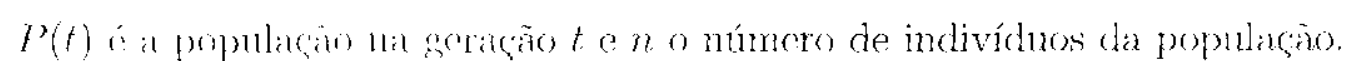

\subsubsection{AEs e Redes Neurais}

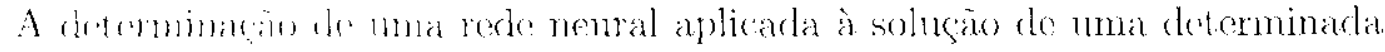

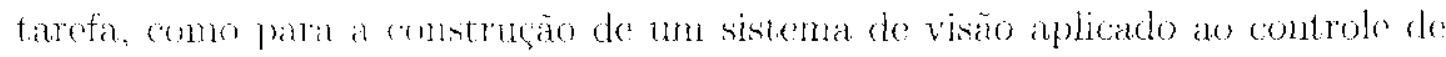

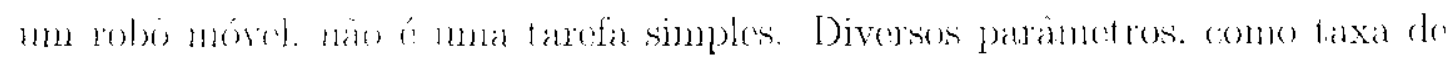

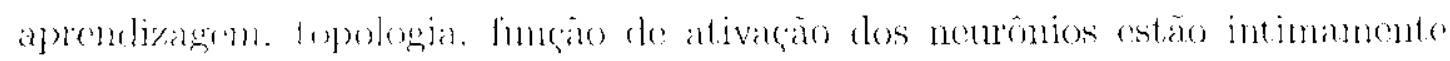

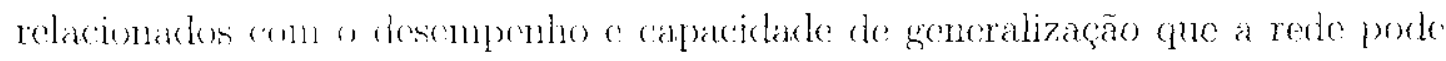

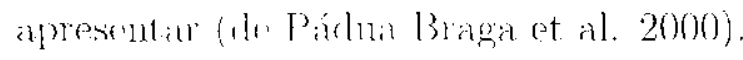

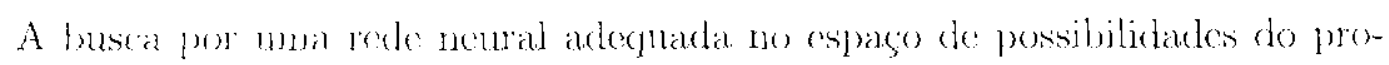

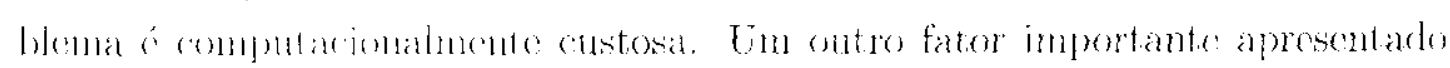




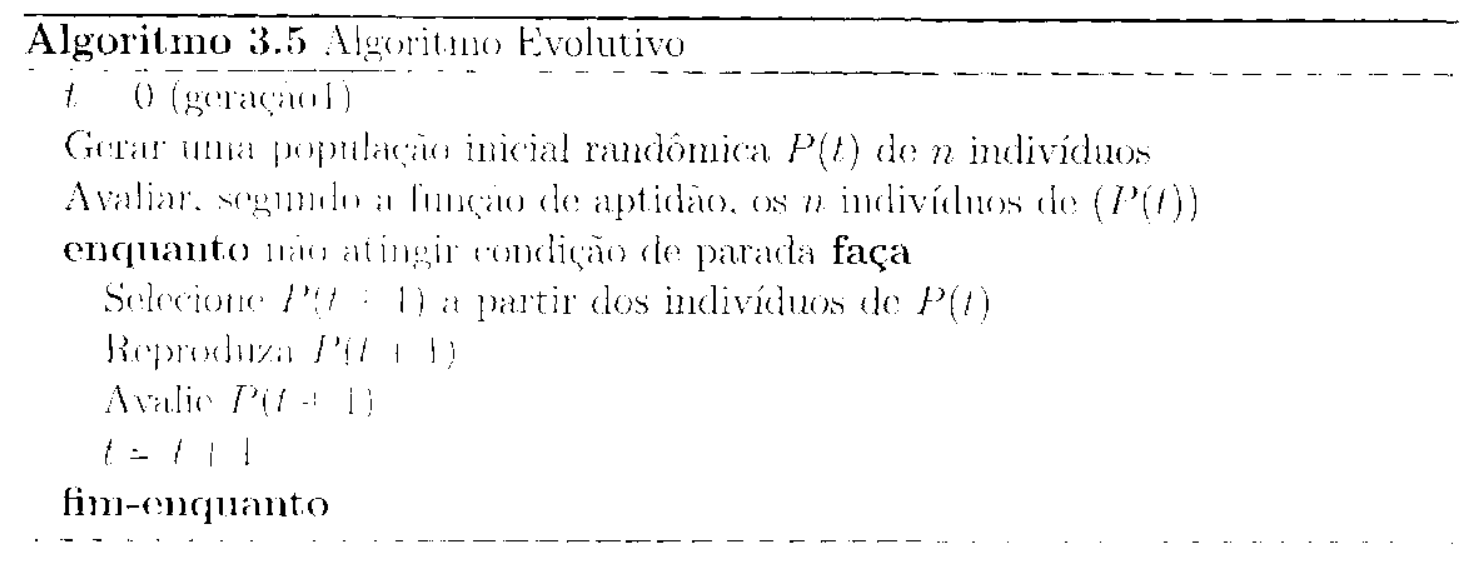

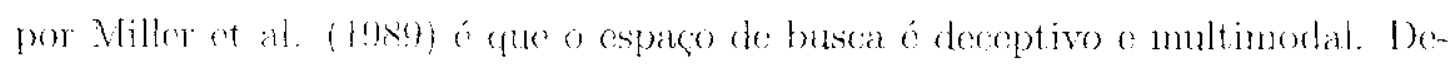

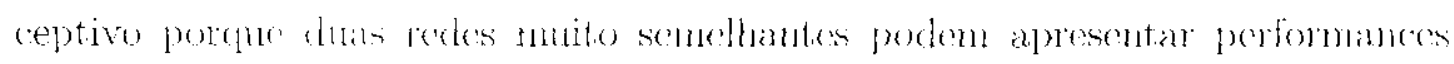

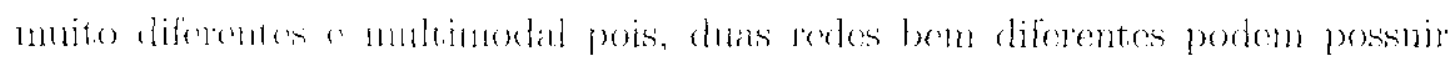
performantes nuthe somethantes.

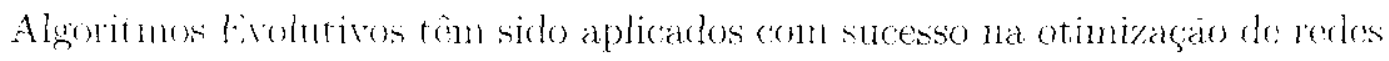

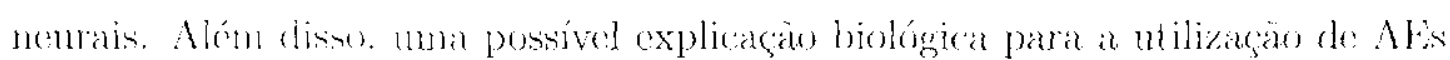

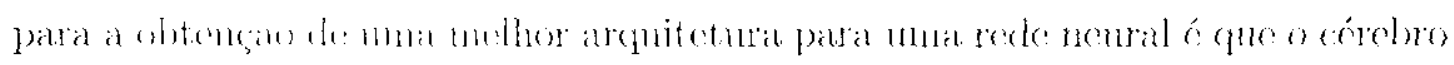

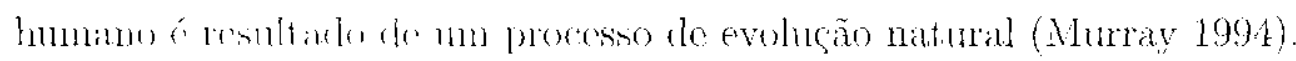

Os algoritmos avolutivos tem sido aplicardos na evoluçào dos diversos pará-

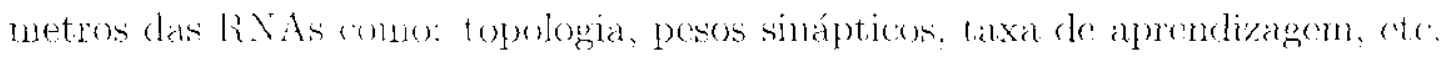

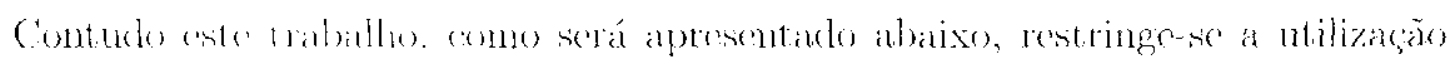

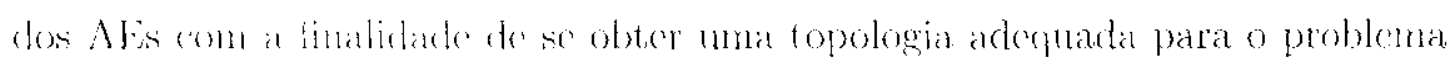
(m)1 s.stinds.

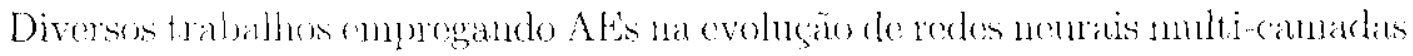

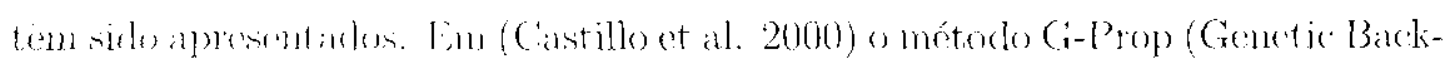

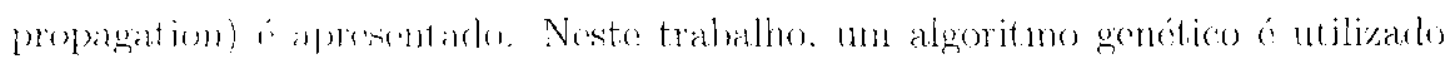

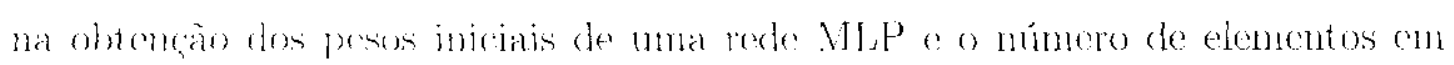

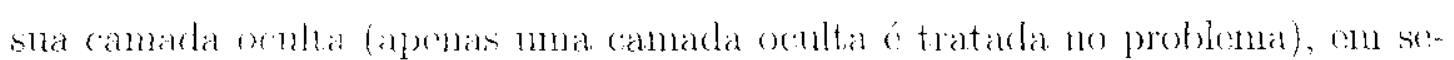

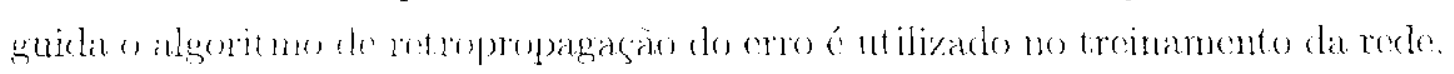

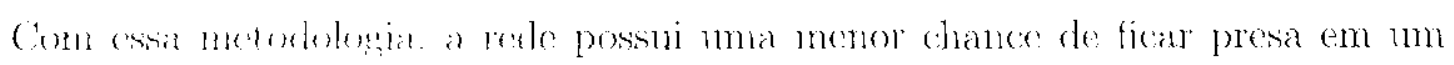

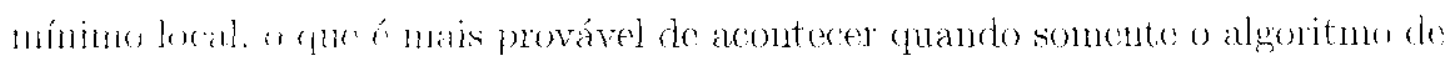

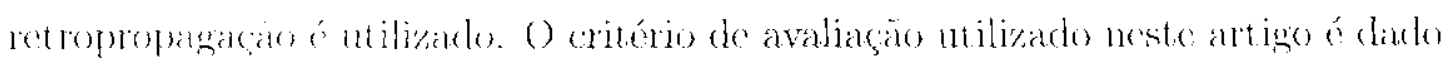

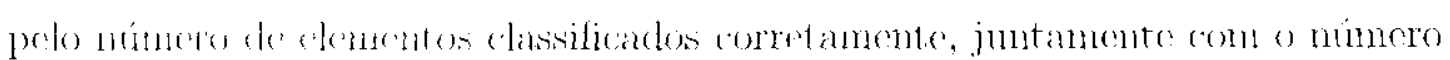

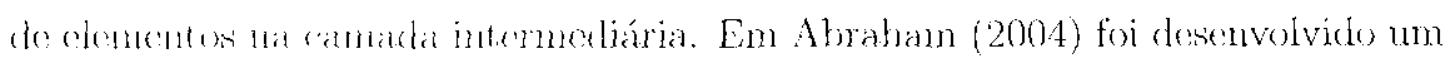
sistema crolution antomático aplicado ao processo de otimizaçăo de redes neurais

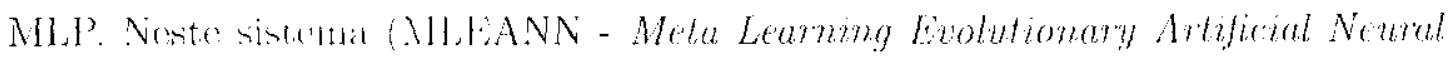

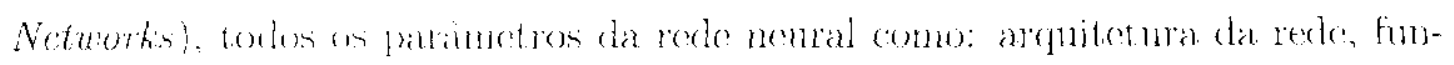

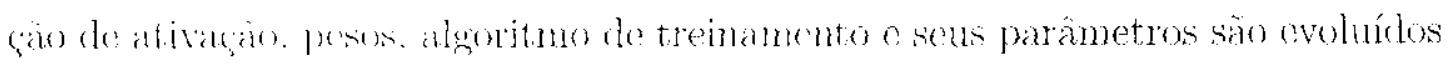




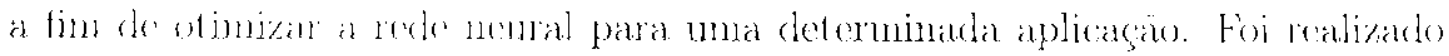

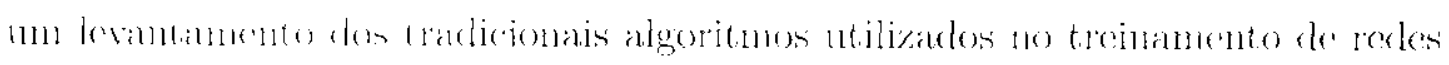

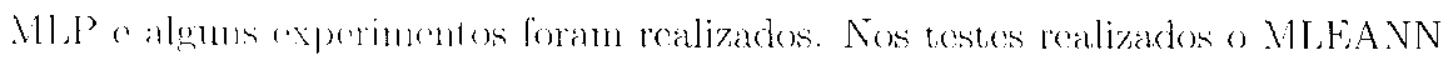

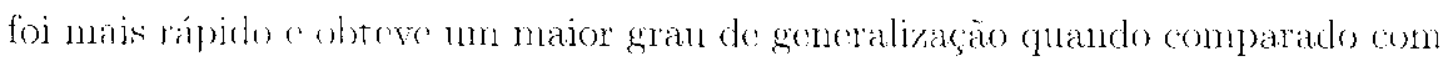

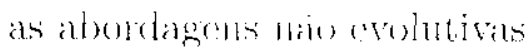

\subsubsection{Algoritmo Evolutivo Desenvolvido}

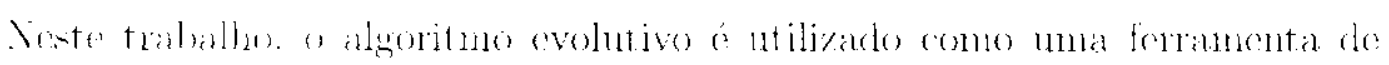

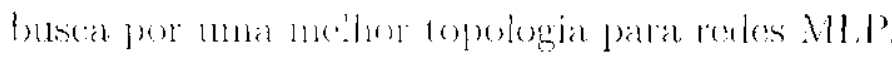

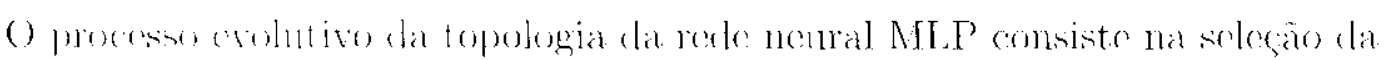

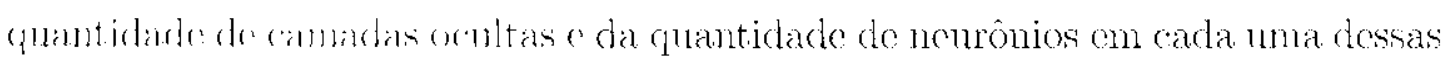
camatlas.

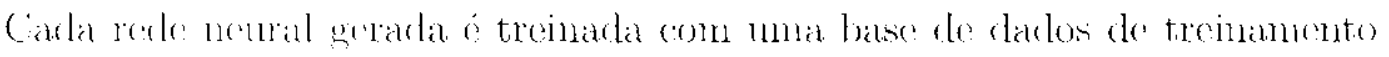

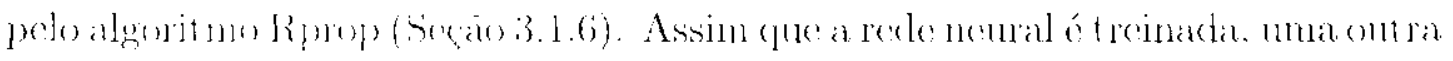

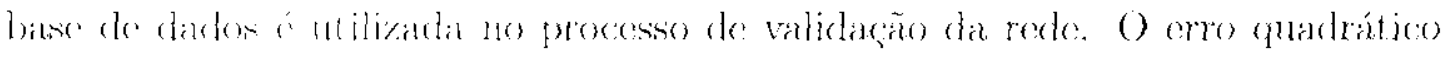

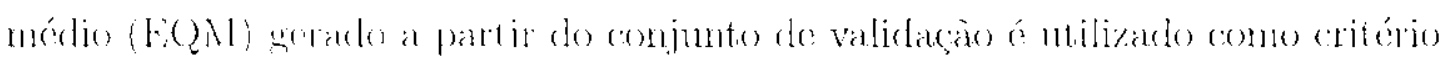

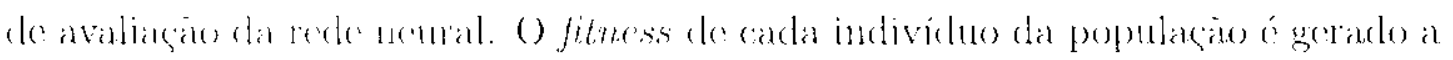

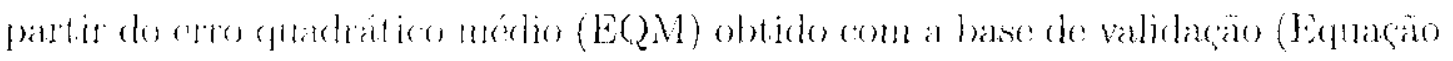
3.23 .

$$
\text { fiturss }=1-\operatorname{leg}
$$

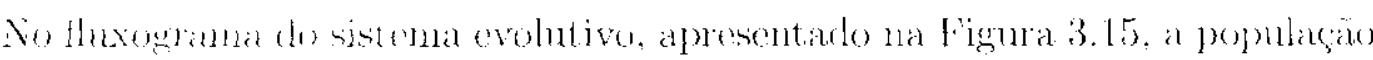

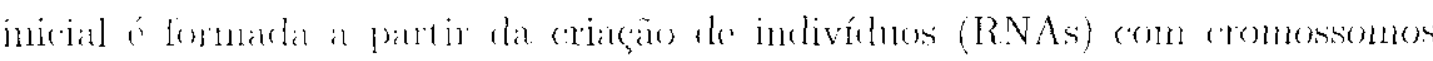
gerades alsatoriamente. Fin seguicla os inclivíduos săo avaliados através do erro

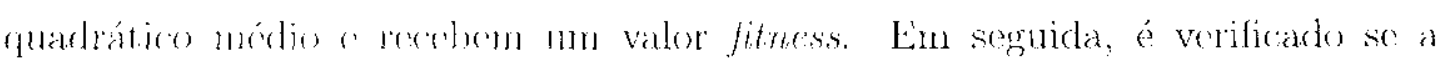

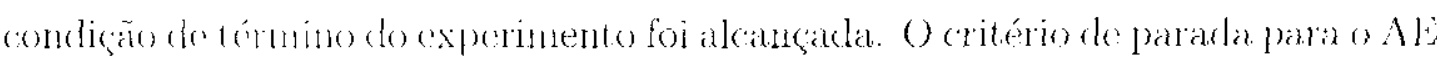

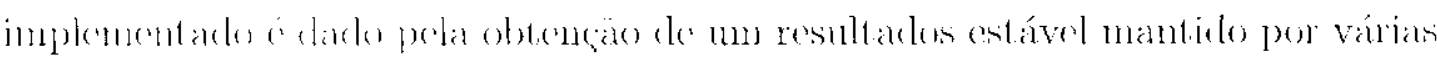

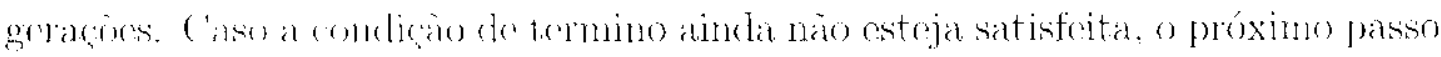

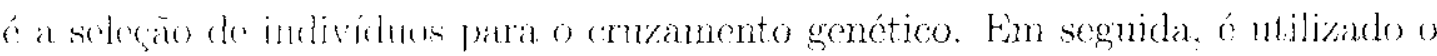

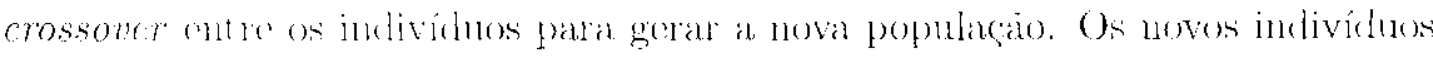

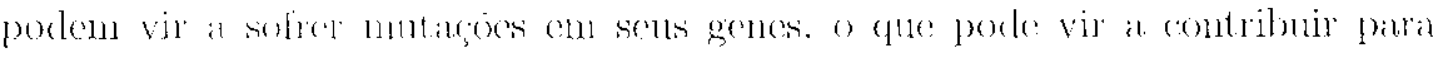

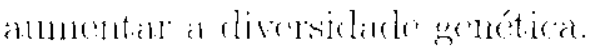

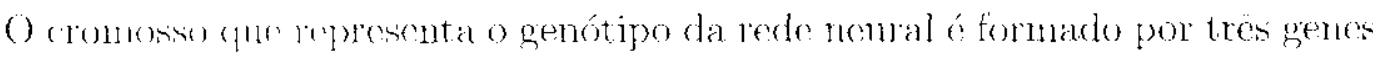

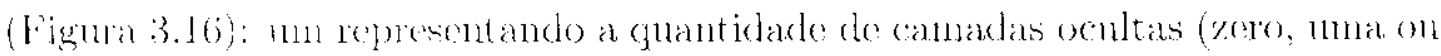

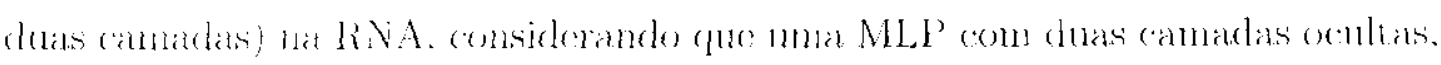

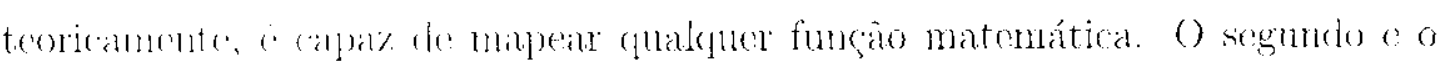
tereciro genes infouman a quantidade de elementos na primeira e na sogunda 


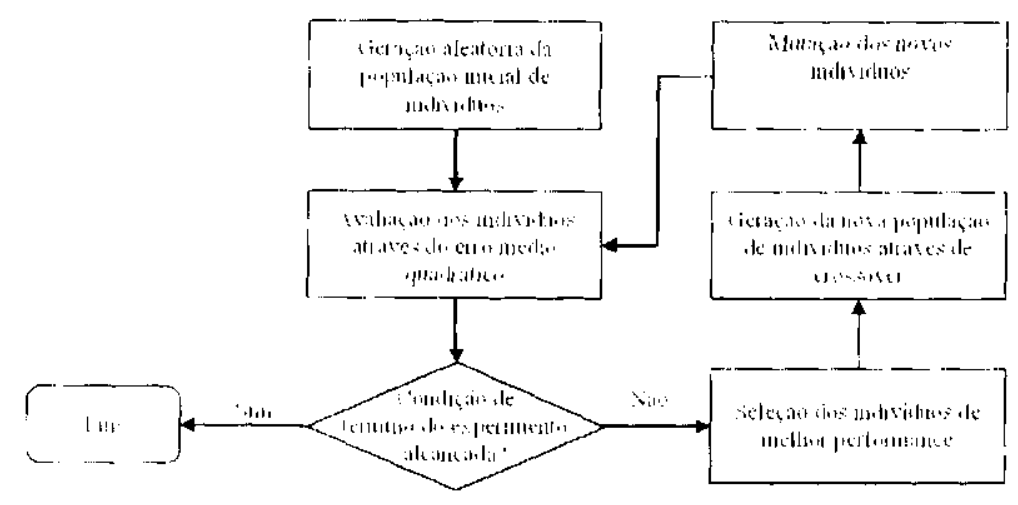

Fingua :3.15: Flaxogranat do sistomal owohtivo implementado

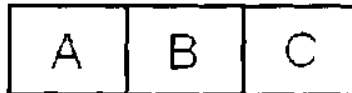

Figura 3.16:0 (Tomossomen

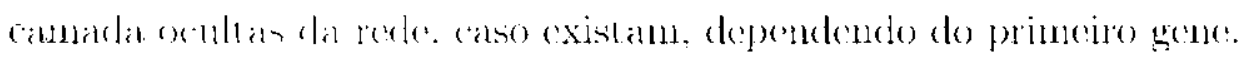

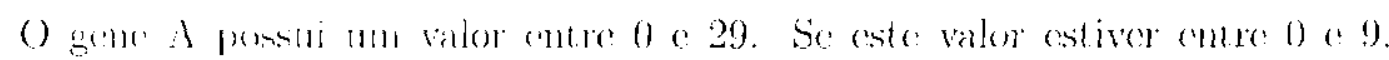

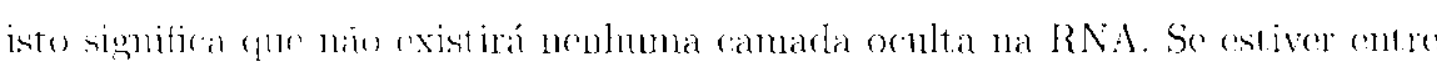

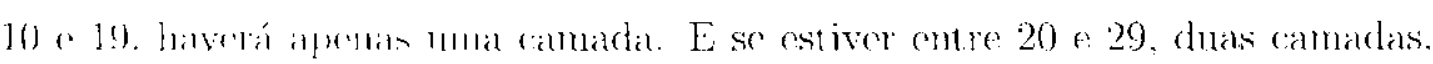

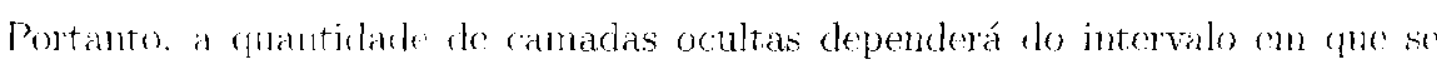

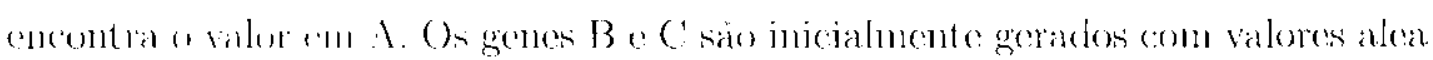

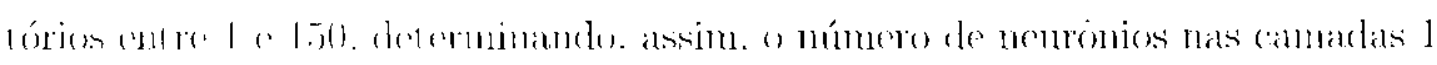

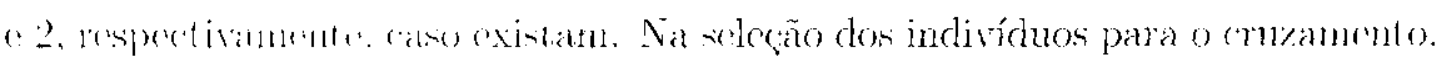

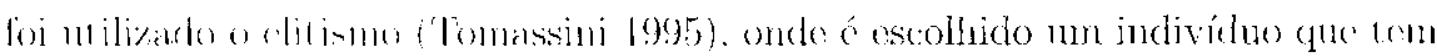

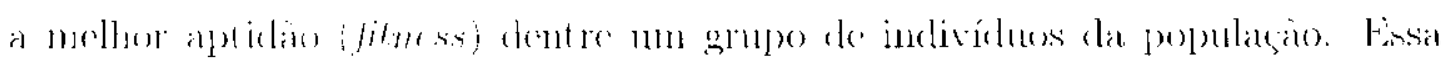

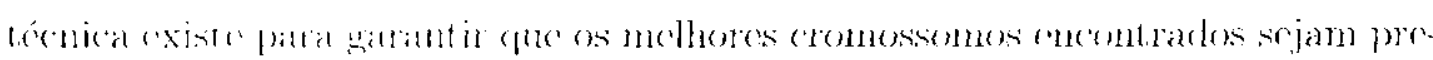

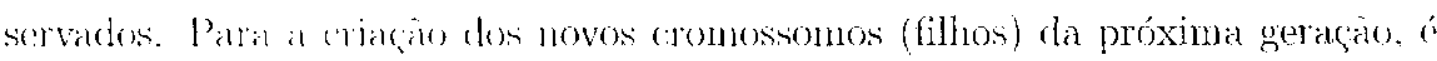

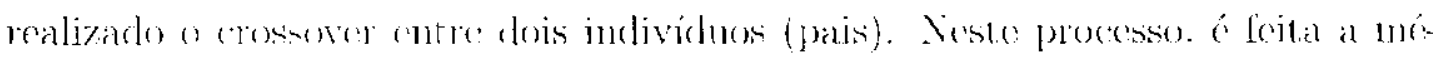

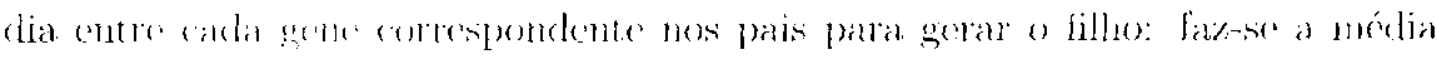

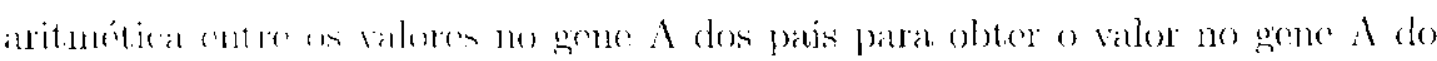

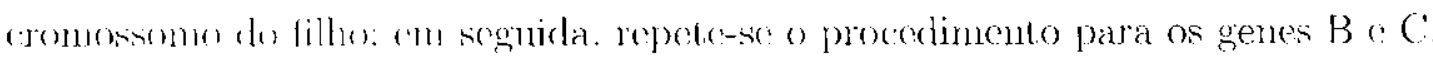

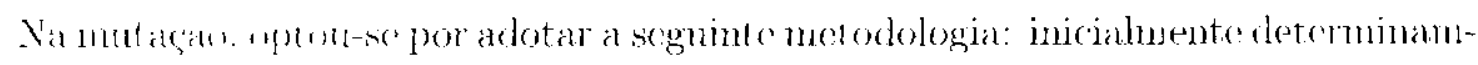

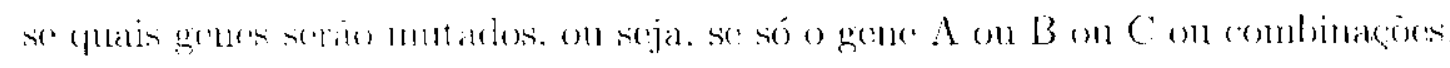

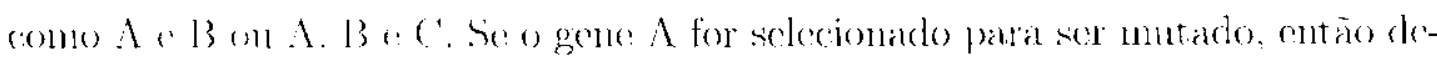

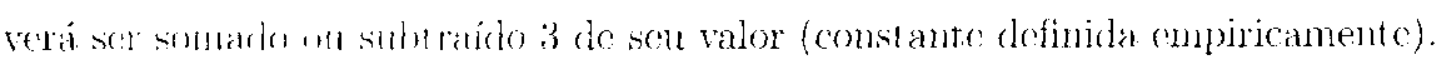

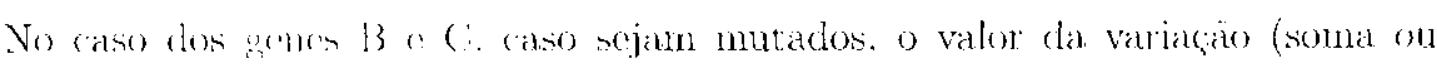

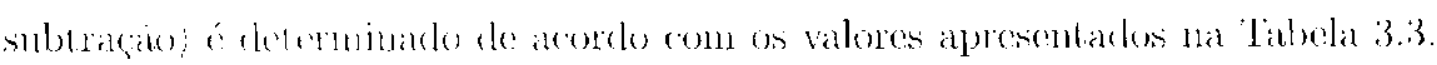

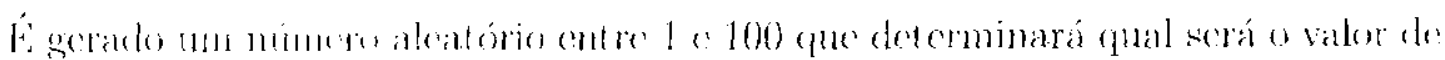


Tatolia 3.3: Valor das variacós dia mutaçăo nos genes B e C

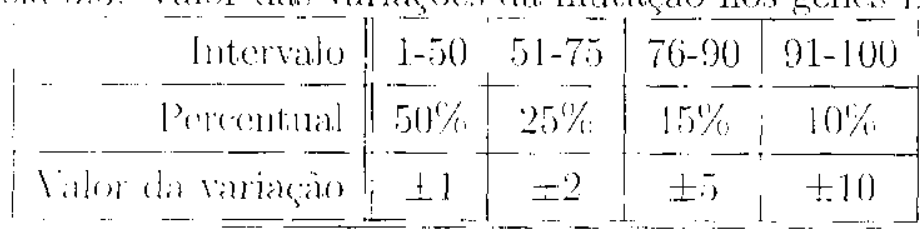

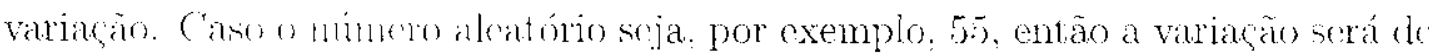

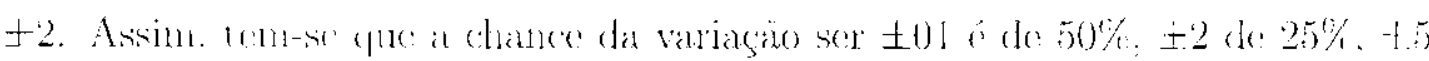

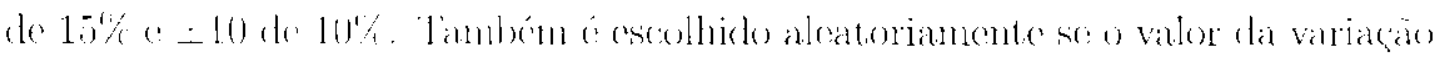

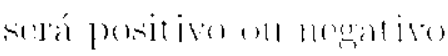

\section{Modificações no Algoritmo Evolutivo (AE-II)}

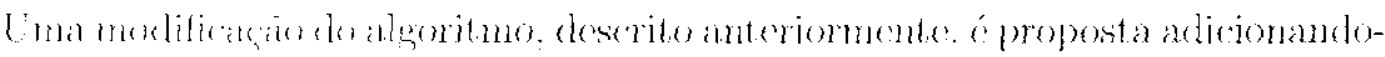

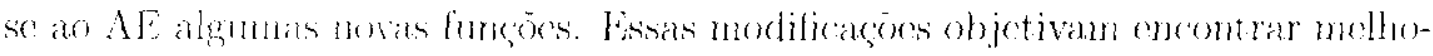

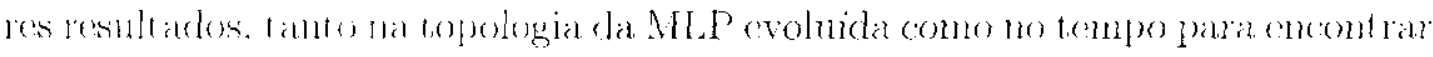
tal sislugine

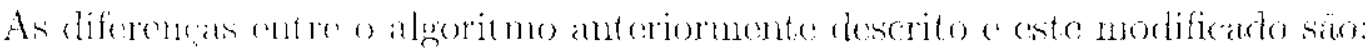

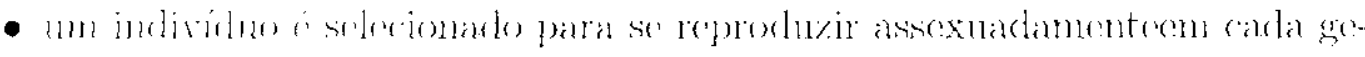
rainis

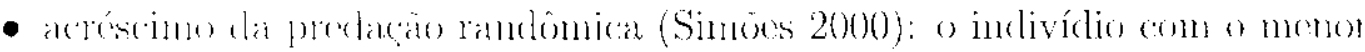

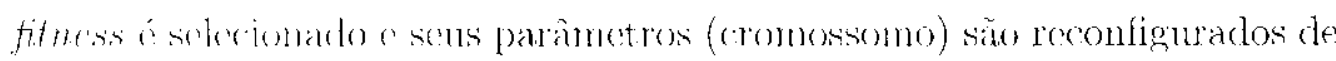

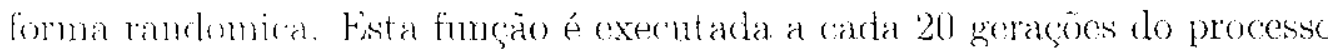
evolutive.

- arrécrino da predacáa por sintese: o individuo con menor fineso (indiví-

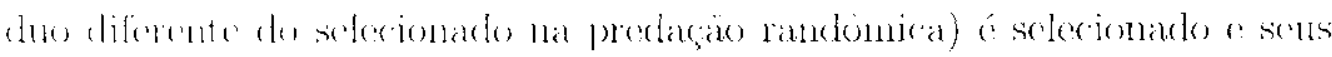

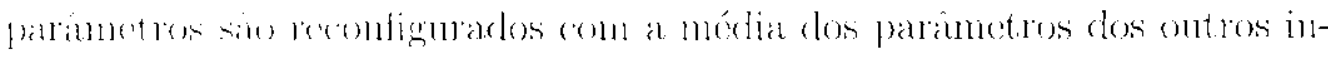
divídum die pupulacăo.

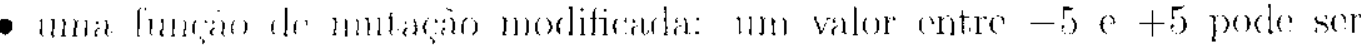
adicionado aos parametros B e C do cromossomo. Fsta função é chamada

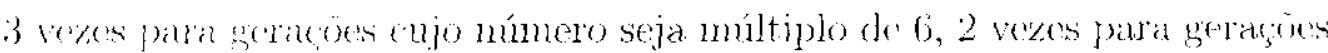
multiples de.2. I ve para as demais geracions.

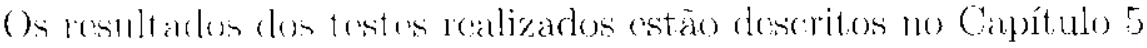

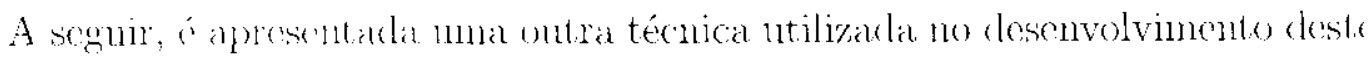
trabalho de mestrade: a termica de: Caunpos Potenciais 


\subsection{Campos Potenciais}

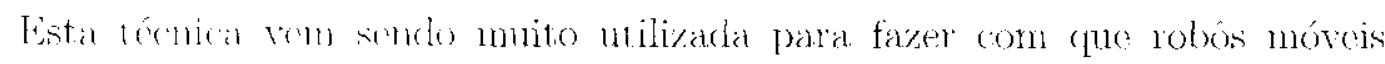

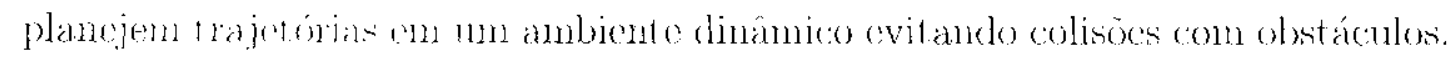

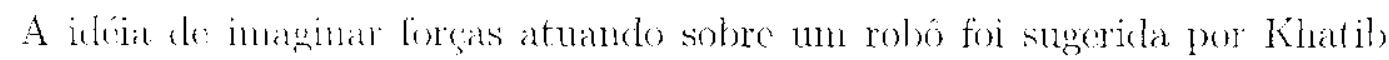

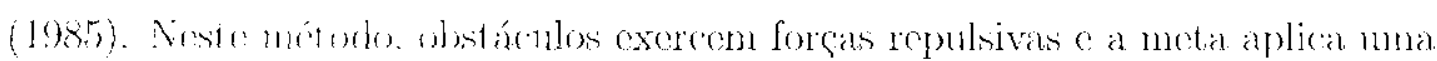
force atrativa sobme orobo. A força resultante $\vec{F}^{?}$ é compesta de uma força atrativa diseromada para a mela oforças repulsivas proveniente de obstáculos.

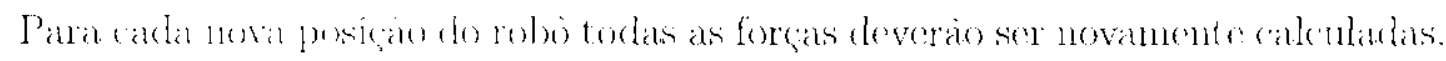

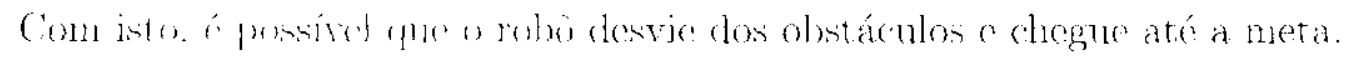

Krogh (198, aprimorom este conceito considerando a volocidade do robo na

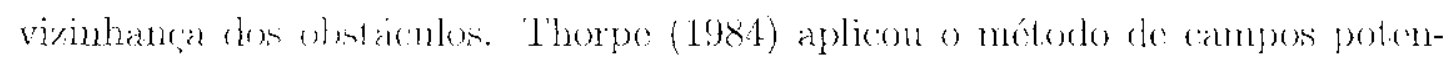

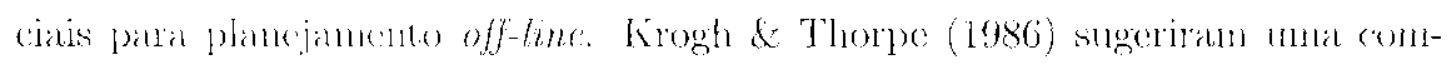

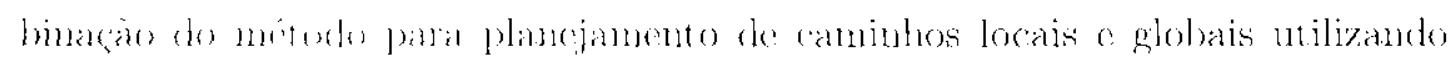

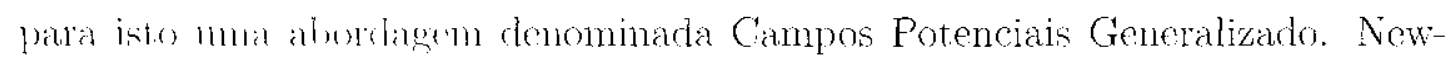
man d Hogan ( INA $\bar{i}$ ) introduziram a construça de funçoes potenciais at ravés da

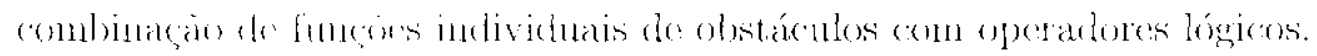

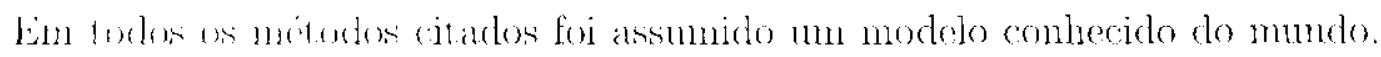

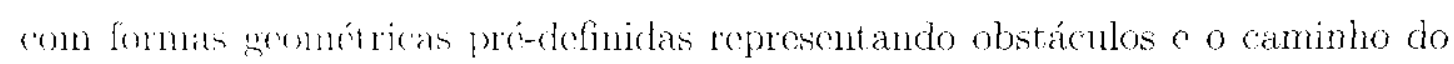
robo fis gerarlo off-lme. No entianto. Brooks (1986) e Arkin (1989) săo os pioneiros

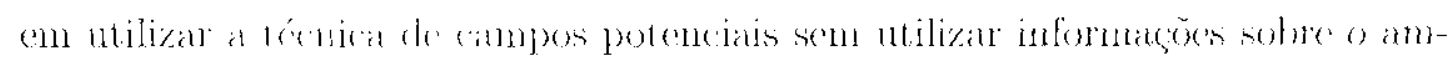

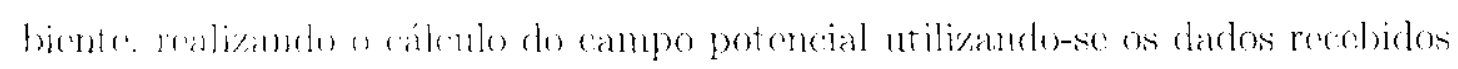

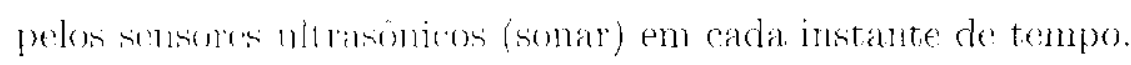

Brooks at ilizon campos potenciais como um controlador roflexivo. O contro-

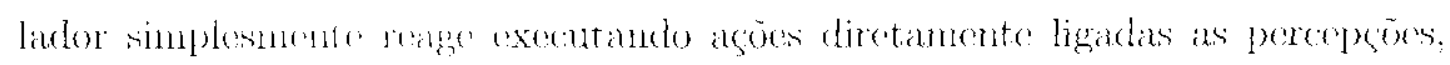

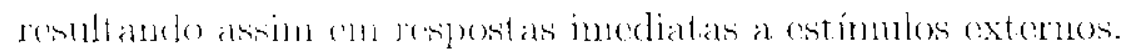

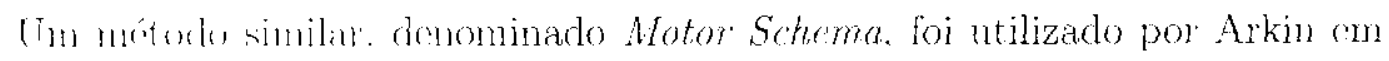
sens robos. Este método consisto en ativar vários comportamentos simult aneos

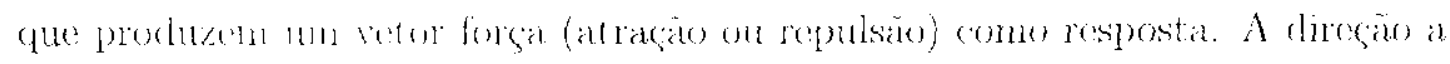

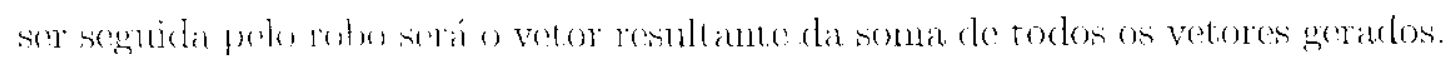

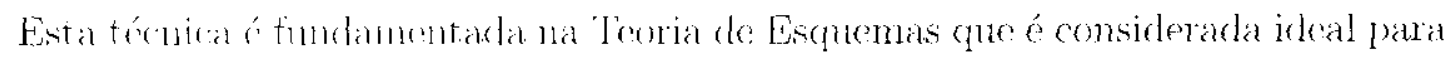

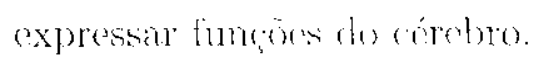

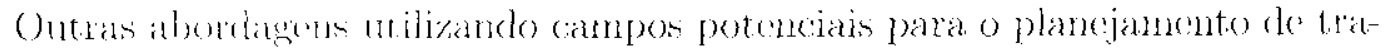

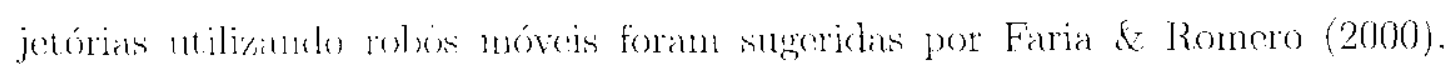
Costa \& Prograno (2000) r Comese Campos (2001).

Várias mótodos pordon sor eseritos para clescrever as forcan que agem soblore o robo. É por nucto da combinaräo destas forcas (lorga resultanto) que se monta

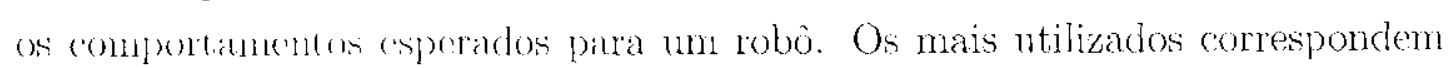


aos compentamentem de husca pelo alvo (força de atraçä) e desvio de obstáculos

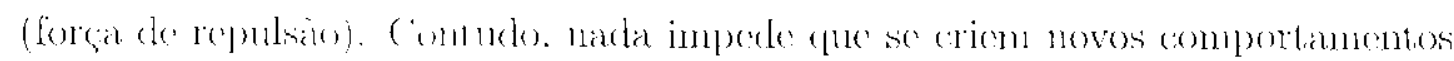

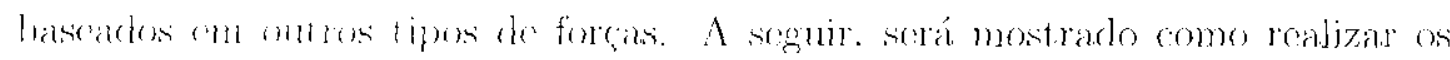

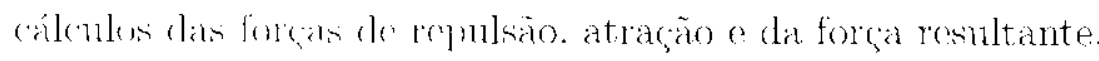

\subsubsection{Força de Repulsão}

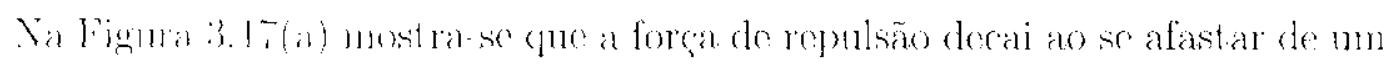
obstáculo. pois csta fim

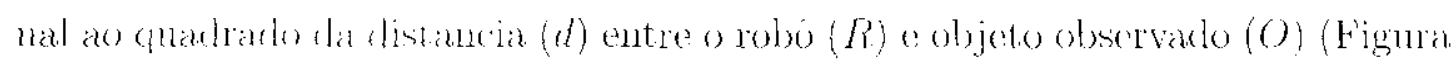
$3.17(1)$,

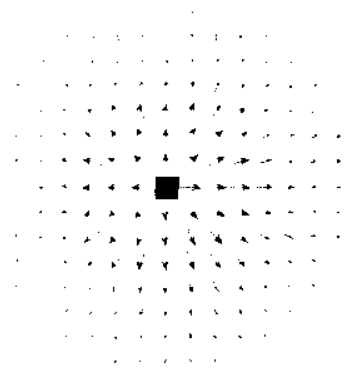

(a)

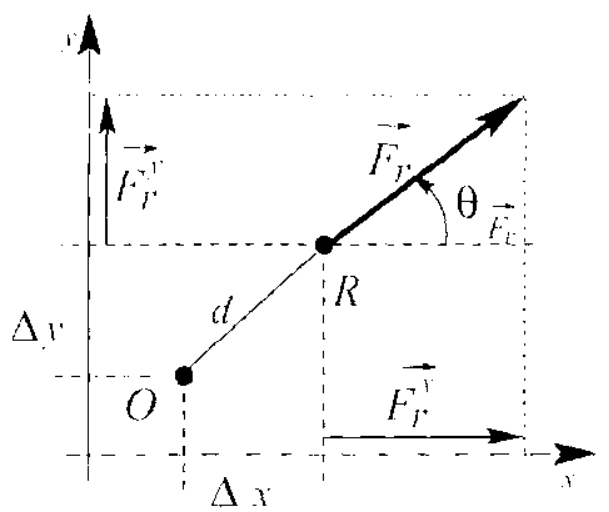

(b)

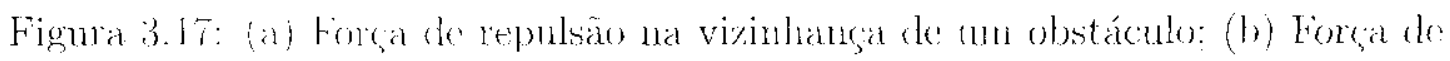

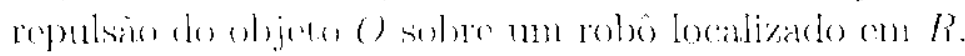

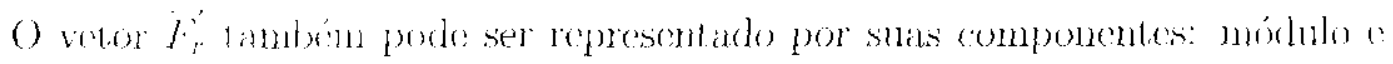

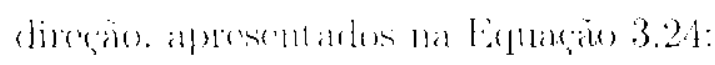

$$
\vec{I}, \vec{l}=\frac{Q}{t^{2}}+\theta_{\overrightarrow{l_{r}}}=\arctan (-\Delta y,-\Delta x)
$$

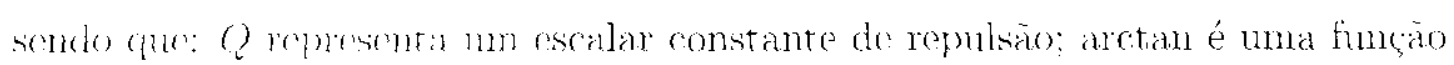

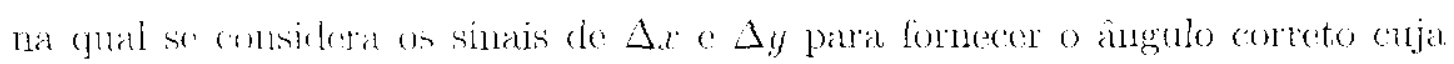

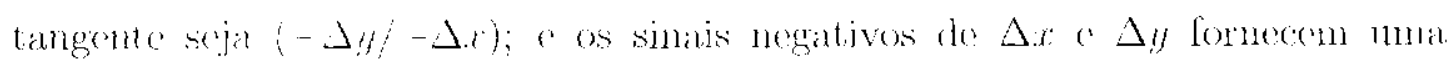

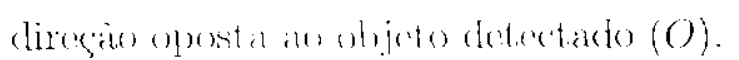

Para calevlar at lurea de repulsăo para vários obstáculos, deve-se fazer o so-

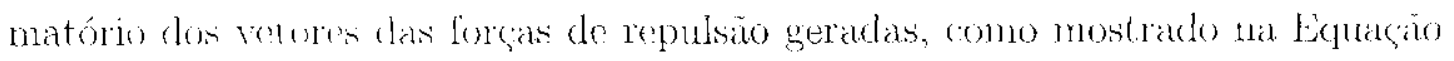
$3.25:$

$$
\overrightarrow{F_{R}}=\sum \overrightarrow{F_{r}}
$$




\subsubsection{Força de Atração}

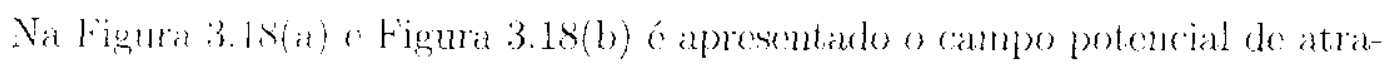

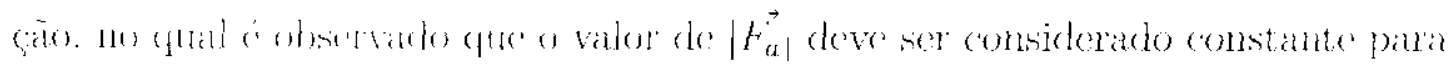

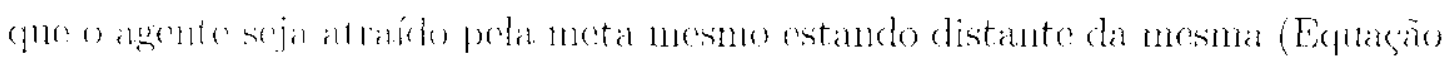
$3.2(6)$

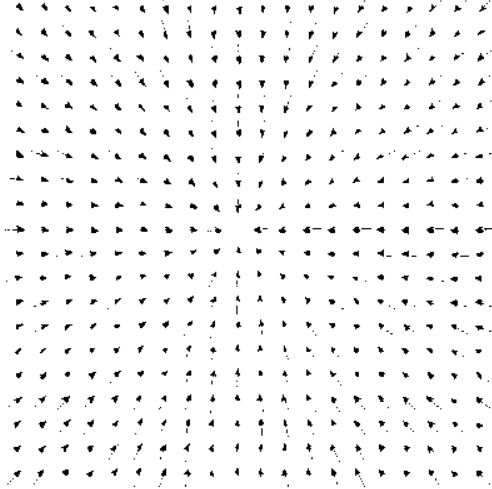

(i)

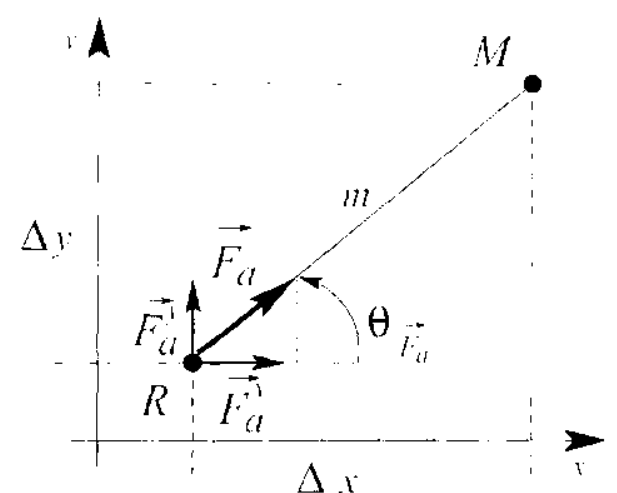

(1)

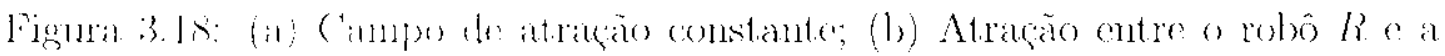
meta $\mathrm{Ml}$

$$
\left|F_{n}^{\prime}\right|=C\left(\theta_{F_{l}} ;=\arctan (\Delta y, \Delta l)\right.
$$

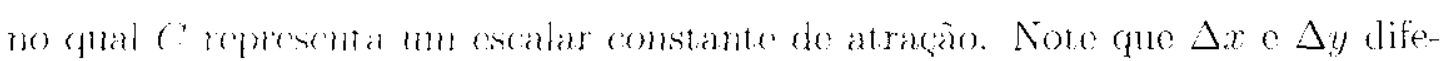

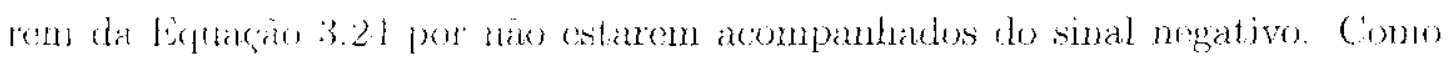

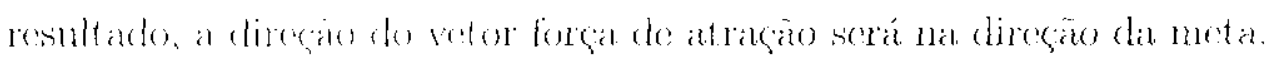

\subsubsection{Força Resultante}

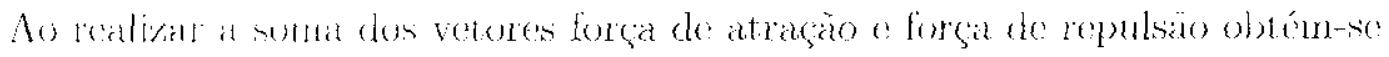

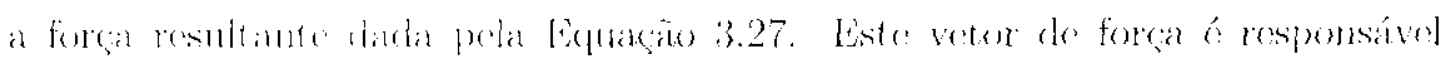

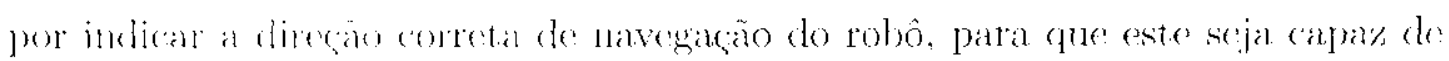
navegat pelo anbiome desviando de possíveis obstáculos.

$$
\vec{F}-\overrightarrow{F_{k}}+\overrightarrow{F_{n}}
$$

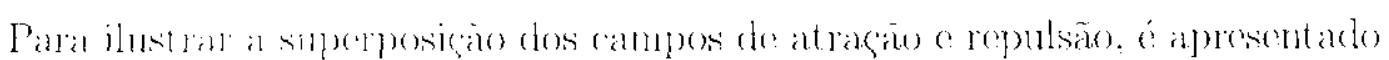

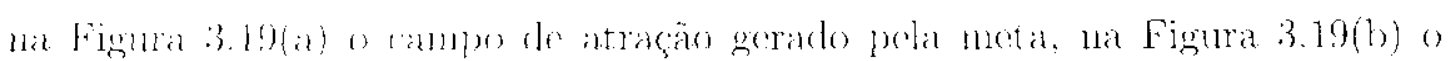
campo de repulsion serrato por dois obstáculos e firalmente na Figura 3.19(e)

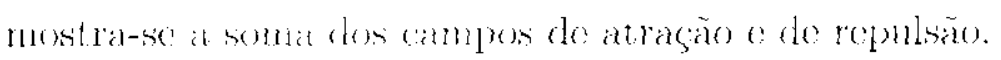

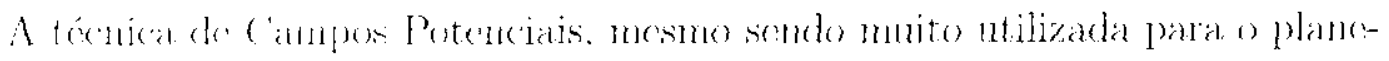

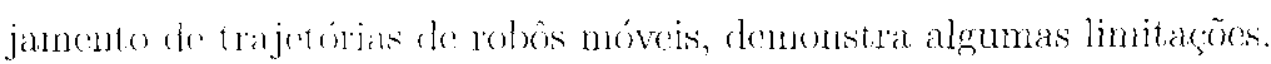




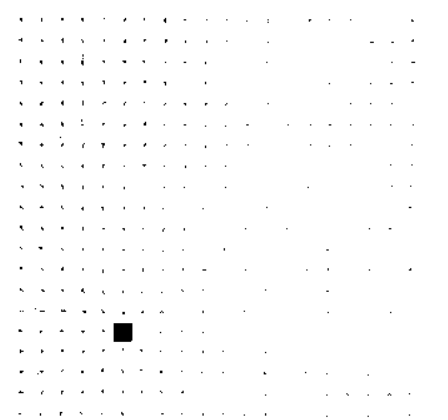

(a)

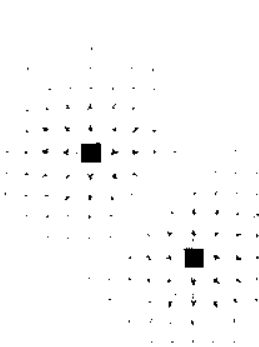

(b)

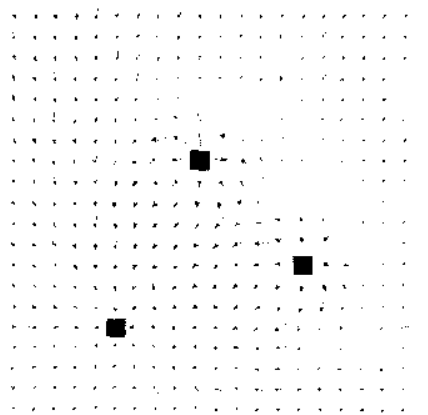

$(c)$

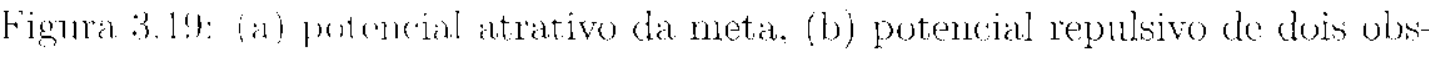

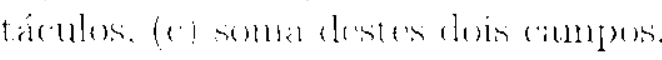

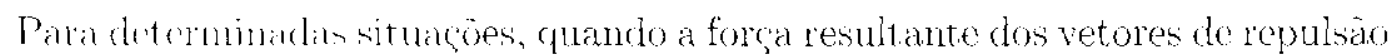

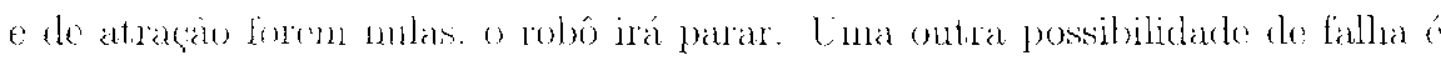

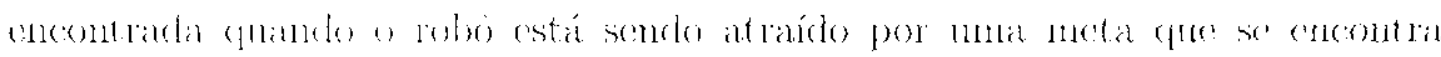

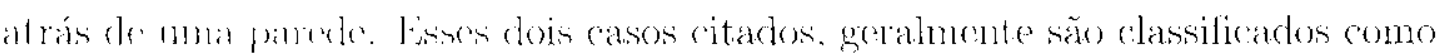

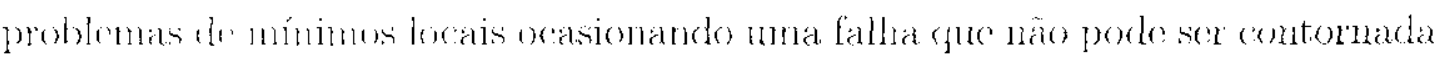

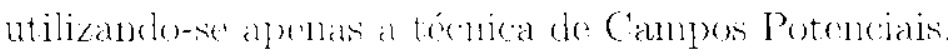

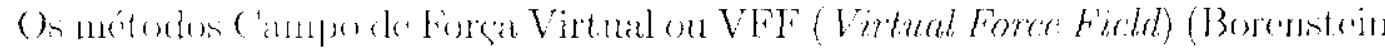

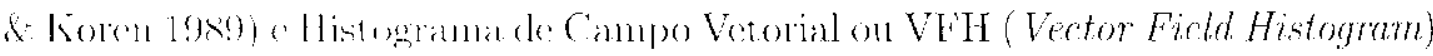
(Borenstrin ( Koron 1991) form propostos por Borenstein \& Koren (1989) a

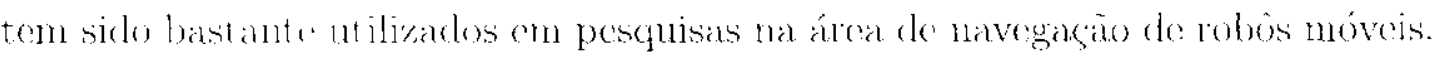

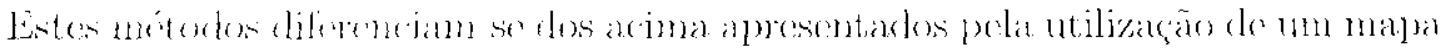

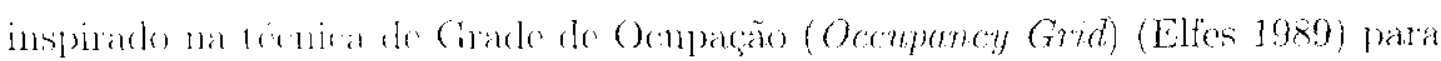

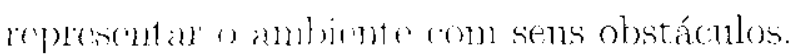

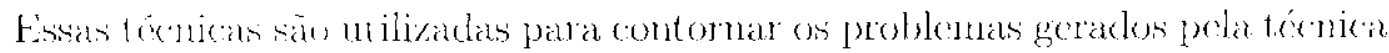

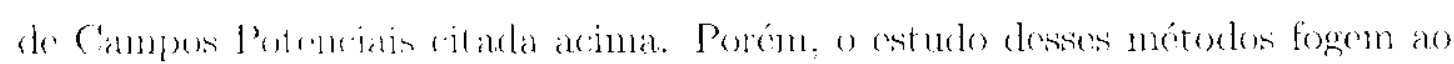

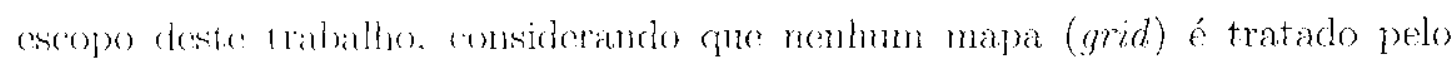
sistemalopopostor 


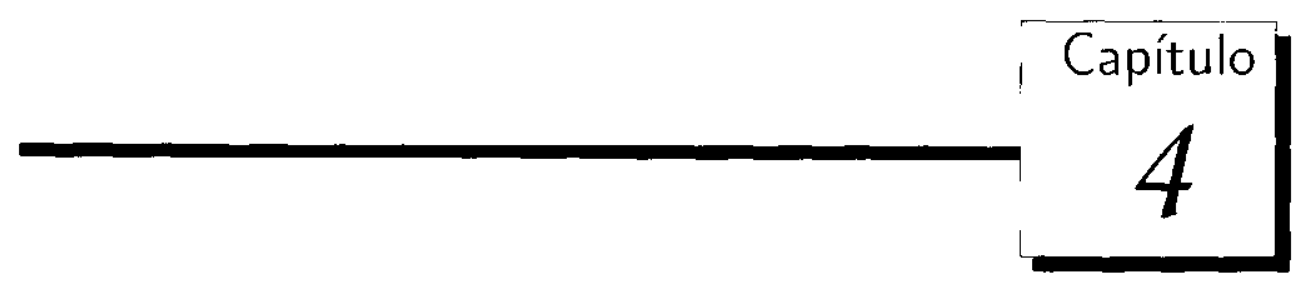

\section{O Sistema Computacional Desenvolvido}

O

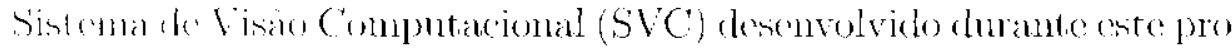

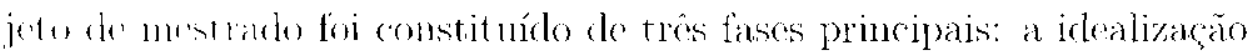
do sistoma a implementacăo es experimentos

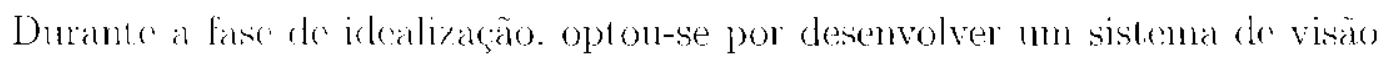

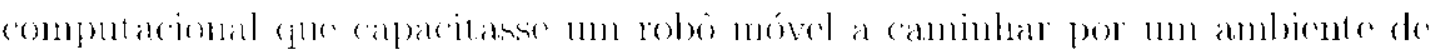

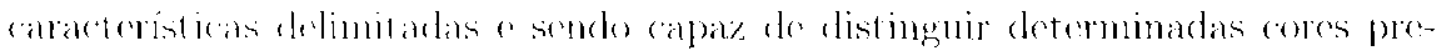

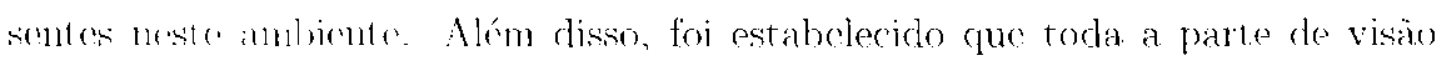

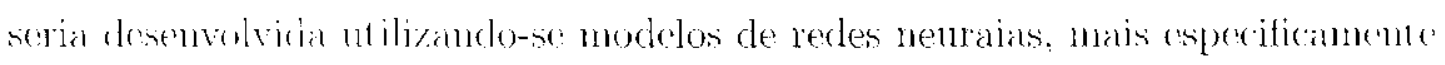
o modelo All' (capitulo 3). o que facilitaria una possivel implementagào deste:

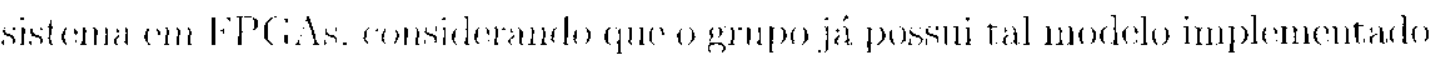
(an hamelware

A lase de inplementaga e de experimentos tramitaran quase que em sua

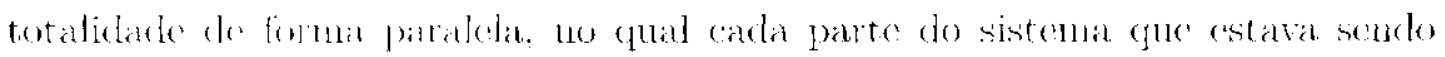

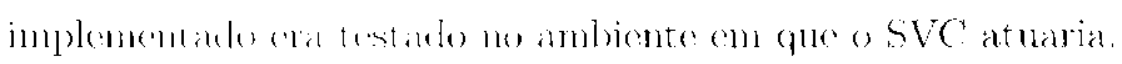

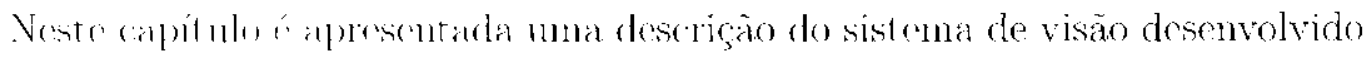

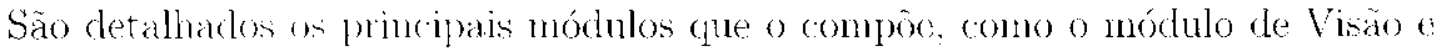

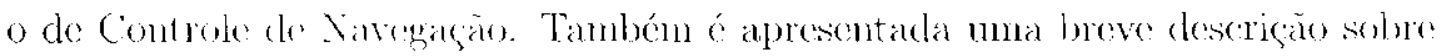
o hardware soleitien. a interface com o usuário o o ambiente Saphira.

\subsection{Uma Descrição Geral do Sistema}

Para o desenolvinento deste projeto de mestrado diversos subsistemas loram

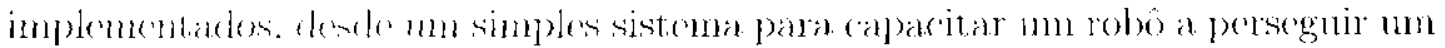

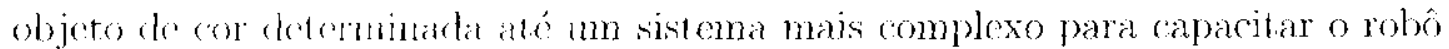
a naverar por 101 ambiente de forma autonoma desriando de obstáculos e sendo atraido por un objen de cor determinada. Contudo, todos esses subsistemas

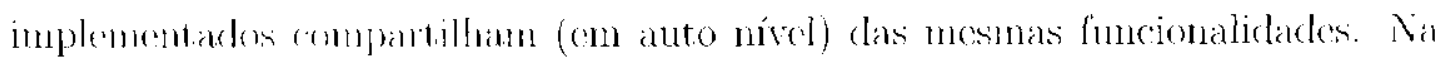




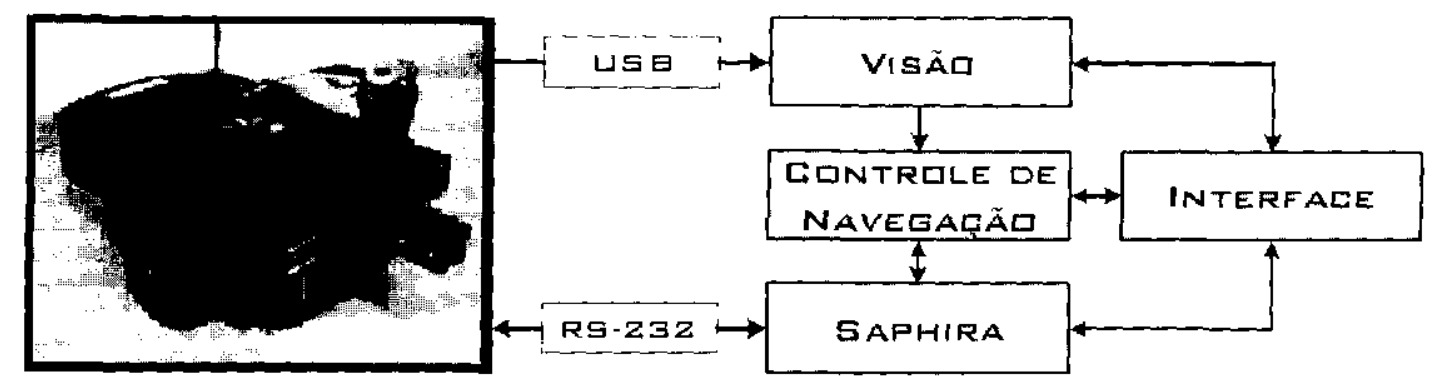

lïgura 4.1: Arquitetura do sistrma

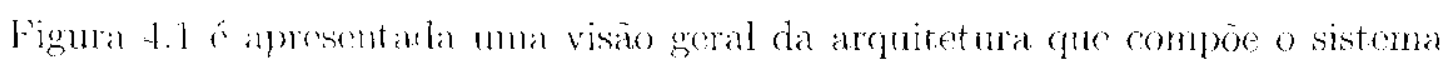
desenvolvido, un chal as solas indicann o fluxo de dadus. A conexán RS232 i utilizada tanto para conviat dados ao robô lex: configurar sua volocidade de trans-

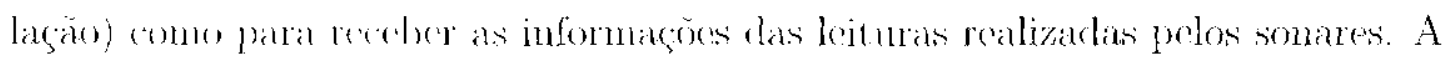

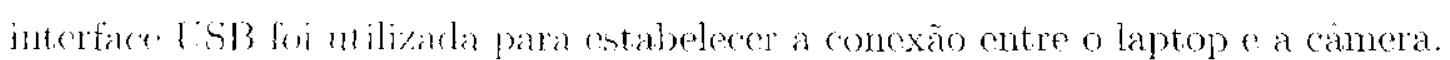

Todo o sistoma implementado segne o paradigma reativo (Arkin 1998), 10

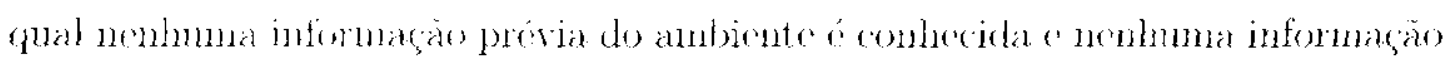
adquirida seshe o ambiente ́a amazenata na memória do robo. O paradignta

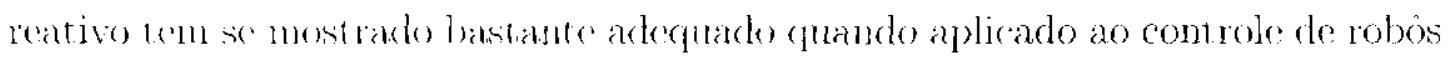

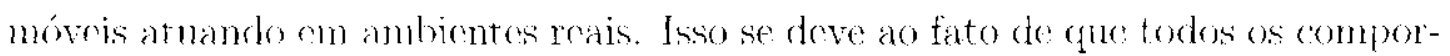

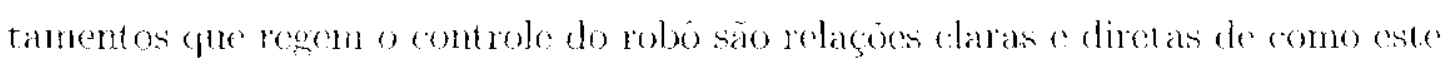

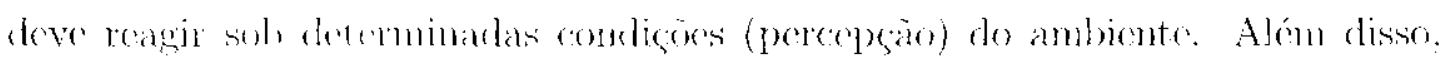
ama rey definides o implententados tais comportanentos reativos. estes poedem servir como base para mat implementagão de sisternas de controle bascados no paradigna hibrido (Arkin 1998). Isto possibilita o robo a realizar tarefias mais complexas. comm por exemples, explorar e criar un mapa do ambiente desvianto

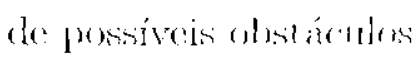

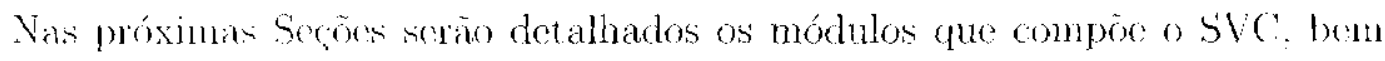

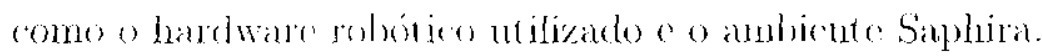

\subsection{O Hardware Robótico}

Thete o desemwelvimento do sistema e experinentos foram realizados sob a plataforma do wobo Pioneer I (Figura 4.1) la Activ Hedia Robotics. Este robo

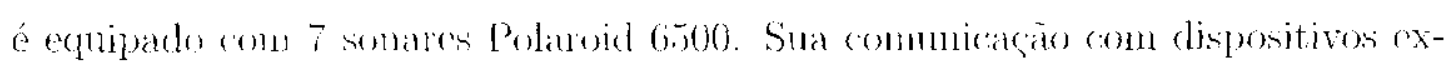
temes (come un computator) pode ser realizada at ravés do rádio o da interface R.S- 232.

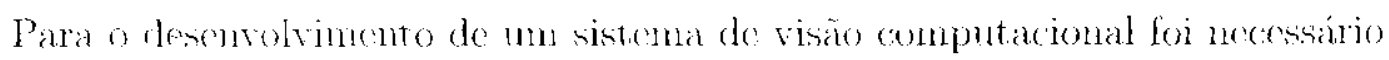

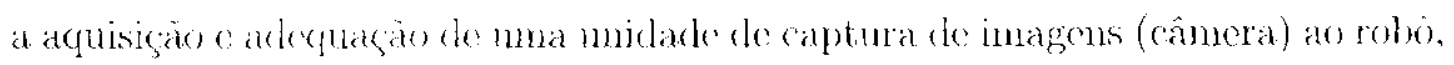

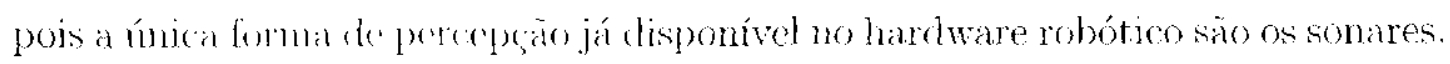




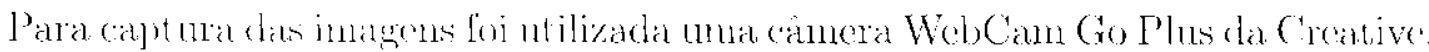

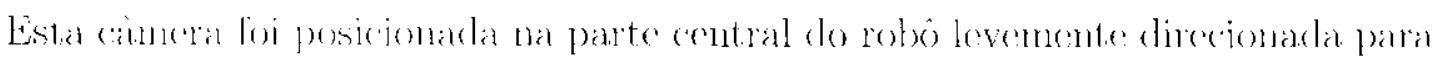

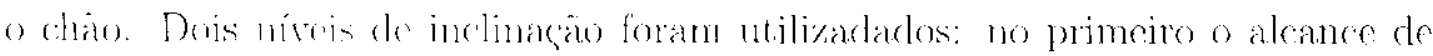

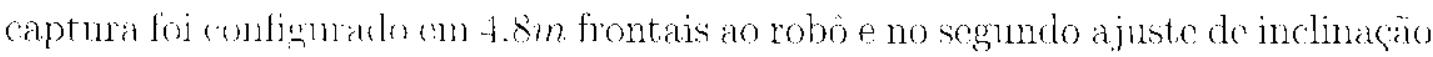

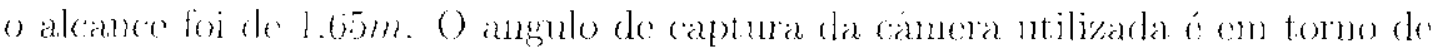
$4 l^{\prime \prime}$

\subsection{O Ambiente Saphira}

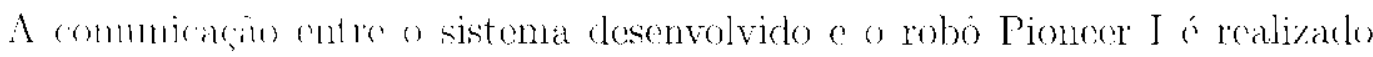

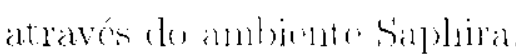

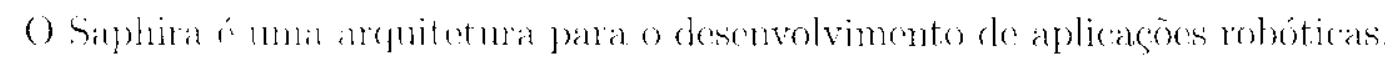
descuvolvido a mint isto pelo Artificial Intelligence Center do Stanfort Researeh

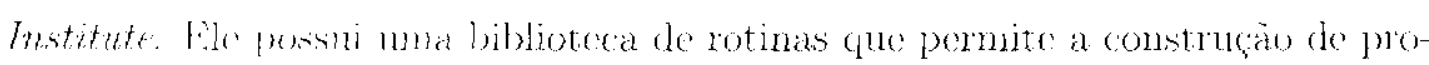

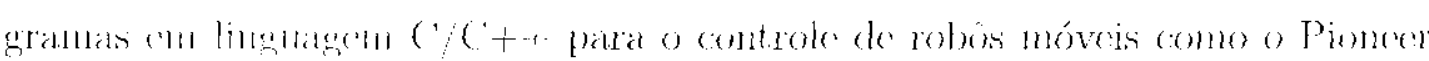

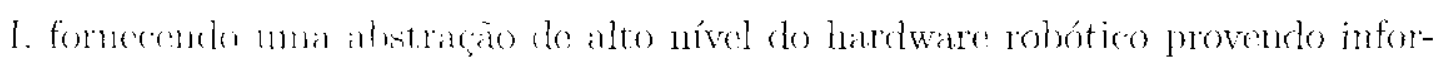
maçós somominis. wmo leituras de somares o encoders o recebendo comandos

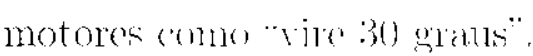

\subsection{A Interface}

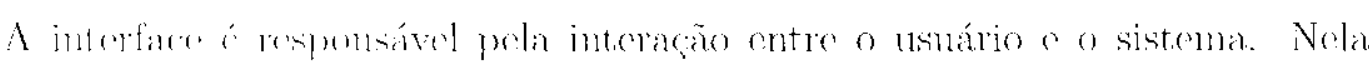

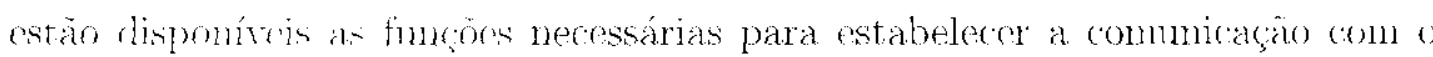

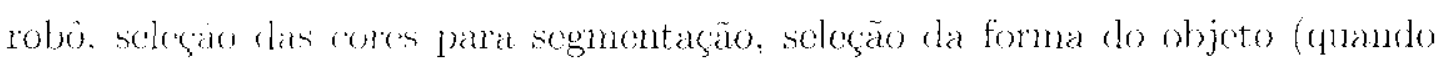

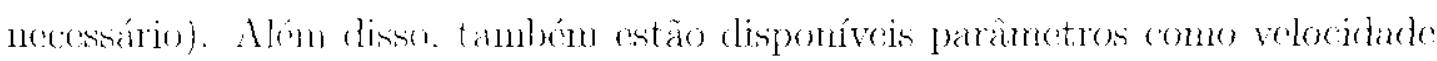
máxinat de tranklavio e rotaçò.

\subsection{Módulo de Visão}

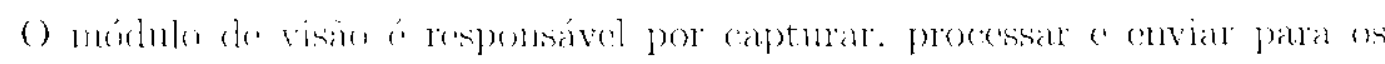

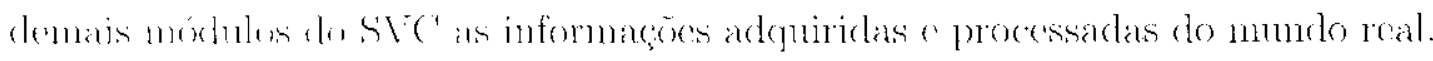
De conta forma. " móslulo de visâo alla como mu tradutor que recebe como entrada un (flartwe do ambiente (formado por an conjunto do poutos) o gera

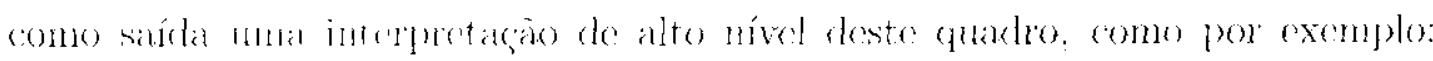

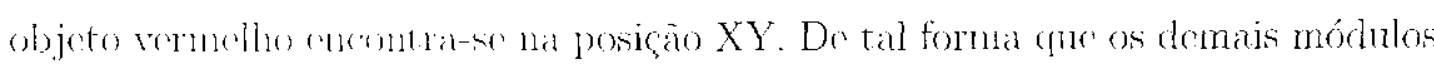

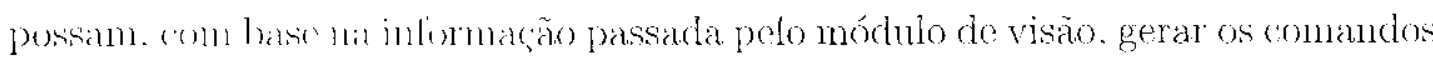

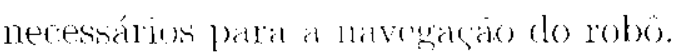

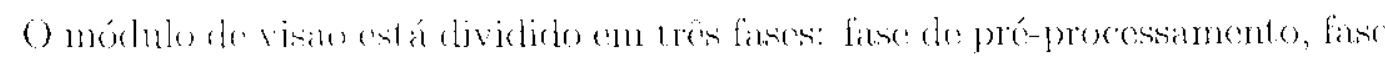

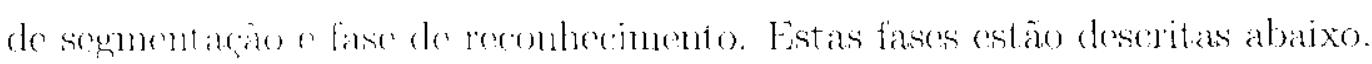




\subsubsection{Pré-Processamento}

A primeina fine a responsanel pola captura dos quadros (imagems) a partir da

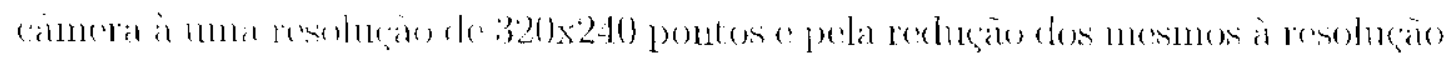

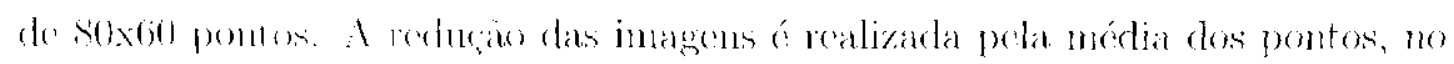

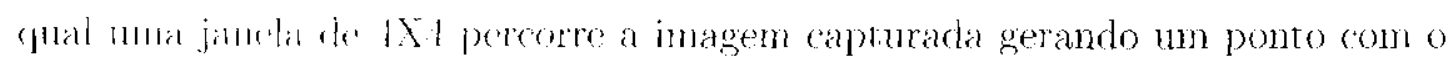
valor módio dos lo ponnes presentes na janela.

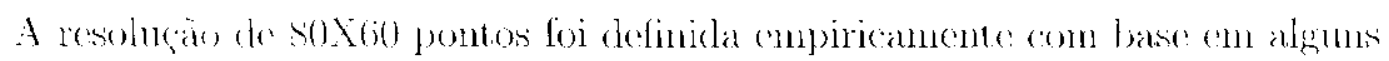

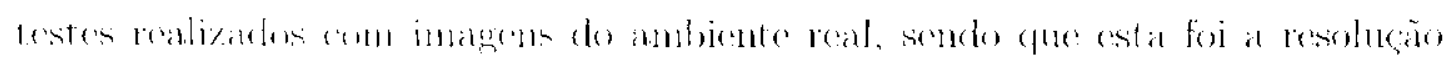

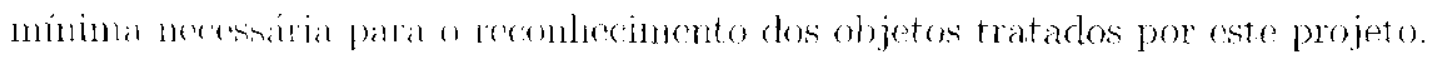

\subsubsection{Segmentação}

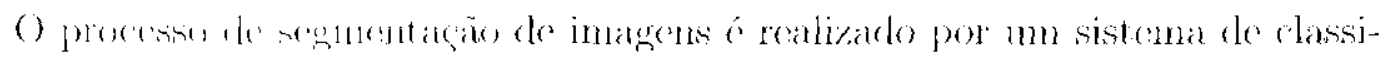

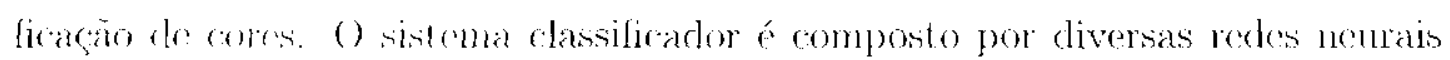

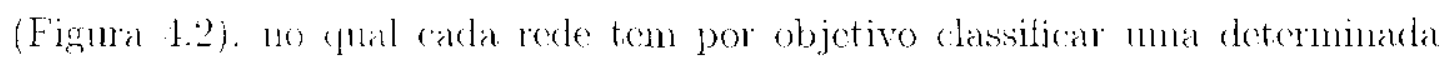

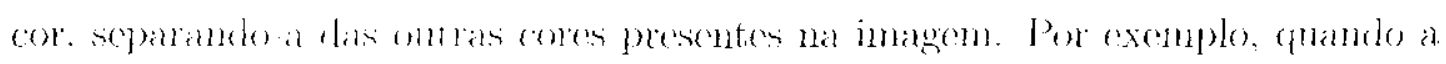

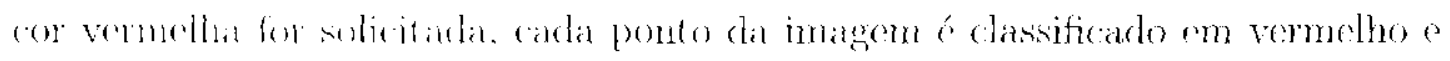

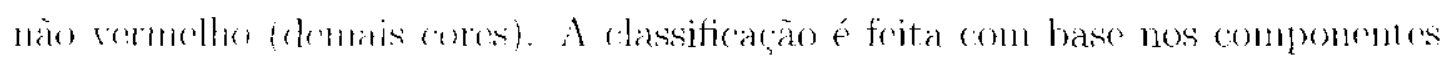

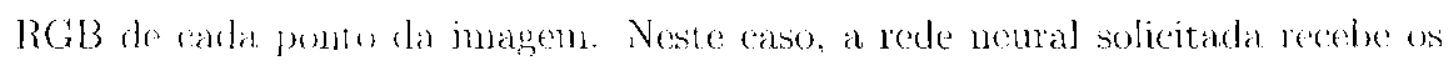

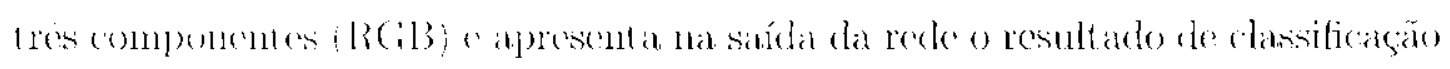

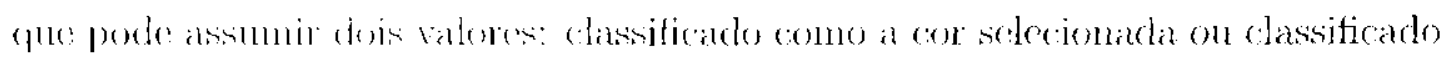

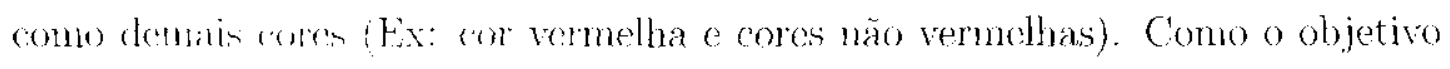

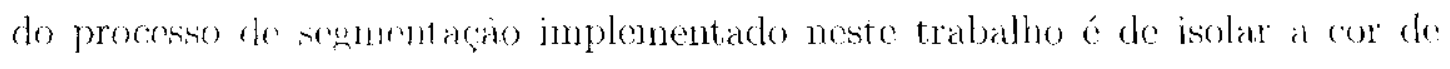

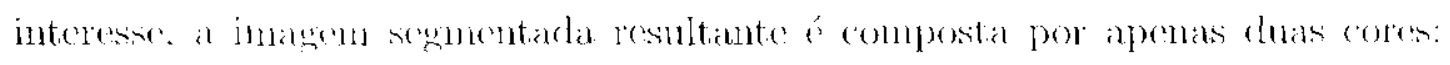

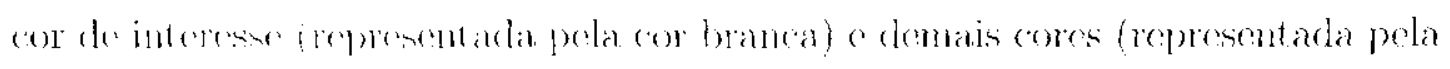
(a) protial.

Tambóm lia innplementado junto com o procosso de segmentagäo, un filtro

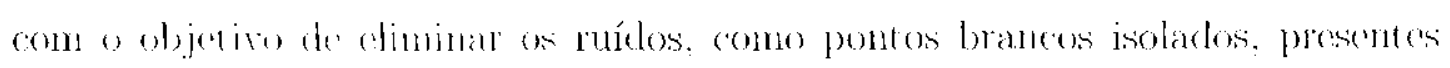

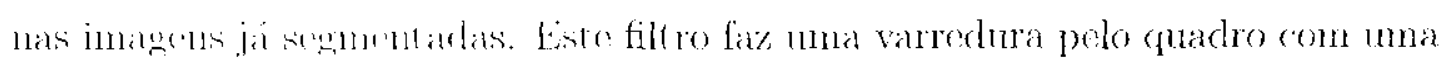

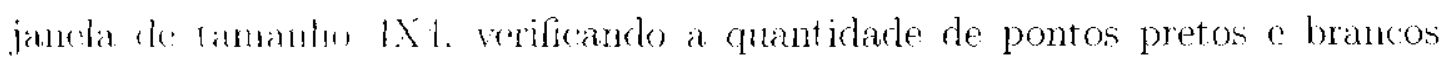
presemes nesta janta. Onando a quantidade de pontos pretos é igual on superion

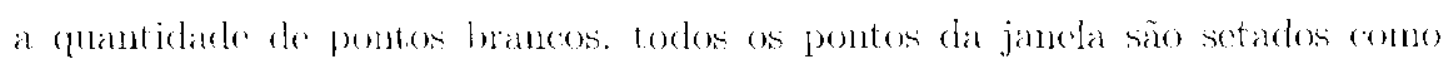

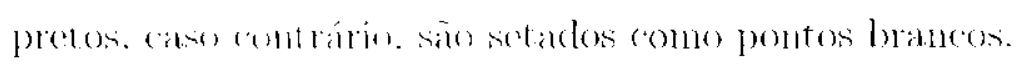

\subsubsection{Reconhecimento}

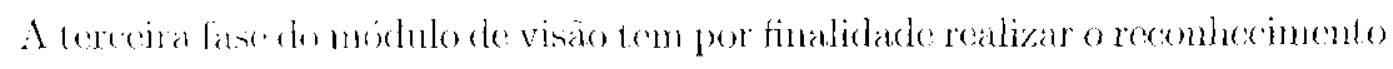

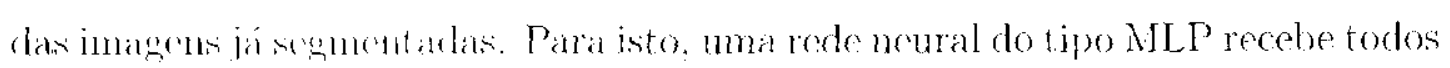
os ponnos quo comstitum a mangem segmontada em suas entradas e informa como 


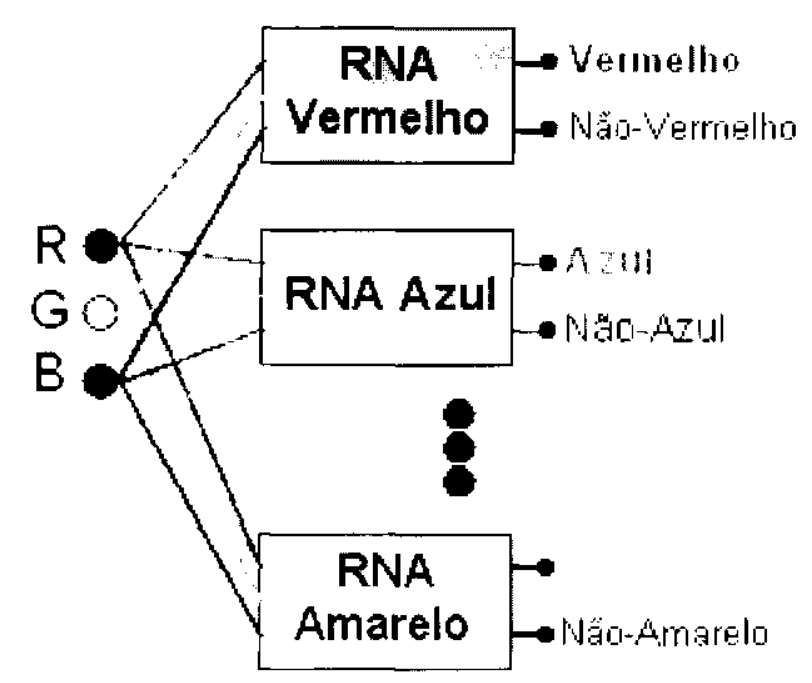

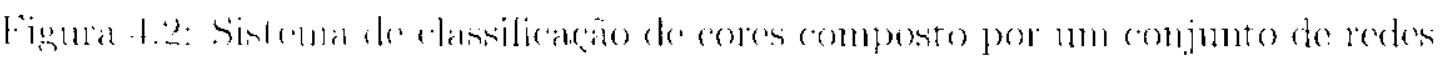

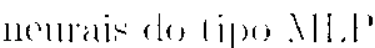

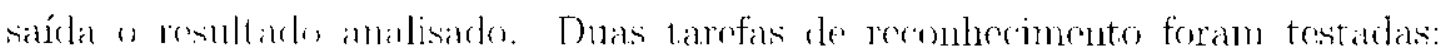

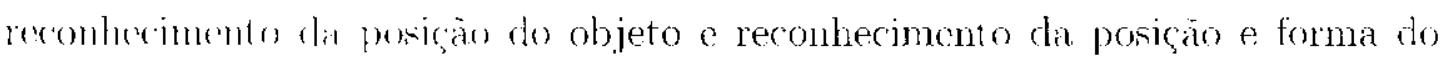
objeto.

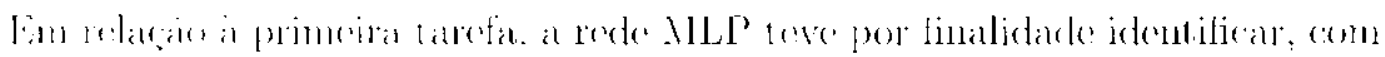

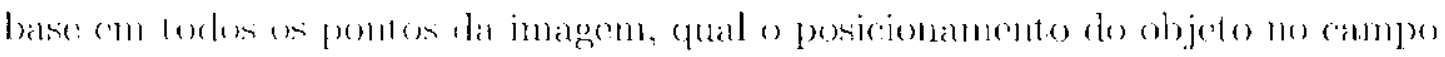
visual. Fata tarefin foi inplementada seguindo duas metodologias diferenciadas

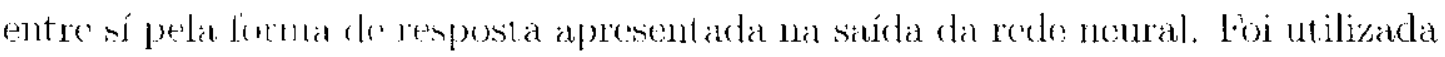

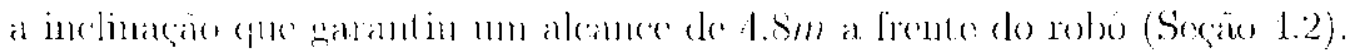

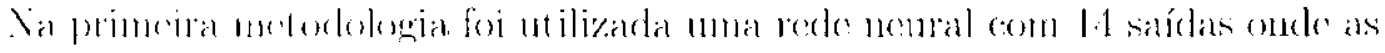

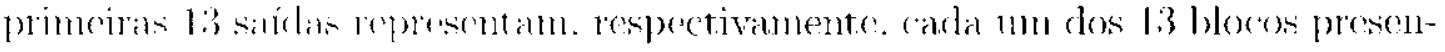

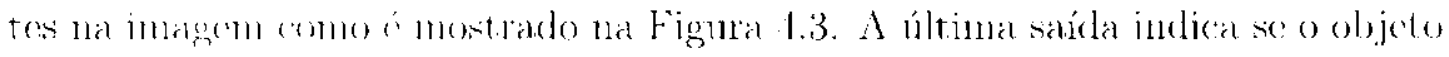

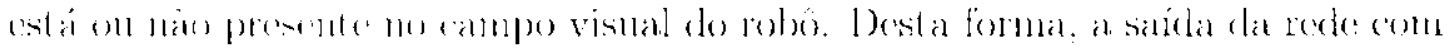

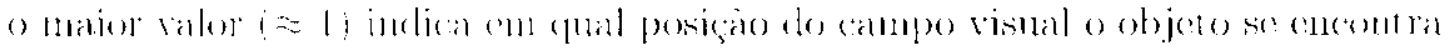

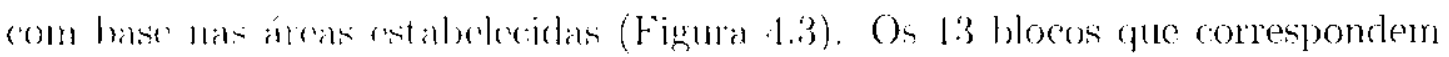

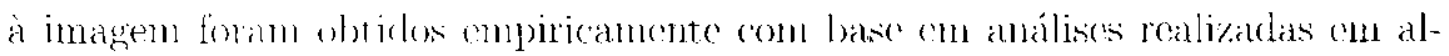

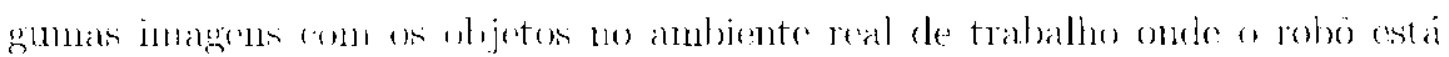
insoriclus.

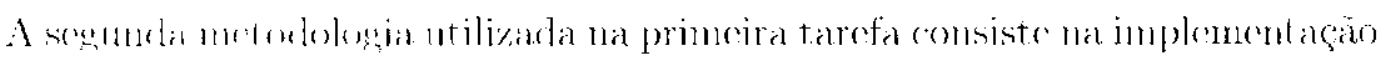

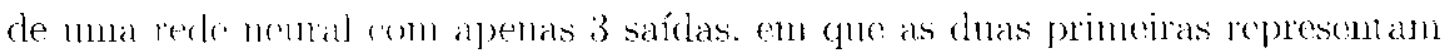

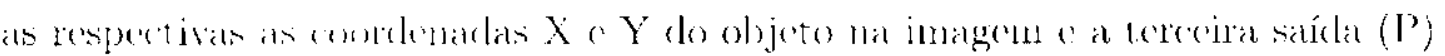

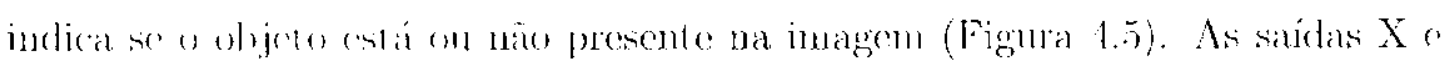

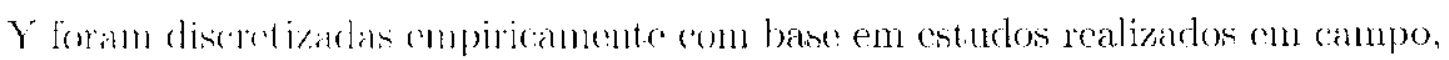

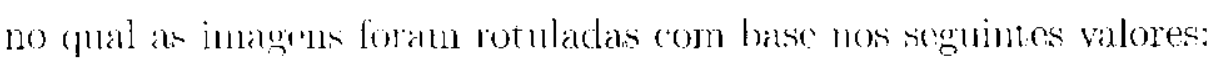




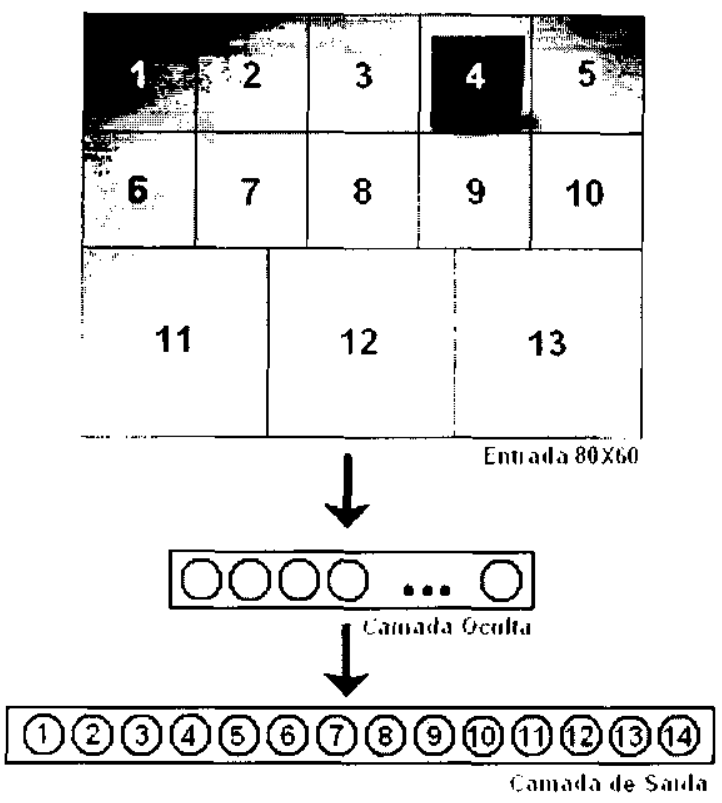

Fingura l.3: R.MA para identificação da posiçăo do objeto (1)

- $x:(1.1) \cdot(1.1 .19 .2 .+\ldots \cdot 1.0$

- $Y: 11.0 .0 .1 .19 .2 \ldots .1 .11$

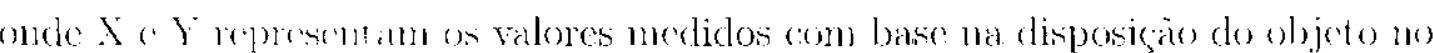

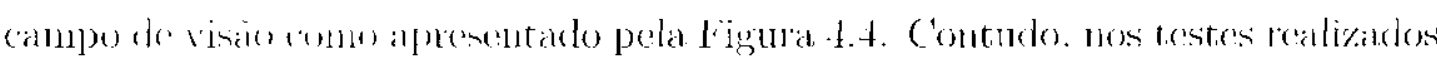

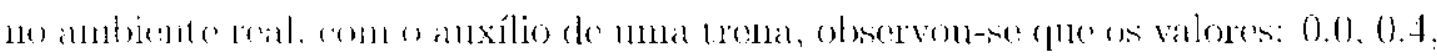

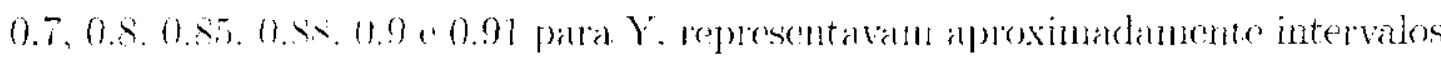

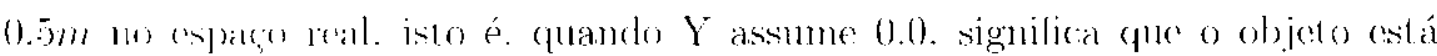

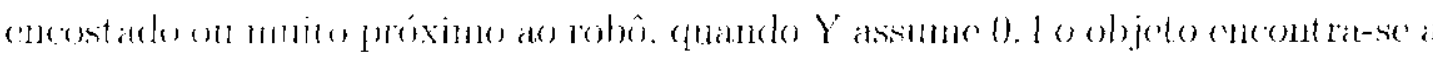

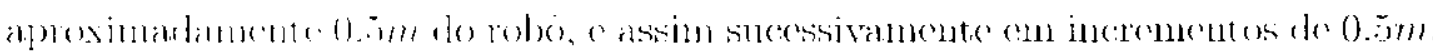

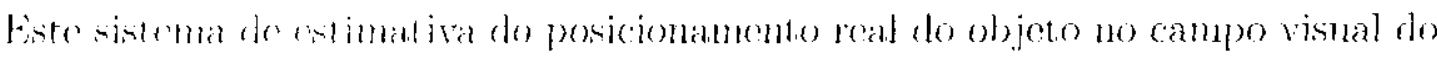

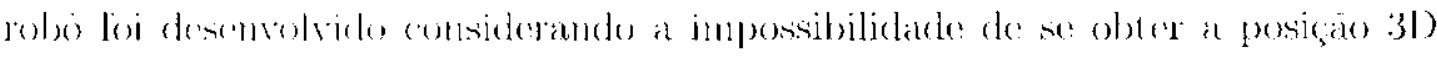

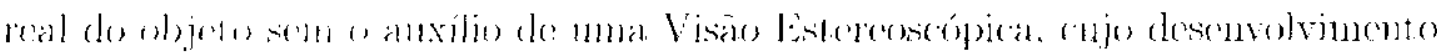

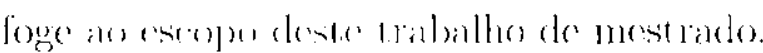

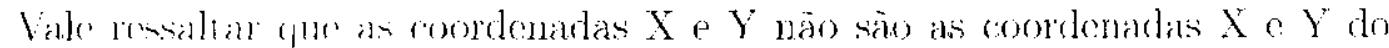

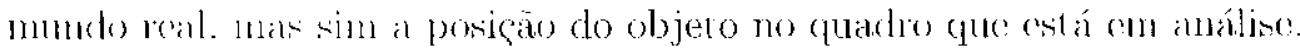

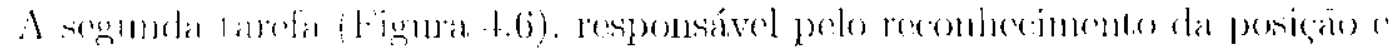

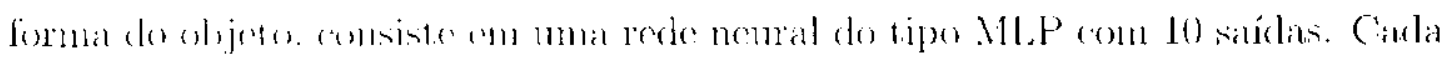

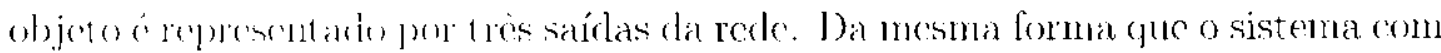

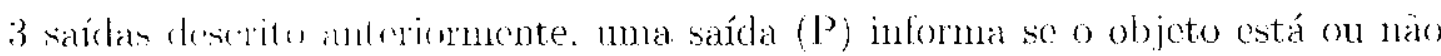

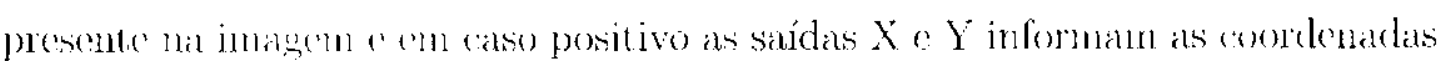

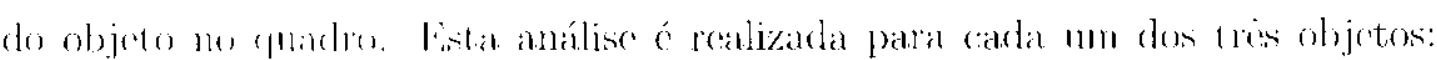




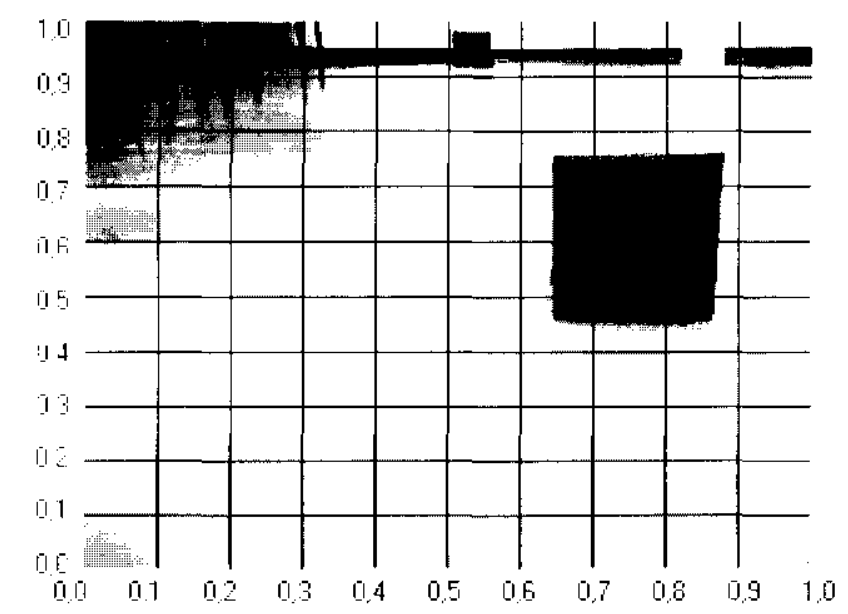

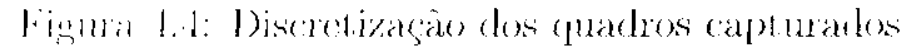

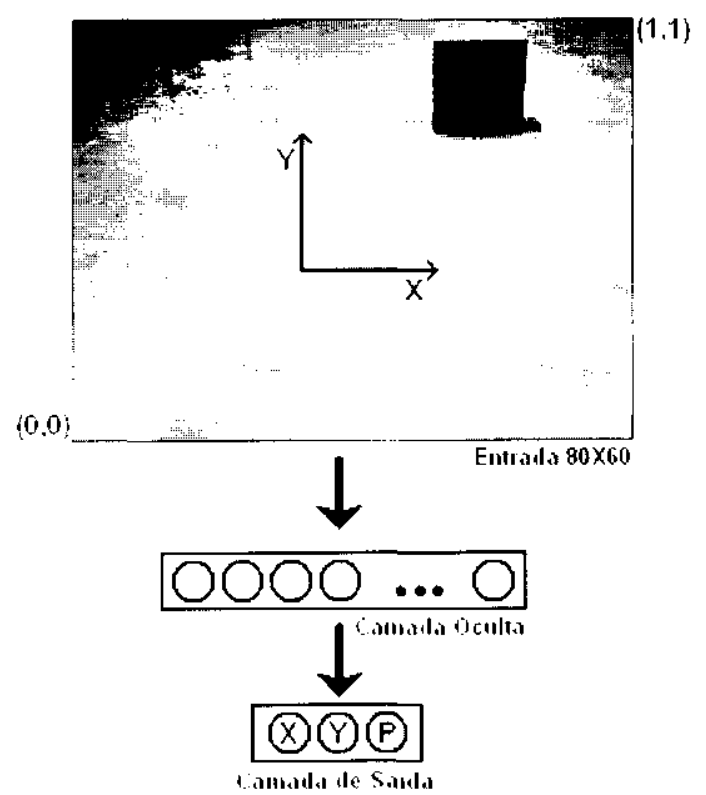

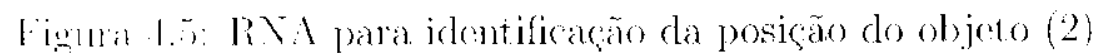




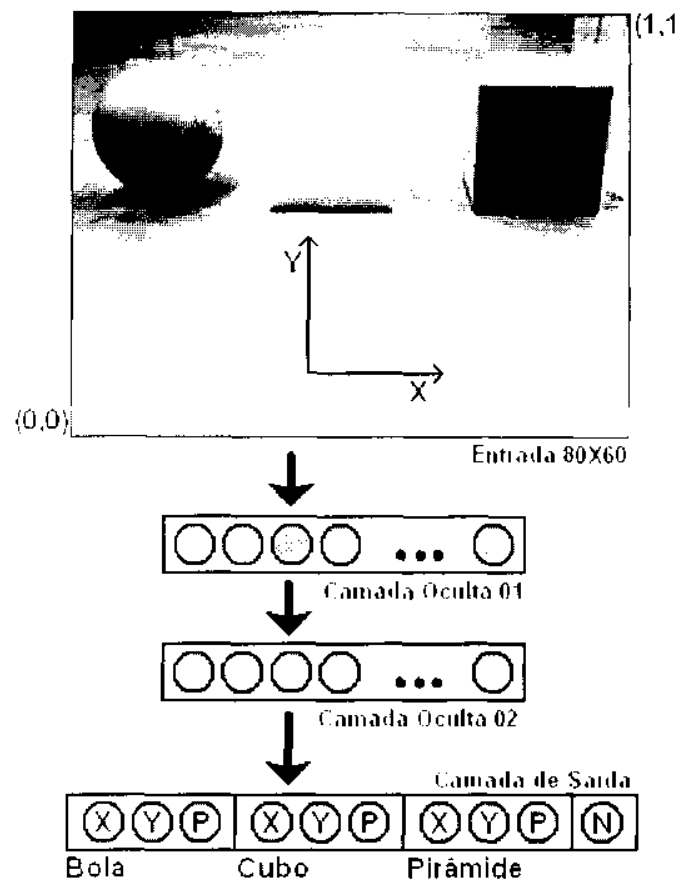

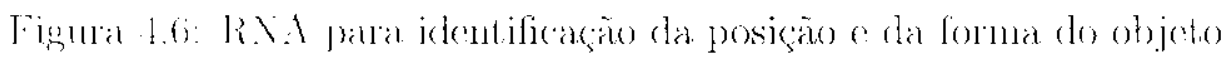

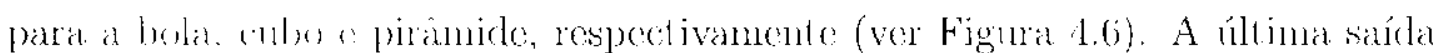

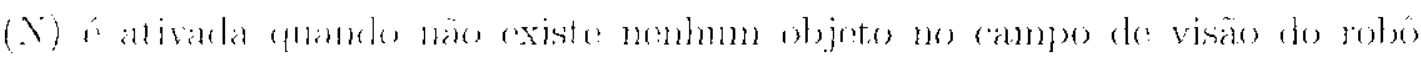
Vale ressallan (une menhunn pré-processamento adicional é realizado na tarefa de identificaçäo da foma do objeto, como por exemplo: centralizaçäo do objeto.

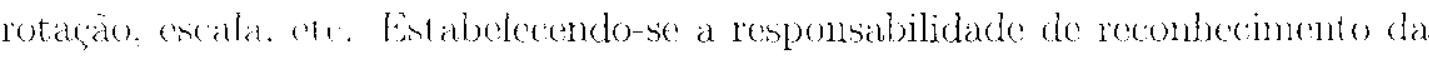

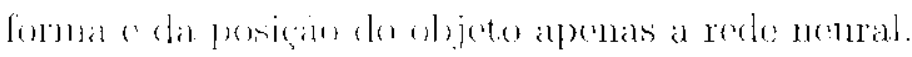

Nesta tarefa foj ut ilizada a inclinação para um alcance do $1.65 \mathrm{~m}$ a frente do robồ (Sogäo 4.2). conviderando que, com a qualidade da imagem cue está sendo tratada. Licaria innpusived reconlecer um objeto a distancia maior que a detinicla (1.65m).

\subsection{Módulo de Controle de Navegação}

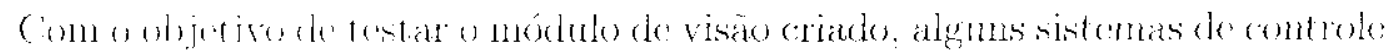

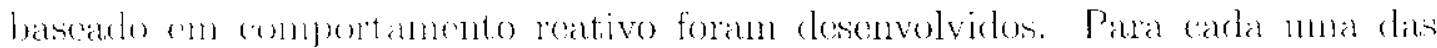

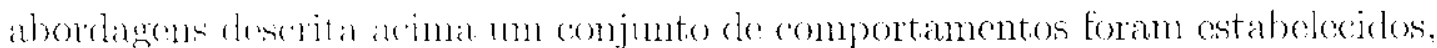
de tal forma gur o antrolador desenvolvido auacitasse o robó a persoguir un

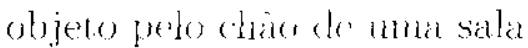

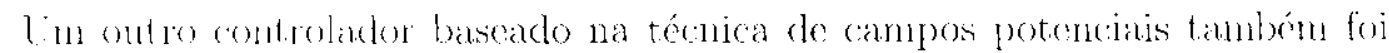
desemvolvide com o oljotivo de capacitar um robô a llavegar de forma andomoma por unn anbirinte denviando do obstáculos como paredes e sendo atraído por uma 


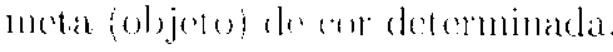

\subsubsection{Controlador 1}

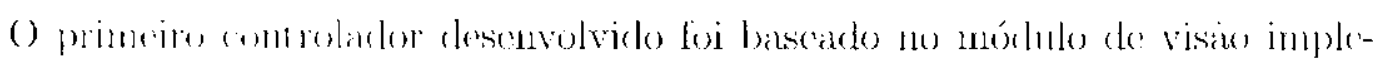

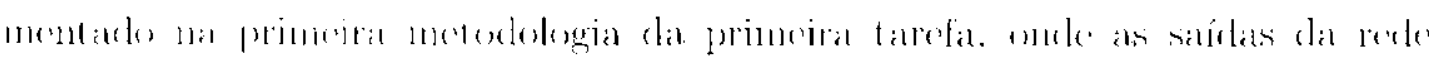

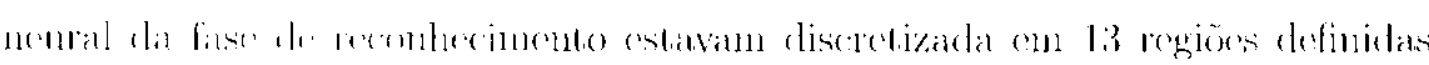

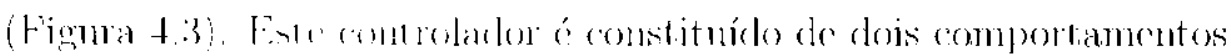

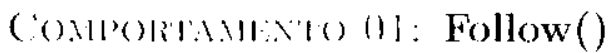

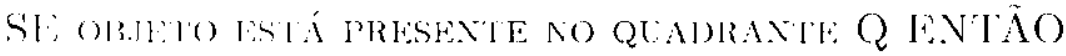
VHIOCHADE DE TRANSLAÇOO - V

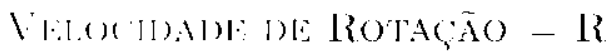

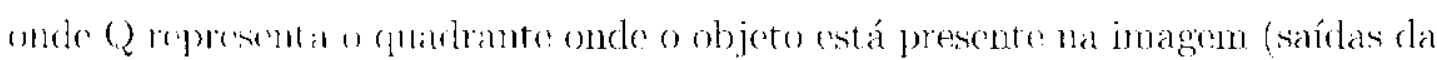

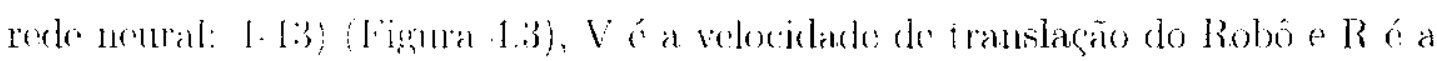

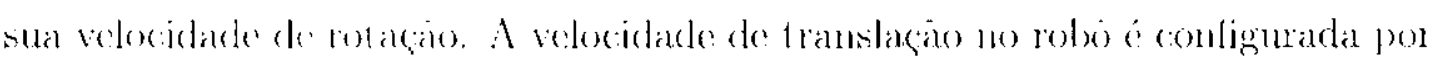

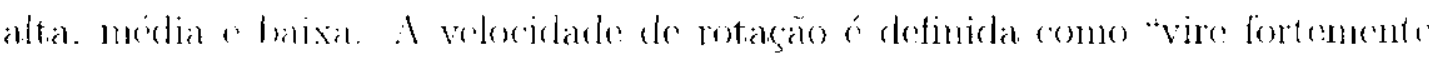

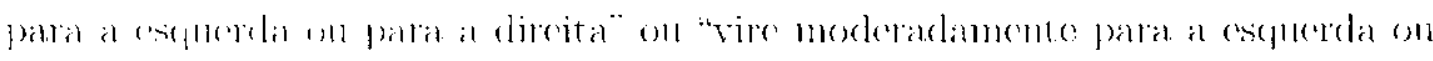

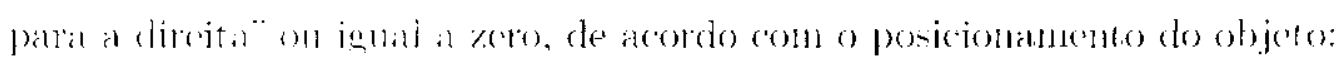

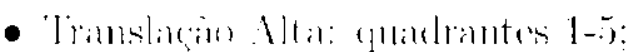

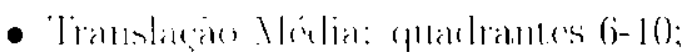

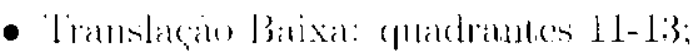

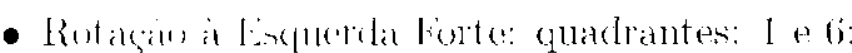

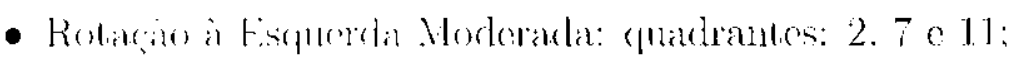

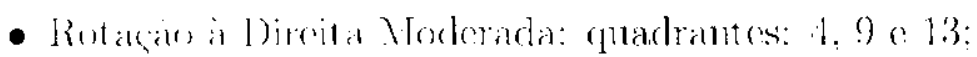

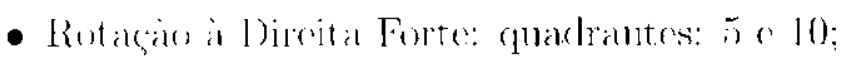

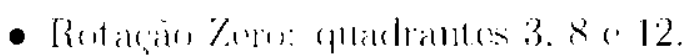

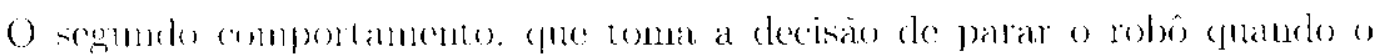

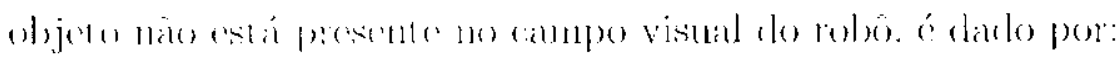

(ONPORTINI:NT) 02: $\operatorname{Stop}()$

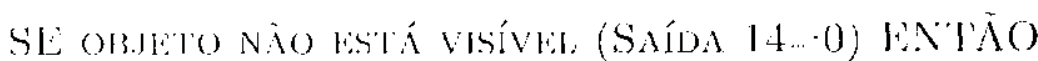

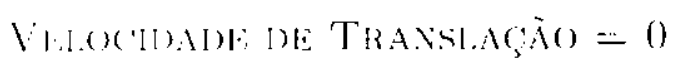


VHOCOLNDE DE ROTAÇAO $=0$

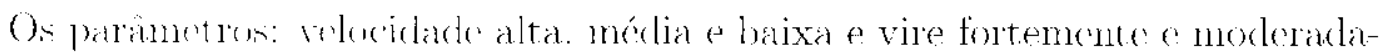
mente form configuratos com base em experimentos realizados no anbionte real c) representant:

- Vulocidarde tha: lasm/s

- Velocistiedr Vúrlin: $10 \mathrm{~mm} / \mathrm{s}$

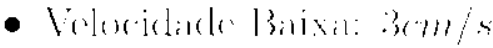

- Vire Fortemente: t100mpraus/s

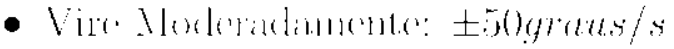

\subsubsection{Controlador II}

() segunde cuntwhartor foi inplementado com base nos dados recebidos do sis-

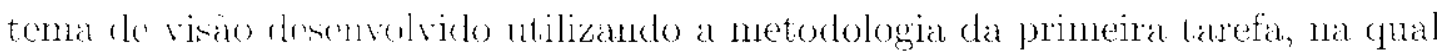

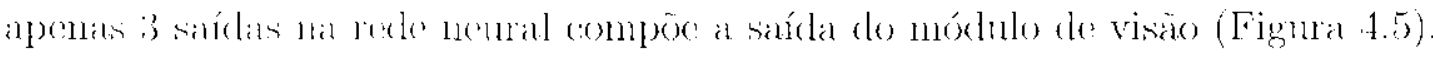

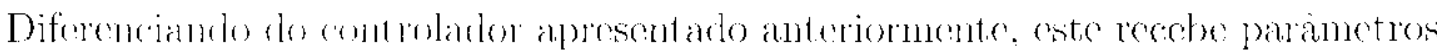

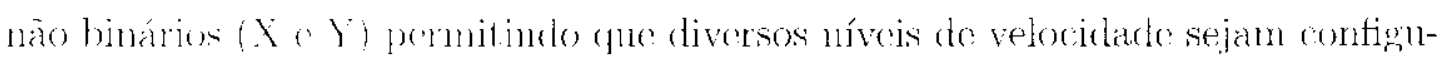

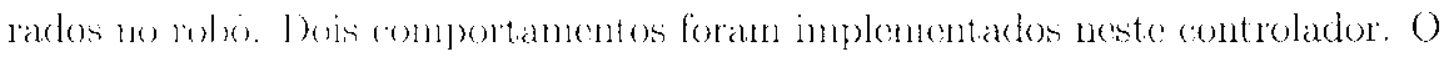

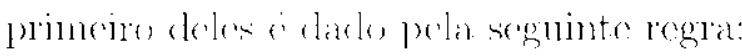

Commommanto 0): Follow()

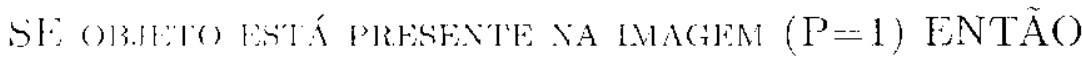

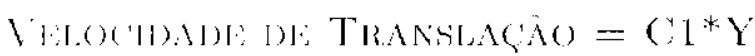

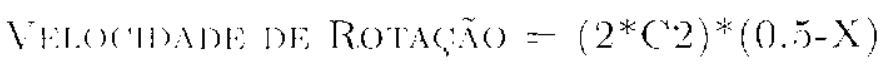

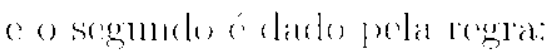

CoMPORTAMENTO (2): Stop()

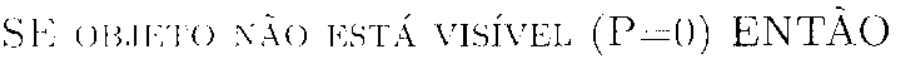

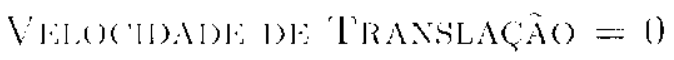

VI:L(NIDADL: D): ROTACNO $=0$

onde: ('1 o (2) san romblantes empíricas que defincm as velocidades máximas

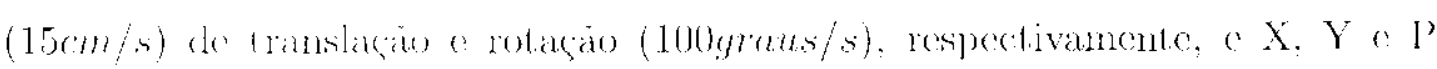

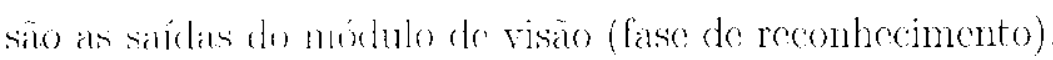




\subsubsection{Controlador III}

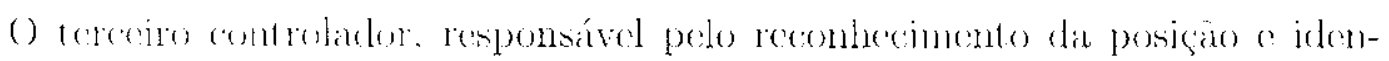

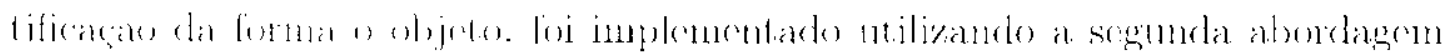

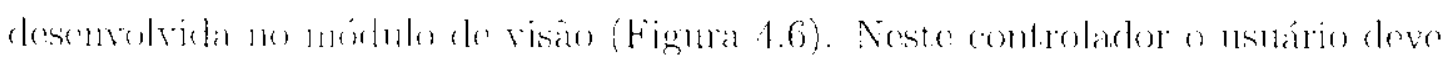

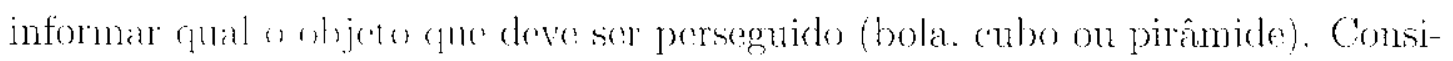

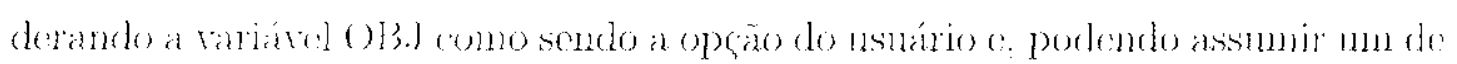

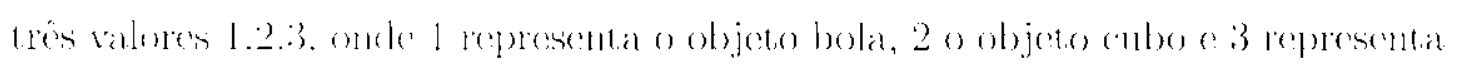

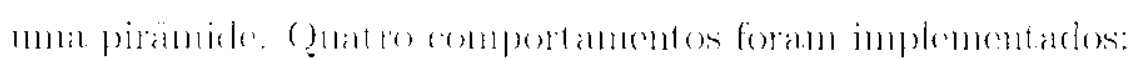

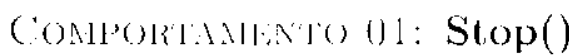

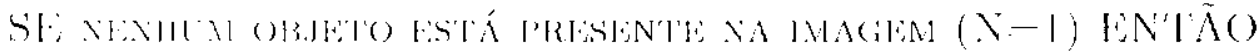

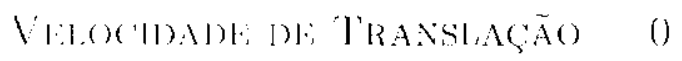

VHLOCIDADE: DE ROTACÄO - ()

Contentiandinlo ()2: Followl3all()

SE: (O)B.I = I) H (P[13OLA] - I) EN

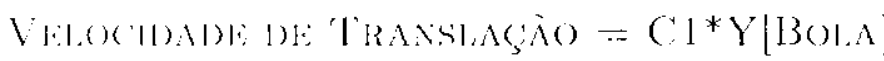

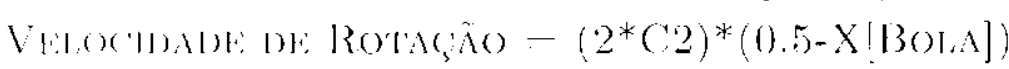

SHNAO

VHOCMDDE DE TRANSIACAOO = 0

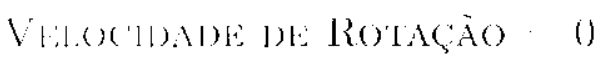

(omerandine (13: FollowCube()

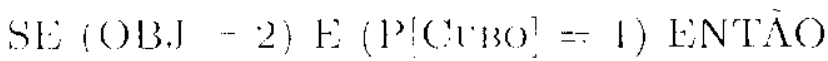

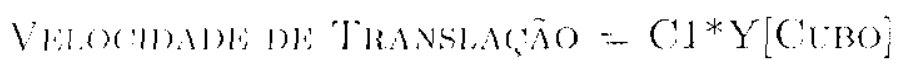

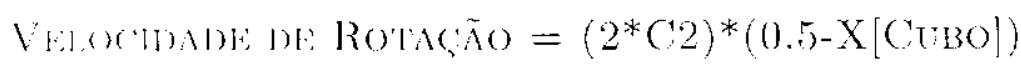

$\operatorname{Sin}()$

VHLOCHOADE: DOE TIRANSIAÇAO=0

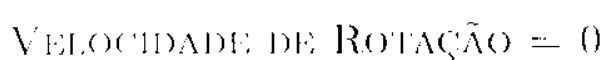

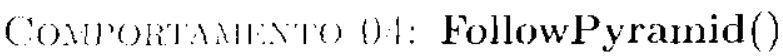

$S E(0) 3 . J-3) E($ PPIRAMLOE] = 1) ENTÃO

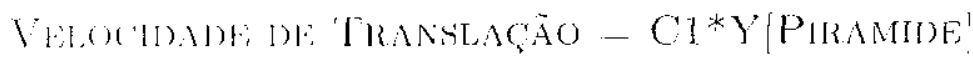

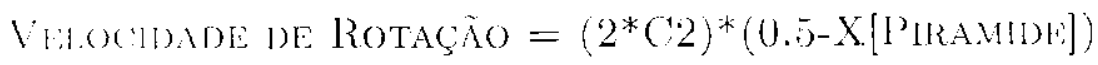




\section{$S F N A O$}

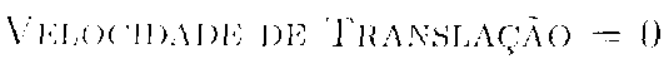

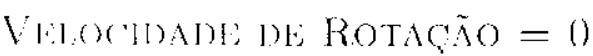

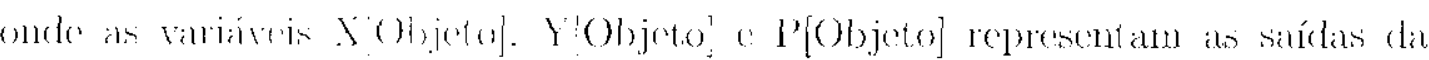

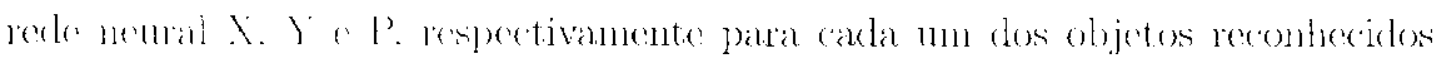

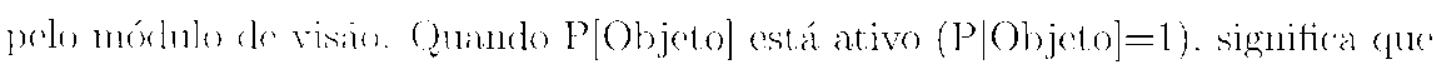

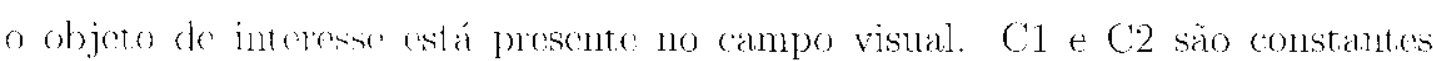

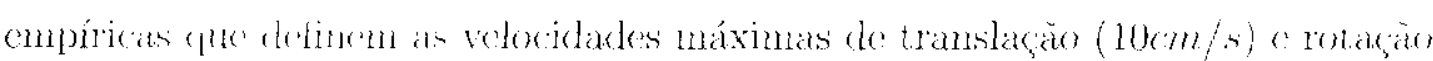

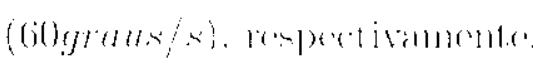

\subsubsection{Controlador IV - Aplicação de Campos Potenciais}

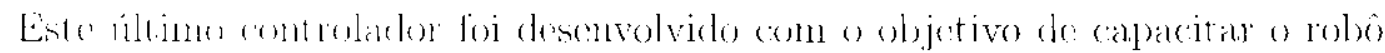

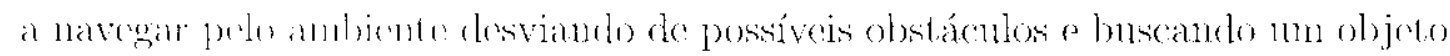

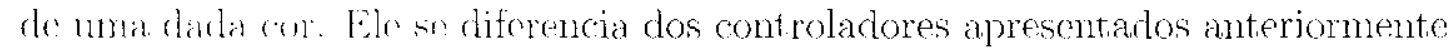

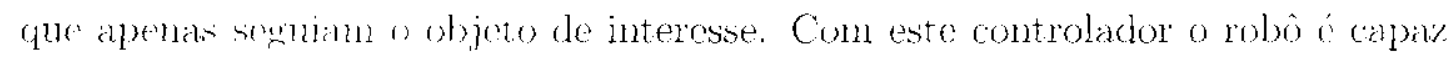

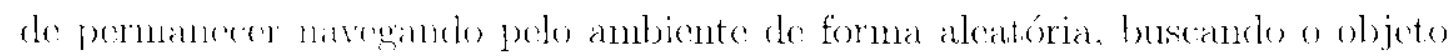

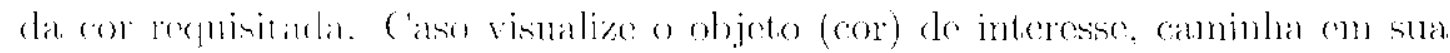
dircecion).

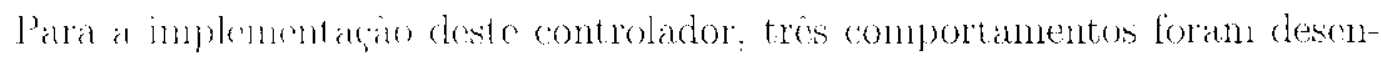

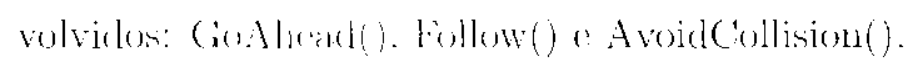

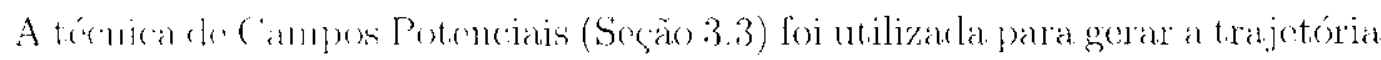

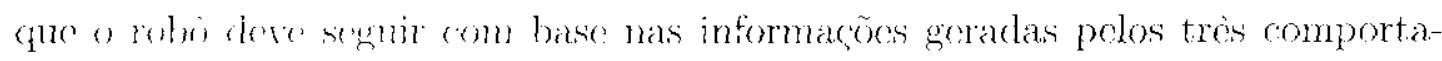
mentos.

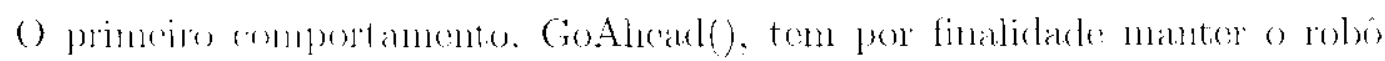

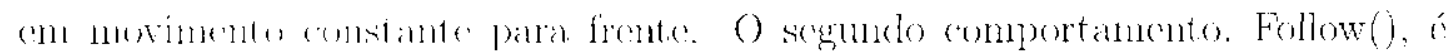

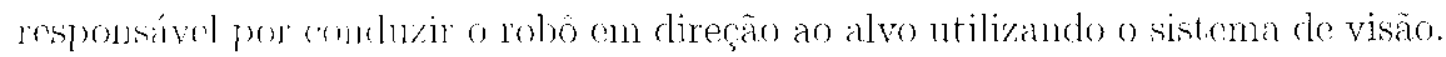

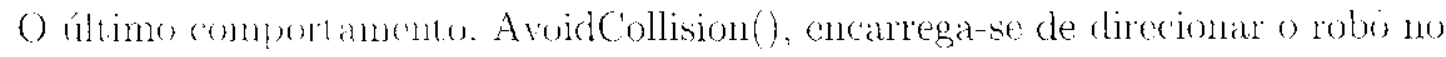

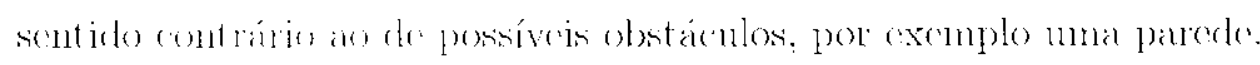

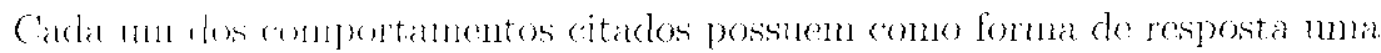

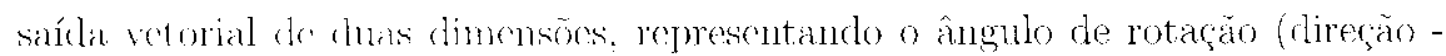
$\left.\theta_{p}\right)$ e magnituke $\left.\mid \vec{F}\right)$.

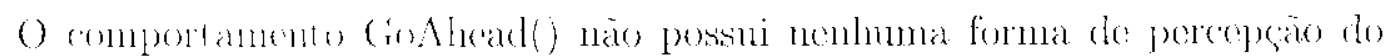

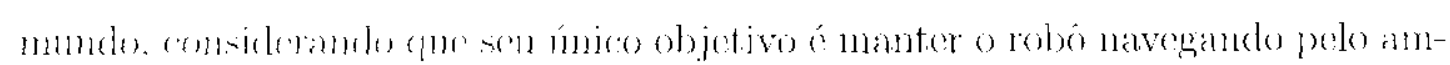

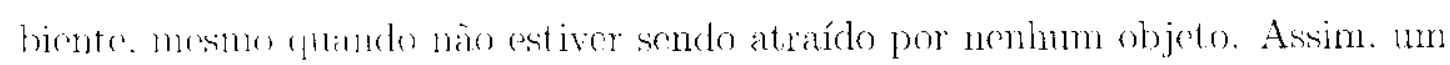
vetor com diregan e magnitude constante $\left(C_{y}\right)$ pode ser nulizado para representar o comportannente) (anmber nutiforme). 


$$
\begin{aligned}
& \left|F_{y}\right|=C_{g} \\
& \theta_{F_{y}}-0
\end{aligned}
$$

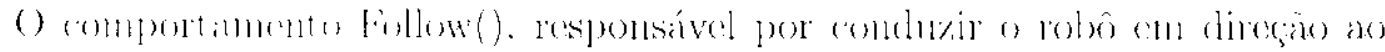

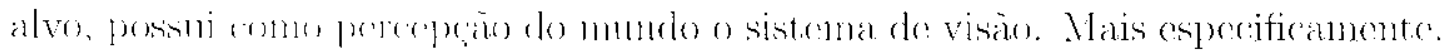

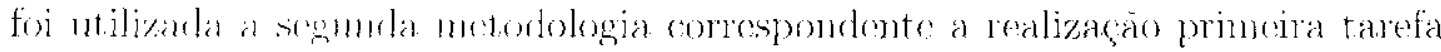

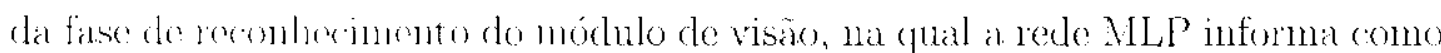

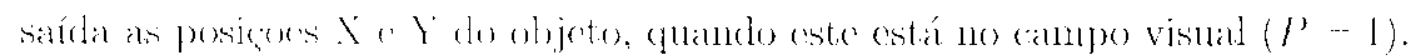

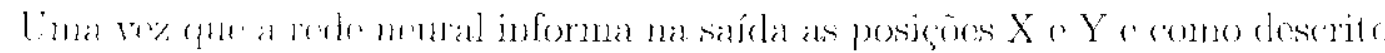

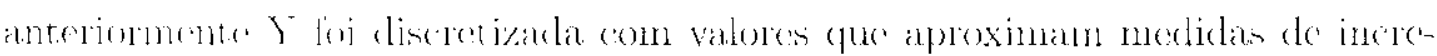

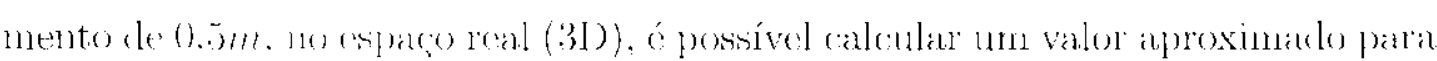

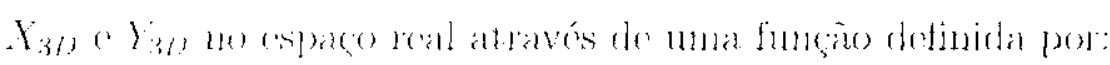

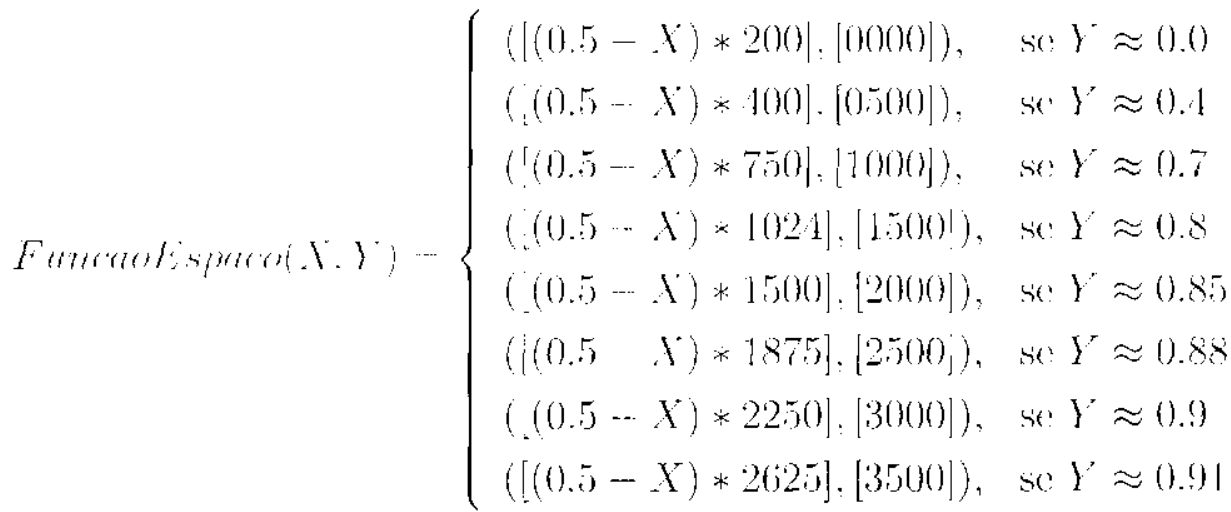

onde esta funcio recter como parametro os valores $\mathrm{X}$ e $\mathrm{Y}$, obthidos a partis da

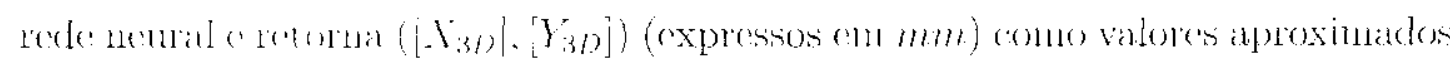

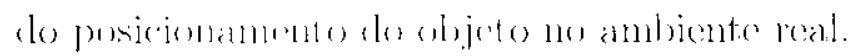

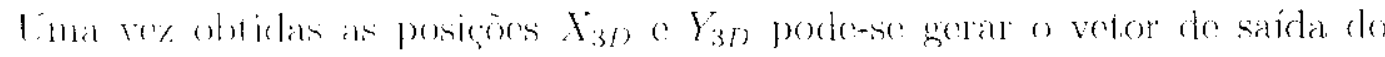
comportansmo follew (1.

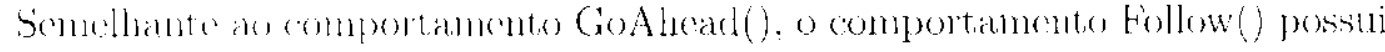

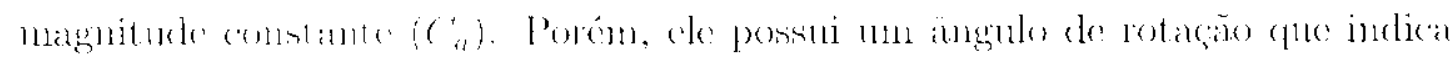

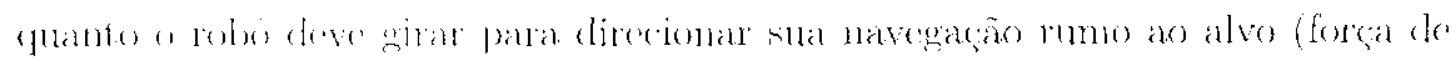

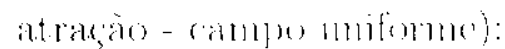

$$
\left|\overrightarrow{F_{a}}\right|-C_{n}
$$




$$
()_{\overrightarrow{F_{i}}}=\arctan \left(X_{3 b}, Y_{31}\right)
$$

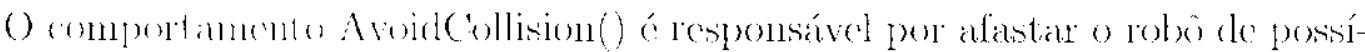

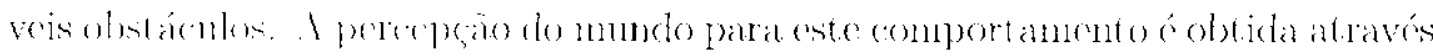
dos somares do roulu. (omsiderando que o robô está equipado com 7 somares. carla

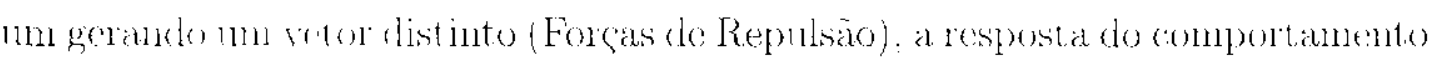

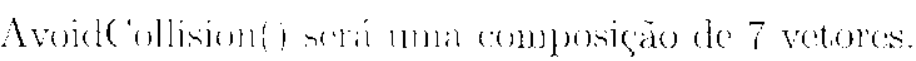

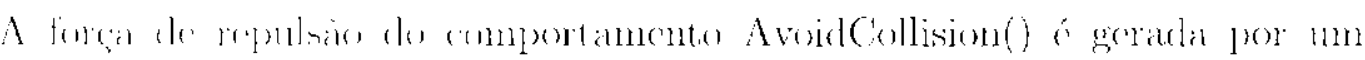

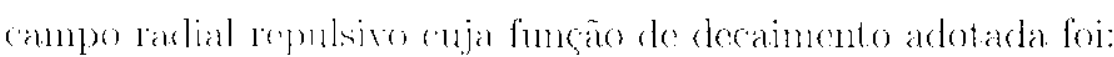

$$
\left.\left|\overrightarrow{F_{r i}}\right|=(x)((-D)+L) / T\right)
$$

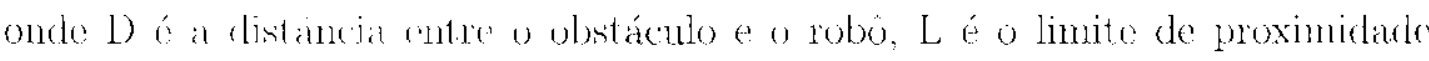

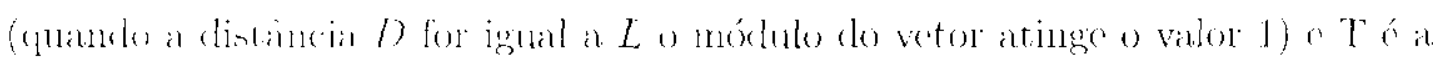

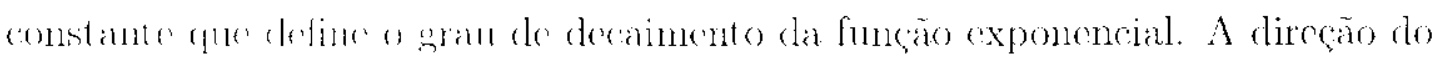

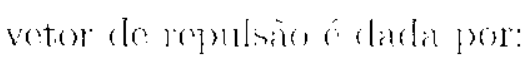

$$
\theta \overrightarrow{F i}-\arctan \left(X S_{i}, \quad Y S_{i}\right)
$$

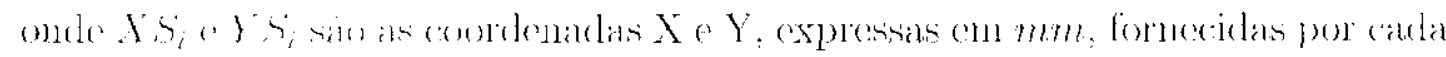

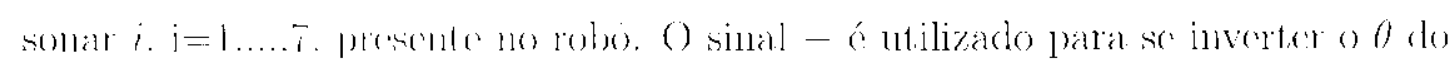

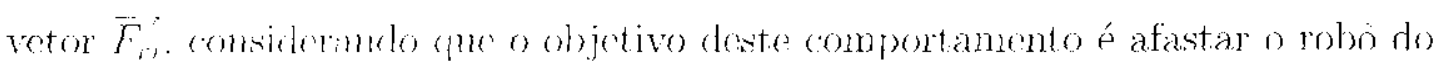
alvo reterectate.

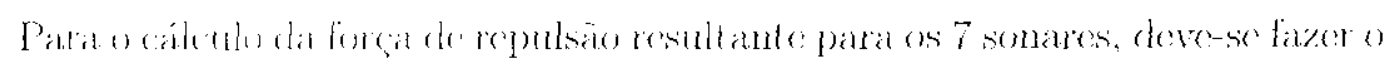

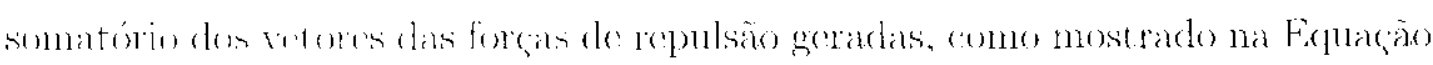
4.8.

$$
\overrightarrow{F_{h}}=\sum_{i} F_{i}
$$

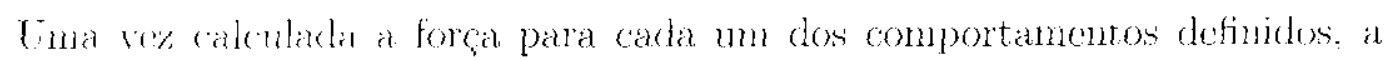

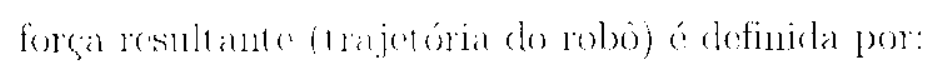

$$
\vec{F}-P_{1} \overrightarrow{F_{G}}+P_{2} \overrightarrow{F_{A}}+P_{3} \overrightarrow{F_{B}}
$$

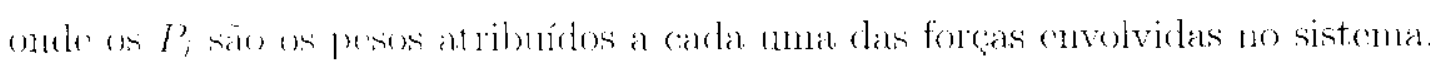
Durante os experimutes (Apresentados no Capitulo 5) os valores de $P_{i}$ foram

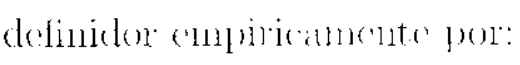

- $P_{1}=0 . \overline{1}$ 
- $r_{1}=1.11$

- $P:=0 . \bar{i}$

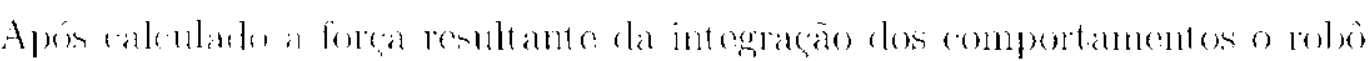

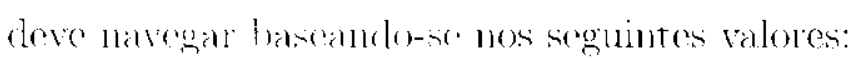

$$
\operatorname{VaT} \mid \vec{F} \text { VHat }
$$

$$
H_{F}=\arctan \left(F_{X}, F_{Y}\right)
$$

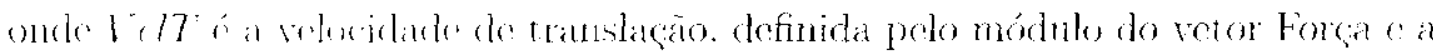

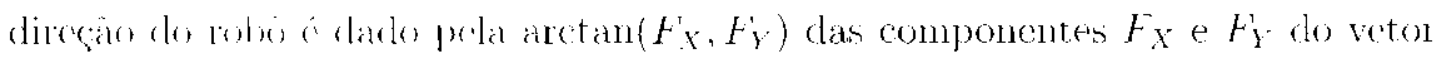

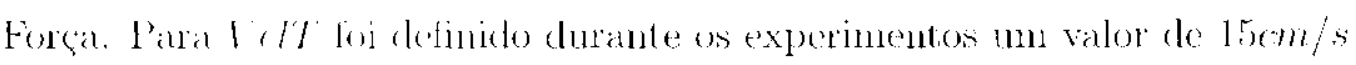

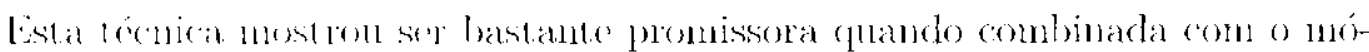
dulo dr vinior desemolvide. Os experimentos e os resultados obtidos em ambientes

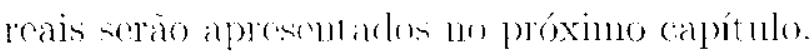




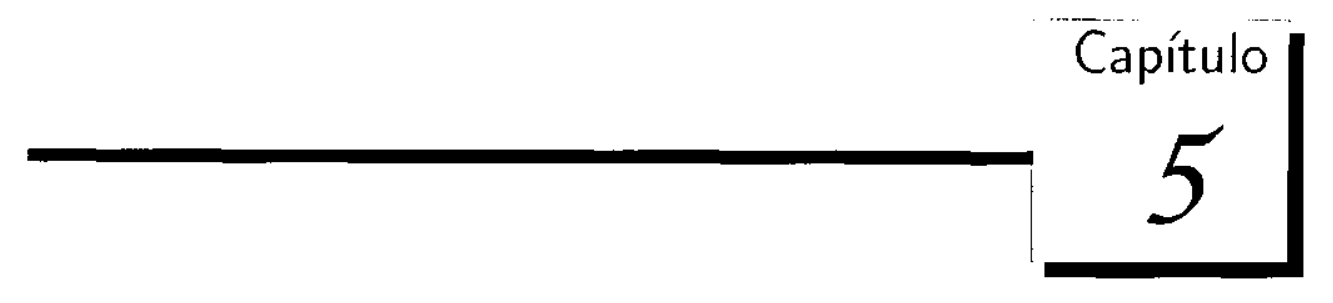

\section{Experimentos}

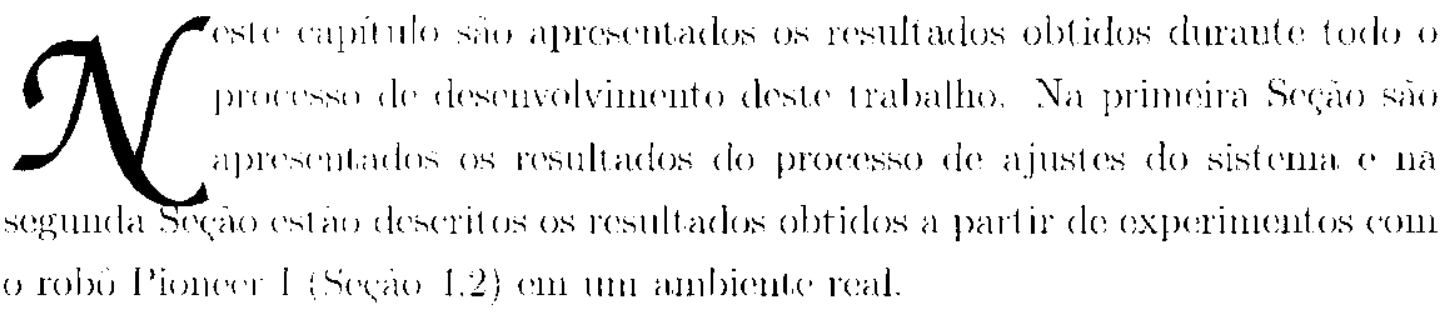

\subsection{Definição dos Parâmetros do Sistema}

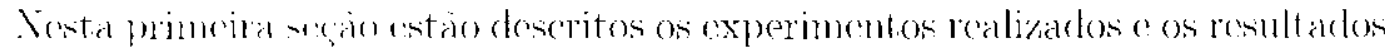

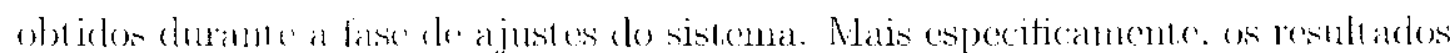

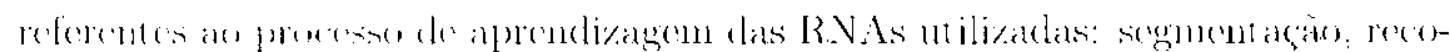

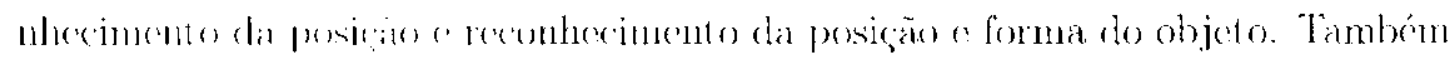

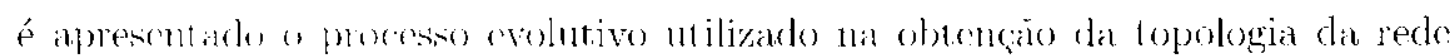

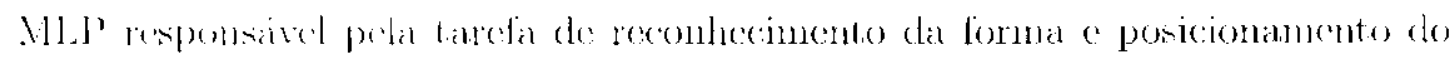
(1).jelus.

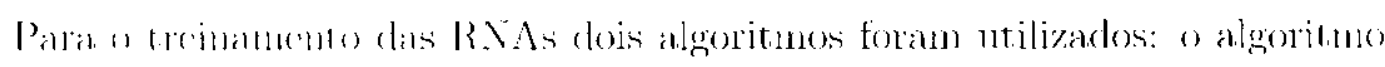

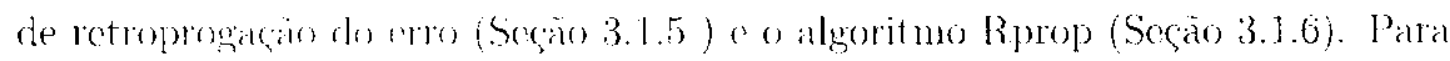

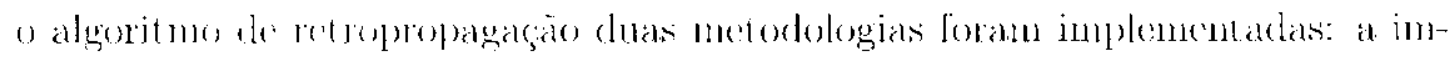

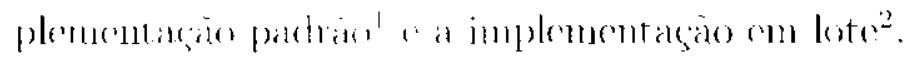

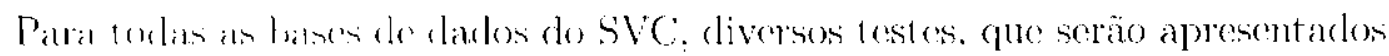
abaixo. foran realizades com o objetivo de enconerar os parametros adeculados

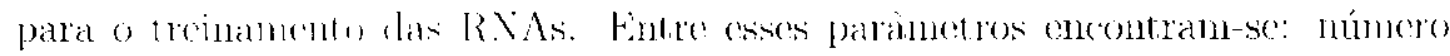

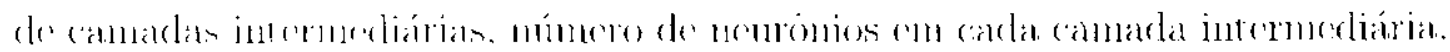

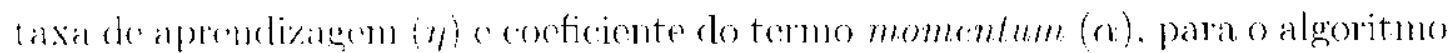

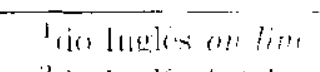

2 do Lnglion baldit 


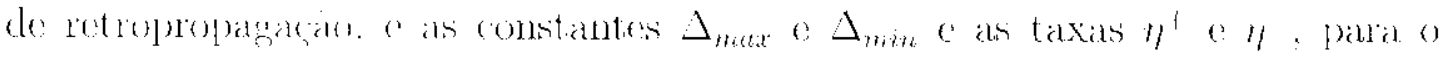
algoritmo) Riprop

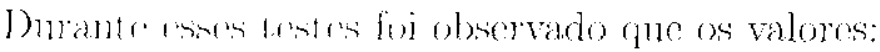

- $11=-0.2$

- $n=0.1$

- $\eta^{\prime}=-1.2$

- $\|=01.5$

- $\Delta_{i m, i, r}=10.11$

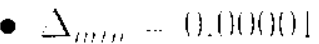

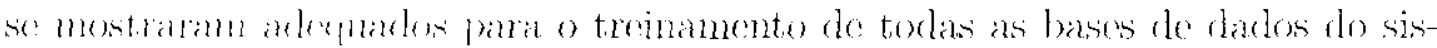

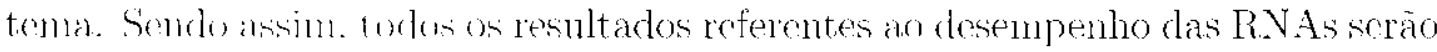
descritos rom base nat utilizaça dosses valores.

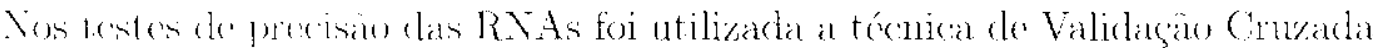

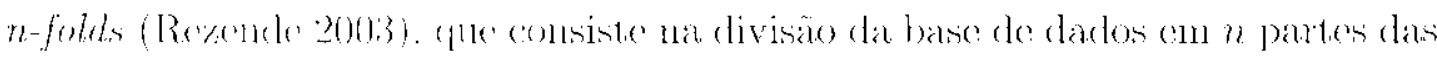

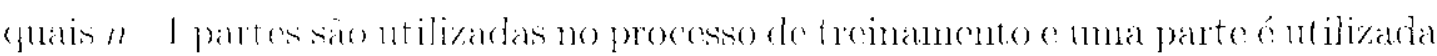

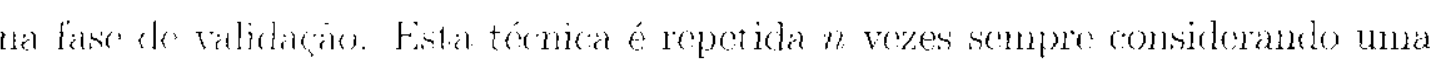

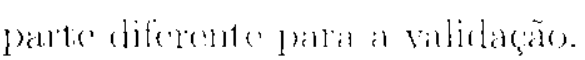

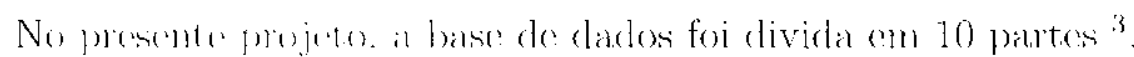

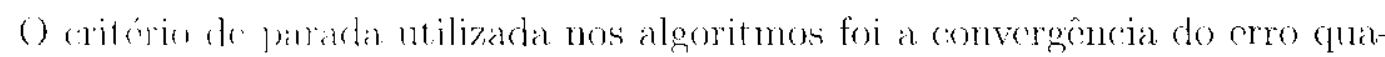
drático médio para comjunto de treinamento a um limiar inferior a $10{ }^{2}$.

\subsubsection{RNA para Segmentação}

Para o tromanumo das reder neurais da lase de segmentação foram montadas

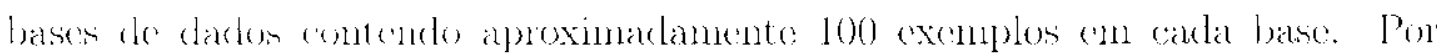

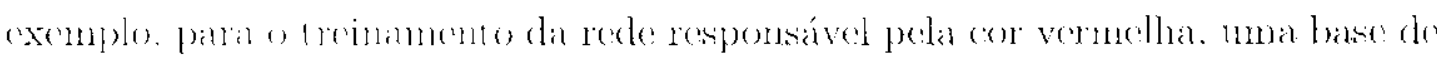

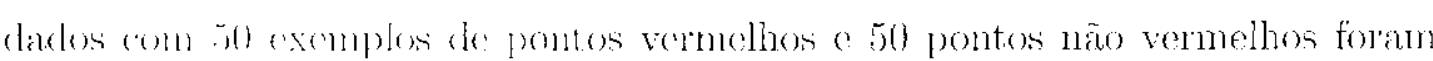
rotulados. Tris come formu consideradas para a tarefa de segmentagào: vermelha, arul o amarala

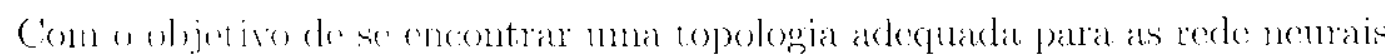
algums tester divielinde se a base de dados em ronjunto de troinamento (80\%) conjunte de validincio (20)/ foram realizados. Nestes testes foram observados

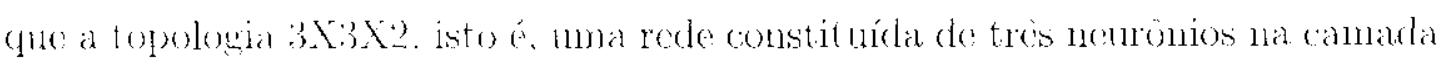

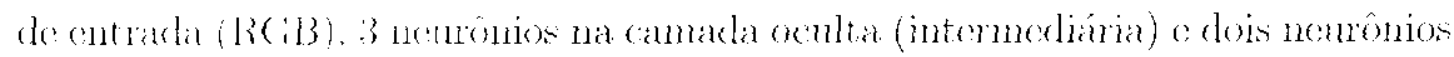

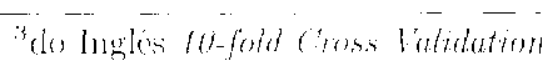




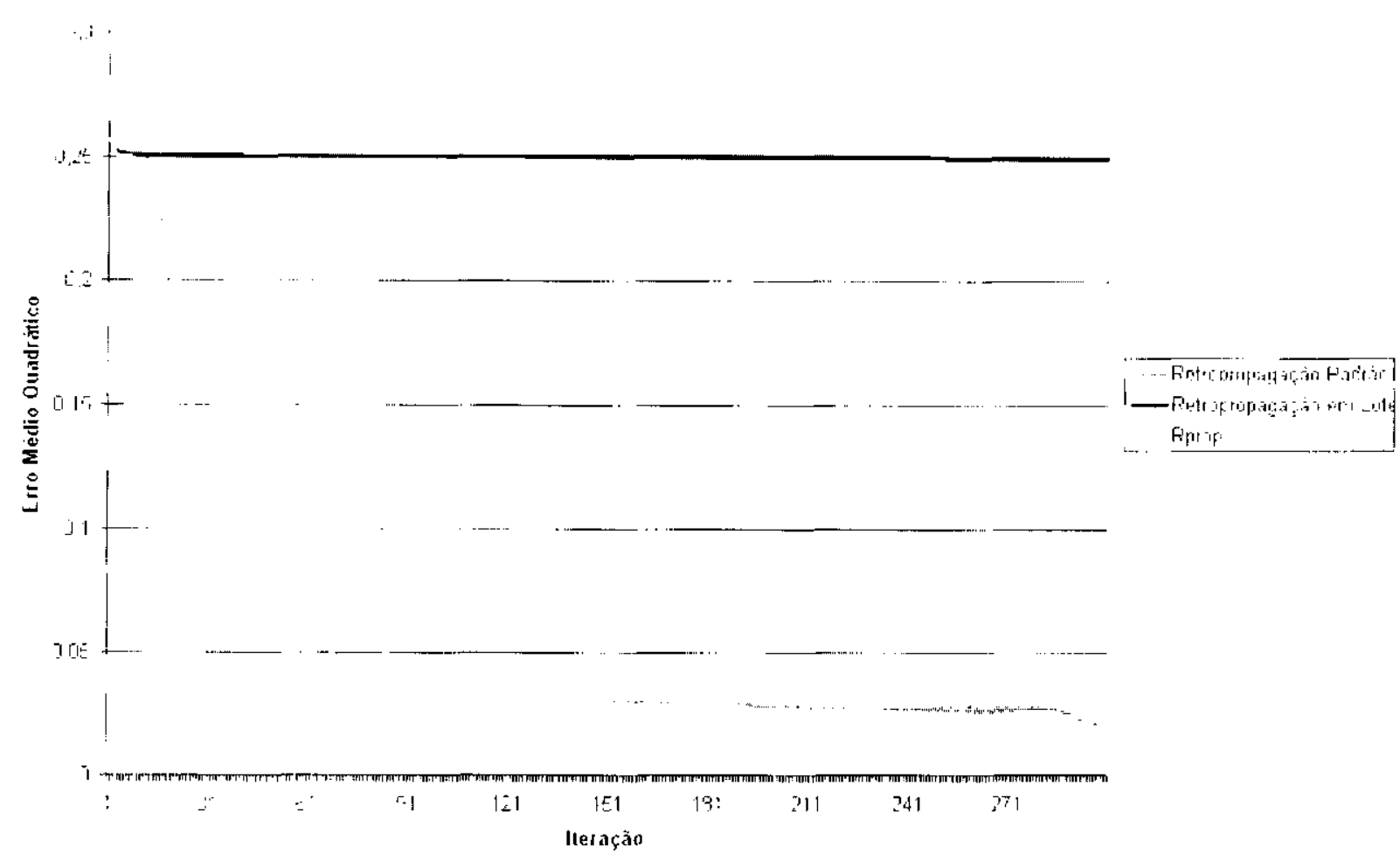

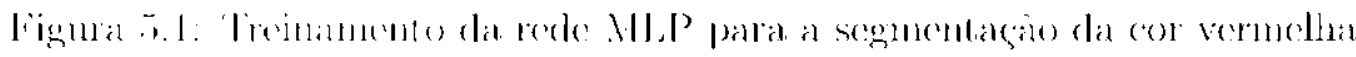

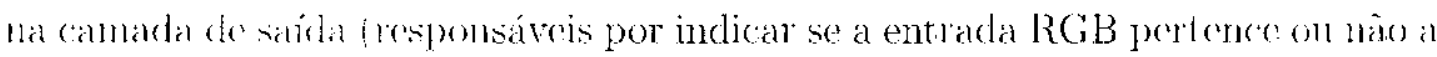

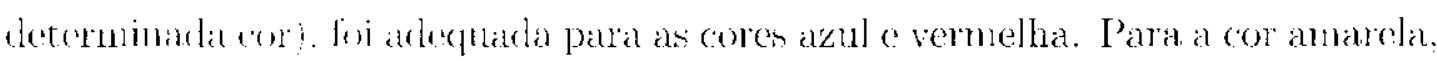

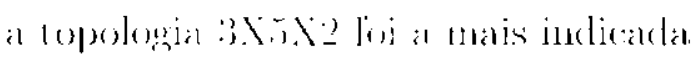

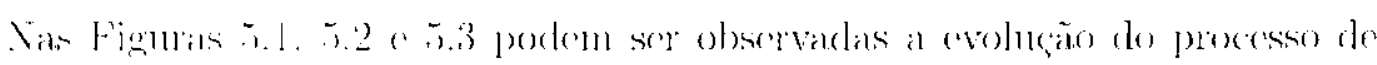

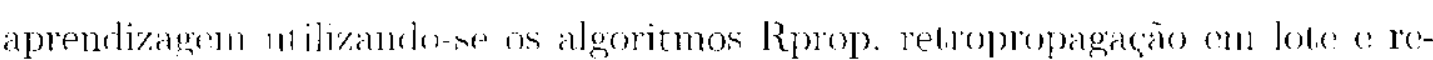

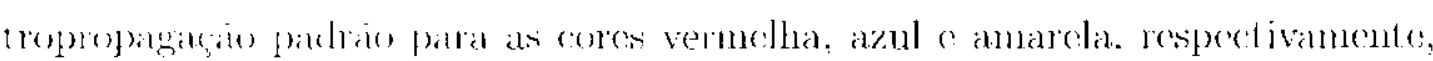

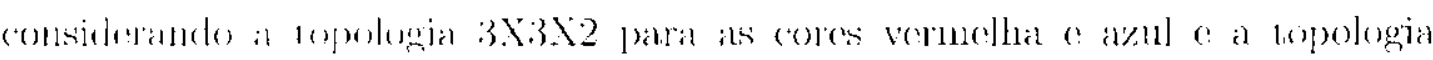

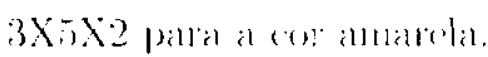

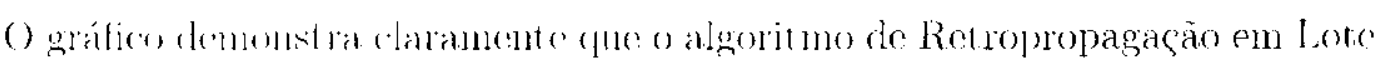

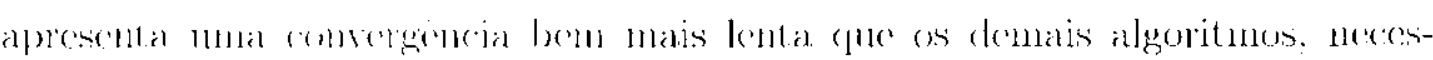

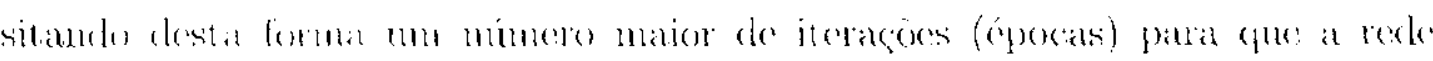

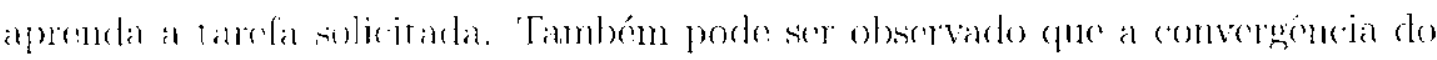

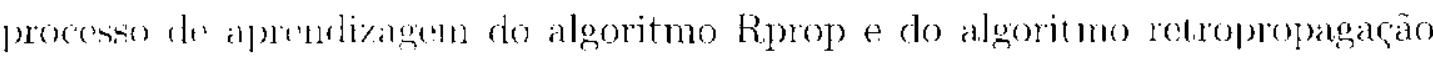

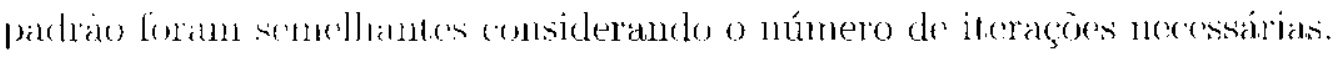

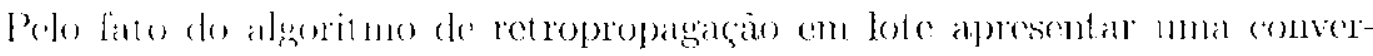

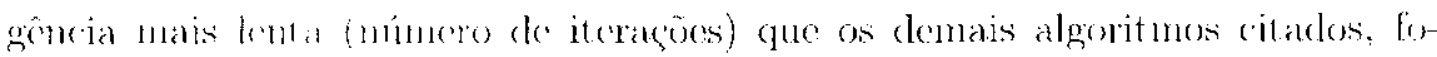
ram realizadoe experimentus utilizando-se um numero maior de itcracoes, pois, o

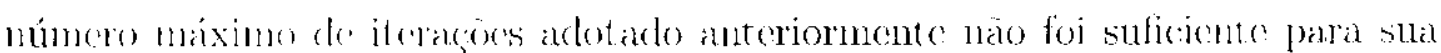




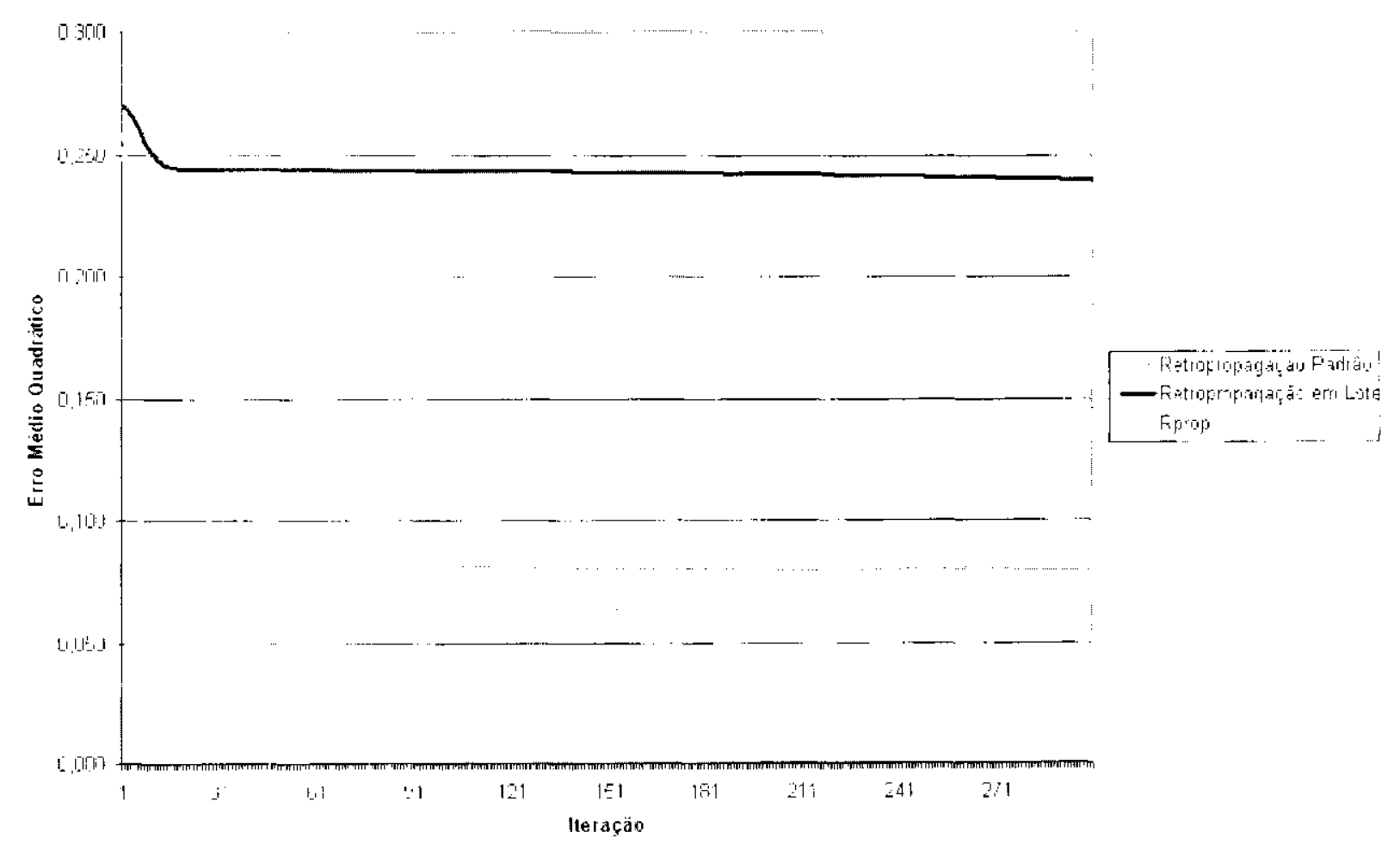

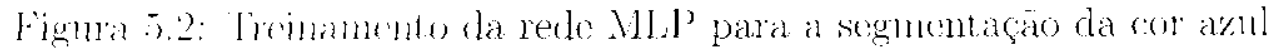

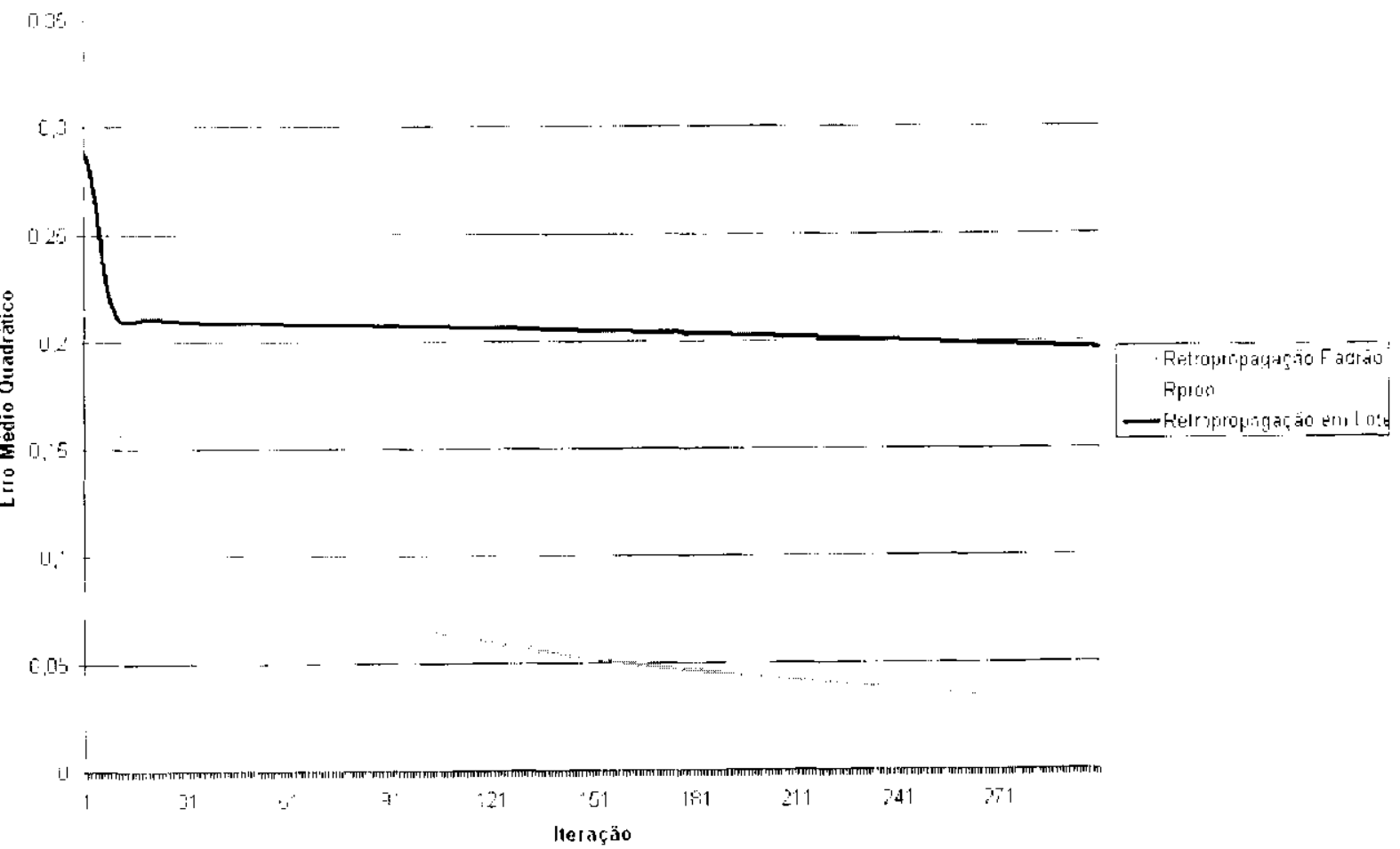

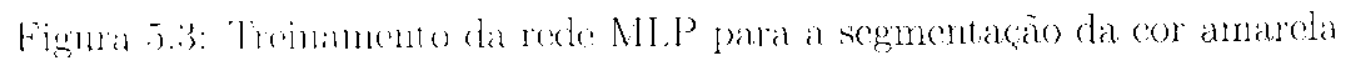




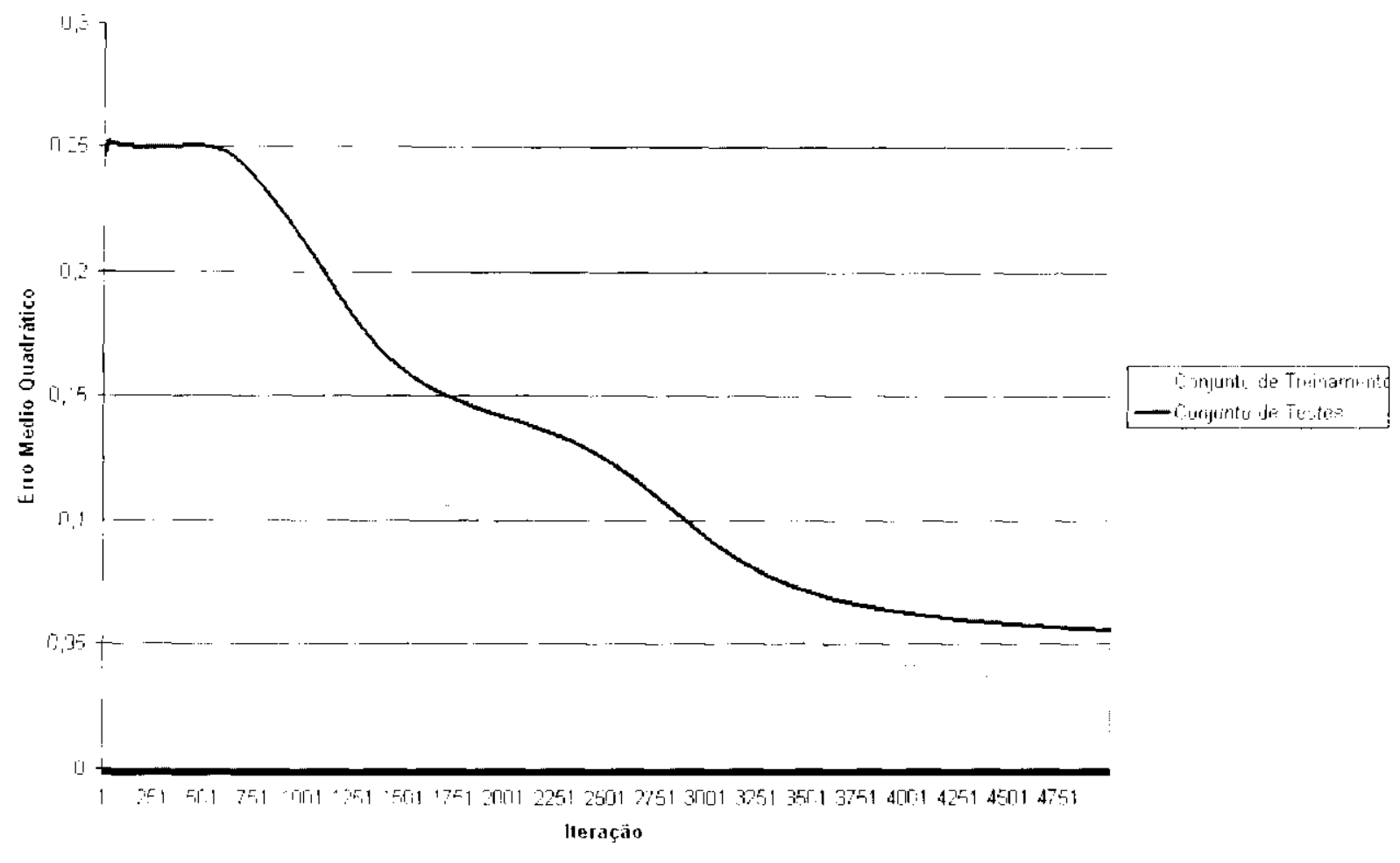

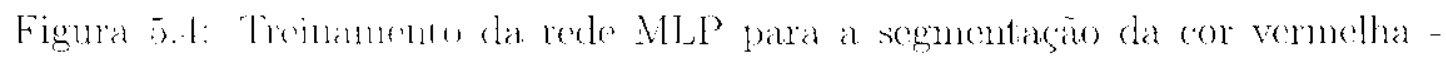

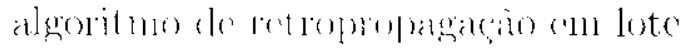

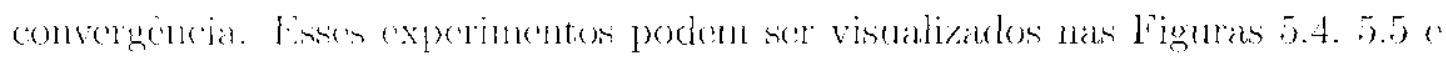

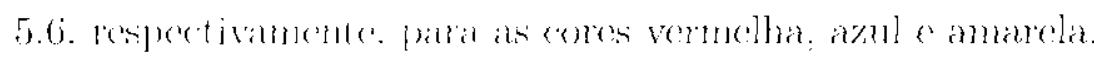

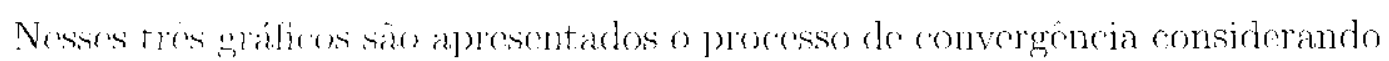

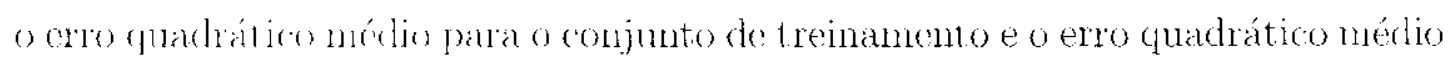

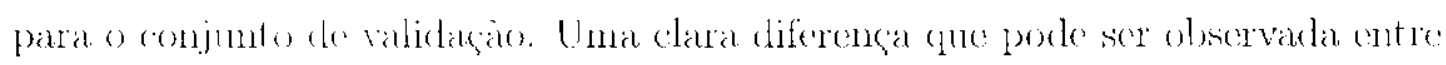

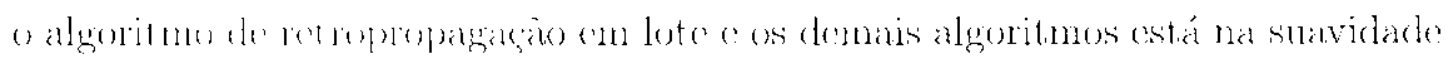
da curva do processo de aprendizagem. Isto se devo an fato de guo o o gradiente obtido pelo prorestamento em lote é uma estimativa mais aproximada do gradi-

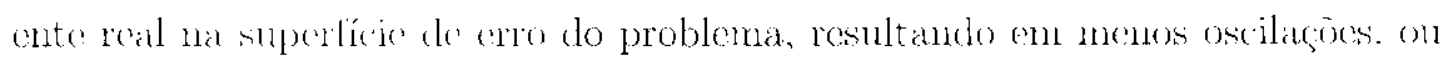

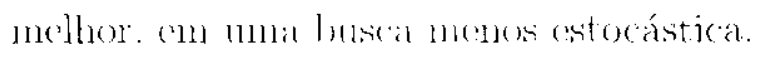

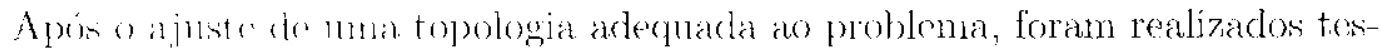

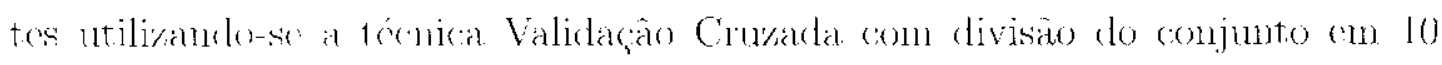

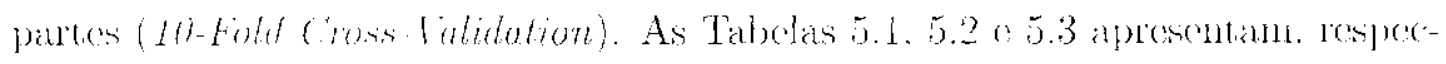

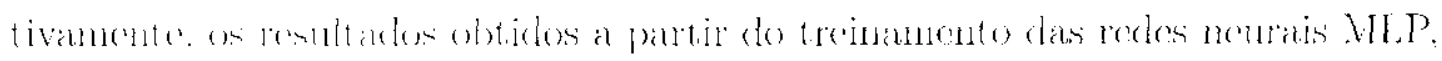

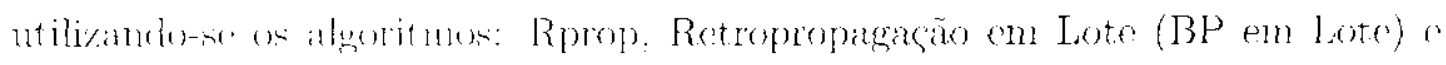

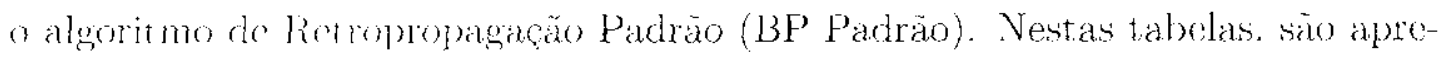

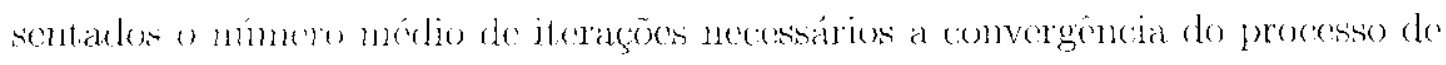

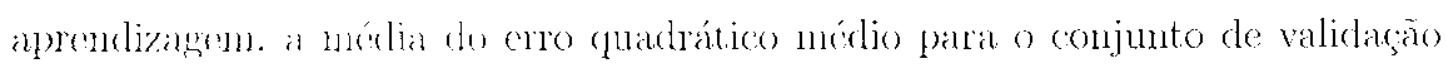




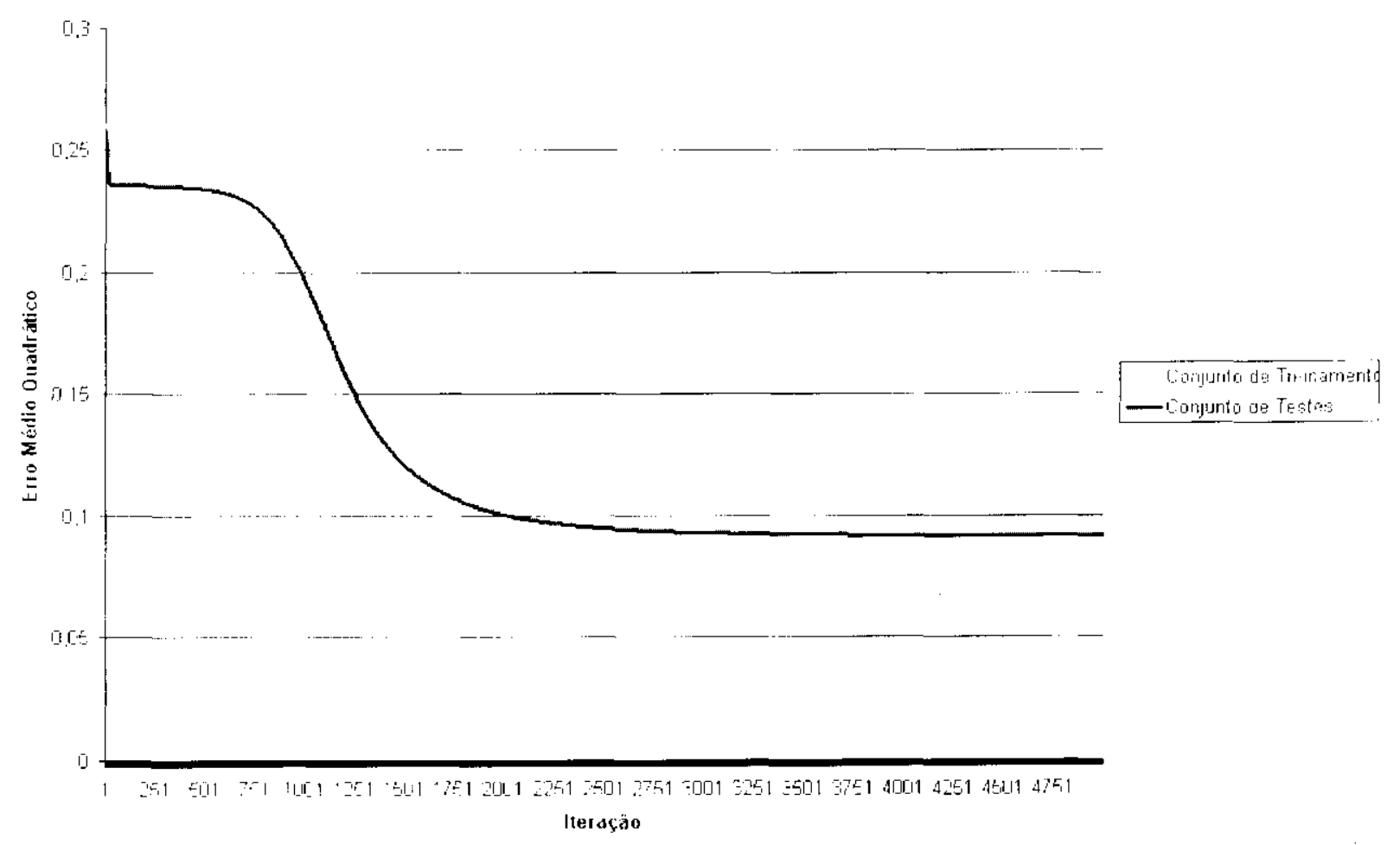

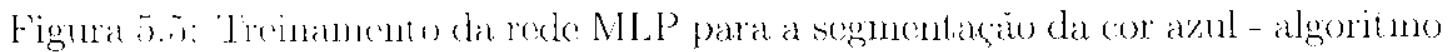

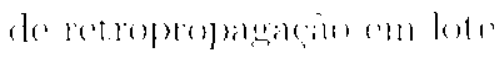




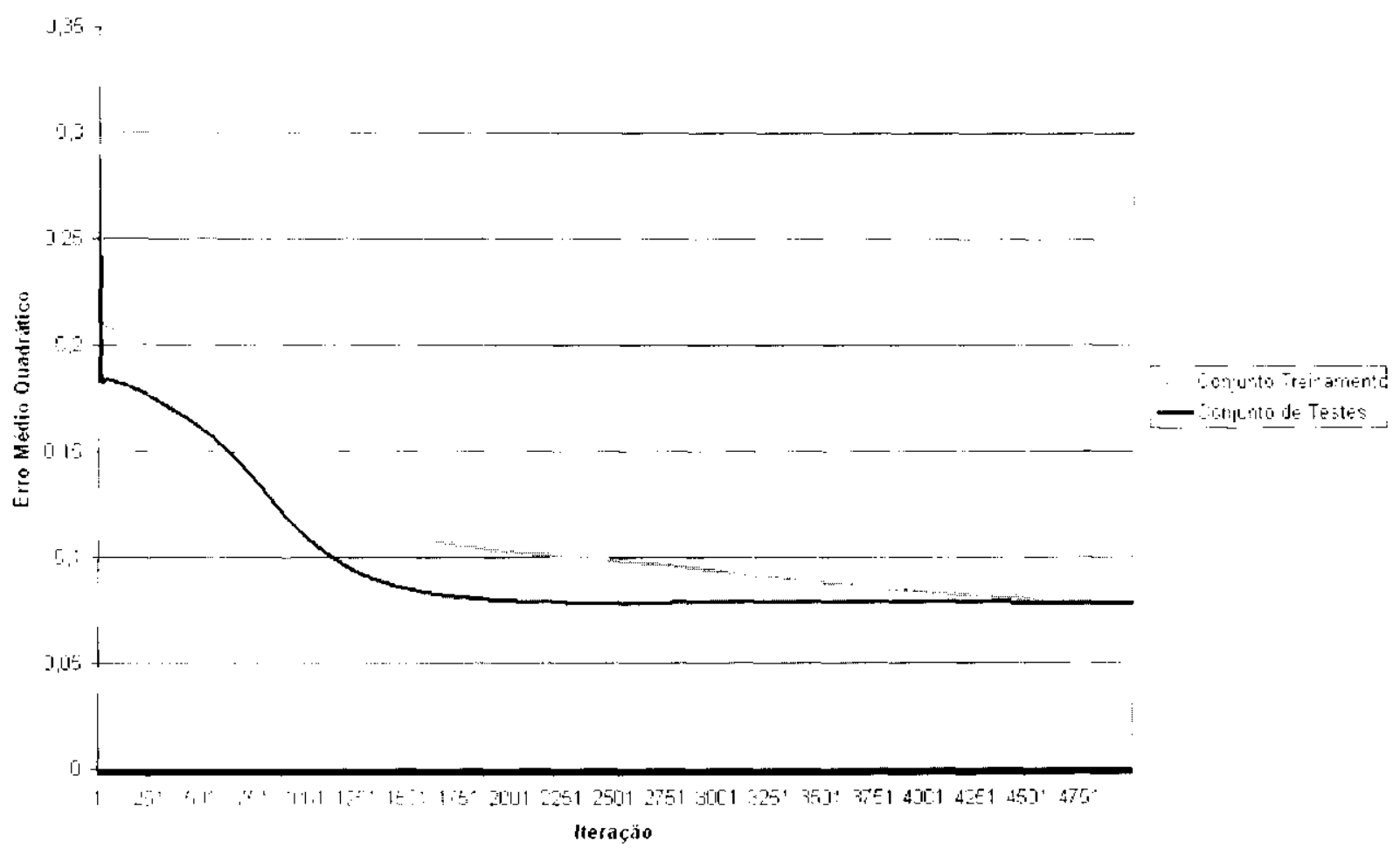

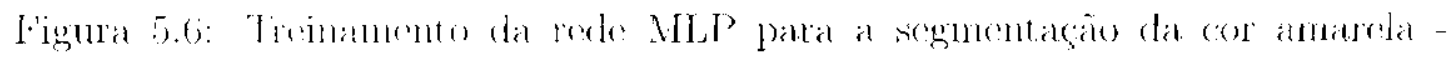

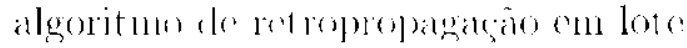

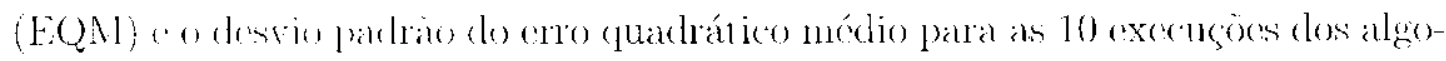

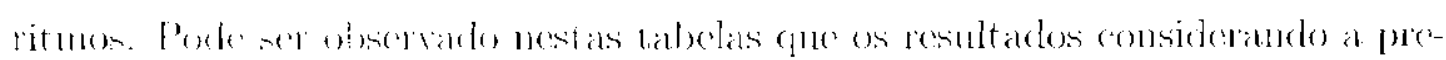

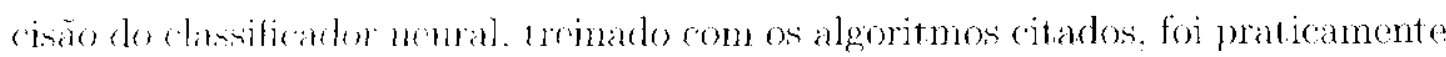

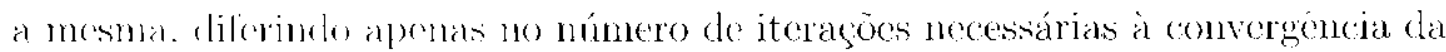
rede . Mll.

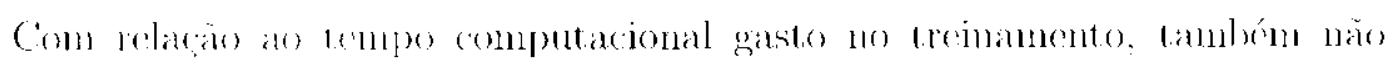
honwe difermea signilicativa entre os algoritmos. Isto se deve ao fato de tanto a hase de dader quantu a lopologia das redes neurais serem pequenas.

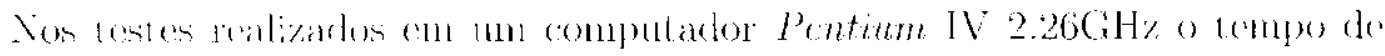

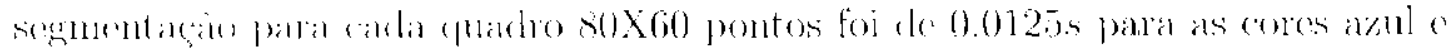

Tabela 5.1: Fisinltado do Processo de Treinanemto da Rode Veural de Sromentaça para a Cor Vermollar

\begin{tabular}{|c|c|c|c|}
\hline & Treracions & EQ.I & I Desvio Padtrão) \\
\hline liprop & 298 & $0,0,390(05,3)$ & 0.03100381 \\
\hline BI' 'mll bote & 5000 & 0.069356 & 0.02955651 \\
\hline B Pl' Parlaño & 477 & 0.014432 & 0.05420535 \\
\hline
\end{tabular}


Tabela 5.2: Resultado do Processo do Treinamento da Rede Neural de Segmen-

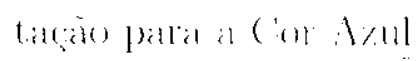

\begin{tabular}{|c|c|c|c|}
\hline & 11 cracions & $\mathrm{HON}$ & 1)(svio Partano \\
\hline$R p(r)\}$ & 300 & 0.085396 .4 & 0.052860000 \\
\hline $33 P^{\prime}$ on Loto & 5000 & 0.0846744 & $(0.05 .525(30488$ \\
\hline$\left|3 \Gamma^{\prime}\right|$ & $51: 3$ & $0.08 \times 38330$ & 0.066881052 \\
\hline
\end{tabular}

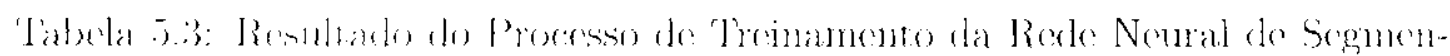

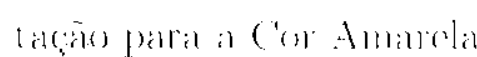

\begin{tabular}{|c|c|c|c|}
\hline & Iteracoses & $\mathrm{EQM}$ & 1)esvio Padrão \\
\hline Rimols & 300 & $0.0661: 33$ & 0.04166800 \\
\hline 'י & 5000 & 0.0999955 & 0.038902008 \\
\hline PSP'Pallaw & 491 & 0.0676599 & (0.045331617 \\
\hline
\end{tabular}

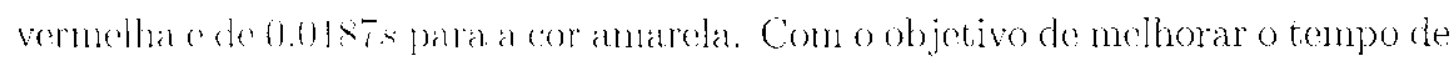

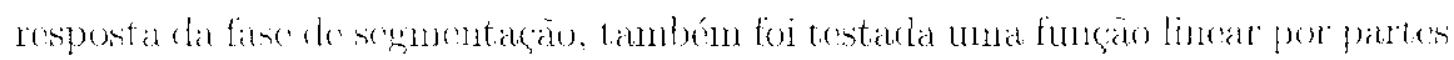

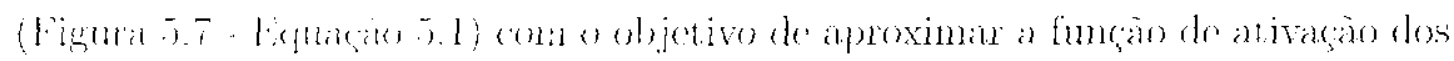

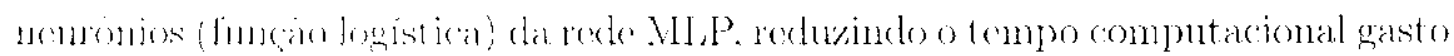

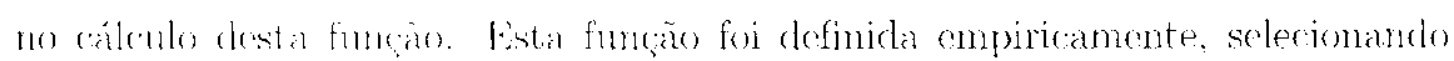

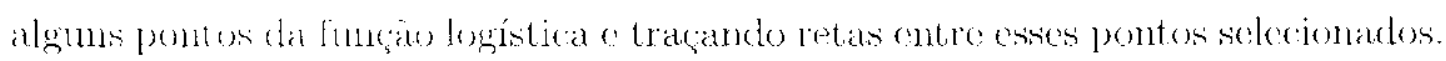

$$
\text { Sigmoideliment } x)= \begin{cases}0, & \text { se } x<0 \\ 0.051+0.0009 * x, & \text { se } x \geq-60 x<-1 \\ 0.222: 0.051 * x, & \text { so } x \geq-40 x<-2 \\ 0.420-0.150 \times x, & \text { se } x \geq-20 x<-1 \\ 0.500+0.230 * x, & \text { st } x \geq 10 x<1 \\ 0.580+0.150 * x, & \text { se } x \geq 10 x<2 \\ 0.778+0.051 * x, & \text { se } x \geq 20 x<1 \\ 0.946-0.009 \times x, & \text { se } x \geq 40 x<6 \\ 1, & \text { se } x \geq 6\end{cases}
$$

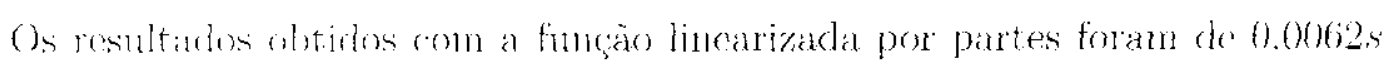

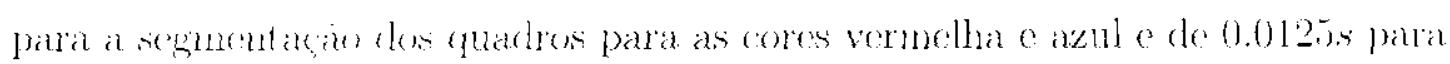

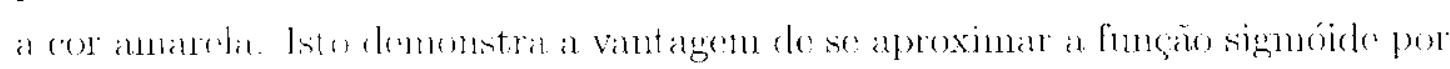

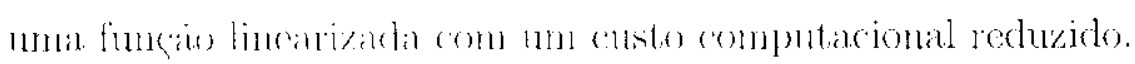

A prialidade do processo de segrnentagào näo foi vistalmonto projudicada 


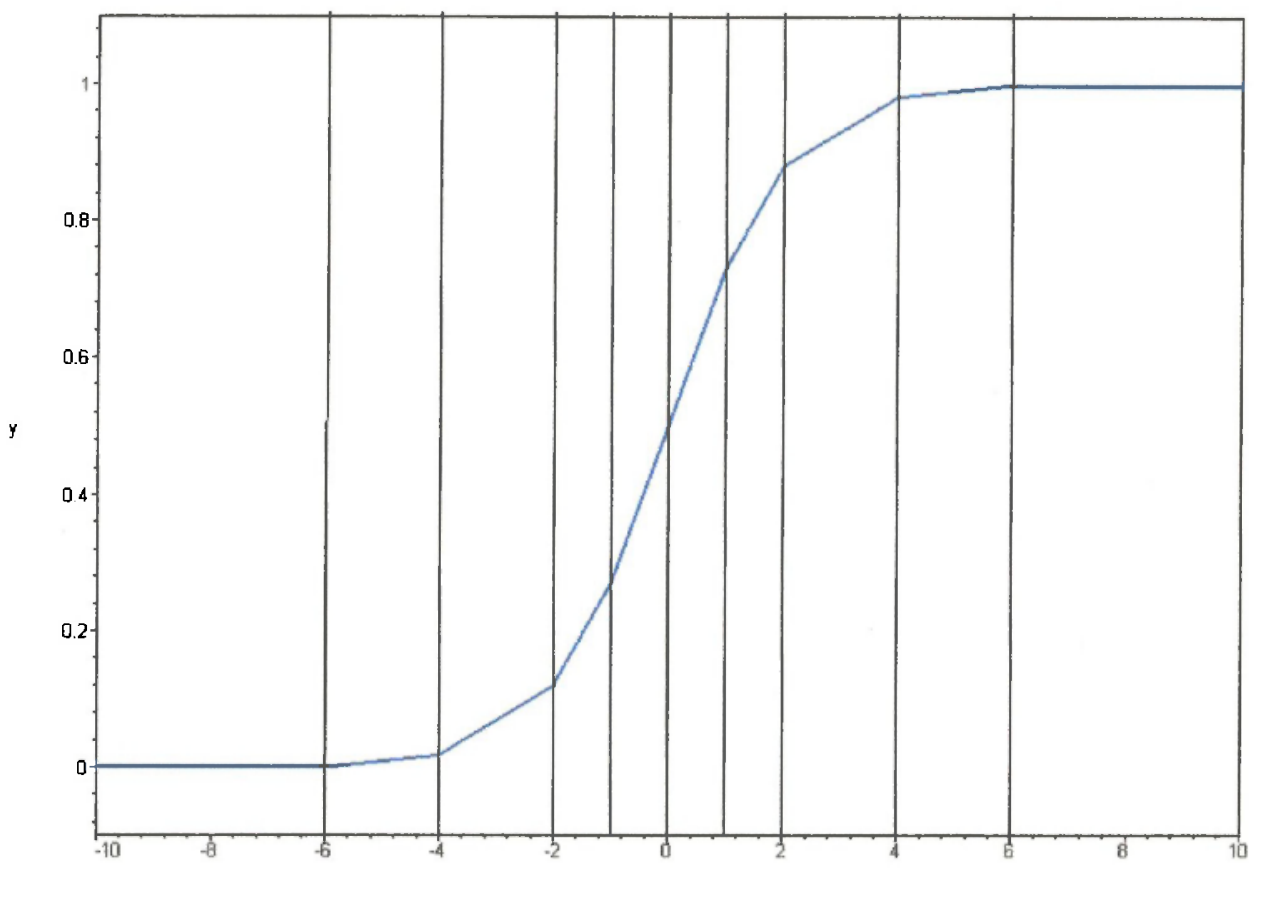

Figura 5.7: Função sigmóide linearizada

quando se utilizou a função linearizada por partes. As Figuras 5.8, 5.9 e 5.10 apresentam o resultado do processo de segmentação para as cores vermelha, azul e amarela respectivamente. Vale observar que esses resultados apresentados por estas Figuras são os mesmos tanto utilizando a função logística, quanto utilizando a função linearizada por partes.

\subsubsection{RNA para Reconhecimento da Posição do Objeto}

A fase de reconhecimento da posição do objeto, como citado na Seção 4.5.3, foi dividida em duas metodologias: a primeira utilizando uma rede MLP com 14 saídas e a segunda metodologia utilizando uma MLP com 3 saídas.

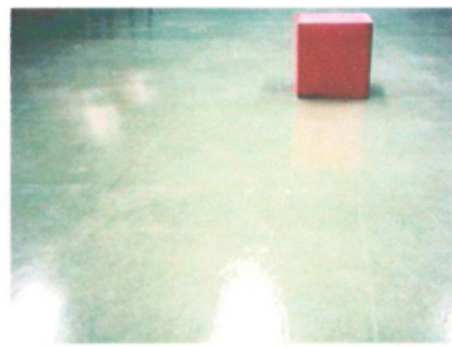

(a)

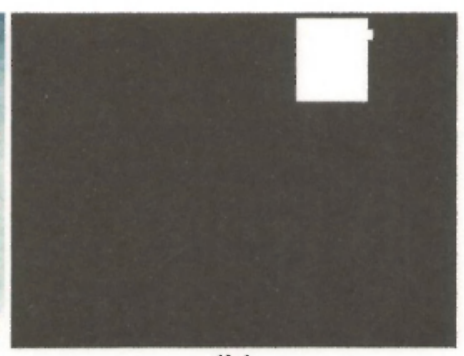

(b)

Figura 5.8: Resultado do processo de segmentação por classificação de cores utilizando a representação de cores RGB. (a) Imagem original, (b) Imagem préprocessada e segmentada para a cor vermelha. 


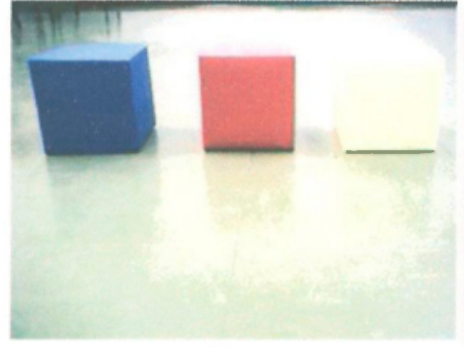

(a)

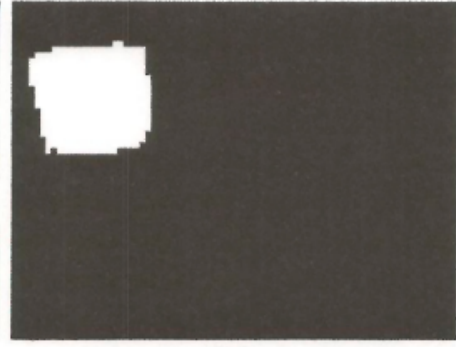

(b)

Figura 5.9: Resultado do processo de segmentação por classificação de cores utilizando a representação de cores RGB. (a) Imagem original, (b) Imagem préprocessada e segmentada para a cor azul.

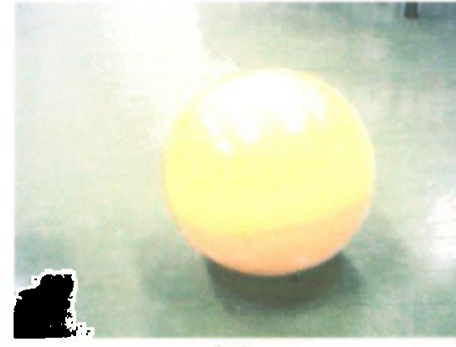

(a)

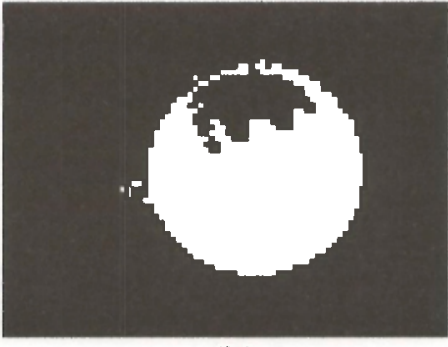

(b)

Figura 5.10: Resultado do processo de segmentação por classificação de cores utilizando a representação de cores RGB. (a) Imagem original, (b) Imagem préprocessada e segmentada para a cor amarela. 


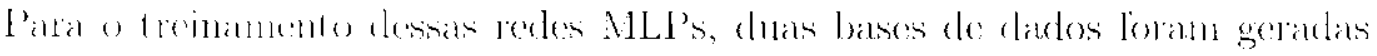

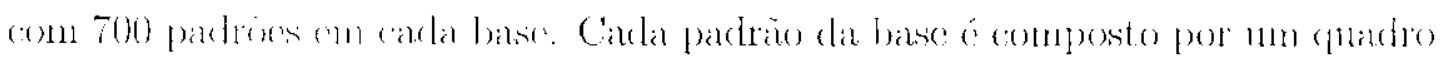

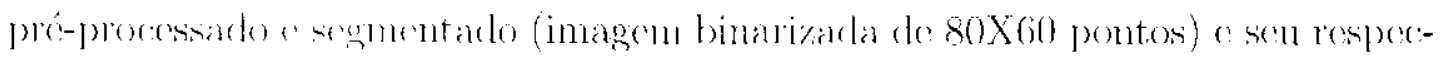
livo rótulo conlenelo a presicà do objoto no campo visual. A única diferenca ontre

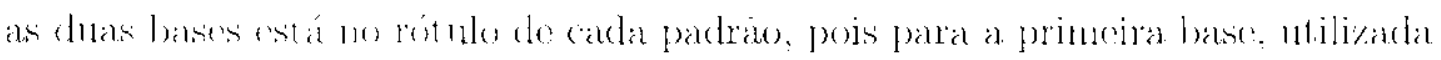

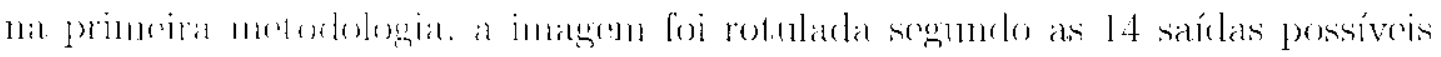

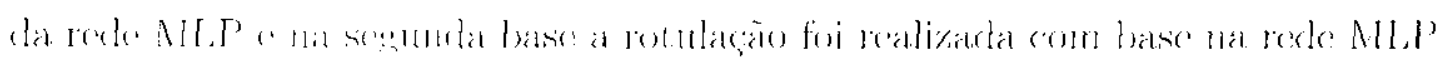

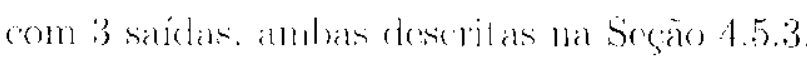

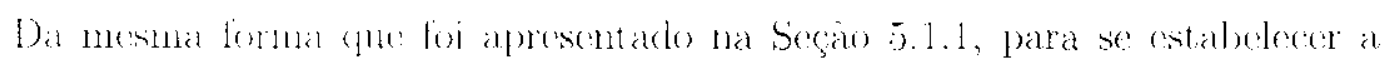

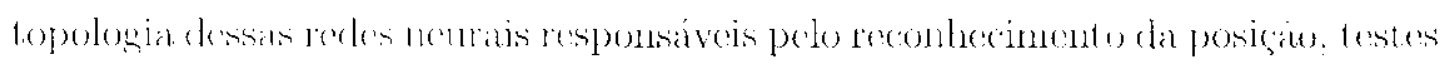

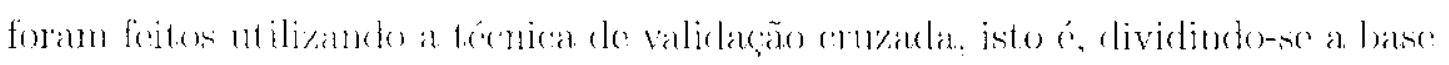
do dados rou duas partes: $80 \%$ trejommento e $20 \%$ validados.

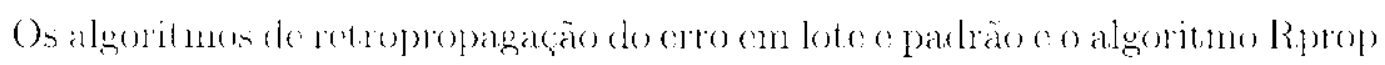

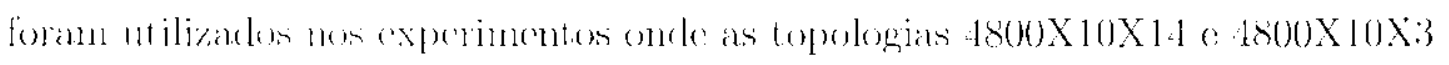

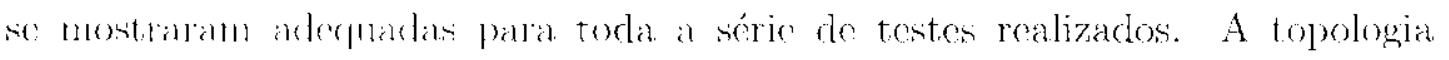

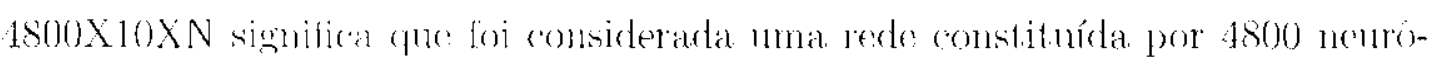

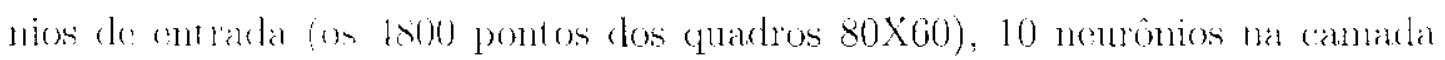

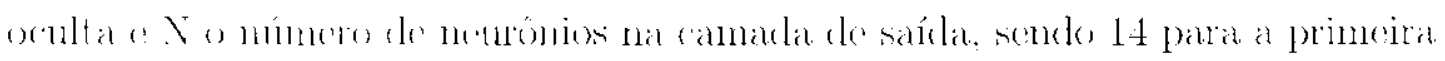

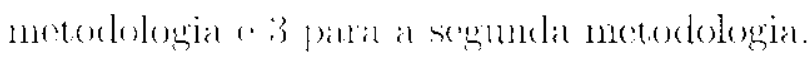

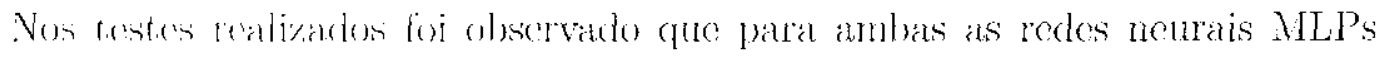
e com qualyuer un des algonitmos utilizados a recle convergin lacilumente para

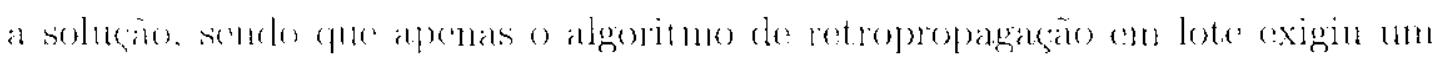

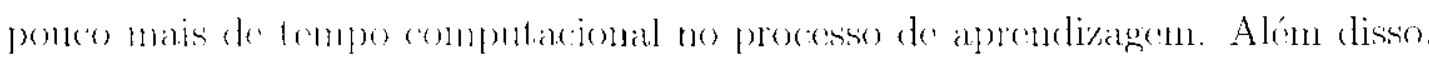

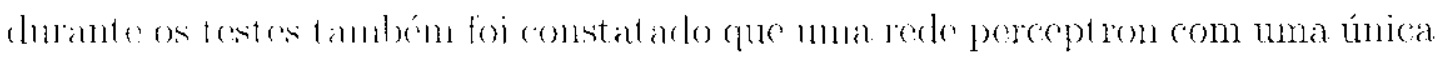

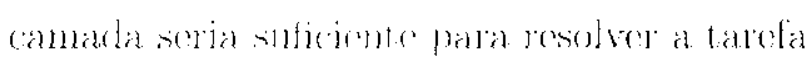

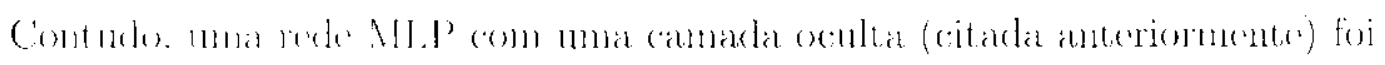

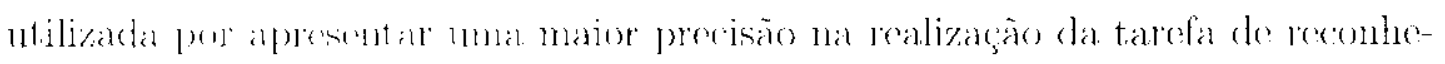
(imentos.

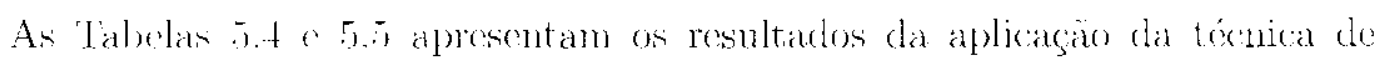

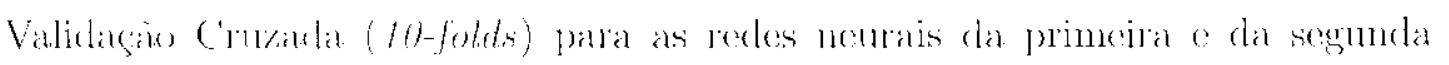

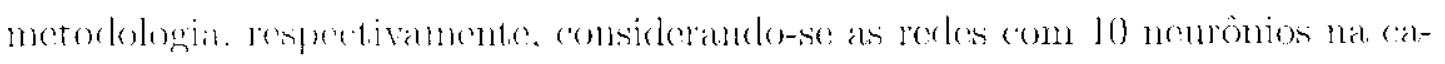

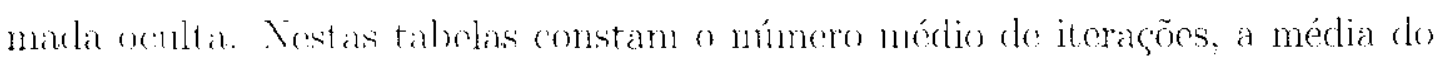

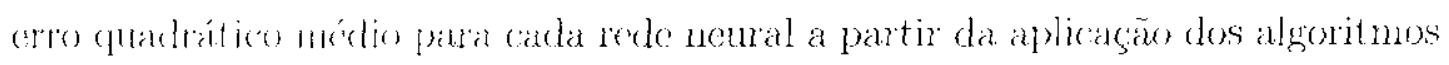

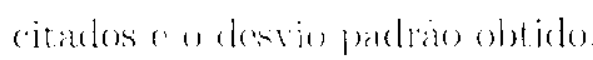

\subsubsection{RNA para Reconhecimento da Posição e Forma do Objeto}

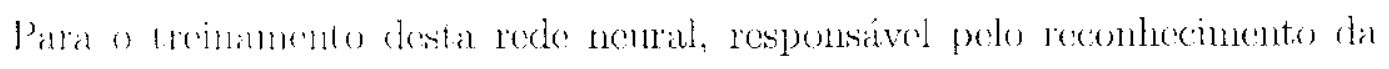

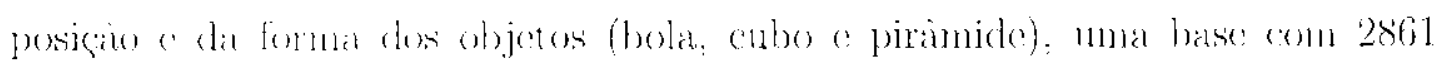


Tabela 5.1: Rosultade do Processo de Treinanento para a Rede Neural de Reco-

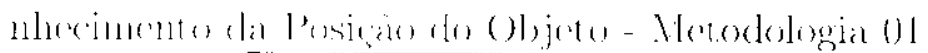

\begin{tabular}{|c|c|c|c|}
\hline & Iteragos & EQM & Desvio Padräo \\
\hline Rprops & 18 & 0.011675 & 0.0036998 \\
\hline 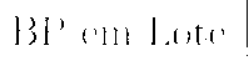 & 1529 & $(0.014143$ & 0.0006344 \\
\hline BP' Padró & 6 & 0.010448 & 0.0003499 \\
\hline
\end{tabular}

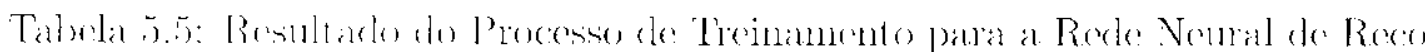

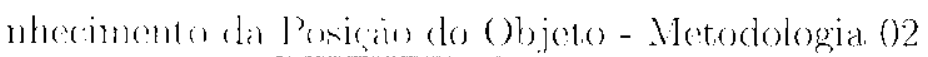

\begin{tabular}{|c|c|c|c|}
\hline & Iteraçoes & EQM & Destio Padrão \\
\hline Ripreps & 6 & 0.00048009 & 0.000883 \\
\hline 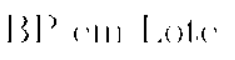 & 5,03 & 0.012650 & $0.00(13,3577$ \\
\hline BP' P'anträo & 2 & 0.0005850 & 0.0001403 \\
\hline
\end{tabular}

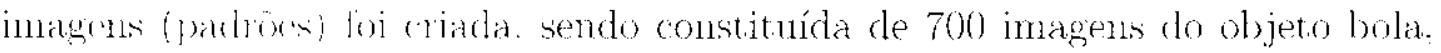

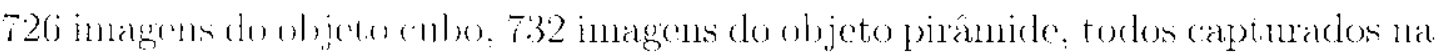

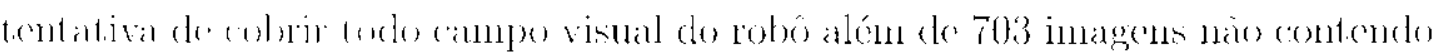

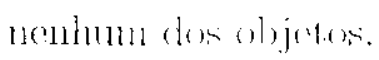

Vale ressialtar yue assa base de dados é constituída dos valores dos 1800 pont os

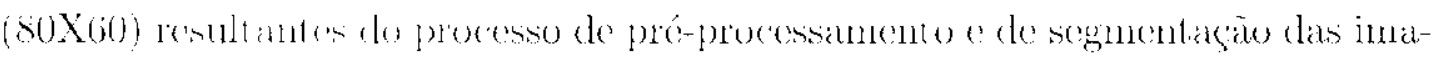

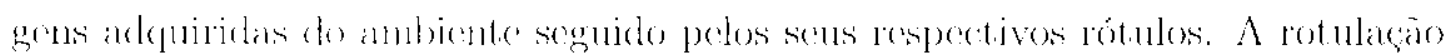

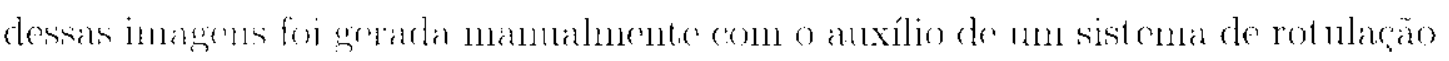
desemvolvido. no gual cata rótulo foi gerado com um vetor de 10 componentes.

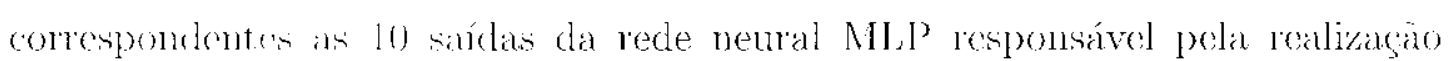

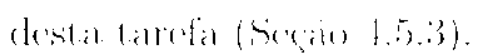

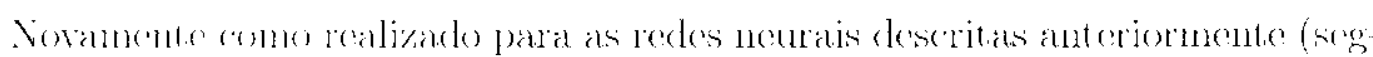

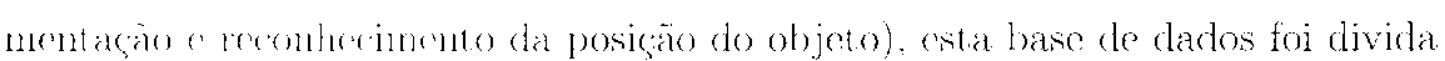

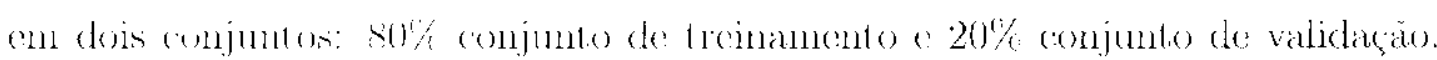

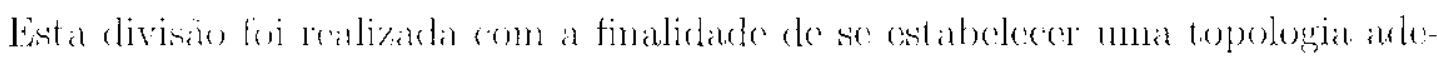

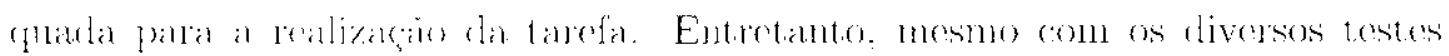
realizados considerando diversas topologias compostas por una on mais camadas

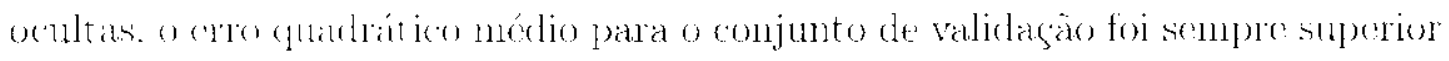

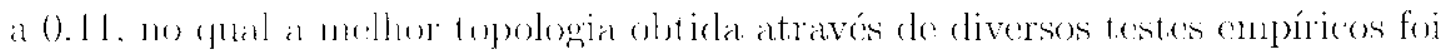
a $1800 \times 150 \times 150 \times 10$

Devido a dificuldade do se estabelecer uma melhor topologia para a redeneural responsável predorenherinento da posigäo e da forma dos objetos, opton-se pela 


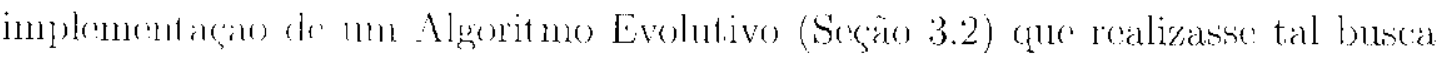

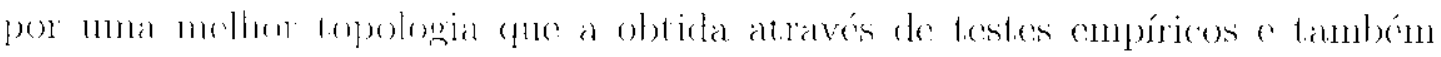

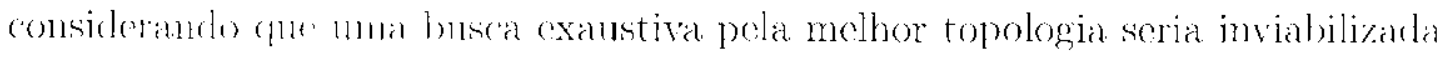

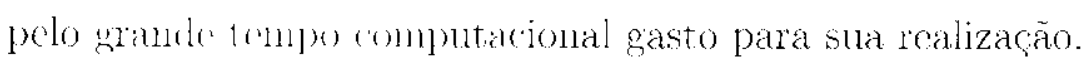

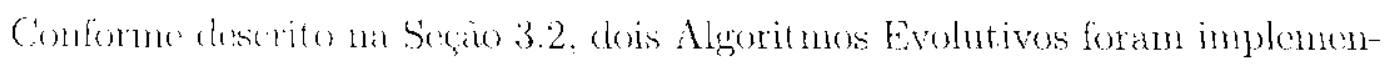

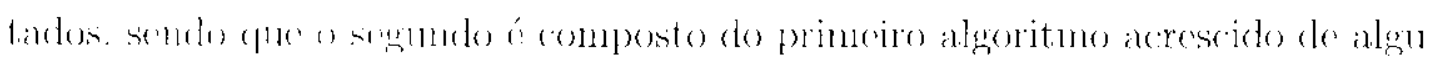

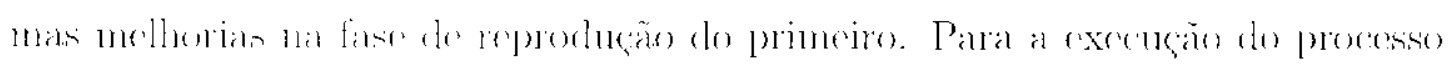

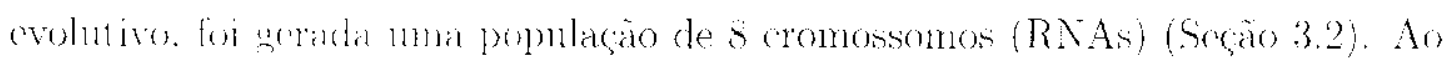

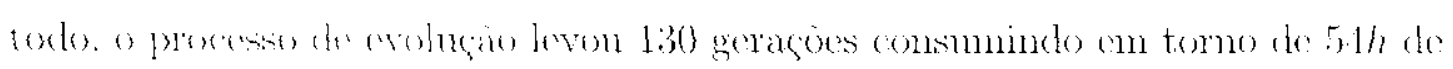

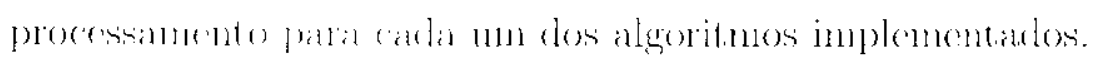

() resultato oblirbe a partit do primeiro algoritmo (AF-I) foi uma rede con

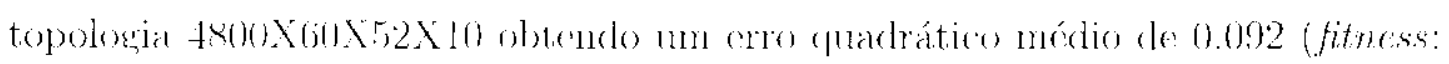

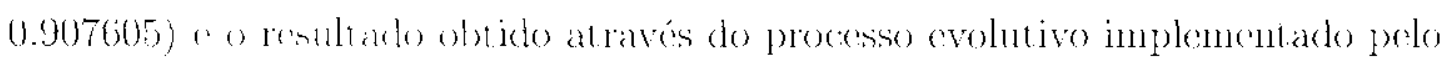

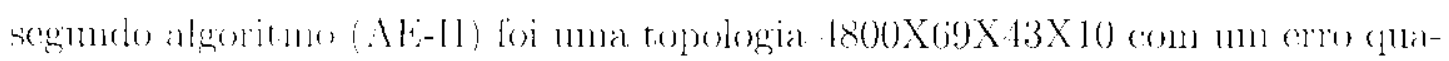

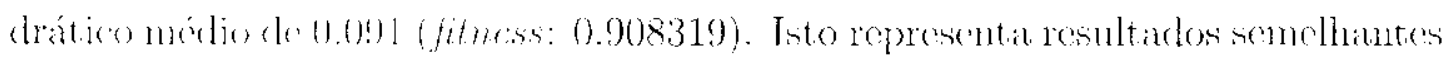

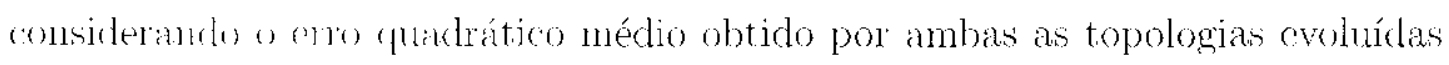
peli) $\Lambda$ :

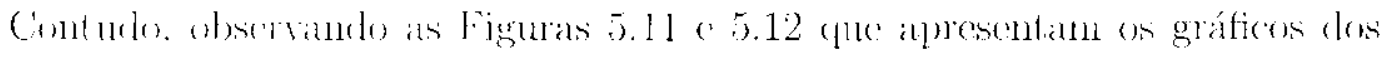

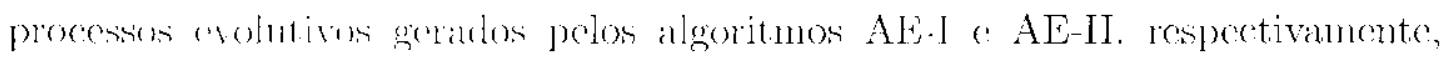
pode so notado ane a segundo algoritmo apresonton uma evoluça mais rápida.

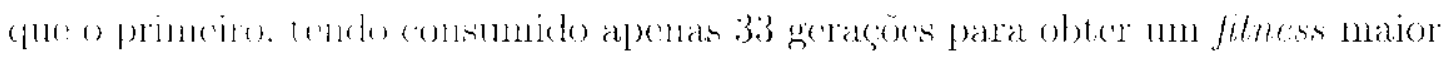

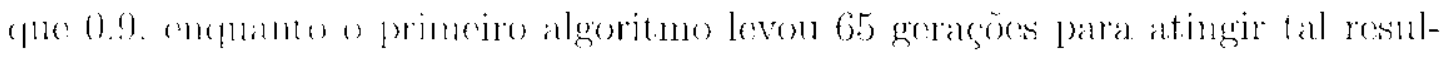

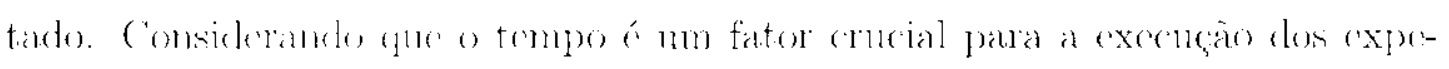

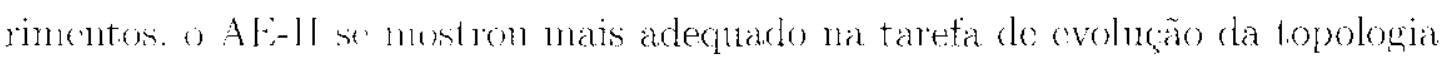
da rexte nemal MLL'.

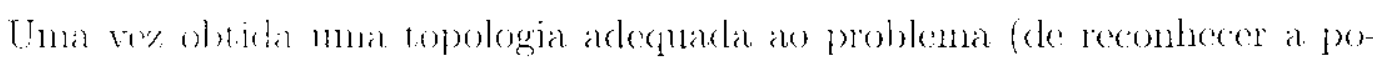

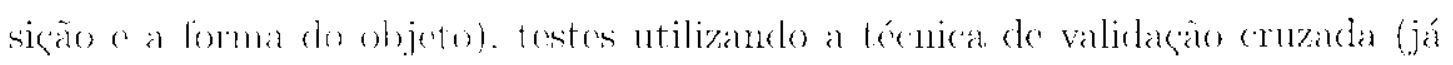
descrita andua toi utilizada para obter um resultado mais ral sobre a precisão

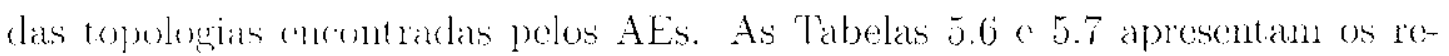

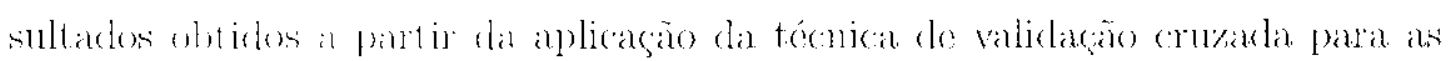

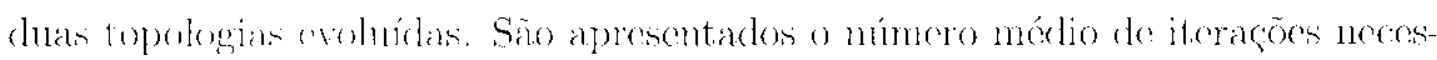
sárias a comerementa a módia do erro quadrático médio o desvio padrăo do erro quadrático mólio o o tempo computacional gasto nat realizagào dos experimentos.

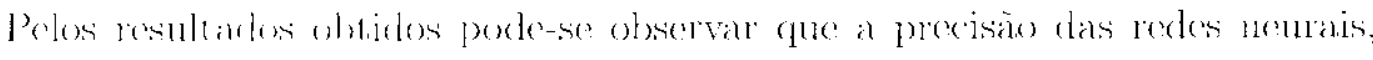

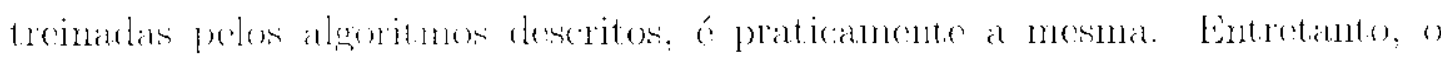

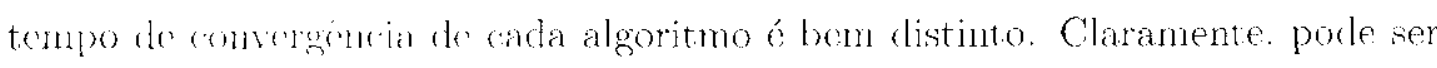
observado (1ue o algonitmo riprop, como já descrito na literatura apresenta um 


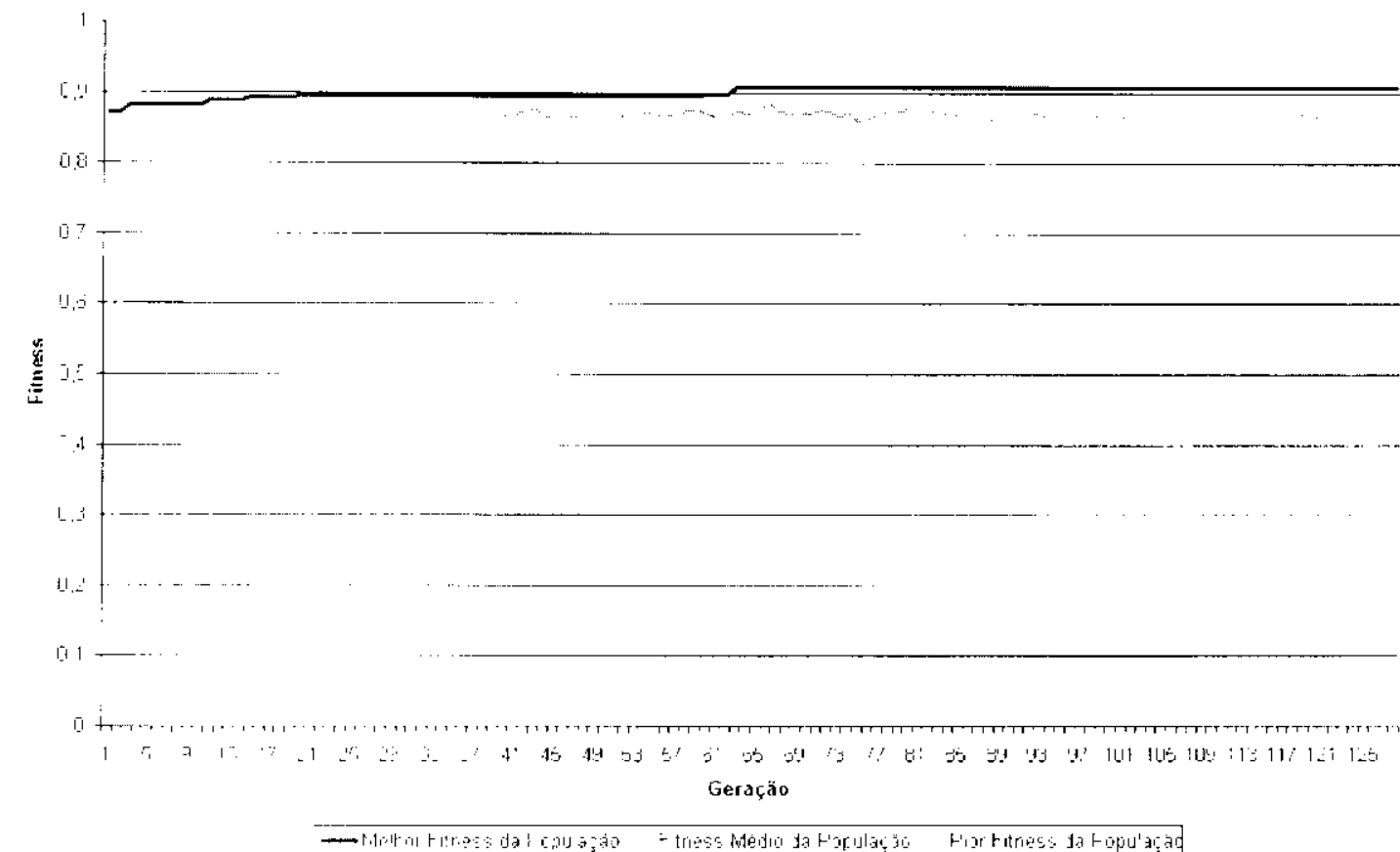

Fignara 5.11: Resuldado do precesso evolutivo gerado a partir do algoritmo l

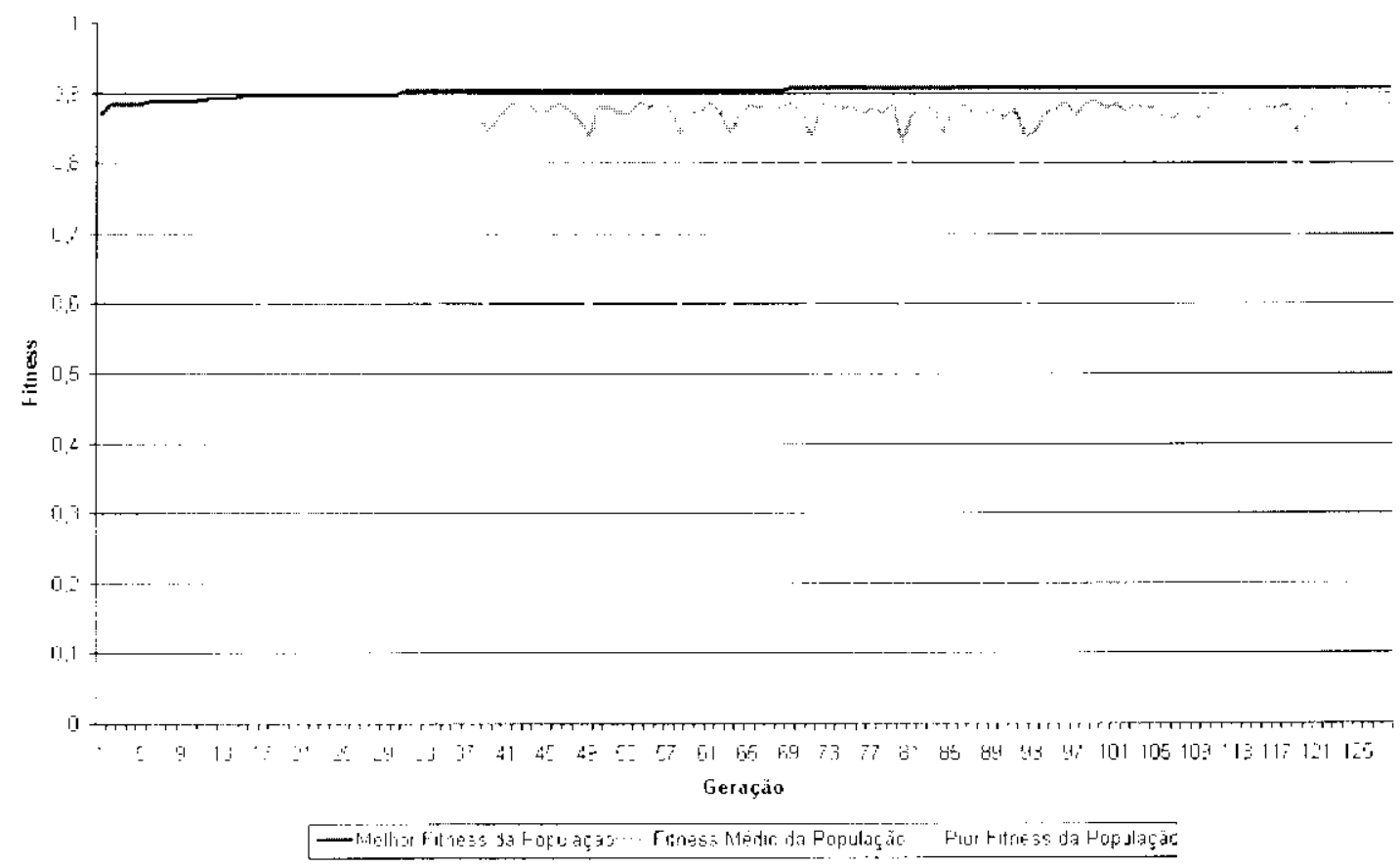

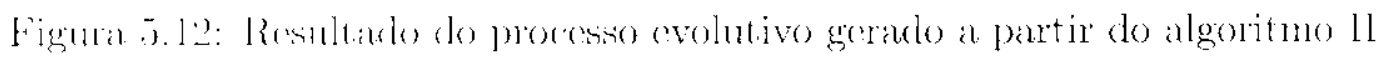




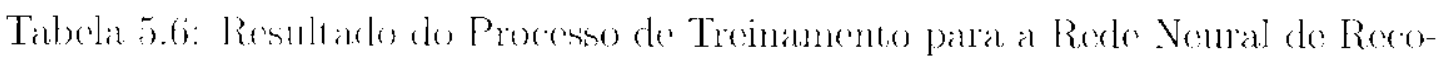

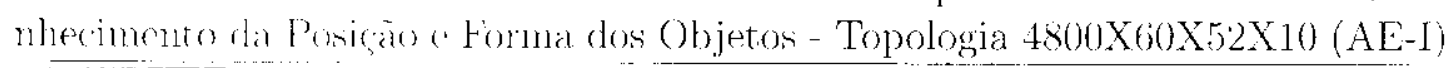

\begin{tabular}{|c|c|c|c|c|}
\hline \multirow{2}{*}{ 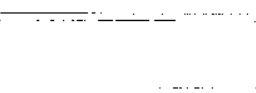 } & \multirow[b]{2}{*}{ le } & \\
\hline & & $\mathrm{EQUI}$ & Desvio Padrấo & Tempo Treinanento \\
\hline IRHop) & 3 & 0.093670 & 0.021530000 & $\approx 50$ minulos \\
\hline HI' & $21: 3: 1$ & 0.102270 & $(1.011250000$ & $\approx 35$ horas \\
\hline BP Parlain & $5(x)$ & $0.0991,53$ & 0.02271200 & $\approx 1$ thins \\
\hline
\end{tabular}

Tabela 5.7: Resultado do Processo de Treinamento para a Rede Neural de Rece-

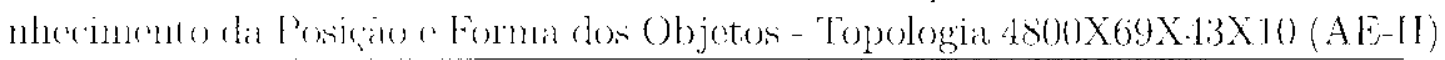

\begin{tabular}{|c|c|c|c|c|}
\hline & Heranges & $\mathrm{EQMI}$ & Desvio Pardräo & 'Tompo Treinamento \\
\hline Rimose & 36 & 0.091108 & 0.000993700 & $\approx 5$ mimutos \\
\hline BP' (molste & 2092 & 0.100966 & 0.01218600 & $\approx 40$ horas \\
\hline BP Patrio & $5(x)$ & 0.0988701 & 0.01351000 & $\approx 16$ dias \\
\hline
\end{tabular}

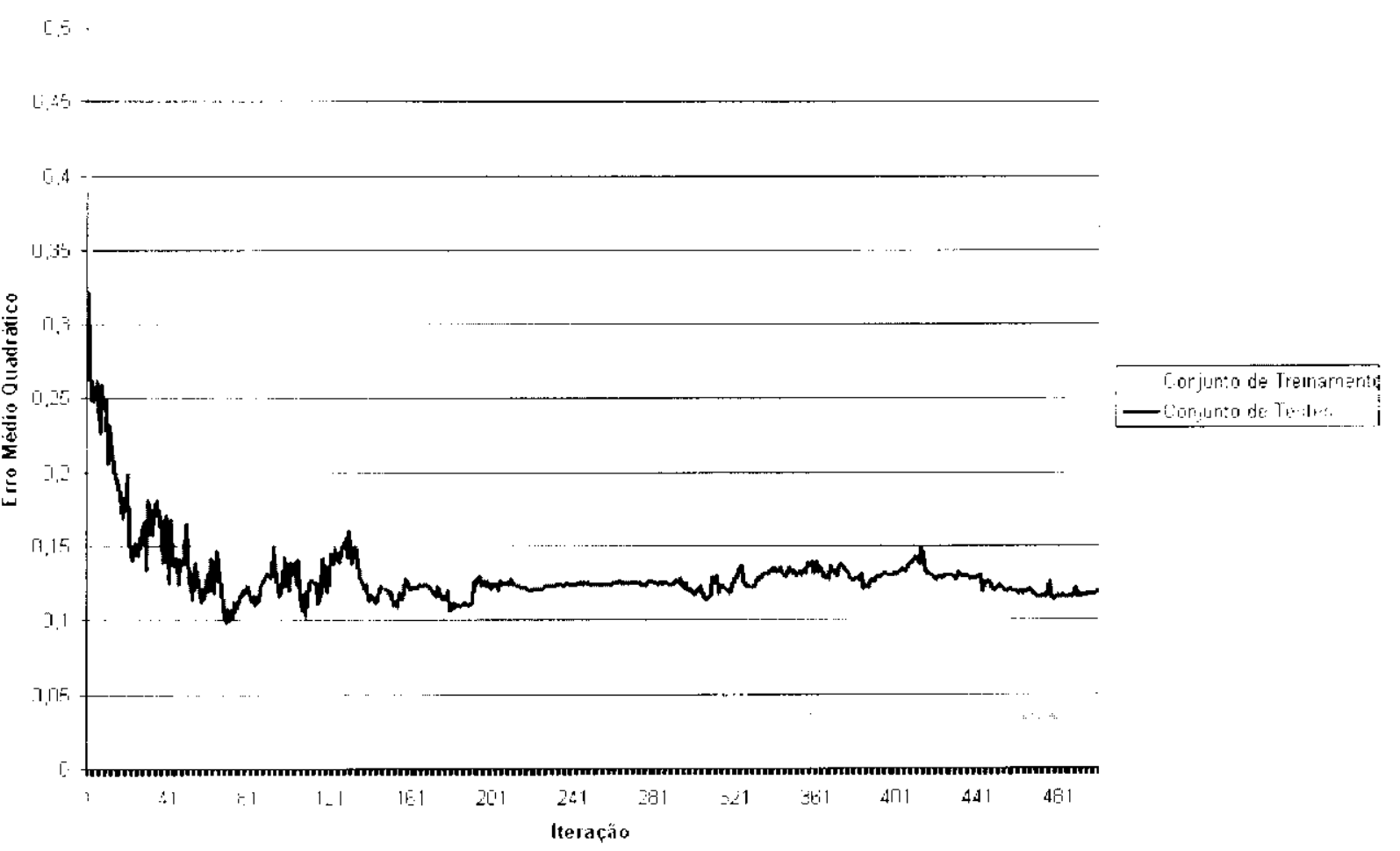

Figura 5.13: Treinamento da rede MLP para o reconhecimento da posição e forma do objeto - topologia $1800 \times 6(0) \times 32 \times 10$ - algoritmo de ret ropropayaçăo padrão 


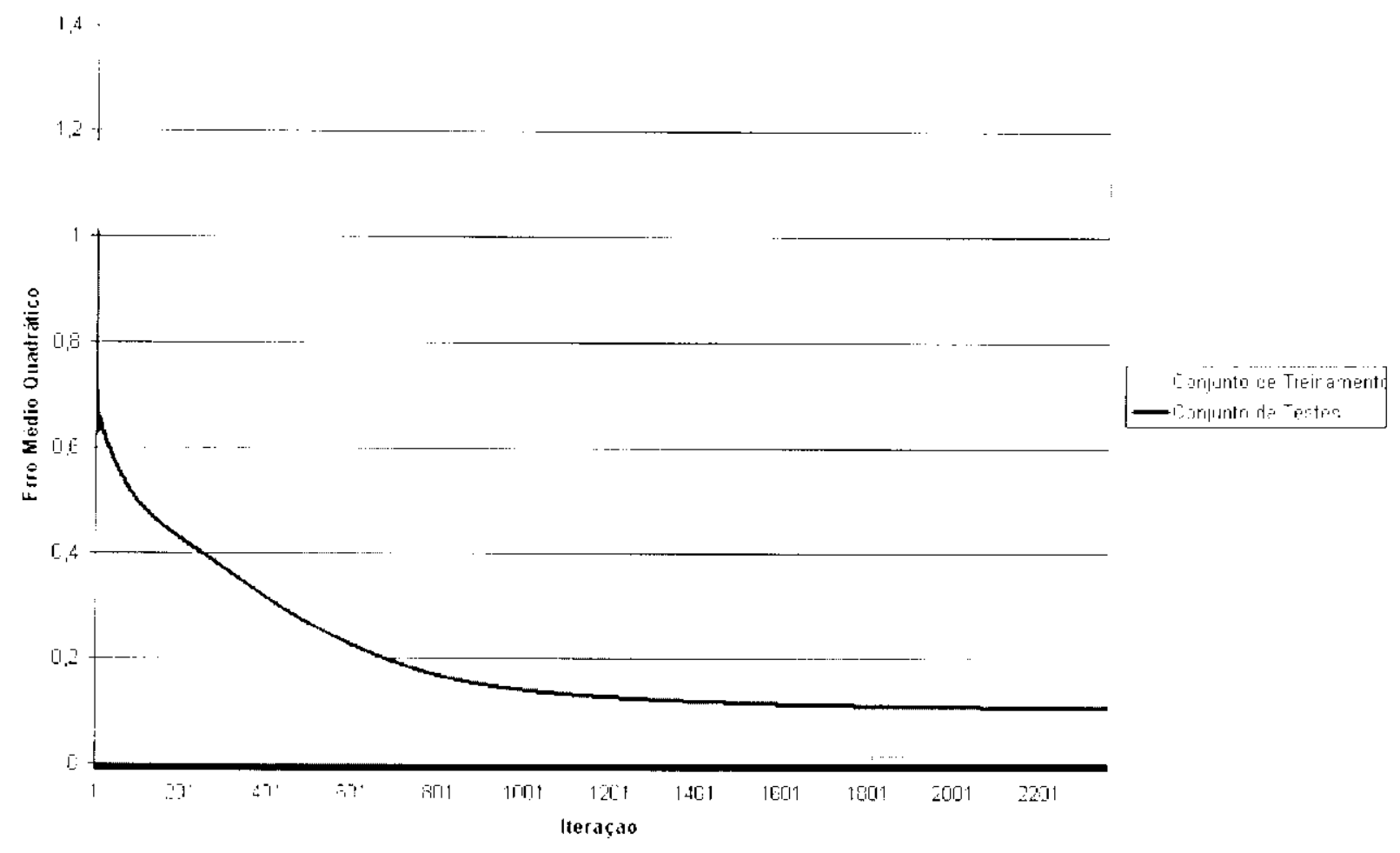

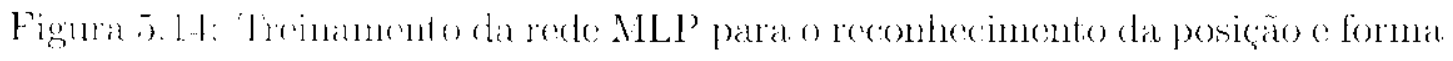

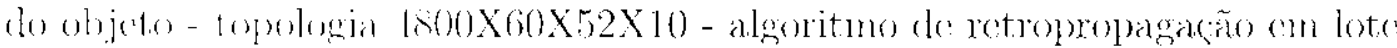

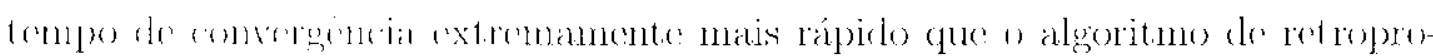

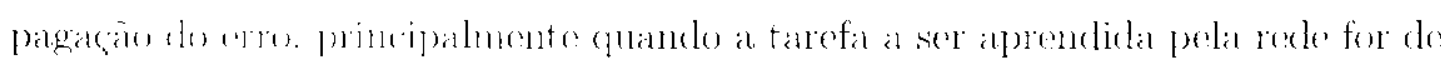

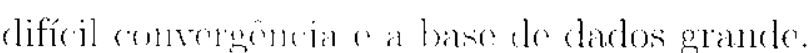

Lin cutro fatur inleresiante tambén observalo ć que o algoritmo de retropro-

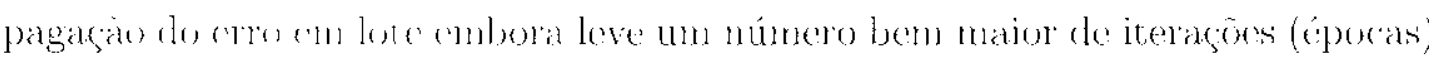

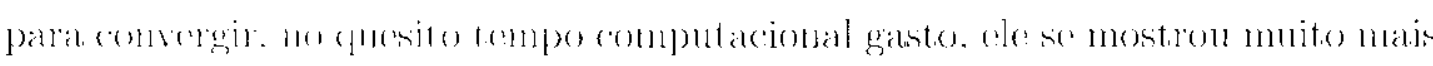

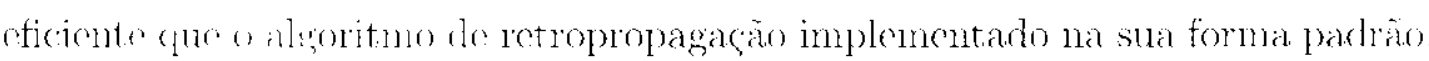

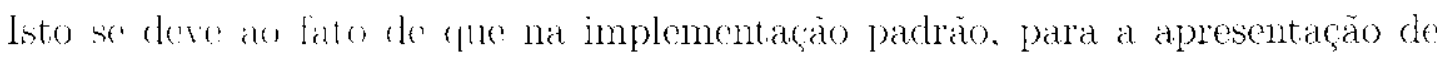

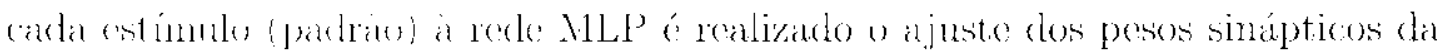

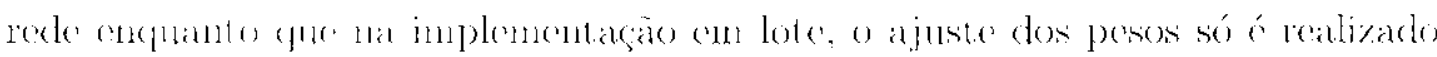

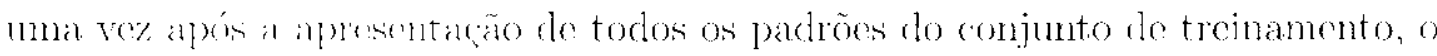
que resulta ch un mornor consumo de tempo para o processo de treinamento.

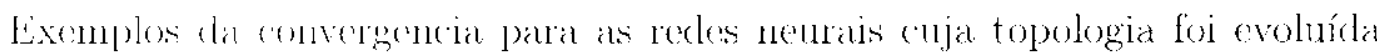

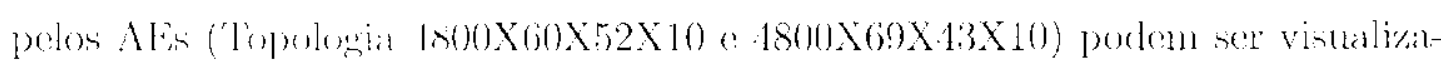

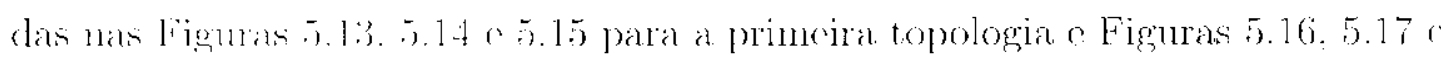
5.18 para a segunda lopologia. Xesses grálicos pode ser claramente destacanto o tipo de convergencia realizanla por cada algoritmo. Para o algoritno de retropro- 


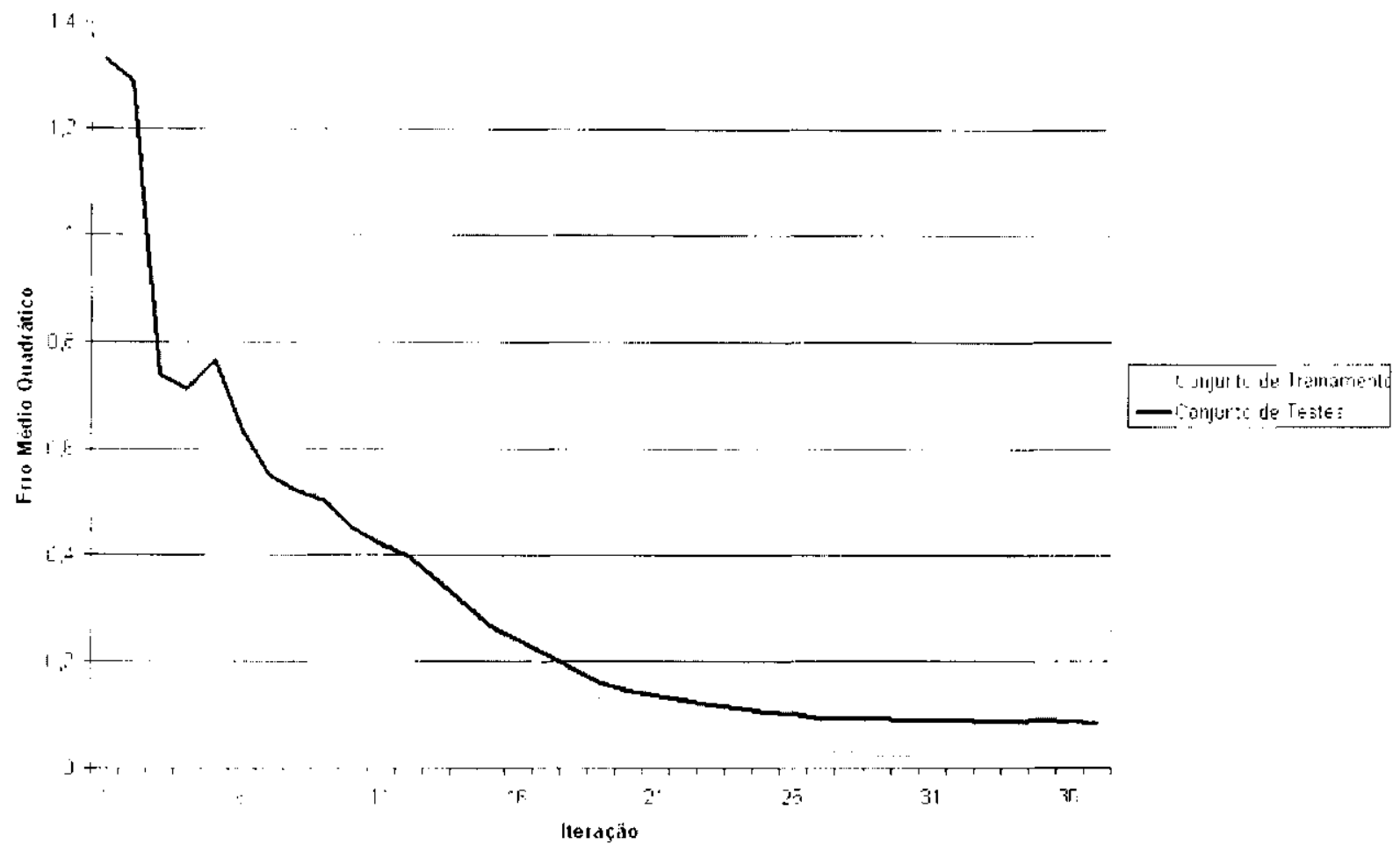

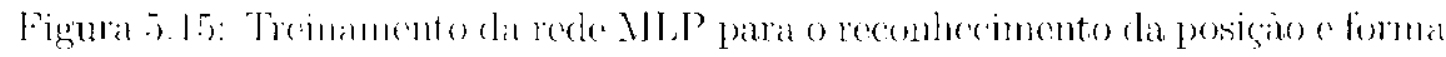

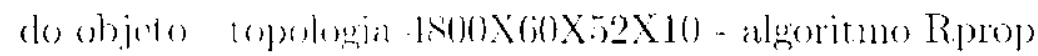

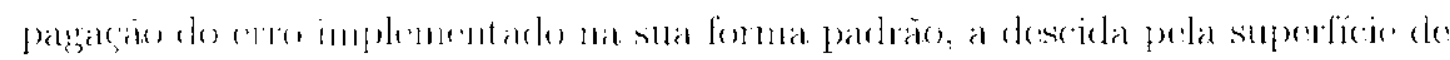

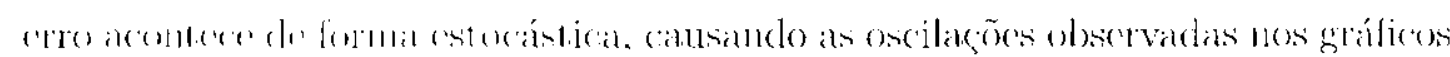
(Figura 5.1:3 1:5.16). (Quando implementado om lote. o algoritmo do retropro-

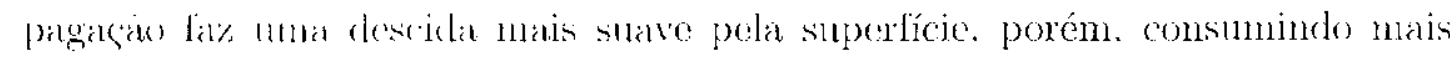

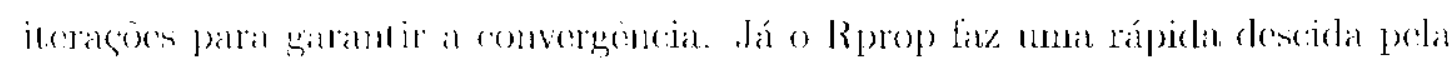

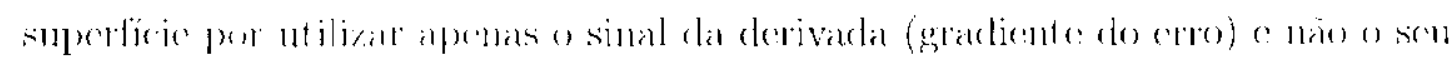

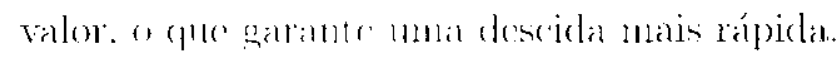

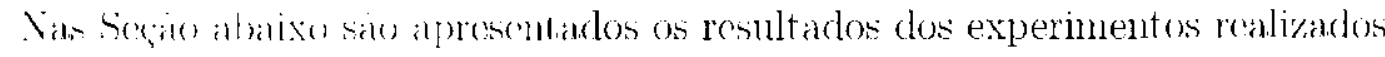

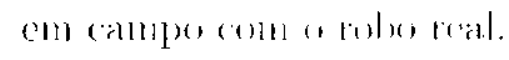

\subsection{Experimentos com o Robô}

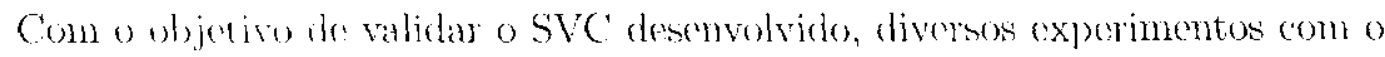

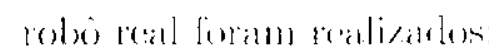

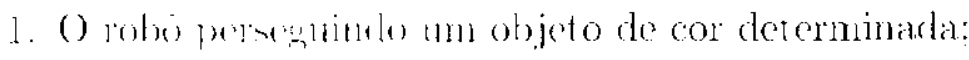

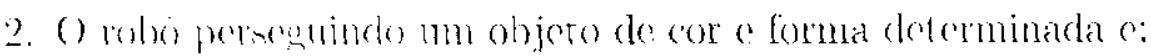

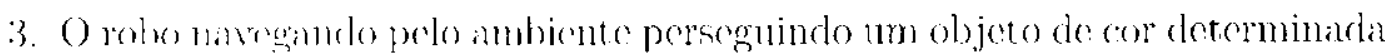




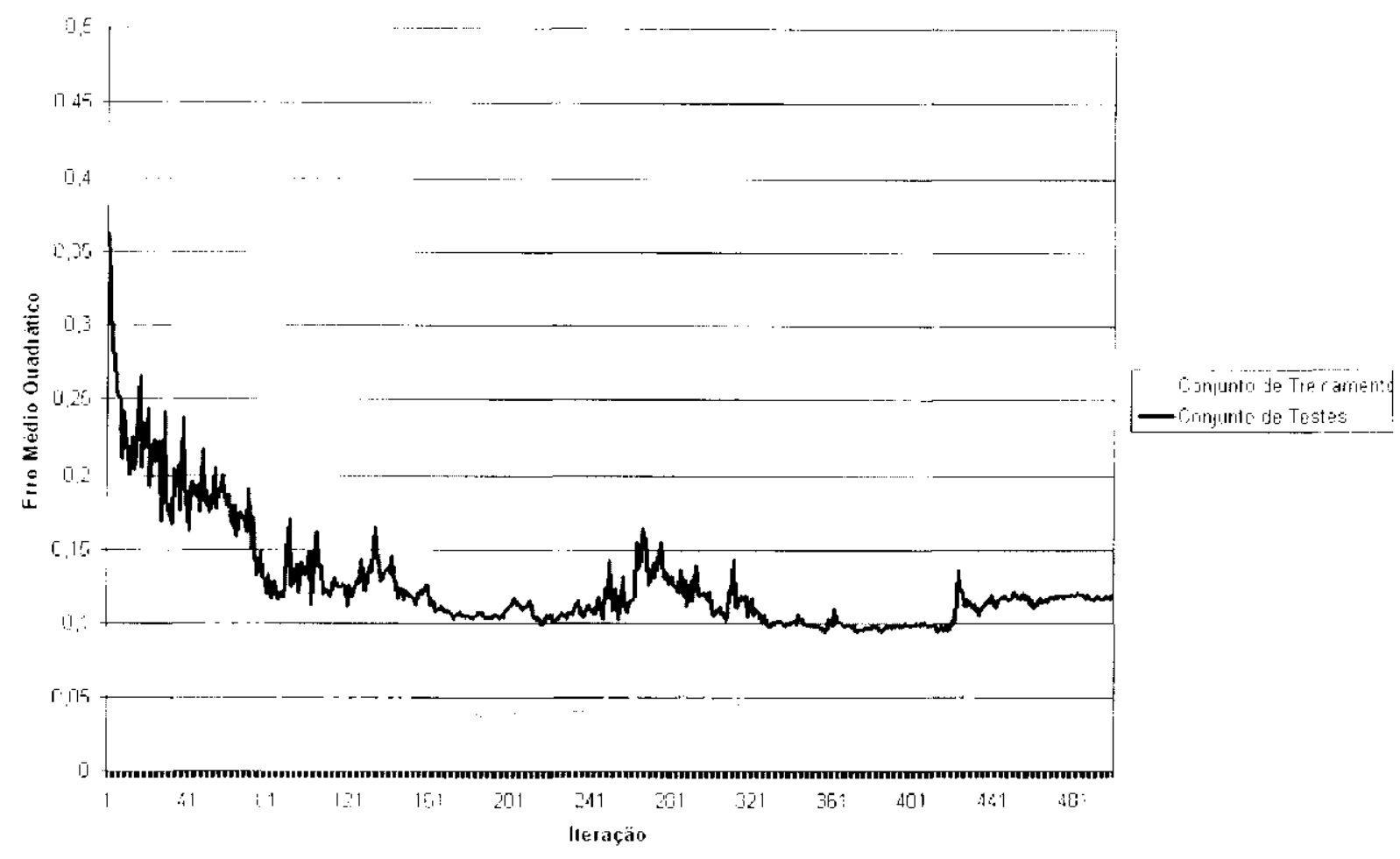

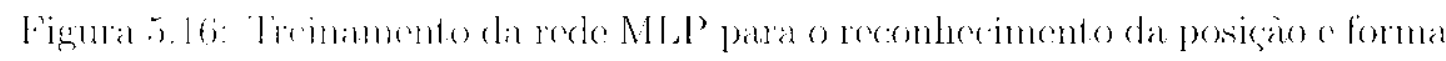

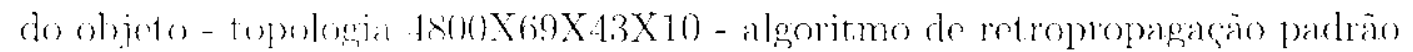

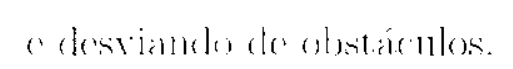

Todos on testen furam desenvolvidos na plataforma do robo Pioncer I (Segâno

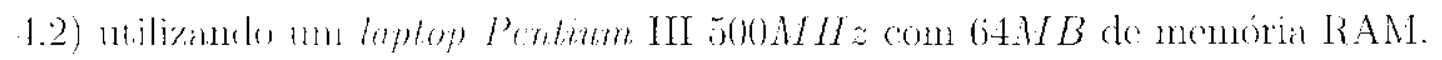

\subsubsection{O Robô Perseguindo Cores}

Conforme aprescutado na Seçăo 4.5.3, duas metodologias foram implenenta-

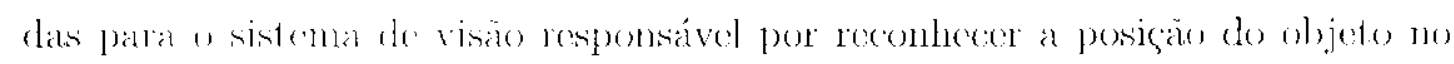

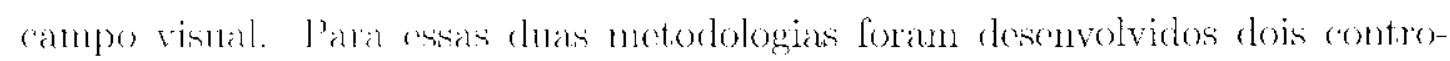

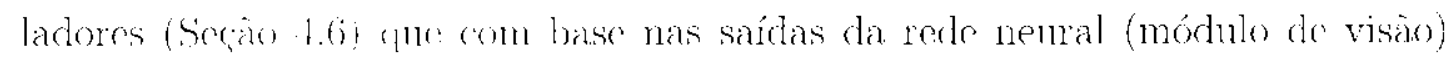

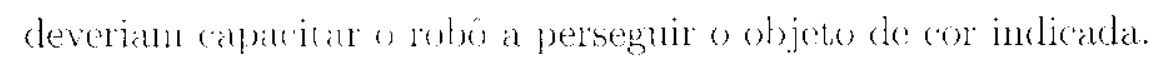

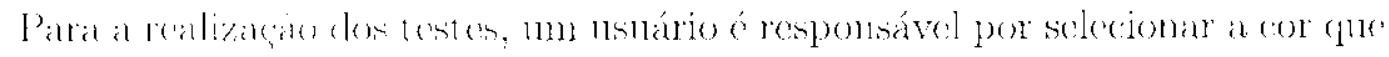

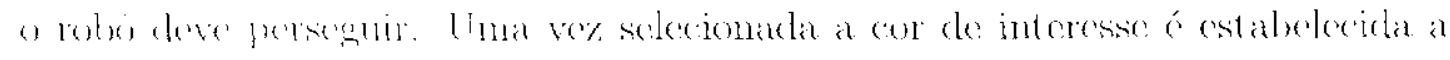

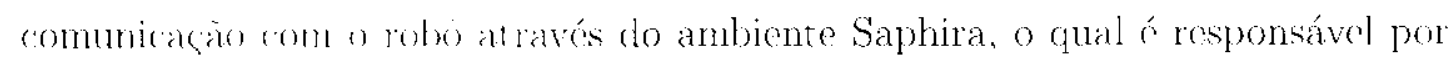
cmivar os comandes an robo. Após conectarto (laptop/robô), objetos deven ser

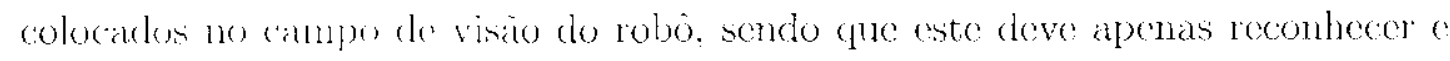

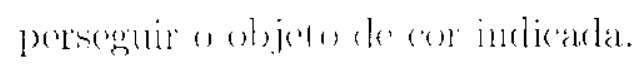

Varios testes formun realizados com as duas metodologias descritas na Seçân 


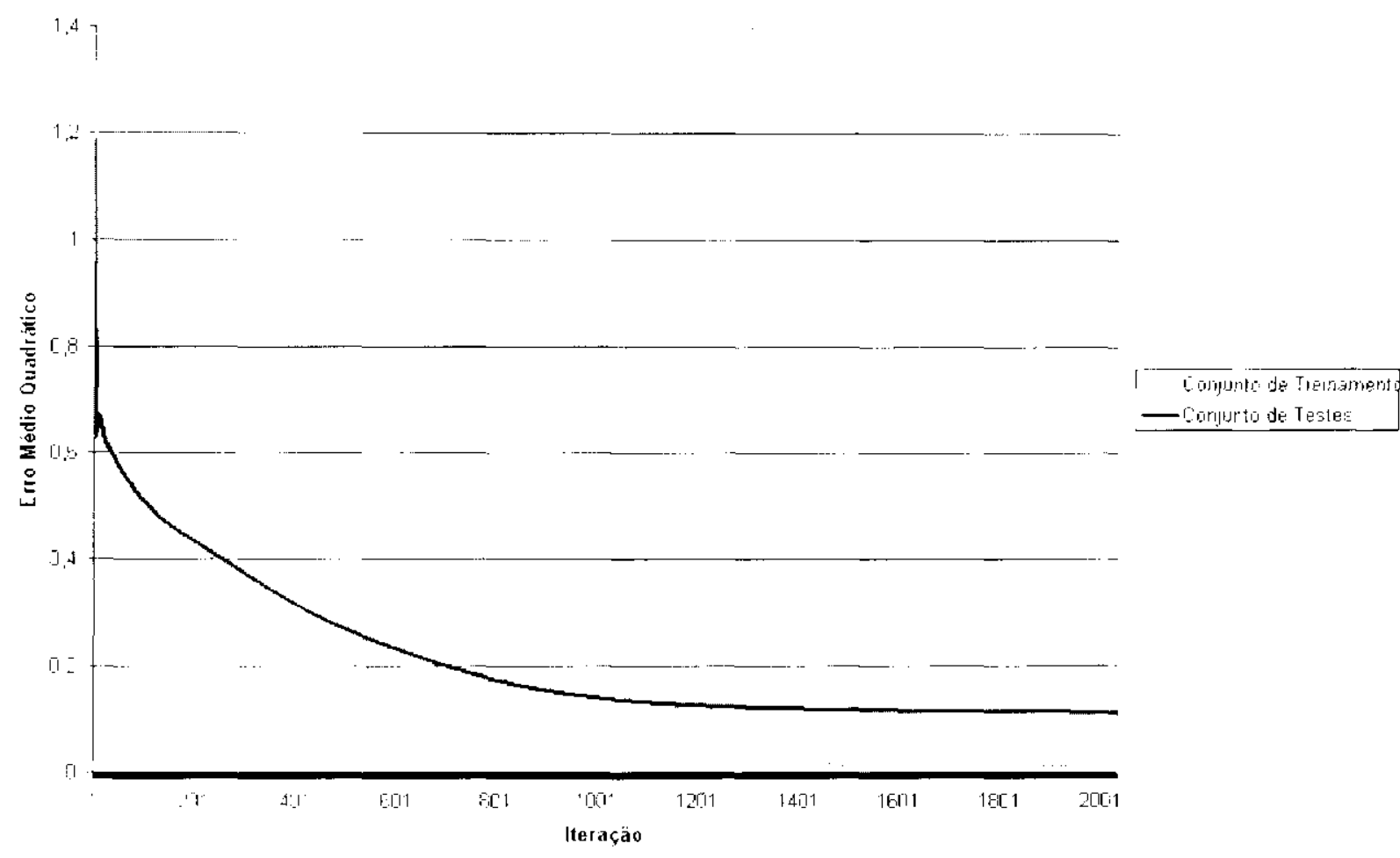

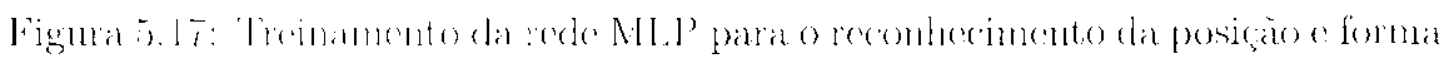

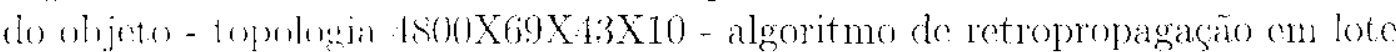

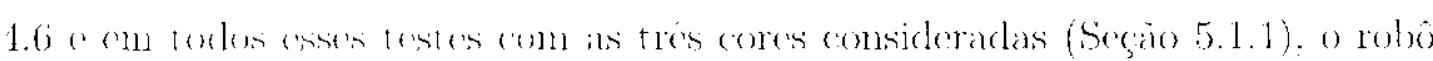

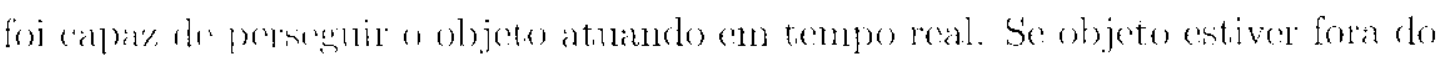
campo de visaio do robo a robó pára.

\subsubsection{O Robô Perseguindo Cores e Formas}

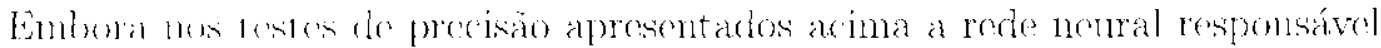
pelo reconhecinento da fomme da posiçäo do objeto tenha obtido bons resulat-

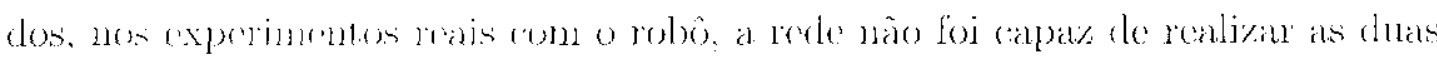

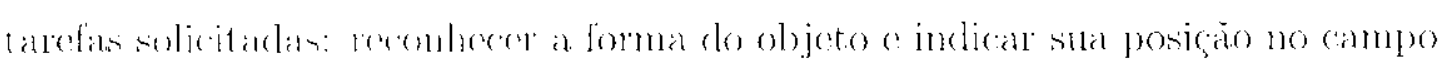
visitinl.

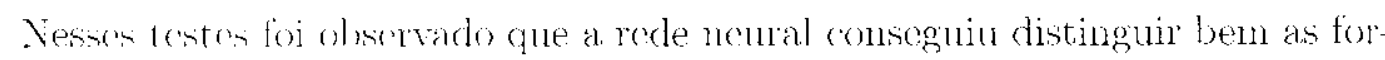

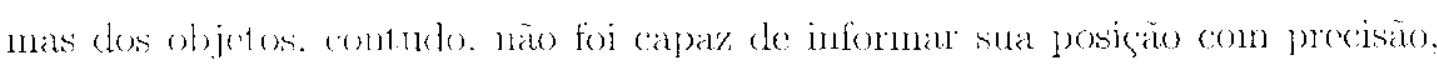

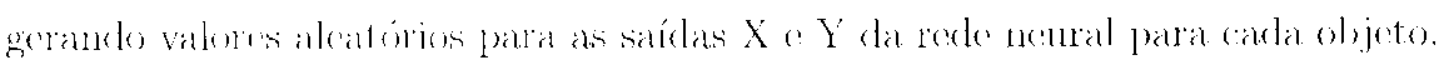

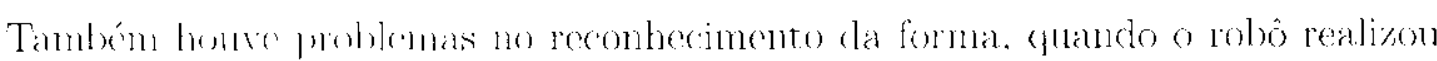

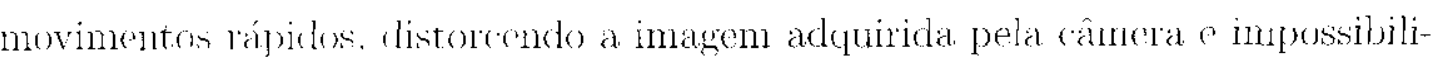
tando o reconherineme dessas imagens pela RNA. Isto se deve ao fato de yue o hardware utjikado i bastante limitado, tanto a câmera quanto o podex de pro-

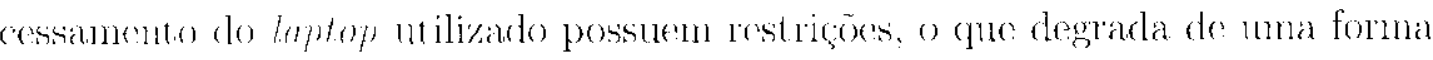




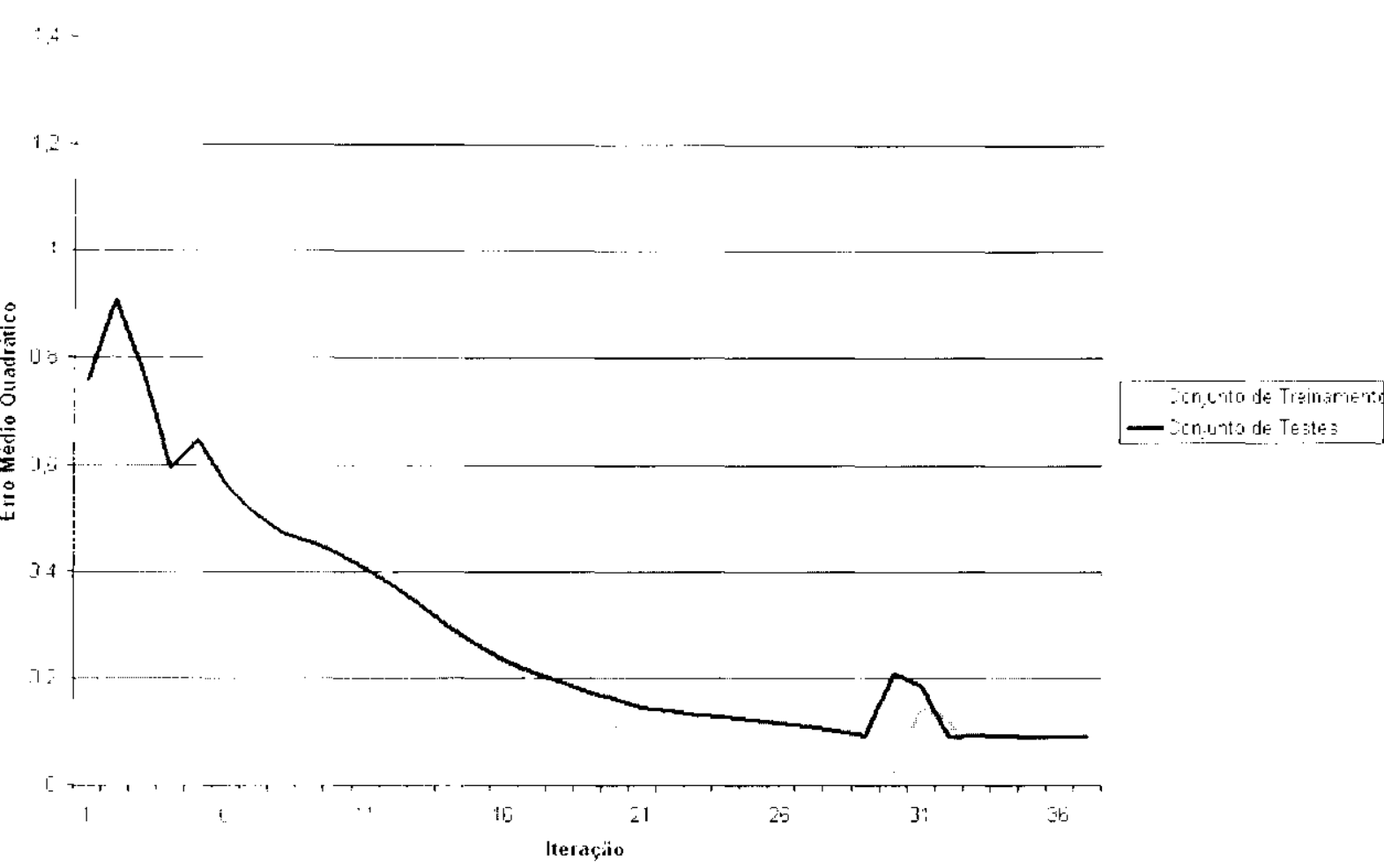

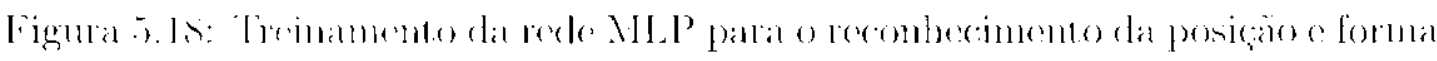

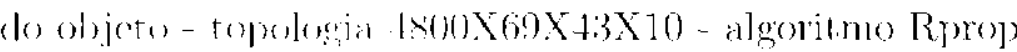

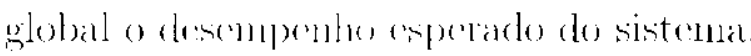

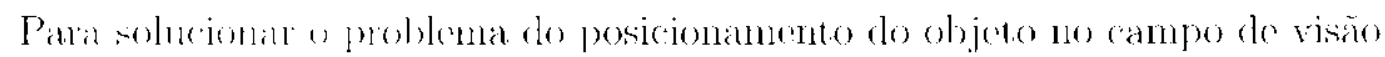
foran ralizatos alentus exporinentos aglomerando a tarofa de reconthecimento

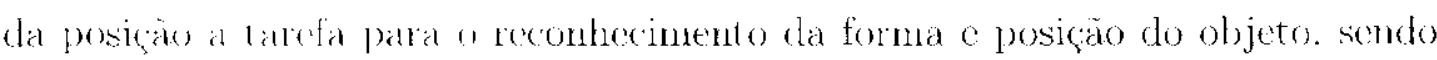

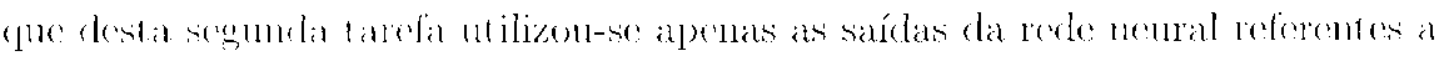

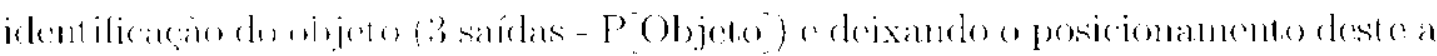
rargo da rede nemal responsivel polo reconhecimento da posição. As duas redes operam en paralele. isto 6 recebem as mesmas chtradas e as slats salídas sâno

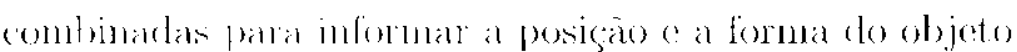

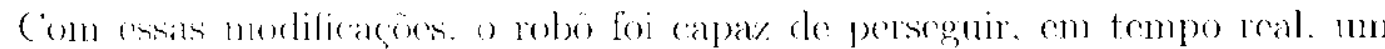

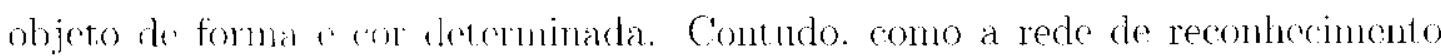

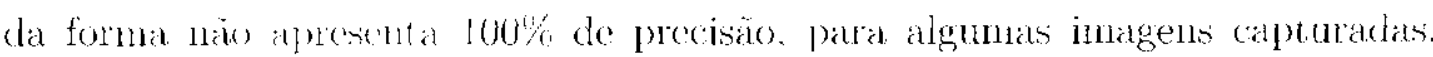

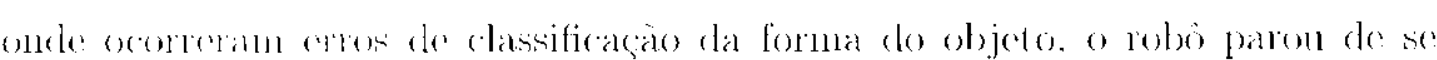

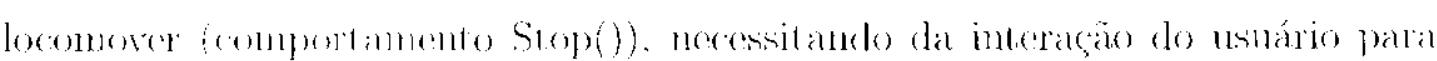

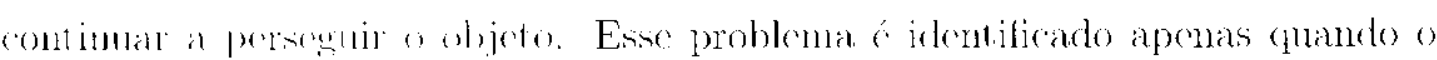

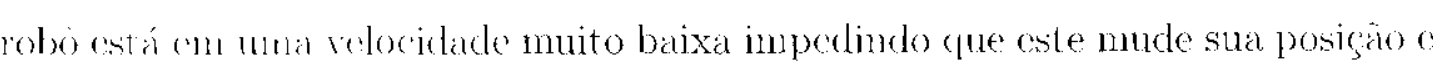

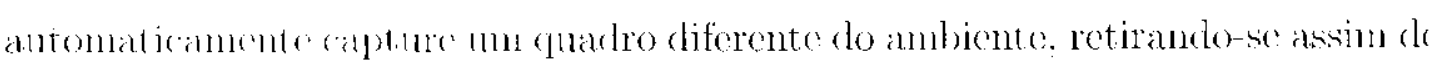

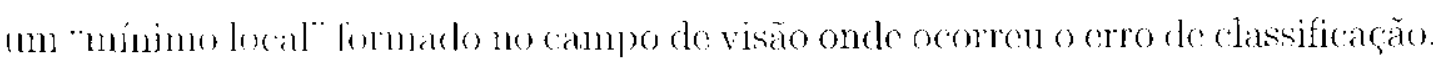




\subsubsection{Aplicação de Campos Potenciais}

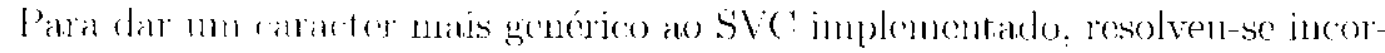

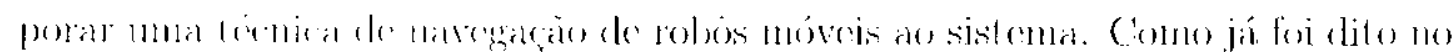

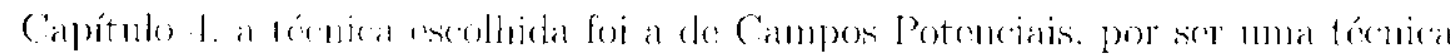
simples o ja restulata por algums membores do grupo de Robótica do ICMC-ESP.

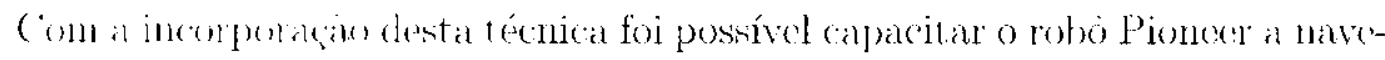

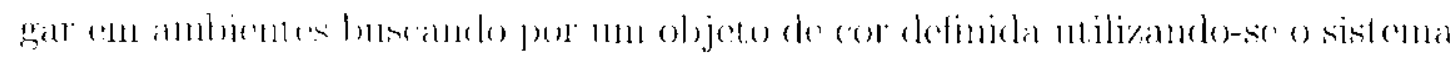

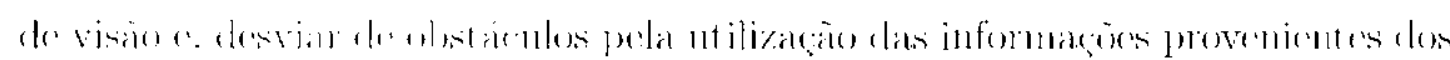
solliales (lo rol) re.

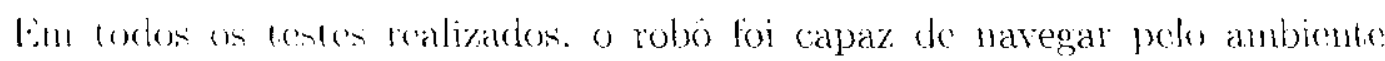

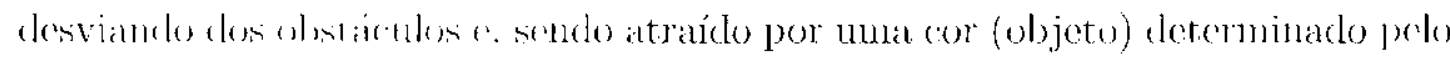

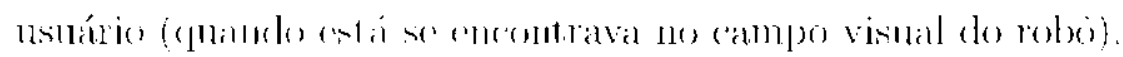

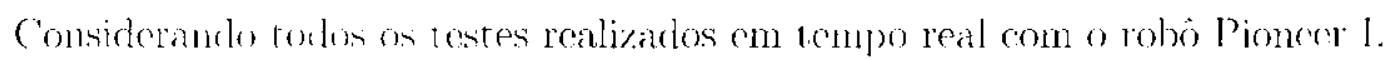

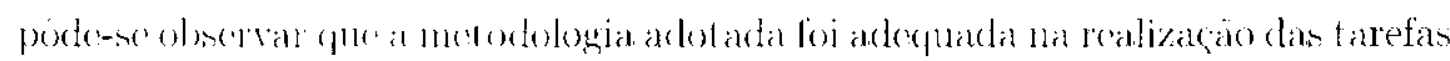

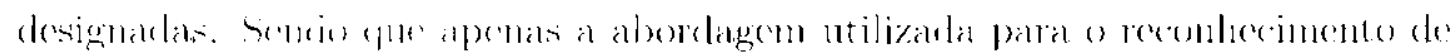

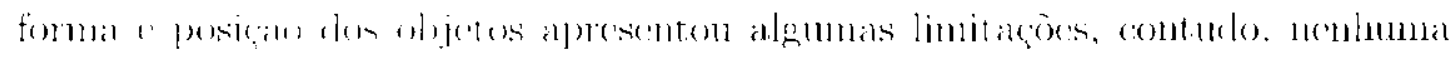

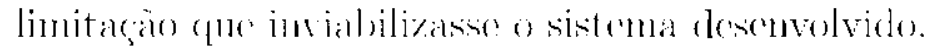

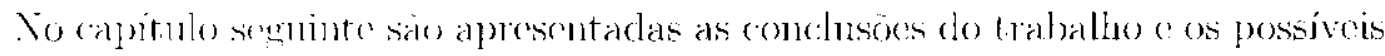
traballas foumos 


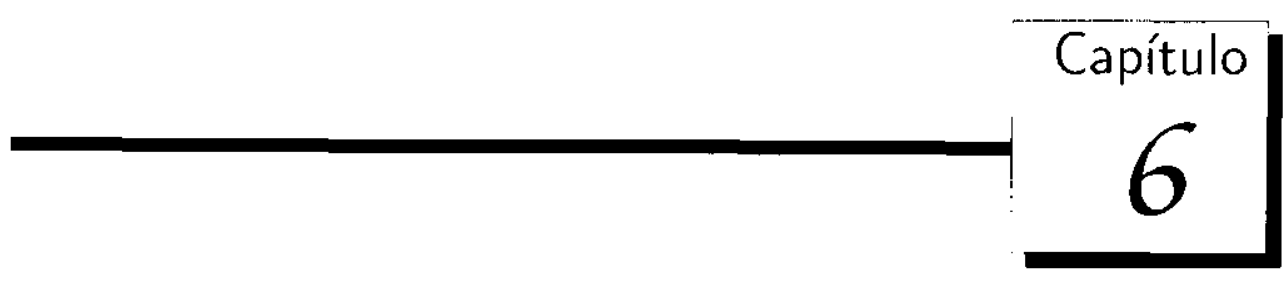

\section{Conclusões}

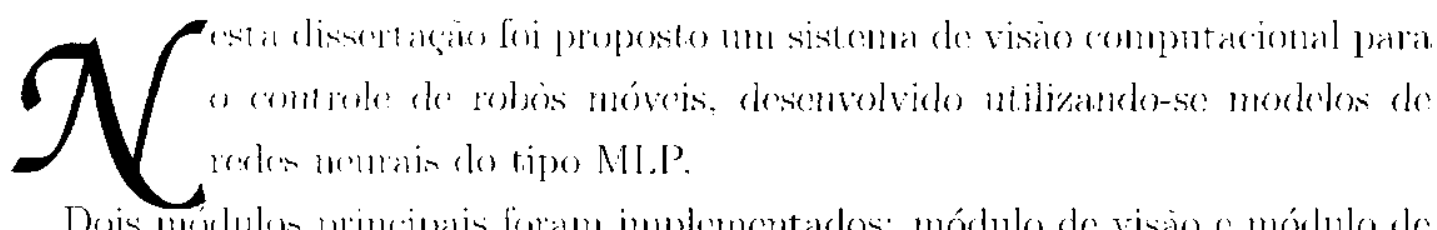

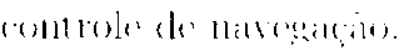

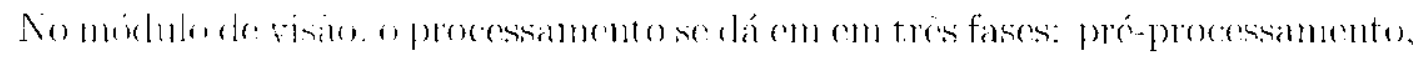

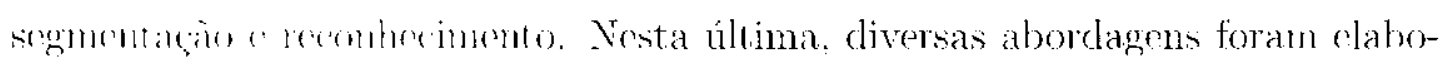
radas.

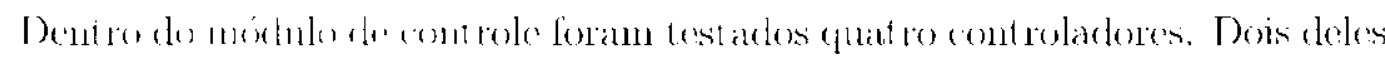

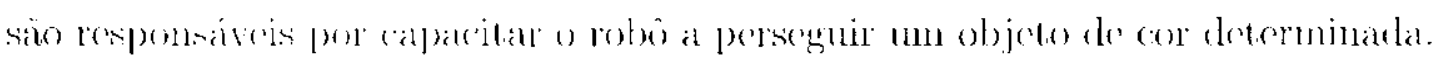

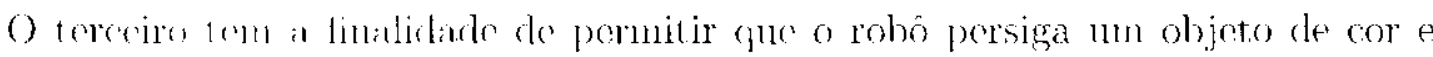

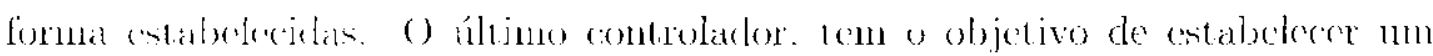

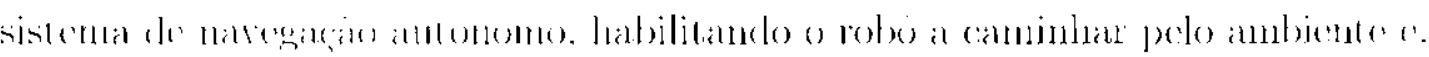

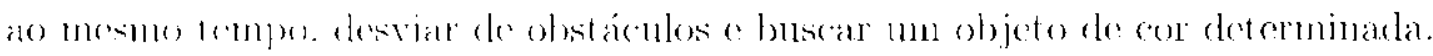

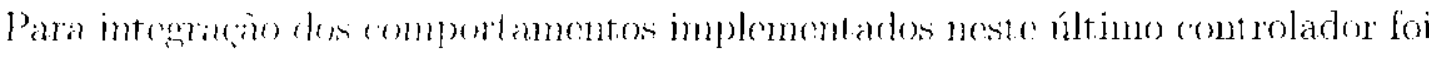
utilizada a tromical a lo (ampos Potenciaris.

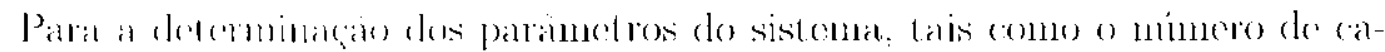

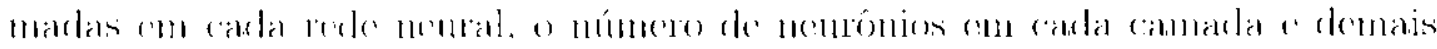

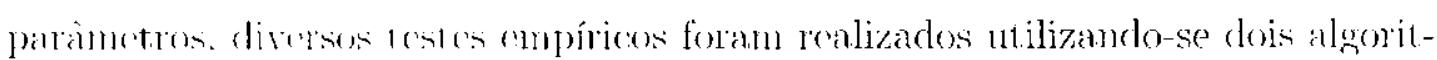

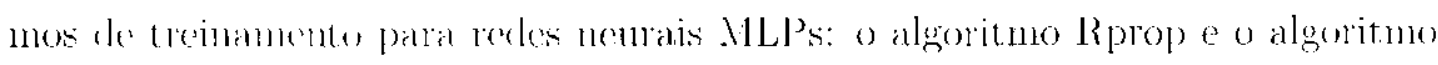

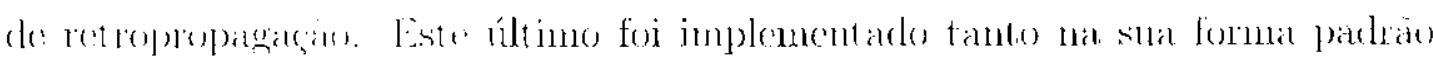

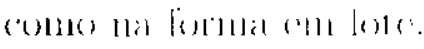

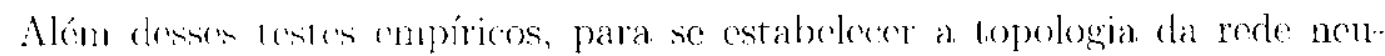

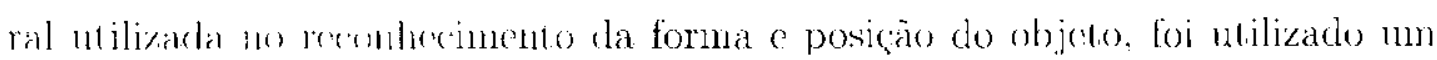

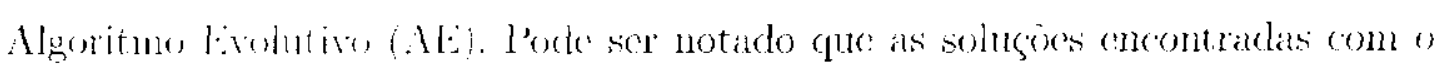

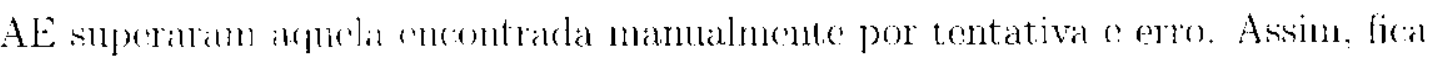


demomstrato o potencial dos $A \mathrm{Es}$ para otimizaça de topologias de RNAs. consi-

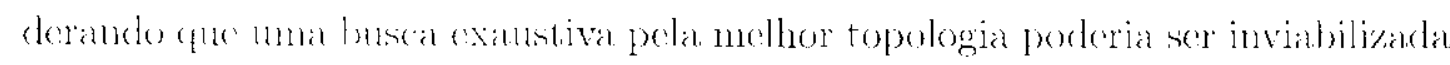

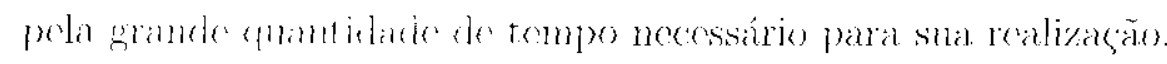

Gom ontro reviltade interessante observado durante o treinamento da rede

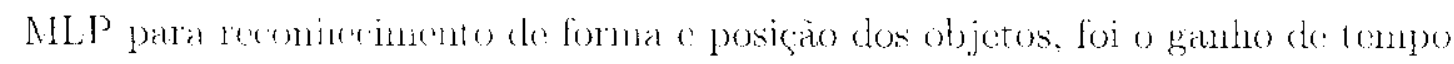

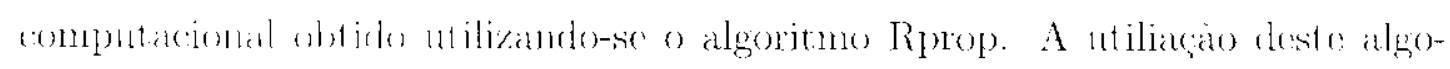

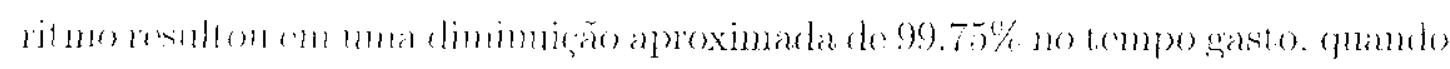

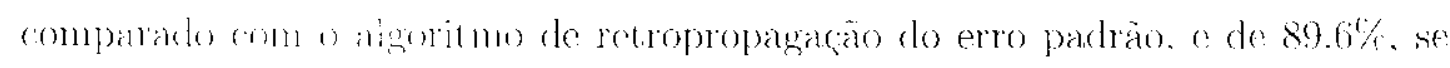
comparado an algeritume de retropropagação en lote.

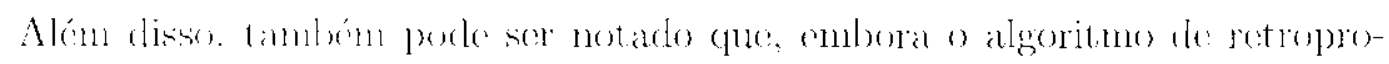

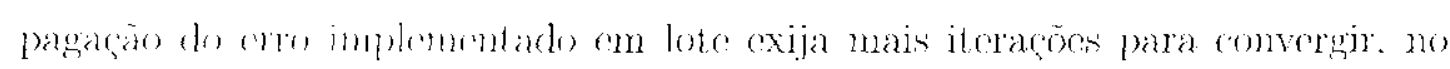
quesite temune computar ional gasto cle foi mais rápido que o algoritmo de retro-

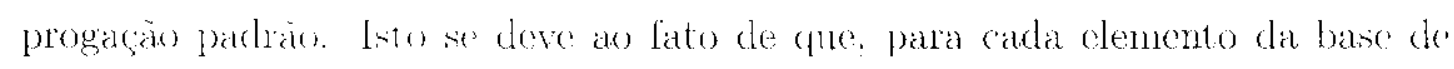

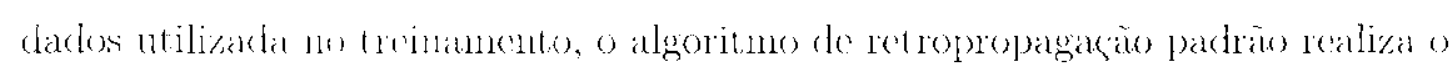

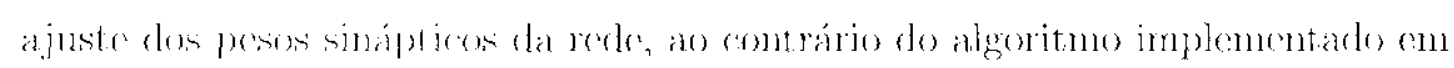
lote. fue realiza o ajulste dos pesos apenas uma vez a cada épora de treinamento.

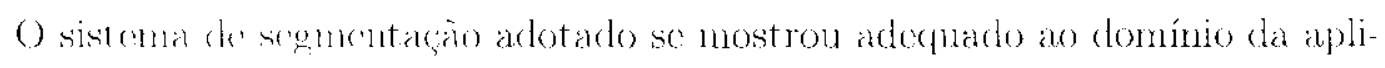

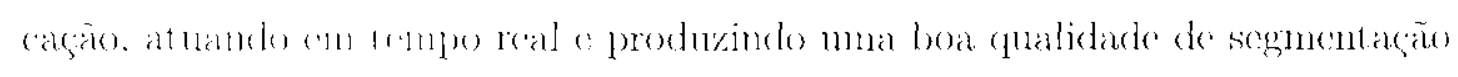

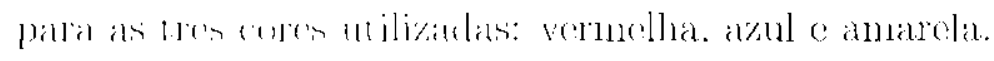

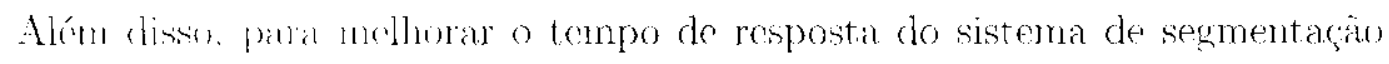

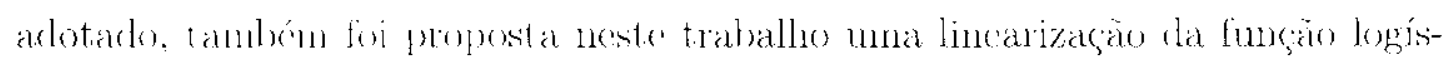

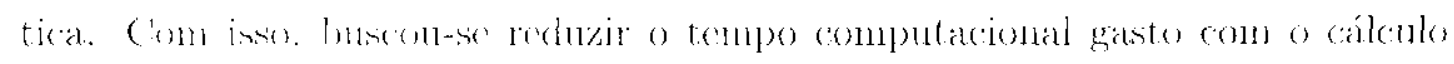

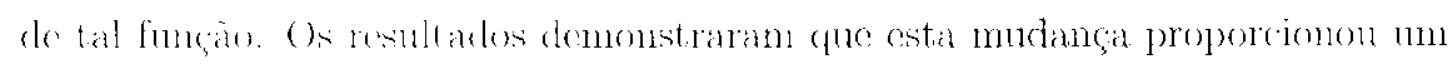

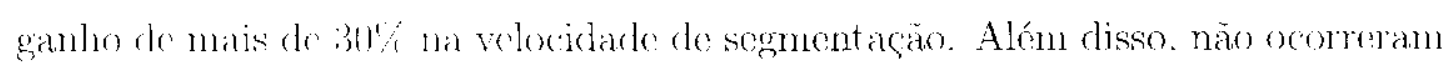

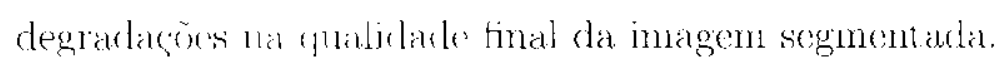

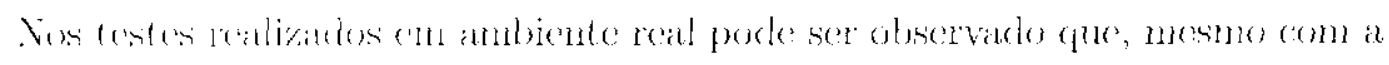

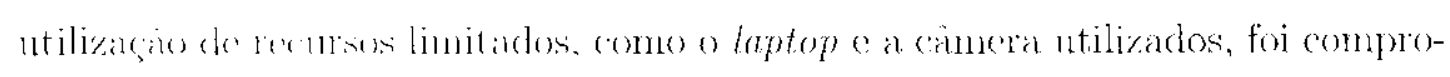

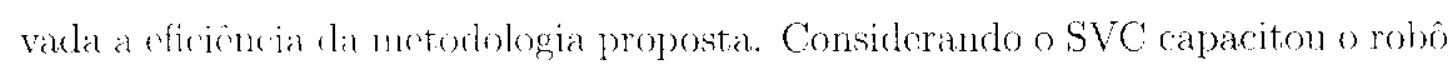
a perseguir nun uhjote "desviar de obstáculos ao navegar pelo ambiente atnianto (min tomper) real.

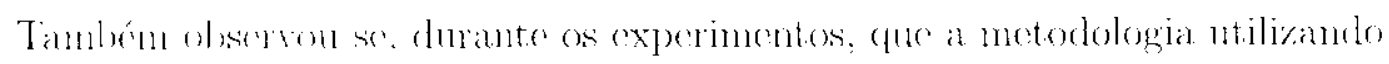

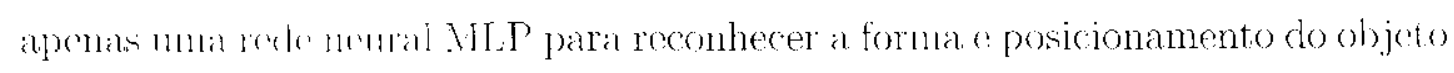

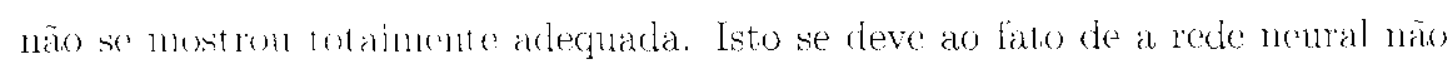

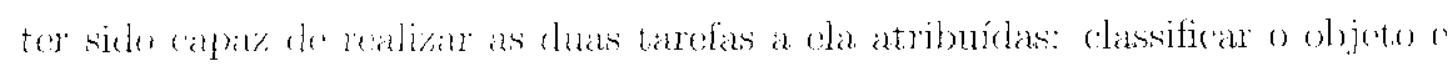

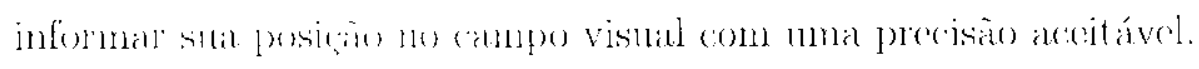

Tal problema foi solueionado ao ntilizar duas redes nenuais, uma para o reconherimento da forlua eout ra para informar a posição do objeto no campo visual. 


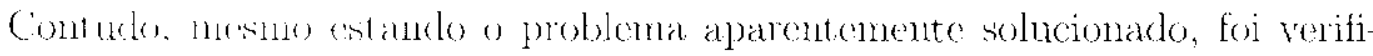

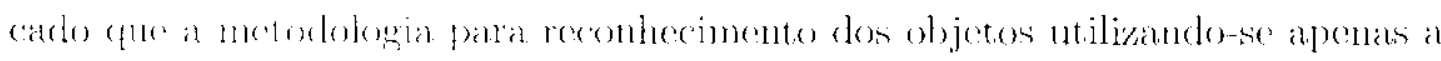

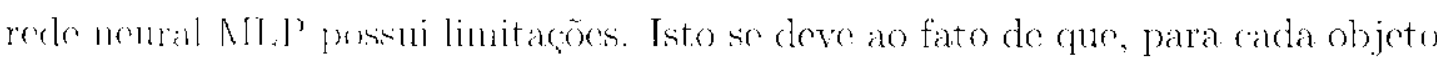

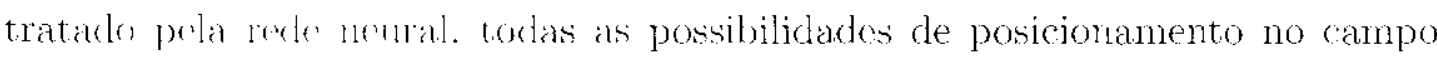

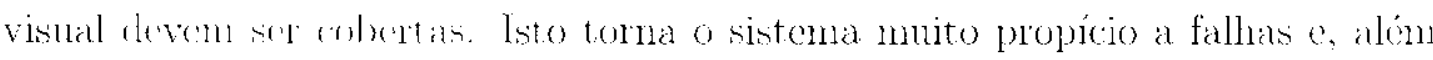

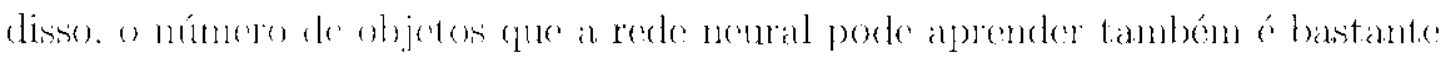
limiliciluts.

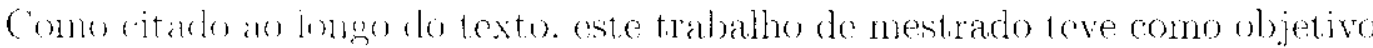

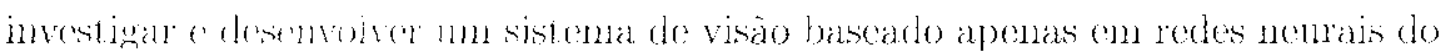

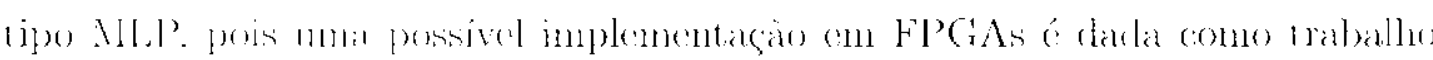

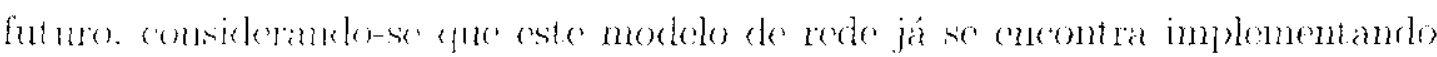

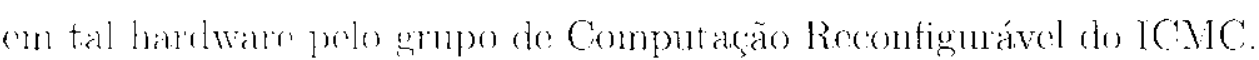

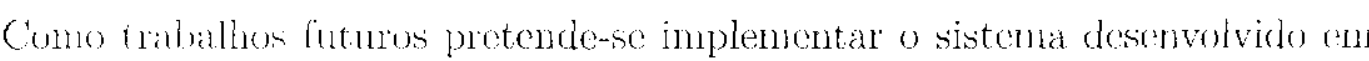

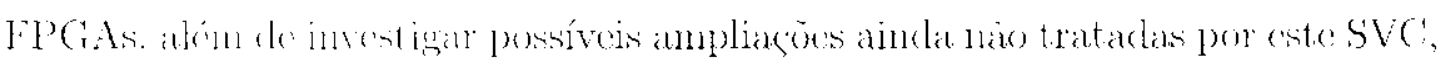

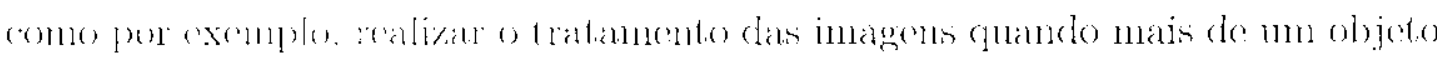

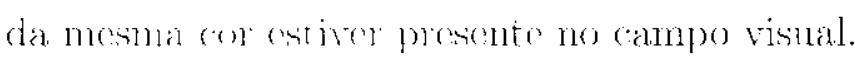

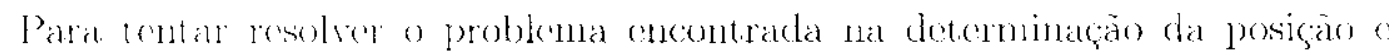

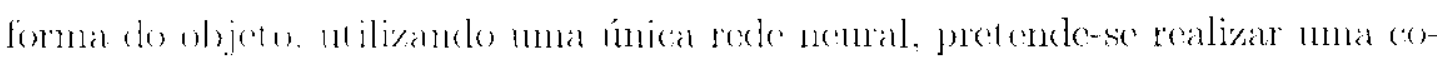

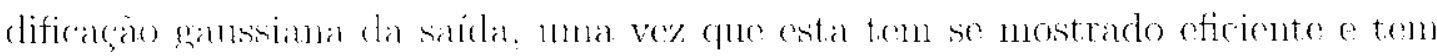

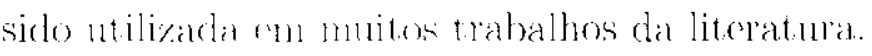

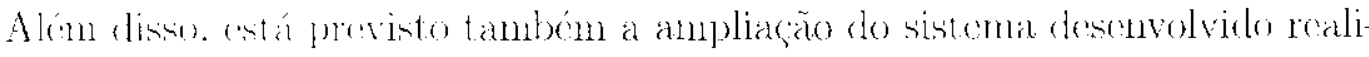

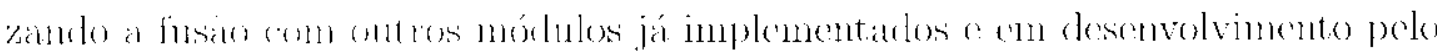

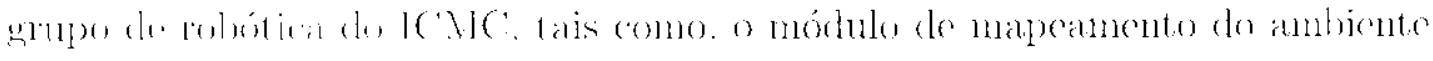
sistema de losalivacion antrole de trajectólia e o módulo de controlo de robo via Web. 


\section{Referências}

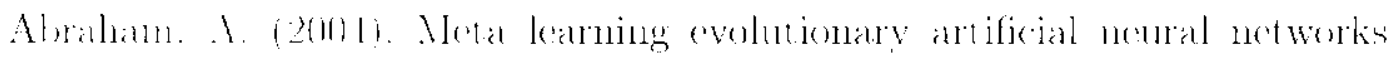

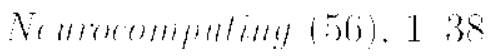

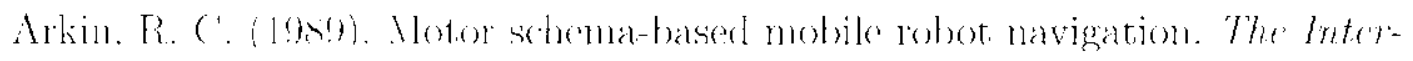
mationat fommat of Robotics Reseom 4(8). 92112.

Arkin. R. (19)s). Behatror Based Robotics. MIT Press.

Berne. R. M. A Invy M. Y. (1996). Fisiologia (3.Ed. ed.). Rio de Janciro: Gianatiana kiongan.

Blank. I). S. (S Roms. I. (). (1997). Incorporating a comectionist vision modute

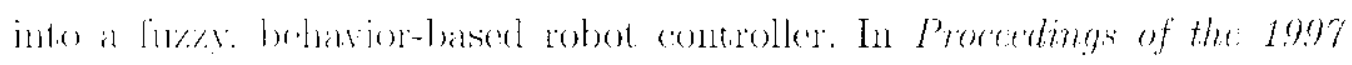

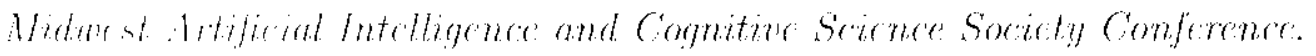

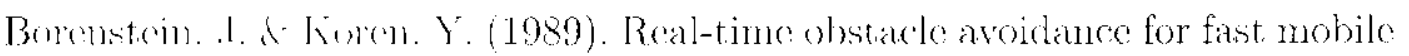

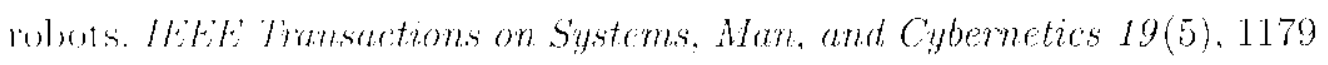
$11 \times 7$.

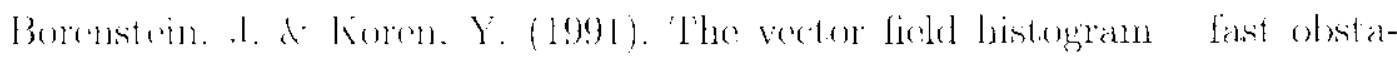

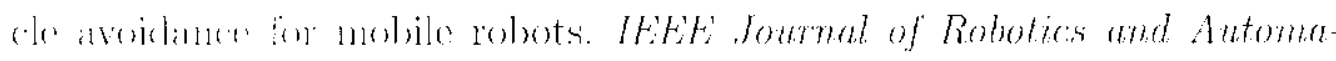

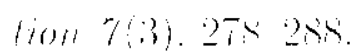

Brooks. R. A. Iflaci]. A molust layered control system for a mobilo robot. IEEE Joumal of liobolics and Automation $2(1), 1.123$.

Castillo. I'. A. Marelo. J. J. Prieto, A. Rivats. V. E Romero, G. (2000)

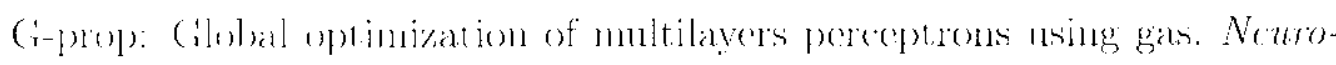
(amputiom (3), 149163.

Cheng. H. 1). Jiang. X. II.. Sun. Y. \& Wang, J. (2001). Color innges segmen tation: alrances and prospects. Pattern Recognition (31). 22592281.

Chen. T. (2. A I.n. Y. (2002). Color image segnentation - an innovative appro-

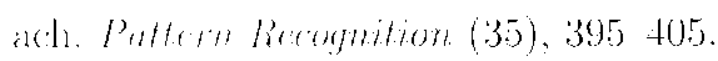




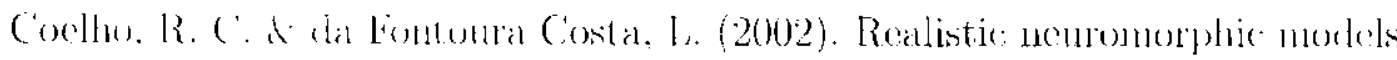

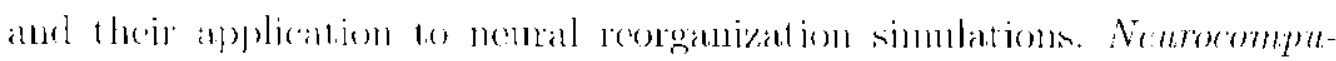
limg las

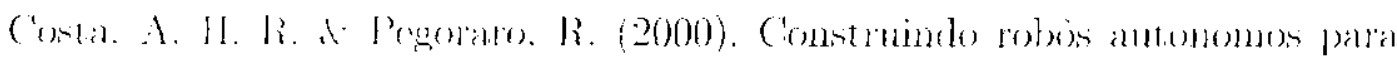

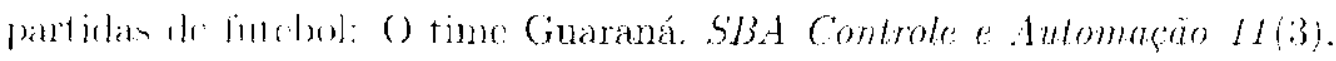
$111+11 \%$

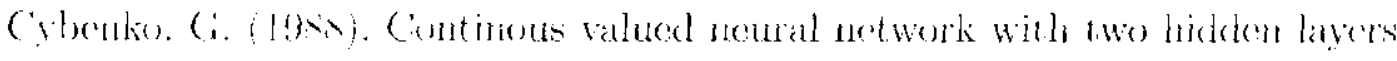

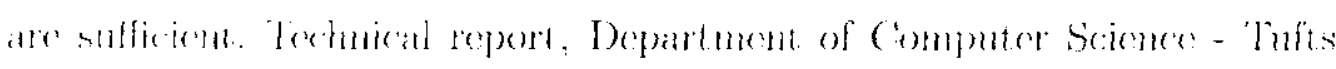
Iniverifl.

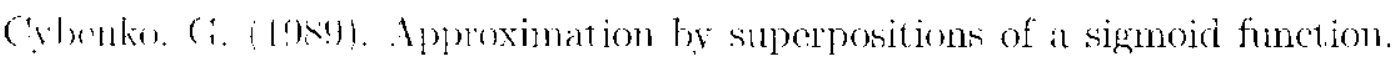
Wathrmatier of combel - Signal and Systems (2), 3033-311.

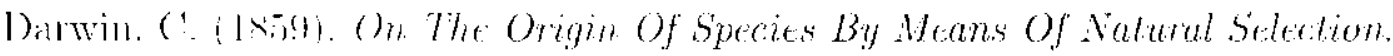

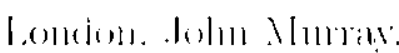

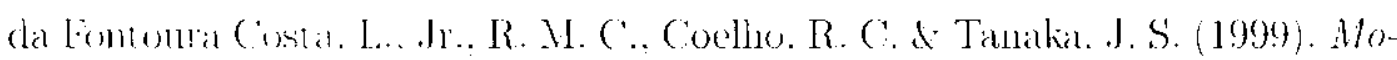

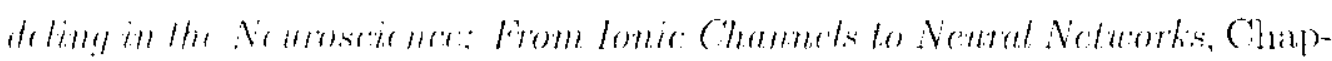

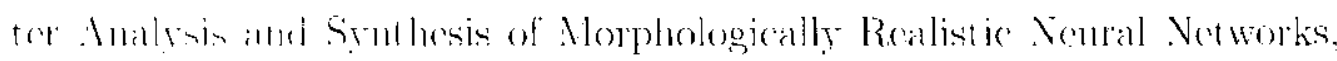

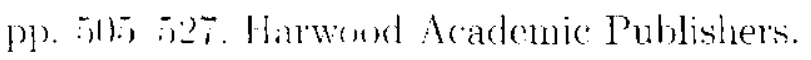

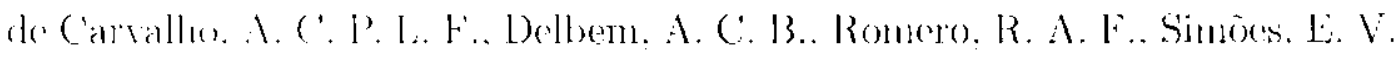

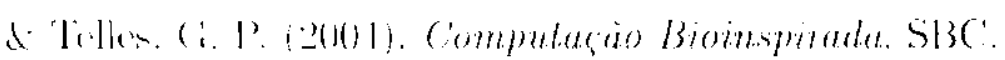

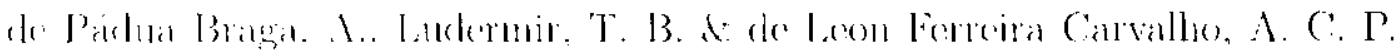

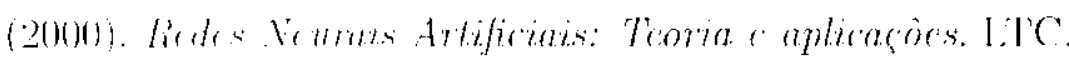

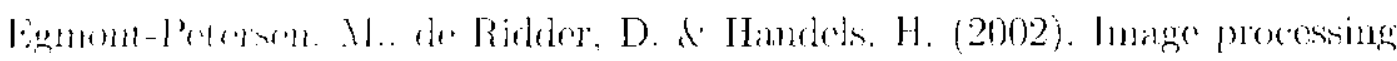

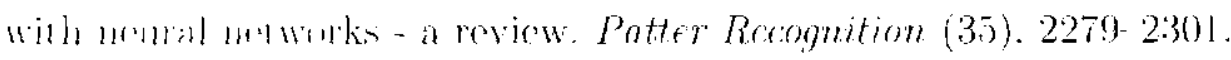

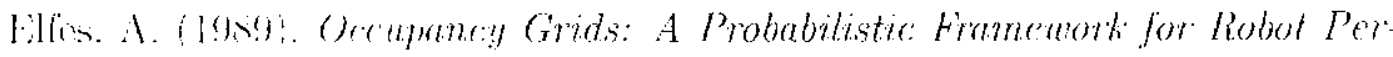

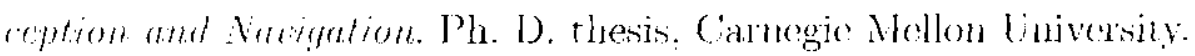

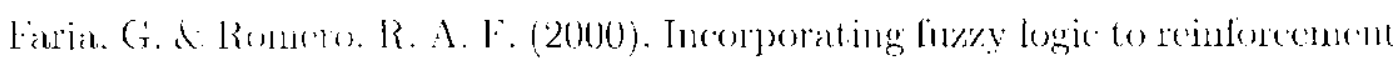

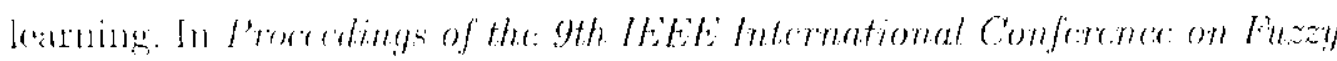

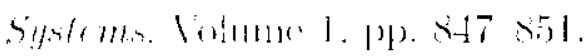

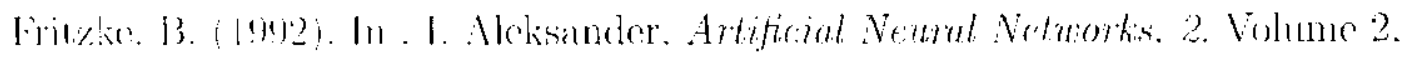

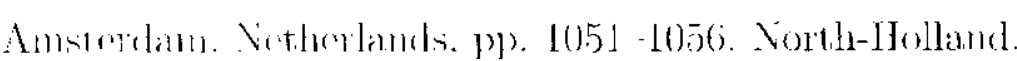

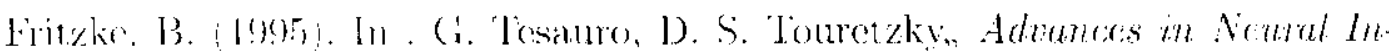
formution Prow sumg Systems 7. pp. 625 6.32. Cambridge MA: MII Press.

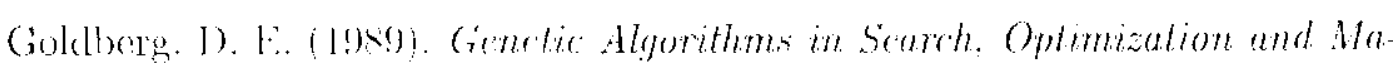

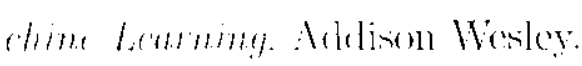


Gomes. M. R. S. L Campos. M. F. M. (2001). Desvio de obstáculos para mitero-

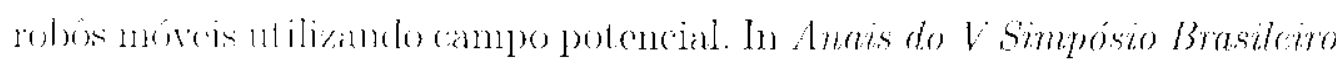
de Automacto Inteligente (SBAJ), Cancla/RS.

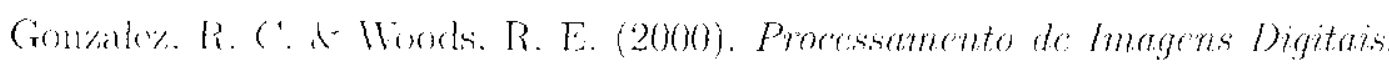

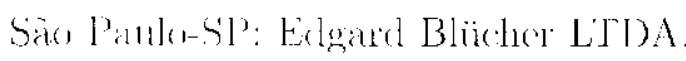

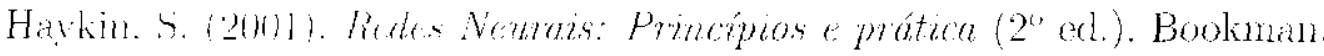

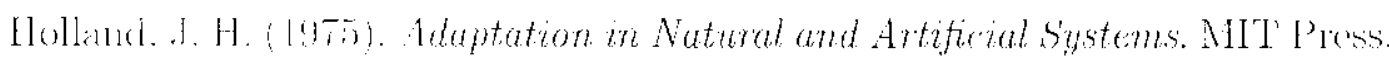

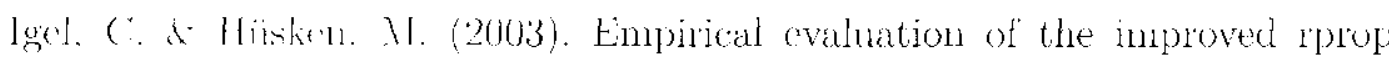

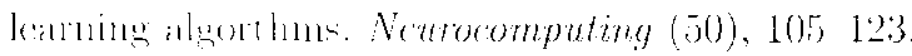

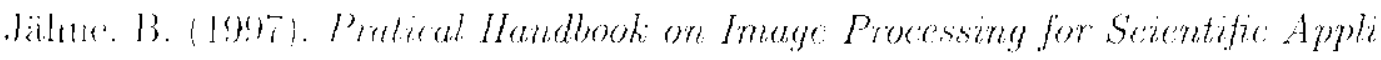
rations. ( 'lic' Prosis.

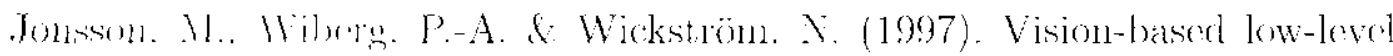
11arigat ionl Hing a feed-forward neural network. In International Workshop

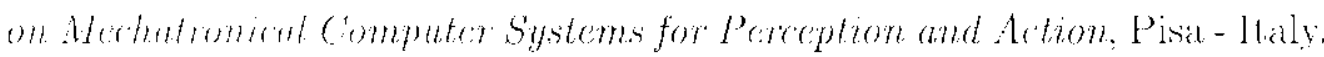

Kanclel. F. R. Selwarty. J. HI. K Jessell, 'T'. M. (1997). Fundamentos da Nea-

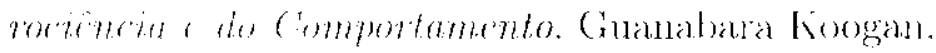

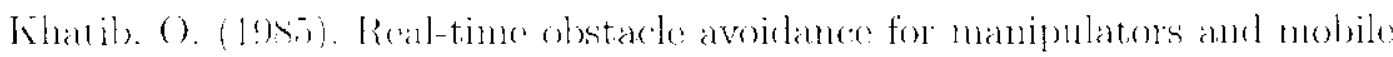

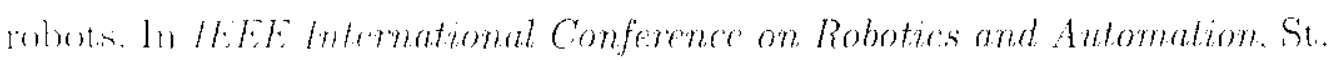

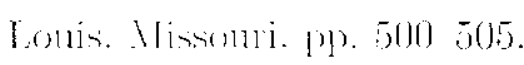

Koch. ('. (19) i. Biophystes of Computation: Information Processing in Single

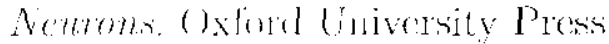

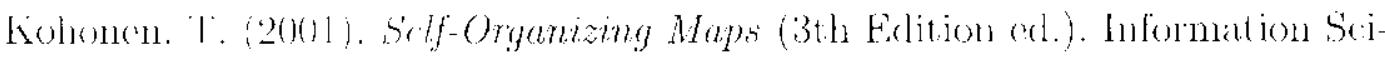

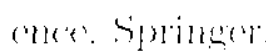

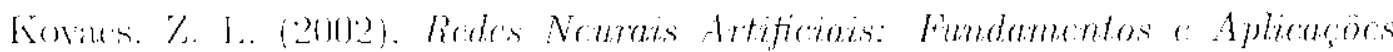

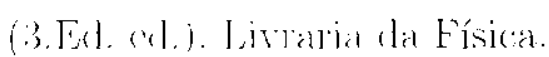

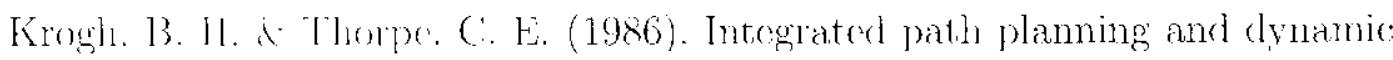
stecring control. In Proeedings of the 1986 IEEE Intemational Conformer on. Robolicis and Automation, San Francisco, California, pls. 16041609

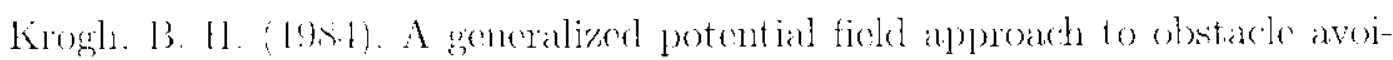

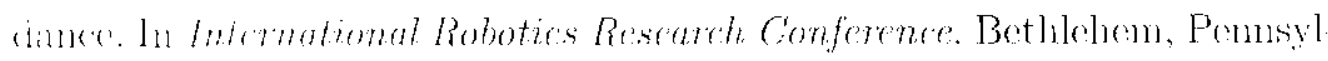
valinit.

Li, B.. Hu. H. (S Sparek, L. (2003). An adaptive color segmentation algorithm

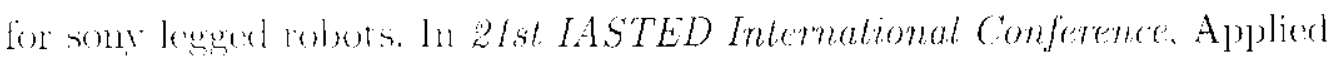

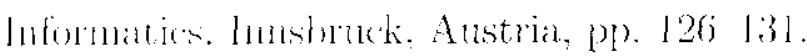




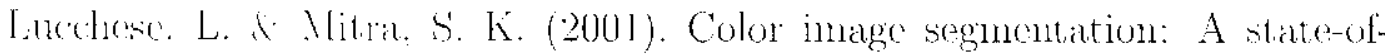

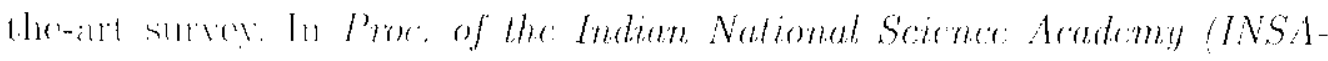

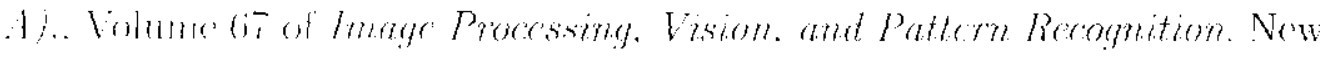

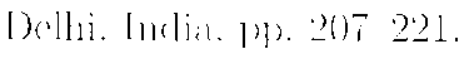

Machado, A. (2000). Neuroanatoma Funcional (2.Ed. od.). Rio de Janeiro: Alicuriu.

Nedeiros. D). M. R. A Romero. R. A. F. (2002). Sistema de controle antó

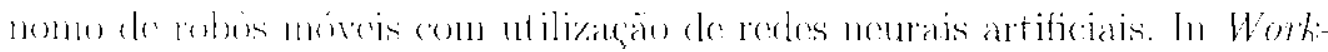

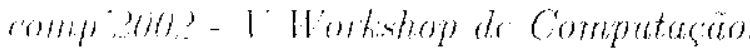

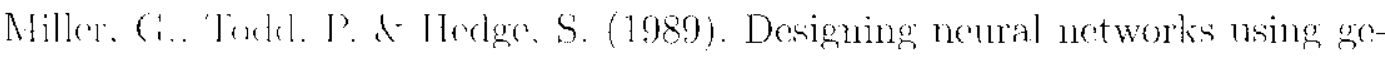
noic alenithus. In and International Conference on Genetic Algonthms, [11. 37938.1.

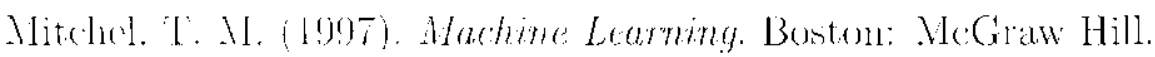

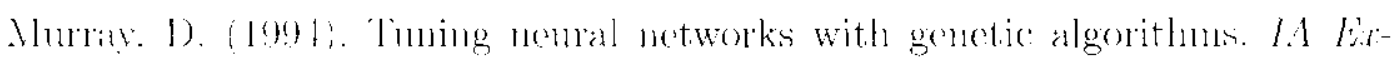
prot (9). 27,3

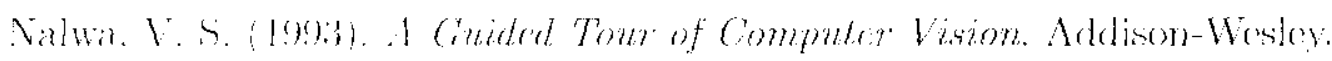

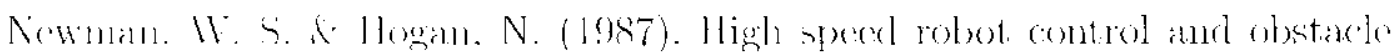
avoiraner. In Procedings of the 1987 HEE International. Raleigh, North

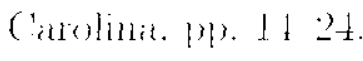

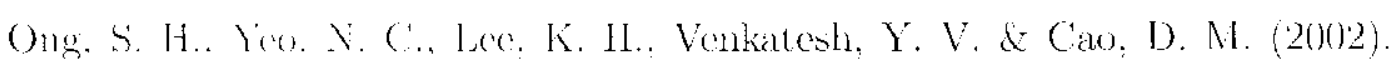
Segmentation of colen images using at two-stage self-organizing network. Imenge and lixim Computing $(20), 270 \cdot 289$.

Pagsllu. F.. Arai. T.. I)ilhuajn, R. \& Stentz, A. (2002). Towards the jntelligent andomomomis systems of the third millenimu. Roboties and Aubonomous Systome (10). (j) 6 (ix

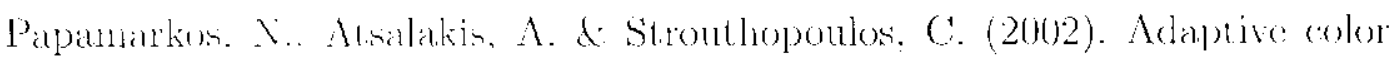

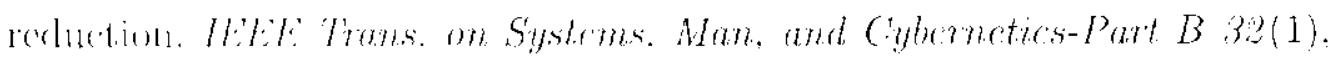
H. 50

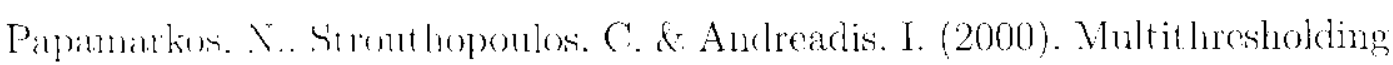
of colon and gray-level intages through a nentral network technique. Imagr

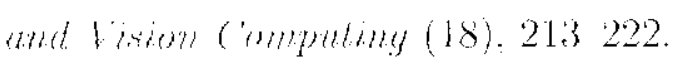

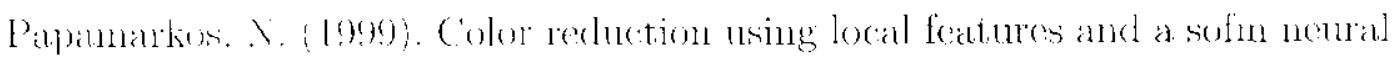
monoti. Int. Tommal of Imaging Systems and Technology 10. 404409. 


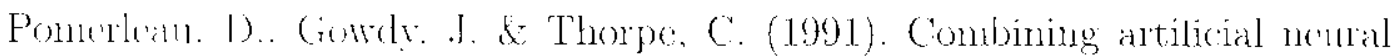

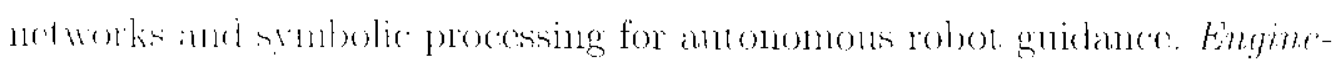

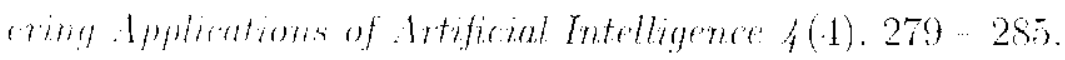

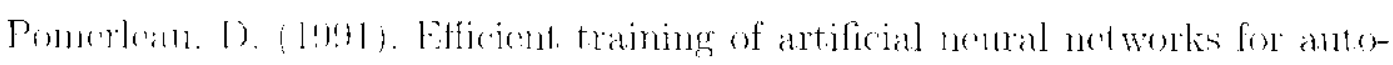
nomols navigation. Nemml Computation $3(1), 88,97$.

Pomelome. 5). (1992). Progress in menal network-based vision for antonomons

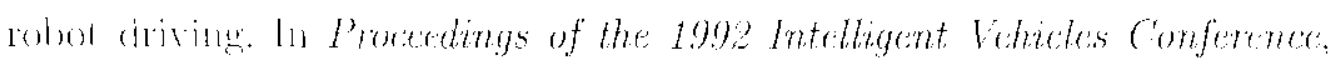
$19.3913 ! 16 \mathrm{i}$

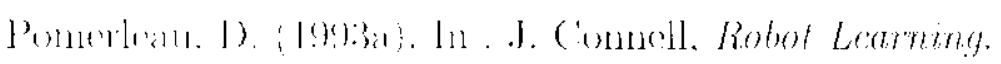

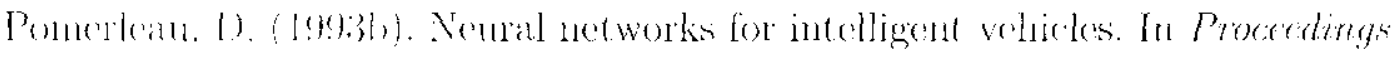

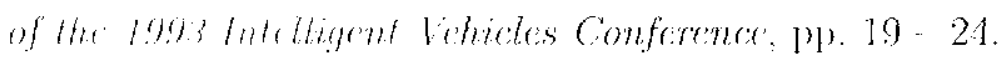

Pomerleall. 1), (1995). Nemal network vision for robot driving. In M. Arbib) (Fid.). The Hundbook of Bram Theory and Neural Networks.

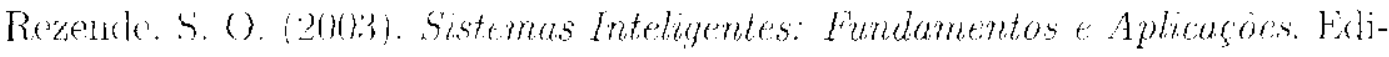
$101: M a 110 k$.

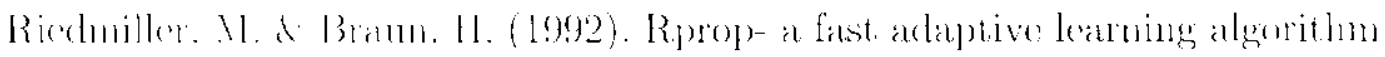

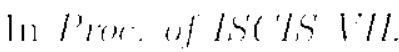

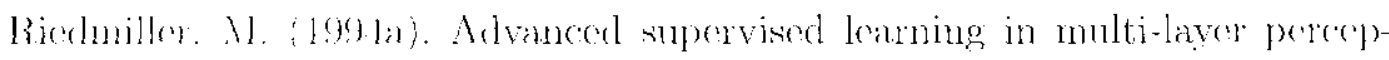

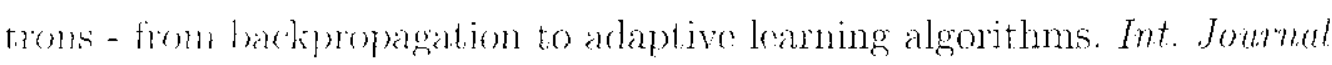
of Computer shandarts and Interfaces (16), 265-278.

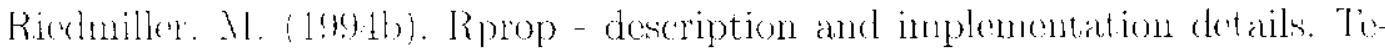

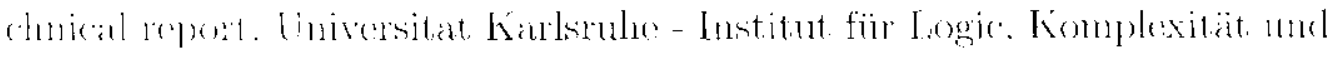

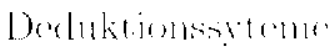

Rummllant. 1). F. (1896). Parullel Distribuled Processing: Foundations. Volumer. Nit Presis.

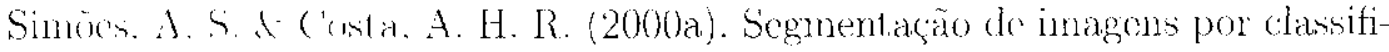

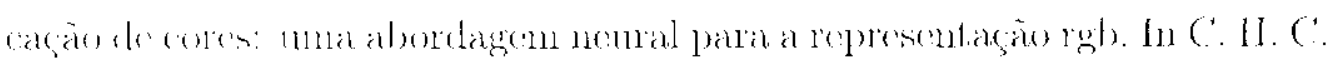

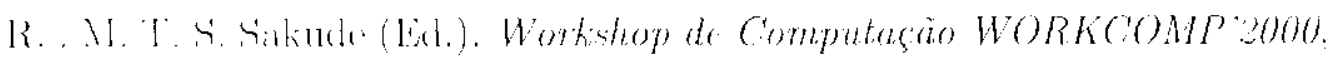

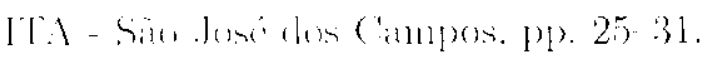

Simoxs. A. S. A ('osta. A. H. R. (2000b). Using nemal color classification in robotic sure domain. In International Joind Conference IBERAMIA' 2000 .

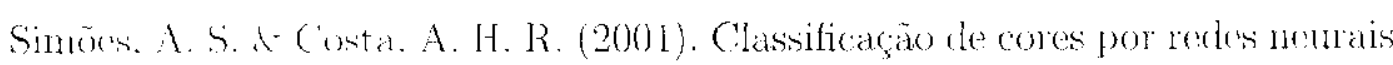

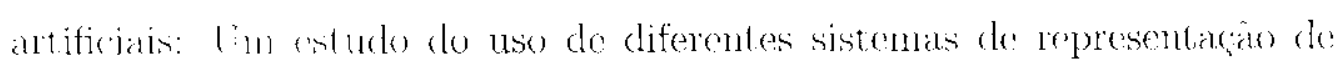

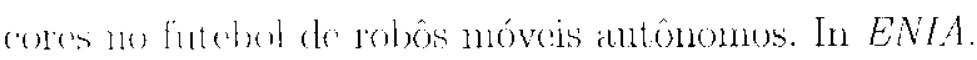


Sinnes, 1: 1). 1. (2000). Denelopment of An Embedded Evolutionary Controller

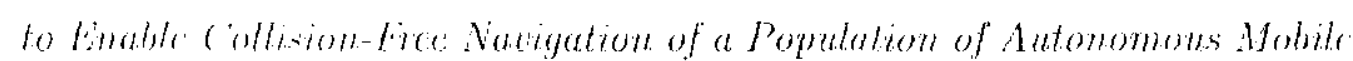

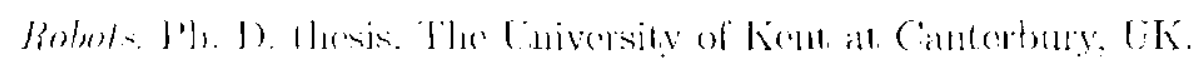

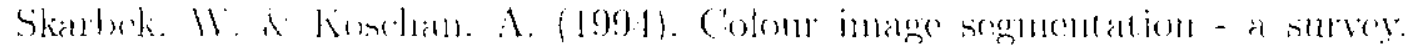

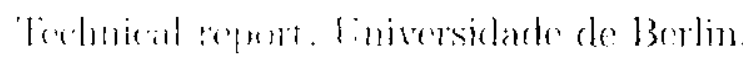

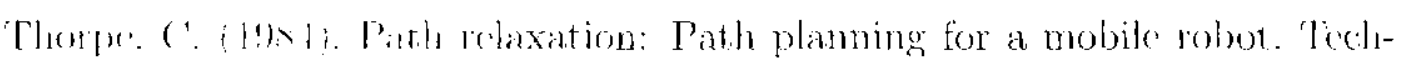

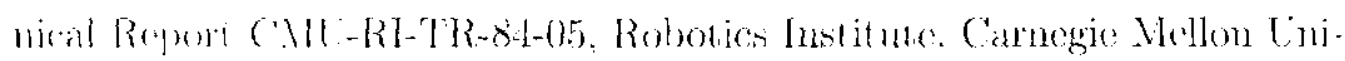
versily l'iltinumb. PA.

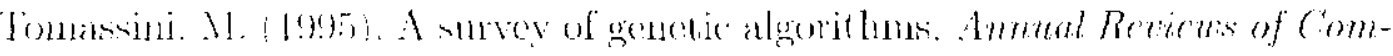

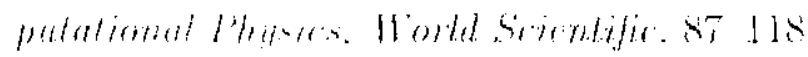

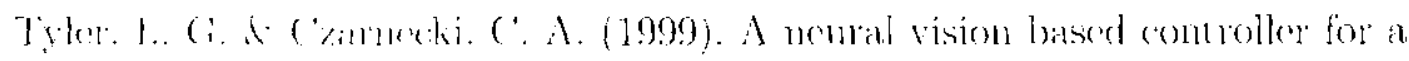

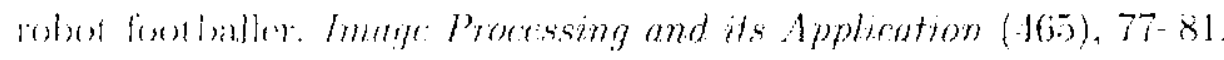

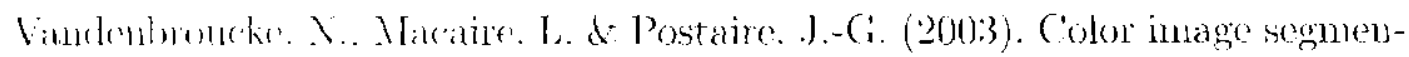
tation by pixol easitication in an andapted bybrid color space, application 1.0 socers image analysis. Computer lasion and Imaye: Cmderstanding (90)). (1) 216

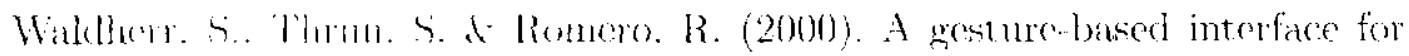

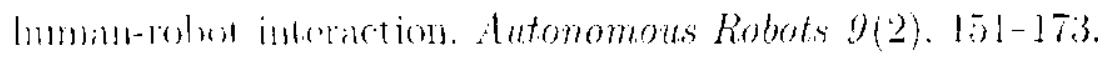

